Rafaela Farias do Nascimento

\title{
Resposta da Plataforma Continental de São Paulo ao vento sinótico: estudos numéricos
}

Dissertação apresentada ao Instituto Oceanográfico da Universidade de São Paulo, como parte dos requisitos para obtenção do título de Mestre em Ciências, Programa de Oceanografia, área de Oceanografia Física

Orientador: Prof. Dr. Marcelo Dottori

São Paulo 


\title{
UNIVERSIDADE DE SÃO PAULO INSTITUTO OCEANOGRÁFICO
}

\section{Resposta da Plataforma Continental de São Paulo ao vento sinótico: estudos numéricos}

\author{
Rafaela Farias do Nascimento
}

Dissertação apresentada ao Instituto Oceanográfico da Universidade de São

Paulo, como parte dos requisitos para obtenção do título de Mestre em Ciências, Programa de Oceanografia, área de Oceanografia Física.

Aprovada em _ I I I

$\operatorname{Prof}(\mathrm{a}) . \operatorname{Dr}(\mathrm{a})$.

conceito

Prof(a). Dr(a).

conceito

Prof(a). Dr(a).

conceito 
Não importa o quão ruim a vida possa ser, há sempre alguma coisa que você pode fazer e ter sucesso. Enquanto há vida, há esperança. 


\section{Sumário}

\begin{tabular}{lll}
\hline & Introdução & 2
\end{tabular}

1.1 Características gerais da área de estudo . . . . . . . . . . . . . . 2

1.2 Principais forçantes . . . . . . . . . . . . . . . 4

1.3 Considerações teóricas e estudos anteriores $\ldots \ldots \ldots \ldots$. . . . . . . . 7

1.4 Hipótese e objetivos . . . . . . . . . . . . . . . . . . . . . . . . . . . . 10

\begin{tabular}{|lll}
\hline 2 & Metodologia & 11
\end{tabular}

2.1 Modelo numérico e sua implementação . . . . . . . . . . . . . . . . . 11

2.1 .1 Descrição . . . . . . . . . . . . . . . . . . 11

2.1 .2 Módulo Hidrodinâmico . . . . . . . . . . . . . . . . . . . . . . 12

2.1 .3 Condições de Contorno . . . . . . . . . . . . . . . . . . . 15

2.1 .4 Grade do modelo . . . . . . . . . . . . . . . . . . . . . . . 17

2.2 Validação do modelo numérico $\ldots \ldots \ldots \ldots \ldots$. . . . . . . . . . 18

2.3 Simulações . . . . . . . . . . . . . . . . . . . . . . . 19

2.3.1 Climatologia de temperatura e salinidade . . . . . . . . . . . . 20

2.3 .2 Condição inicial de vento . . . . . . . . . . . . . . . . . 20

2.3 .3 Modelo de frente fria . . . . . . . . . . . . . . . . . 20

2.3 .4 Simulações de controle . . . . . . . . . . . . . . . . . 22

2.3 .5 Simulações Vento Remoto Sul . . . . . . . . . . . . . . . . . . . . 22

2.3 .6 Simulações Vento Total na PCSE $\ldots \ldots$. . . . . . . . . . . . . 23

\begin{tabular}{|lll}
\hline & Resultados e Discussão & 24
\end{tabular}

3.1 Simulações Controle . . . . . . . . . . . . . . . . . . . . . . 25

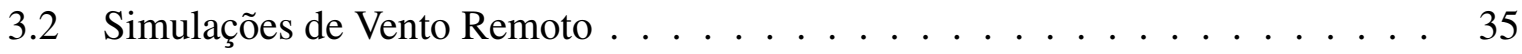

3.3 Simulações de Vento em toda a grade . . . . . . . . . . . . . . . . 53

3.3.1 Frentes com tempo de permanência inferior a 40 horas na PCSE . . . . 53

3.3.2 Frentes com tempo de permanência entre 40 a 60 horas na PCSE . . . . 65

3.3.3 Frentes com tempo de permanência superior a 60 horas na PCSE. . . . 77

\begin{tabular}{lll}
\hline Conclusões & 93
\end{tabular} 


\section{Agradecimentos}

Primeiramente gostaria de agradecer ao subsídio cedido pela $\mathrm{CNPq}$ para realização desse trabalho, e ao Programa de Pós-Graduação do Instituto Oceanográfico da Universidade de São Paulo.

Gostaria de agradecer a paciência e dedicação do meu orientador, Prof. Dr. Marcelo Dottori. Obrigada por ter aceitado aquela ligação via Skype há três anos atrás, para conversarmos sobre meu desejo de voltar à vida acadêmica. Minha vida desde aquela ligação deu um giro de $180^{\circ}$ que eu, às vezes, custo a acreditar.

Gostaria de agradecer ao meus pais, Núbia e Hélio, pela total confiança, apoio psicológico durante as semanas de provas e da entrega da dissertação. Mãe, obrigada pelos lanchinhos gostosos quando eu não tinha coragem de sair da frente do computador, para não diminuir o rendimento. Pai, obrigada pelos livros, pelo incentivo e pelos beijinhos na testa. À minha irmã Gabriela, obrigada por me alcamar nas crises de ansiedade, pelas pausas forçadas para desanuviar e as idas sem culpa ao cinema.

São tantas pessoas que acreditaram que, no fim, tudo daria certo, que provavelmente esquecerei a maioria. O que nunca poderei esquecer são os ensinamentos que tive o privilégio de receber dos melhores professores que uma oceanógrafa poderia ter: Prof. Belmiro, obrigada pelas reuniões de quarta e pela melhor caligrafia que eu já vi; ao Prof. Ilson, pela porta sempre aberta, o sorriso no rosto e pela apostila raríssima do Prof. Miranda; ao Prof. Joseph, obrigada por me ensinar a importância do MATLAB e da modelagem numérica; ao Prof. Paulo e a Profa. Olga, por me mostrar as maravilhas de um tanque rotatório e que como é difícil escrever um relatório de um experimento do tanque rotatório; e ao Prof. Miranda as aulas inspiradoras de estuário.

Mas, na minha caminhada, havia uma turma que nunca acreditou que daria certo, mas no fim deu: obrigada aos meus parceiros e amigos de pós-graduação Leandro, Thiago, Piero, Pedim e Pedrox. As depressões pós provas semestrais jamais serão as mesmas sem vocês! Sentirei falta de todos, das noites mal dormidas, da feijoada do Lele, das cervejas na Poli, das listas intermináveis e da ansiedade durante a espera das notas.

Aos meus companheiros de laboratório e de cafés: Danilo, Paulinha, Carine, Zé Roberto, Iago, Guilherme, Dalton, e demais! Trabalhar com um grupo assim era tudo que eu pedi na vida, afinal, nem toda a conversa entre oceanógrafos é sobre oceanografia.

Aos meus amigos que, de perto ou de longe, viveram comigo essa fase: as mafiosas Sis, Be e Thai, obrigada por me fazerem rir em momentos inadequados, aos passeios de obesianes, as convenções e aos surtos coletivos... Amo muito vocês; minhas amigas véias, Cá e Jac, obrigada por entender e incentivar, não deixando que eu esmorecesse; a família Quiloa: Danikita, Carol, Felipe, Hellen, Lígia, Rô, pai Jota, Lorena, KK, Lets, Audrey e aos demais irmãos de axé que vibraram comigo para que tudo desse certo (sinto saudades de vocês todos os dias!); a minha 
casa Ylê Axé Oxum Deym, vó Maria da Quixaba, mãe Joana e a todas as minhas irmãs e irmãos! Obrigada por estarem ao meu lado... Sei que posso caminhar em segurança sabendo que vocês sempre estarão comigo. 


\section{Resumo}

Com o intuito de estudar a resposta da Plataforma Continental Sudeste, e particularmente na Plataforma Continental de São Paulo (PCSP), aos ventos sinóticos, foram realizadas simulações numéricas através do modelo sECOM. As simulações prognósticas consideraram campos estratificados de temperatura e salinidade. Como forçante externa, foi introduzido o cisalhamento do vento de nordeste, típicos do centro de Alta Pressão do Atlântico Sul, e ventos sinóticos de sudoeste de um sistema frontal de baixa pressão (frente fria). Os resultados obtidos com a forçante vento atuando apenas no sul da PCSE mostraram que os ventos remotos são capazes de excitar perturbações do nível do mar sob a forma de Ondas de Plataforma Continental (OPC), principalmente na PCI e na PCM da PCSP. A velocidade de propagação da OPC foi entre 9.2 e 10.2 $\mathrm{ms}^{-1}$ na região sul da PCSE. Na região norte, com maior variabilidade, os valores foram entre 2.4 e $5.0 \mathrm{~ms}^{-1}$. O vento remoto de sudoeste foi capaz de inverter o sentido da corrente superficial de nordeste para sudoeste e, após a inversão, a corrente apresentou oscilação natural com período de 30 horas nas regiões próximas da atuação do vento. Nos experimentos com o vento atuando em toda a plataforma, as correlações do nível do mar entre as radiais de estudo foram máximas na PCI e na PCM da região sul da PCSE, com OPCs se propagando a $15.3 \mathrm{~ms}^{-1}$. Na região norte, as OPCs apresentatam velocidades de 3.6 a $7.2 \mathrm{~ms}^{-1}$, dependendo da velocidade das frentes frias. As simulações ainda revelaram ressonância da corrente superficial associada com a velocidade de propagação dos sistemas frontais, com correntes na região de Cananéia se amplificando com frentes se deslocando a $11.4 \mathrm{~ms}^{-1}$. A região de Santos e Ubatuba apresentou corrente máxima com frentes se propagando a $9.5 \mathrm{~ms}^{-1}$. As correntes superficiais geradas nas simulações de vento em toda a plataforma também apresentaram oscilações inerciais na PCM e PCE da PCSE, após a inversão dos ventos.

Palavras-chave: modelagem numérica, vento remoto, vento sinótico, Ondas de Plataforma Continental, PCSE, PCSP. 


\section{Abstract}

Numerical simulations were made using the sECOM model to study the response of the South Brazilian Bight (SBB), especially the São Paulo Continental Shelf (SPCS), to synoptic winds. Prognostic simulations were performed using a stratified sanility and temperature fields as initial conditions. Two different wind shear forcing were included: the northeast winds derived from the South Atlantic High, and the southweast synoptic winds from low pressure frontal systems. Results from the wind forcing experiments only in the south of SBB showed that the remote winds are capable of exciting sea level disturbances in the form of continental shelf waves (CSW), mainly in the inner and middle shelf of SPCS. Phase speed between 9.2 and $10.2 \mathrm{~ms}^{-1}$ were found at southern of the SBB. The northern region showed high variability, with values between 2.4 e $5.0 \mathrm{~ms}^{-1}$. Southwest remote wind was able to reverse the direction of the surface current from northeast to southweast. Such the inversion promoted natural oscillation of surface current with period of 30 hours in regions close to the wind action. In the wind experiments acting over the SBB, the cross correlation between the sea level of differents stations were highest at the southern portion of the inner and middle shelf, displaying CSW phase speed of $15.3 \mathrm{~ms}^{-1}$. In the northern region, CSW phase speed ranges from 3.6 to 7.2 $\mathrm{ms}^{-1}$, depending on the velocity of the frontal systems propagation. Numerical simulations results revealed the resonance of the surface current associated with the speed propagation of the frontal systems. Currents off Cananéia amplified when fronts propagate at speeds of 11.4 $\mathrm{ms}^{-1}$. Continental shelf regions off Santos and Ubatuba exhibit maximum currents with fronts moving at $9.5 \mathrm{~ms}^{-1}$. Surface currents resulting from local wind forcing showed the occurrence of inertial oscillations after the inversion of the winds, mainly in middle shelf and outer shelf of SBB.

Key-words: numerical modeling, remote wind, synoptic wind, continental shelf waves, SBB, SPCS. 


\section{Lista de Figuras}

1.1 Plataforma Continental Sudeste. A isobatimétrica pontilhada de $200 \mathrm{~m}$ indica a profundidade aproximada máxima da quebra da plataforma continental. Figura extraída de Gregório (2014). . . . . . . . . . . . . . . . . . . . . . . . 3

1.2 Esquema da compartimentação dinâmica da Plataforma Continental Sudeste. PCI: plataforma continental interna; PCM: plataforma continental média; PCE: plataforma continental externa; ACAS: Água Central do Atlântico Sul; AT: Água Tropical. Figura baseada em Castro (1996) e Gregório (2014). . . . . . . . . . . . . . . . . . . . 3

1.3 Modelo conceitual de frente fria para a PCSE. Figura extraída de Stech e Lorenzzetti

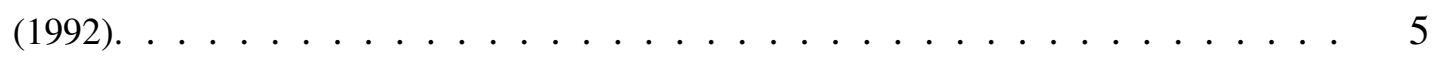

1.4 Modelo de frente fria típica de verão sobre a PCSE proposto por Coelho (2007). Figura extraída de Mazzini (2009). . . . . . . . . . . . . . . . . . 6

$2.1 \quad$ Sistema de coordenada sigma $(\sigma)$. Figura extraída de Blumberg (2010). . . . . . . . . 12

2.2 Grade curvilínea e ortogonal utilizada nas simulações adaptada de Pereira et al. (2007). Figura extraída de Morais (2016). . . . . . . . . . . . . . . . . . . . 18

2.3 Vento característico da ASAS, elaborado a partir de dados do dia 17/03/2000-12H. . . 20

2.4 Modelo de frente fria: frente (a) no Cabo de Santa Marta-SC; (b) em Cananéia-SP; (c) em Santos-SP; (d) em Ilha Grande-RJ; (e) em Cabo Frio-RJ; e (f) após Cabo Frio-RJ. . 21

2.5 Ventos forçados na porção sul da PCSE: (a) ventos de nordeste típicos da ASAS e (b) ventos de sudoeste típicos de frente fria. . . . . . . . . . . . . . 23

3.1 Localização das radiais na grade do modelo. [1] Radial Cananéia, [2] Radial Santos, [3] Radial Ubatuba e [4] Radial Cabo Frio. . . . . . . . . . . . . . . . . . . . . . 24

3.2 Mapas de elevação da superfície do mar nos experimentos (a) SC1 e (b) SC2. . . . . . 26

3.3 Séries temporais de elevação nas radiais (a) Cananéia e (b) Cabo Frio no experimento SC1; (c) Cananéia e (d) Cabo Frio no experimento SC2. . . . . . . . . . . . . . 28

3.4 Mapas de velocidade máxima na superfície e mapas de velocidade média na PCSE, no experimento SC1 (a) e (b), e experimento SC2 (c) e (d). . . . . . . . . . . . . . . 29

3.5 Séries temporais de velocidade na superfície, das radiais Santos e Cabo Frio, simulação SC1. . . . . . . . . . . . . . . . . . . 31 
3.6 Séries temporais de velocidade na superfície das radiais Santos e Cabo Frio, simulação

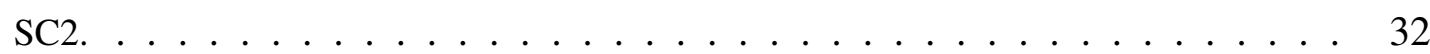

3.7 Série temporal de elevação e perfis verticais de velocidade perpendicular (U) e paralela (V) após 10 dias de simulação, experimento SC1. (a) radial Santos e (b) radial Cabo Frio. 33

3.8 Série temporal de elevação e perfis verticais de velocidade perpendicular (U) e paralela (V) após 10 dias de simulação, experimento SC2. (a) radial Santos e (b) radial Cabo Frio. 34

3.9 Mapas de elevação máxima do nível do mar nos experimentos (a) RS1, (b) RS2, (c) RS3 e (d) RS4. . . . . . . . . . . . . . . . . . . . 36

3.10 Séries temporais de elevação na radial Cananéia. (a) experimento RS1, (b) RS2, (c) RS3 e (d) RS4. . . . . . . . . . . . . . . . . . . . . . . . . . 38

3.11 Mapas de correlação da elevação do nível do mar em relação ao ponto de referência (ム), em (a) RS1, (b) RS2, (c) RS3 e (d) RS4. . . . . . . . . . . . . . . . . . . . . . 39

3.12 Isopletas de elevação da Onda de Plataforma Continental, nos experimentos (a) RS1 , (b) RS2, (c) RS3 e (d) RS4. Dados filtrados em 40 horas. . . . . . . . . . . . . . . . 41

3.13 Mapas de velocidade máxima na superfície da PCSE. (a) RS1, (b) RS2, (c) RS3 e (d)

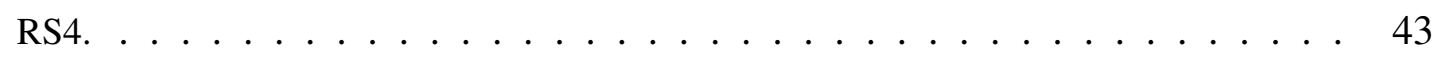

3.14 Mapas de velocidade média na PCSE. (a) RS1, (b) RS2, (c) RS3 e (d) RS4. . . . . . . 45

3.15 Séries temporais de velocidade na superfície na radial Cananéia, simulação RS1. . . . 46

3.16 Séries temporais de velocidade na superfície na radial Cananéia, simulação RS2. . . . 46

3.17 Séries temporais de velocidade na superfície na radial Cananéia, simulação RS4. . . . 48

3.18 Série temporal de elevação e perfis verticais de velocidade perpendicular (U) e paralela (V) em Cananéia, simulação RS2. . . . . . . . . . . . . . . . . . . . . . . 49

3.19 Série temporal de elevação e perfis verticais de velocidade perpendicular (U) e paralela (V) em Santos, simulação RS4. . . . . . . . . . . . . . . . . . . . . . 50

3.20 Série temporal de elevação e perfis verticais de velocidade perpendicular (U) e paralela (V) em Ubatuba, simulação RS3. . . . . . . . . . . . . . . . . . . . . . . . 51

3.21 Série temporal de elevação e perfis verticais de velocidade perpendicular (U) e paralela (V) em Cabo Frio, simulação RS3. . . . . . . . . . . . . . . . . . . . . . . 52

3.22 Mapas de elevação máxima do nível do mar nos experimentos (a) SVT1, (b) SVT2,(c) SVT3 e (d) SVT4. . . . . . . . . . . . . . . . . . . . . . . . . . . . . . 54

3.23 Séries temporais de elevação, sendo (a) radial Cananéia e (b) radial Ubatuba no experimento SVT1, e (c) radial Cananéia (d) Radial Ubatuba no experimento SVT4. . . . . . 55

3.24 Mapas de correlação da elevação do nível do mar em relação ao ponto de referência (ム) em (a) SVT1, (b) SVT2, (c) SVT3 e (d) SVT4. . . . . . . . . . . . . . . . . . . . . 56

3.25 Isopletas de elevação da Onda de Plataforma Continental, nos experimentos (a) SVT1, (b) SVT2, (c) SVT3 e (d) SVT4. Dados filtrados em 40 horas. . . . . . . . . . . . . 58

3.26 Mapas de velocidade máxima na superfície da PCSE. (a) SVT1, (b) SVT2, (c) SVT3 e (d) SVT4. . . . . . . . . . . . . . . . . . . . . . . . 60

3.27 Séries temporais de velocidade na superfície na radial Cananéia, na simulação SVT4. . 62 
3.28 Séries temporais de velocidade na superfície na radial Ubatuba, na simulação SVT4.

3.29 Série temporal de elevação e perfis verticais de velocidade perpendicular (U) e paralela (V) durante a passagem da primeira frente fria na radial Cananéia no experimento SVT1. 63

3.30 Série temporal de elevação e perfis verticais de velocidade perpendicular (U) e paralela (V) durante a passagem da terceira frente fria na radial Santos no experimento SVT4. . 63

3.31 Intensidade dos ventos de frente fria sobre sul da PCSE. . . . . . . . . . . . . . 64

3.32 Série temporal de elevação e perfis verticais de velocidade perpendicular (U) e paralela

\begin{tabular}{|c|}
\hline (V) durante a passagem da primeira frente fria na radial Ubatuba no experimento SVT4. 65 \\
\hline
\end{tabular}

3.33 Mapas de elevação máxima do nível do mar nos experimentos (a) SVT5, (b) SVT6,(c)

SVT7 e $(\mathrm{d}) \mathrm{SVT}$. . . . . . . . . . . . . . . . . . . 66

3.34 Séries temporais de elevação, sendo (a) radial Ubatuba e (b) radial Cabo Frio do experimento SVT5, e (c) radial Ubatuba (d) Radial Cabo Frio do experimento SVT8. . . . 67

3.35 Mapas de correlação da elevação do nível do mar em relação ao ponto de referência (ム), em (a) SVT5, (b) SVT6, (c) SVT7 e (d) SVT8. . . . . . . . . . . . . . . . . 68

3.36 Isopletas de elevação da Onda de Plataforma Continental, nos experimentos (a) SVT5, (b) SVT6, (c) SVT7 e (d) SVT8. Dados filtrados em 40 horas. . . . . . . . . . . . . 70

3.37 Mapas de velocidade máxima na superfície da PCSE. (a) SVT5, (b) SVT6, (c) SVT7 e (d) SVT8. . . . . . . . . . . . . . . . . . . . . . 72

3.38 Séries temporais de velocidade na superfície na radial Santos nos experimentos (a) SVT5 e (b) SVT8. . . . . . . . . . . . . . . . . . . . . . . . . . . . . . 74

3.39 Séries temporais de velocidade na superfície na radial Ubatuba nos experimentos (a) SVT5 e (b) SVT8. . . . . . . . . . . . . . . . . . . . . . . . 75

3.40 Série temporal de elevação e perfis verticais de velocidade perpendicular (U) e paralela (V) na radial Santos no experimentos SVT8. . . . . . . . . . . . . . . . 76

3.41 Série temporal de elevação e perfis verticais de velocidade perpendicular (U) e paralela (V) na radial Ubatuba no experimentos SVT5. . . . . . . . . . . . . . . . . 76

3.42 Mapas de elevação máxima do nível do mar nos experimentos (a) SVT9 e (b) SVT10. . 78

3.43 Séries temporais de elevação, sendo (a) radial Santos e (b) radial Cabo Frio do experimento SVT9, e (c) radial Santos (d) Radial Cabo Frio do experimento SVT10. . . . . 79

3.44 Mapas de correlação da elevação do nível do mar em relação ao ponto de referência (ム), em (a) SVT9 e (b) SVT10. . . . . . . . . . . . . . . . . . . . . . . . 80

3.45 Isopletas de elevação da Onda de Plataforma Continental, nos experimentos (a) SVT9 e (b) SVT10. Dados filtrados em 40 horas. . . . . . . . . . . . . . . . . . . . . 82

3.46 Mapas de velocidade máxima na superfície da PCSE. (a) SVT9 e (b) SVT10. . . . . . . 84

3.47 Séries temporais de velocidade na superfície na radial Ubatuba, experimento SVT9. . . 85

3.48 Séries temporais de velocidade na superfície na radial Ubatuba, experimento SVT10. . 85

3.49 Séries temporais de velocidade na superfície na radial Ubatuba, experimento SVT1. . . 86

3.50 Série temporal de elevação e perfis verticais de velocidade perpendicular (U) e paralela (V) durante a passagem da primeira frente fria na radial Ubatuba, experimento SVT10. 
3.51 Série temporal de elevação e perfis verticais de velocidade perpendicular (U) e paralela (V) durante a passagem da terceira frente fria na radial Cabo Frio no experimento SVT10. 90

3.52 Componentes da velocidade, sob ação de frentes se propagando a (a) $11.4 \mathrm{~ms}^{-1}$, (b)/(c) a $9.5 \mathrm{~ms}^{-1}$, e (d) a $4.7 \mathrm{~ms}^{-1}$. . . . . . . . . . . . . . . . . . 91

3.53 Intensidade dos ventos de frente fria sobre (a) sul da PCSE, (b)-(c) centro da PCSE e (d) norte da PCSE. . . . . . . . . . . . . . . . . . . . . . . 92 


\section{Lista de Tabelas}

2.1 Relação dos fundeios selecionados por Morais (2016) para a validação do modelo númerico na PCSE. . . . . . . . . . . . . . . . . . 18

2.2 Velocidade de propagação média e desvio padrão da média para as frentes frias que se deslocam desde Cabo de Santa Marta a Cabo de São Tomé, durante o verão. . . . . . . 22

2.3 Características das Simulações de Vento Remoto Sul, onde Tempo de Permanência é o tempo de ação da frente na região sul da PCSE. . . . . . . . . . . . . . . . . 22

2.4 Características das Simulações de Vento Total na PCSE, onde Vel Prop. é a velocidade de propagação de cada frente fria, e Tempo de Permanência é o tempo total da frente na PCSE. . . . . . . . . . . . . . . . . . 23

3.1 Relação dos valores de atraso e velocidade de propagação da Onda de Plataforma Continental, nos experimentos remotos de Sul. . . . . . . . . . . . . . . . . . . 42

3.2 Relação dos valores de atraso da correlação e velocidade de propagação da Onda de Plataforma Continental, nos experimentos SVT1, SVT2, SVT3 e SVT4. ..... 59

3.3 Relação dos valores de atraso da correlação e velocidade de propagação da Onda de Plataforma Continental, nos experimentos SVT5, SVT6, SVT7 e SVT8. .... . . 71

3.4 Relação dos valores de atraso da correlação e velocidade de propagação da Onda de Plataforma Continental, nos experimentos SVT9 e SVT10. . . . . . . . . . . . . . . 82

3.5 Dados de período inercial médio, variância e desvio padrão calculados para a PCI, PCM e PCE, em horas, nas radiais Cananéia, Santos, Ubatuba e Cabo Frio. . . . . . . . . . 87

3.6 Período estimado, em horas, das oscilações naturais após a passagem das frentes frias na PCI, PCM e PCE nas radiais Cananéia, Santos, Ubatuba e Cabo Frio. . . . . . . . 88 


\section{Lista de Siglas}

ACAS Água Central do Atlântico Sul.

ASAS Alta Subtropical do Atlântico Sul.

AT Água Tropical.

CB Corrente do Brasil.

CFSR Climate Forecast System Reanalysis.

DEPROAS Dinâmica do Ecossitema de Plataforma da Região Oeste do Atlântico Sul.

DHN Diretoria de Hidrografia e Navegação.

ECOSAN Influência do Complexo Estuarino da Baixada Santista sobre o Ecossistema da Plataforma Adjacente.

FHS Frente Halina Superficial.

FTP Frente Térmica Profunda.

NCEP National Centers for Envirommental Prediction.

OB Ondas de Borda.

OCC Ondas Confinadas Costeiras.

OK Ondas de Kelvin.

OPC Onda de Plataforma Continental.

PCE Plataforma Continental Externa.

PCI Plataforma Continental Interna.

PCM Plataforma Continental Média. 
PCSE Plataforma Continental Sudeste.

PCSP Plataforma Continental de São Paulo.

POM Princeton Ocean Model.

SECOM Stevens Institute Estuarine and Coastal Ocean Hydrodynamic Model.

T/S temperatura e salinidade. 


\section{Capítulo 1}

\section{Introdução}

\subsection{Características gerais da área de estudo}

Inserida na Plataforma Continental Sudeste (PCSE), que se estende desde Cabo Frio $\left(23^{\circ} \mathrm{S}\right)$, no litoral norte do Rio de Janeiro, até o Cabo de Santa Marta (28.5 $\left.{ }^{\circ} \mathrm{S}\right)$, em Santa Catarina, a Plataforma Continental de São Paulo (PCSP) corresponde a parte central desta região (Figura 1.1 , com cerca de $400 \mathrm{~km}$ de extensão e possui dinâmicas típicas de plataformas continentais de latitudes médias (Castro 1996), ou seja, está suficientemente afastada do Equador para que o efeito de rotação da Terra e consequentemente o efeito de Coriolis sejam importantes. Deste modo, assume perfil geostrófico para movimentos em escala temporal maiores que o período inercial e escalas espaciais superiores ao raio de deformação de Rossby.

Com largura entre 150 e 230 km, sendo mais estreita ao largo da Ilha de São Sebastião e mais larga em frente a Santos, a PCSP possui topografia com inclinação suave, da ordem de 1/1000, com isóbatas posicionadas paralelamente à linha de costa, sendo que a quebra da plataforma ocorre aproximadamente num intervalo de $120 \mathrm{~m}$ a $180 \mathrm{~m}$ de profundidade (Zembruscki 1979; Castro 1996). O alinhamento da costa é cerca de $50^{\circ}$ leste do norte verdadeiro, e abrange uma série de baías de dimensões médias à pequenas, especialmente na sua porção mais à leste.

De modo geral a PCSP tende a ser verticalmente homogênea em decorrência dos processos de mistura e advectivos associados aos ventos e a maré. No entanto, observa-se uma marcante termoclina e picnoclina nas profundidades de $25 \mathrm{~m}$ a $30 \mathrm{~m}$ durante o verão e, durante o inverno, a camada de mistura é geralmente bem desenvolvida sobre a maior parte da plataforma, com a coluna d'água mostrando apenas pequenas variações de temperatura e densidade sobre essas profundidades (Miranda 1982).

Considerando as características termohalinas da plataforma continental, Castro (1996) dividiu a região norte da Plataforma Continental Sudeste em três setores, divisão que pode ser aplicada à região da PCSP, Plataforma Continental Interna (PCI), Plataforma Continental Média (PCM) e Plataforma Continental Externa (PCE). Essas três zonas são delimitadas essencialmente por duas frentes: a Frente Térmica Profunda (FTP) e a Frente Halina Superficial (FHS), 


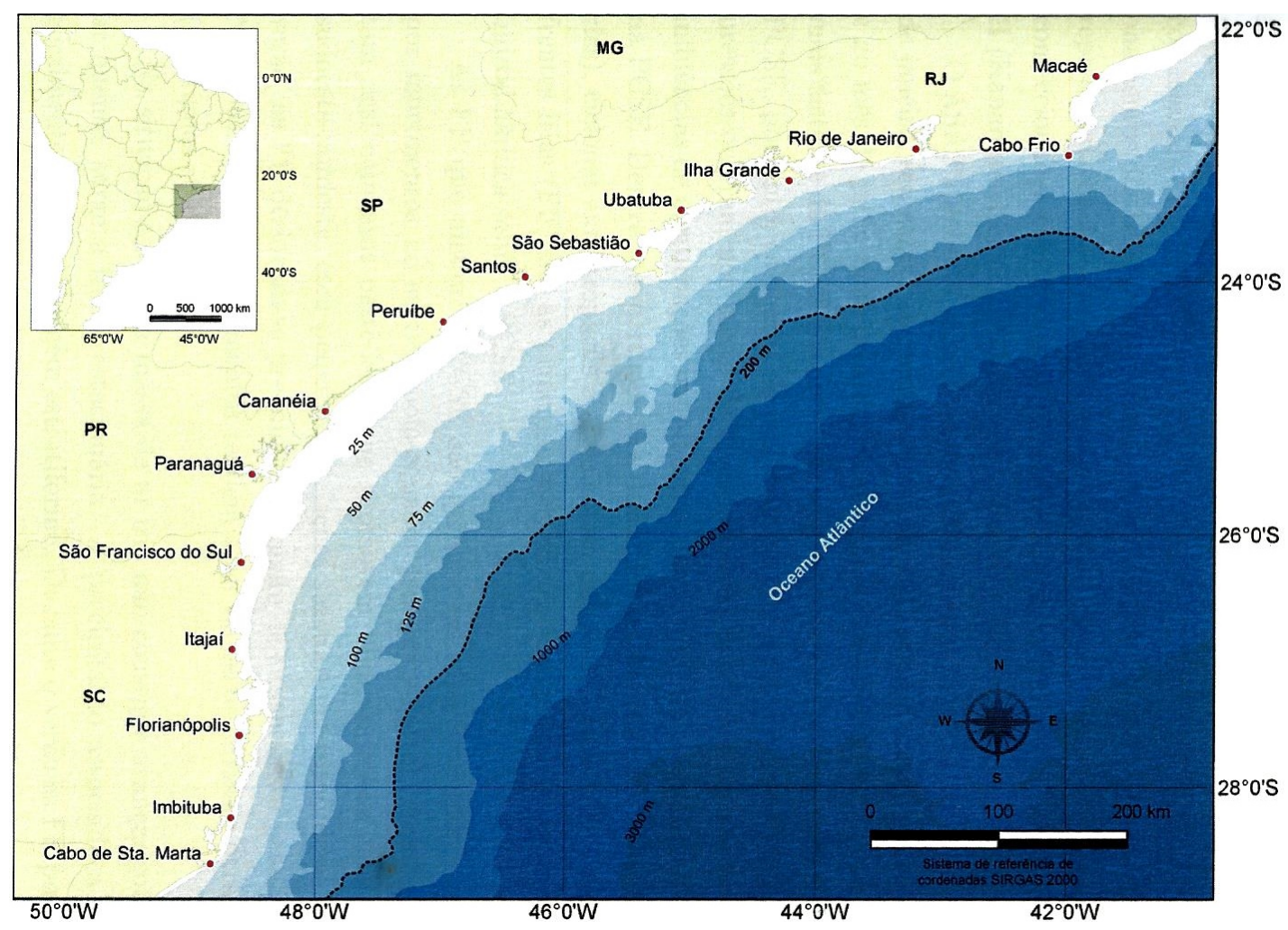

Figura 1.1: Plataforma Continental Sudeste. A isobatimétrica pontilhada de $200 \mathrm{~m}$ indica a profundidade aproximada máxima da quebra da plataforma continental. Figura extraída de Gregório (2014).

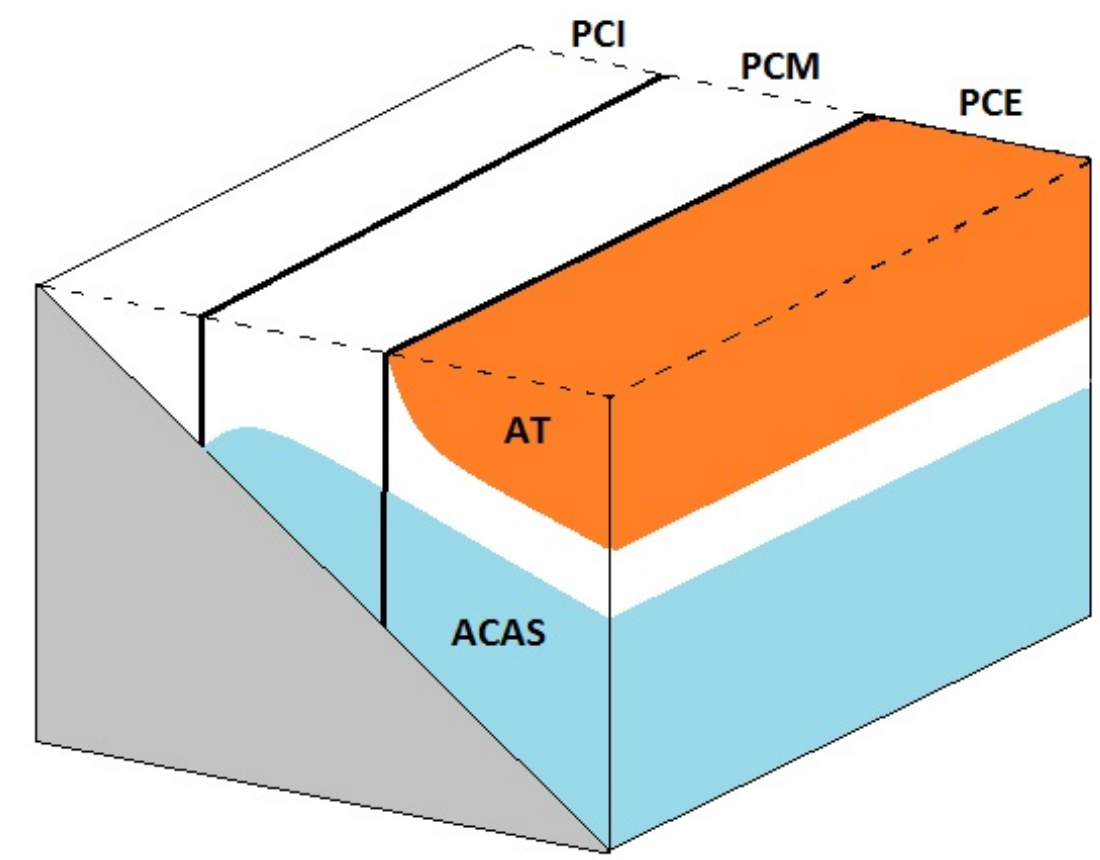

Figura 1.2: Esquema da compartimentação dinâmica da Plataforma Continental Sudeste. PCI: plataforma continental interna; PCM: plataforma continental média; PCE: plataforma continental externa; ACAS: Água Central do Atlântico Sul; AT: Água Tropical. Figura baseada em Castro (1996) e Gregório (2014). 
A FTP corresponde à intersecção da termoclina sazonal com o fundo, abrangendo temperaturas de $18^{\circ} \mathrm{C}$ a $22^{\circ} \mathrm{C}$, definindo o limite interno da Água Central do Atlântico Sul (ACAS), situada na camada mais funda das águas residentes na plataforma continental. A FHS corresponde ao limite interno da Água Tropical (AT) na camada superficial e é caracterizada pela isohalina de 36.

Como mostra a Figura 1.2, a $\mathrm{PCI}$ estende-se entre a costa e a FTP, a $\mathrm{PCM}$ corresponde a área entre a FTP e a FHS, e a PCE estende-se entre a FHS e a quebra da plataforma.

\subsection{Principais forçantes}

A região da $\mathrm{PCSP}$ está sob regime de diferentes forçantes, que atuam de forma combinada ou dominante em algumas regiões da plataforma, em distintas escalas espaciais e temporais, tais como a Corrente do Brasil (CB), as marés, os ventos e as descargas fluviais.

Derivada do ramo mais boreal da Corrente Sul Equatorial (Peterson e Stramma 1991), que gira anticiclonicamente para sul próximo à $10^{\circ} \mathrm{S}$, a $\mathrm{CB}$ é a corrente de contorno associada ao Giro Subtropical do Atlântico Sul e tem sua magnitude calculada em cerca de 4 Sv $\rrbracket^{1}$ nessa latitude, fluindo para sudoeste acompanhando a linha de quebra da plataforma. Logo imediatamente ao sul de Cabo Frio, onde a orientação da costa de NE-SW muda abruptamente para E-W, a conservação de vorticidade potencial força a $\mathrm{CB}$ a girar ciclonicamente para oeste, aproximando-se novamente da plataforma continental em cerca de $24^{\circ} \mathrm{S}$ (Castro 1996).

No que se refere ao transporte, Campos, Gonçalves, e Ikeda (1995), usando medições hidrográficas estimaram, através do cálculo dinâmico, cerca de 7,3 Sv da CB entre aproximadamente $23^{\circ} \mathrm{S}$ e $24^{\circ} \mathrm{S}$, sendo que cerca de $1 / 10$ do transporte da $\mathrm{CB}$ ocorre sobre a plataforma continental (Castro 1996).

A região mais interna da PCSE, e consequentemente da PCSP, não sofre, em geral, influência direta da $\mathrm{CB}$, as correntes de maré nesta plataforma são pouco energéticas, apesar do movimento ser dominado pelas componentes diurnas (O1 e K1) e semi-diurnas (M2 e S2), e não há deságue de grandes rios (Castro 1996). Assim, supostamente, uma das forçantes mais energéticas da PCSE e da PCSP é o vento.

Em relação à oscilações de baixa freqüência, na escala de tempo subinercial, o cisalhamento do vento associado ao centro de Alta Pressão do Atlântico Sul (ASAS) e a passagem de sistemas meteorológicos frontais (frentes frias), são os principais geradores de movimentos na região (Emilsson 1962; Kvinge 1967; Castro 1990; Dottori e Castro 2009).

A Alta Subtropical do Atlântico Sul (ASAS) é um sistema de alta pressão que rege o padrão de ventos da PCSP, cuja direção predominante dos ventos é de E-NE, ou seja, orientados paralelamente à linha de costa da região (Castro 1996; Rahy 2006, Mazzini 2009). Periodicamente a climatologia de ventos muda, forçada por sistemas frontais, que são sistemas sinóticos ciclô-

\footnotetext{
${ }^{1} 1 \mathrm{~Sv}$ equivale a $10^{6} \mathrm{~m}^{3} \mathrm{~s}^{-1}$
} 


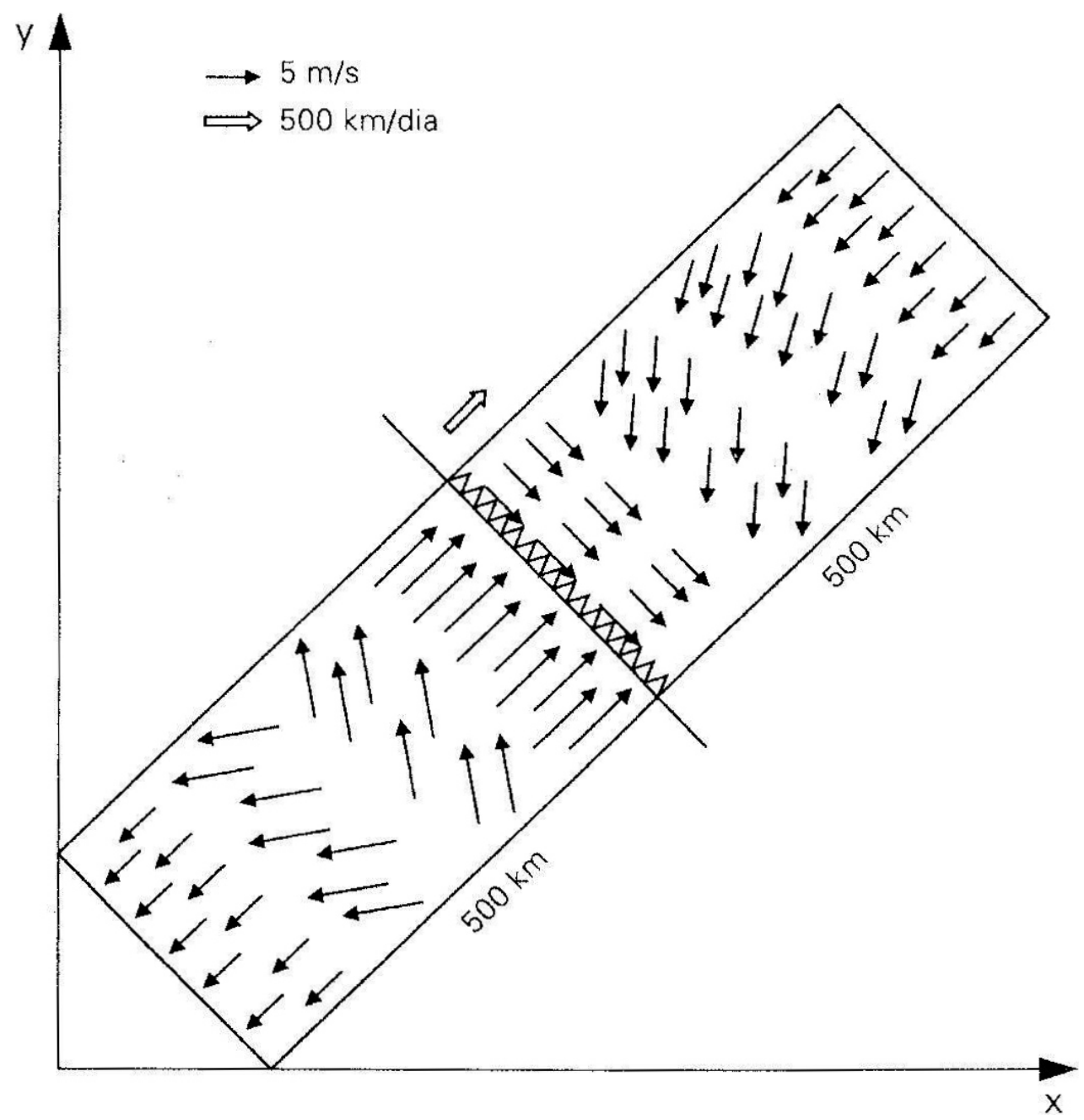

Figura 1.3: Modelo conceitual de frente fria para a PCSE. Figura extraída de Stech e Lorenzzetti (1992).

nicos, de baixa pressão, responsáveis por ventos de direção predominante S-SW, com sentido oposto ao padrão médio de ventos da região.

Castro (1996) utilizando dados interpolados por Samuels e Cox (1987) a partir de dados históricos, descreveu a climatologia da tensão de cisalhamento do vento da Plataforma Continental Norte de São Paulo onde, durante o verão, são observados ventos predominantes do E-NE sobre a região costeira, entre $15^{\circ} \mathrm{S}$ e $35^{\circ} \mathrm{S}$, e durante o inverno, a banda de ventos provenientes de E-NE fica confinada entre as latitudes $20^{\circ} \mathrm{S}$ a $25^{\circ} \mathrm{S}$, sendo a plataforma continental localizada ao sul de $25^{\circ} \mathrm{S}$ forçada por ventos predominantes oriundos de W-SW.

Stech e Lorenzzetti (1992) usando imagens termais do satélite GOES e cartas meteorológicas sinóticas, definiram um modelo conceitual para as frentes frias na Platadorma Continental Sudeste (Figura 1.3), verificando que a velocidade máxima de um sistema frontal, com deslocamento SW-NE, é de aproximadamente de $500 \mathrm{~km} / \mathrm{dia}$.

Segundo Oliveira (1986), as frequiências das frentes frias tende a diminuir em direção ao Equador e a aumentar durante o inverno. Logo, entre $20^{\circ} \mathrm{S}$ e $34^{\circ} \mathrm{S}$, a ocorrência de sistemas frontais varia ao longo do ano entre 3 e 6 por mês, resultando em intervalos de frentes frias de 

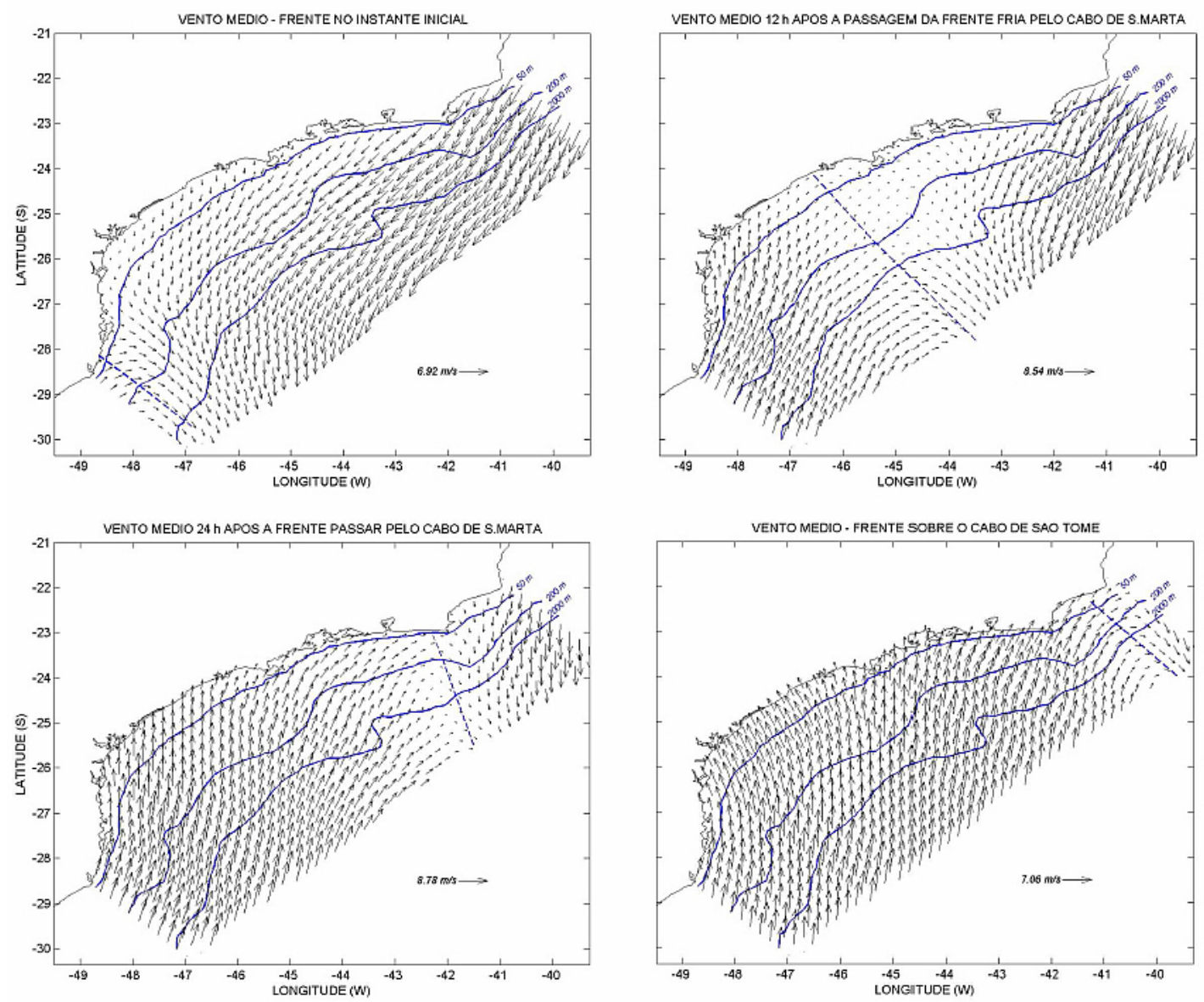

Figura 1.4: Modelo de frente fria típica de verão sobre a PCSE proposto por Coelho (2007). Figura extraída de Mazzini (2009).

5 a 10 dias.

Um modelo mais recente para frentes frias foi proposto por Coelho (2007), elaborado a partir de cartas sinóticas fornecidas pela Diretoria de Hidrografia e Navegação (DHN) referentes ao período entre 1998 e 2005 (Figura 1.4). O autor selecionou 12 frentes frias e suas velocidades foram calculadas considerando uma propagação linear paralela à costa, de SW para NE, concluindo que as velocidade média de propagação das frentes frias é mais rapida no verão do que no inverno, com velocidade típica de verão de aproximadamente $9.1 \mathrm{~ms}^{-1}$, percorrendo cerca de $1000 \mathrm{~km}$ em pouco mais de 30 horas.

Em estudo sobre a hidrodinâmica da PCI de São Paulo, Morais (2016), ao analisar dados de corrente subinerciais em fundeios nas regiões ao sul e ao norte da Ilha de São Sebastião, concluiu que durante o verão as correntes na PCI ao sul de São Sebastião tem sentido predominante para nordeste, deixando a costa a esquerda, e ao norte o sentido da corrente apresenta maior variabilidade, com frequentes inversões no sentido. $\mathrm{O}$ autor considerou que durante o verão, onde é evidente o aumento das precipitações sobre o continente, espera-se que o aporte de águas de origem continental seja intensificado, o que provocaria o aumento do gradiente de pressão perpendicular à costa, originando correntes geostróficas que deixam a costa à esquerda do movimento. Ao norte da ilha a competição entre as correntes geradas pelo fluxo de flutuabilidade 
(para nordeste), intensificado pelo aporte fluvial, e as geradas pelo vento (para sudoeste), são intensificadas, o que justifica a maior variabilidade da componente paralela à costa da corrente.

\subsection{Considerações teóricas e estudos anteriores}

A tensão de cisalhamento do vento é uma das principais forçantes para movimentos na plataforma continental, cuja resposta à essa forçante tem escala espacial de meso a larga $\left(>10^{3} \mathrm{~m}\right)$ e temporal de subinercial a sazonal (dias a anos). Em regiões sujeitas à passagem de sistemas meteorológicos frontais, a variabilidade das correntes em escala subinercial, principalmente em regiões internas e médias da plataforma continental, é forçada pela variabilidade sinótica do campo de ventos. Essa resposta pode ocorrer praticamente em fase com o vento, quando a forçante local é dominante em regimes altamente friccionais, como aqueles estudados por Csanady (1978). Entretanto, quando o atrito entre a corrente e o fundo do mar aparece na equação do movimento como termo de menor ordem, a resposta pode ser dominada pela variabilidade do vento remoto. Nesse caso, perturbações geradas remotamente propagam-se ao longo da costa como Ondas de Plataforma Continental (OPC, Gill e Schumann 1974).

A Onda de Plataforma Continental (OPC) é uma variedade de Ondas Confinadas Costeiras (OCC), que são ondas denominadas subinerciais ou submaregráficas, oscilações forçados pelo vento sinótico, confinados à costa devido ao gradiente topográfico e a presença da margem continental (Wang e Mooers 1976; Huthnance 1975), e se propagam mantendo a costa à direita no Hemisfério Norte e à esquerda no Hemisfério Sul. Tais ondas de baixa frequência exercem significantes influências na dinâmica e na variabilidade de fluxos ao longo da plataforma, uma vez que causam variações no nível do mar e flutuações nas correntes longitudinais à linha de costa (França 2013).

Segundo Huthnance (1975), tanto a presença da margem continental quanto da declividade de fundo, no espectro subinercial, proporciona o aprisionamento junto à costa de três tipos distintos de OCC: Ondas de Kelvin (OK), Ondas de Borda (OB) e Ondas de Plataforma Continental (OPC).

Ondas de Kelvin (OK) são definidas como ondas gravitacionais, sob influência da rotação terrestre junto a uma fronteira lateral, cuja amplitude decai exponencialmente em direção ao oceano. As OK são mantidas por um equilíbrio entre a força de Coriolis e gradiente de pressão normal à costa.

Ainda conforme Huthnance (1975), as Ondas de Borda (OB) são modos de oscilações com frequência maior que a inercial, e que dependem do aumento da profundidade da coluna d'água ao largo da plataforma continental.

Descritas pela primeira vez por Robinson (1964), OPC são ondas de vorticidade, aprisionadas sobre a margem continental através da conservação de vorticidade potencial. $\mathrm{O}$ alongamento ou compressão da coluna d'água, proporcionada pela variação topográfica, gera uma diferença de vorticidade que tende a dirigi-la para sua posição original, mantendo-a confinada à costa 
(Wang e Mooers 1976), e diferentemente de uma OB, aPC se propaga ao longo da costa.

Gill e Schumann (1974) mostraram que as OPCs não seriam formadas com a ausência de uma margem continental, pois com a presença da costa, o fluxo de Ekman na camada de Ekman Superficial é bloqueado, e por continuidade, um fluxo compensatório em sentido oposto é gerado nas camadas mais profundas. Assim, em uma região submetida a um regime de ventos que origine um fluxo perpendicular na camada superficial em direção à costa, o contrafluxo nas camadas inferiores será em direção ao largo, e quando esse fluxo cruzar as isóbatas, mudanças na vorticidade relativa local serão geradas por estiramento do tubo de vórtice, e para preservar sua vorticidade potencial, o fluxo ficará confinado à profundidades mais rasas (Brink 1991) Rahy 2006).

Concentrando a atenção nos movimentos subinerciais, nos estudos de Castro (1996) e Dottori e Castro (2009), o comportamento das águas na PCSP quando forçadas por ventos subnerciais, ou seja, sistemas frontais, é essencialmente barotrópico. Estes autores estimaram a contribuição do modo barotrópico na variabilidade dos movimentos subinerciais na região em mais de $90 \%$, de maneira geral. Além dos movimentos horizontais gerados pelo vento local, também são observadas variações no nível do mar, geradas por forçantes remotas associadas às Ondas de Plataforma Continental (Castro e Lee 1995).

Castro e Lee (1995) ao estudarem o comportamento das ondas subinerciais na costa brasileira, observaram OCPs ao longo da costa sudeste, onde encontraram as maiores amplitudes ao sul, com velocidade de propagação para nordeste de cerca de $10 \mathrm{~ms}^{-1}$, com picos de energia na faixa temporal de 9 a 12 dias, e na faixa de 6 a 7 dias, picos estes associados à dados de nível do mar, ventos e pressão atmosférica. Para esses picos, os autores observaram o nível do mar respondendo predominantemente a ventos com orientação SSW para NNE e SSE para NNW, respectivamente. Além disso, esse autores obtiveram maior correlação entre o nível do mar e os ventos mais ao sul da região estudada, indicando maior influência de forçantes remotas na gerações de ondas subinerciais.

Em trabalho anterior, Castro (1990), ao estudar simultaneamente dados de vento, corrente e nível do mar no Canal de São Sebastião, e de pressão atmosférica e nível do mar na PCSE verificou que as correntes com escala subinercial são principalmente forçadas pelo vento, sendo que a variação causada pelo efeito de maré é pequena. A melhor correlação entre a corrente subinercial e o vento corresponde a uma defasagem temporal de 12-18 horas, indicando que as correntes dirigidas pelo vento não são totalmente forçadas pelo vento local, sendo ligada a circulação da plataforma interna, englobando uma região mais ampla. O autor verificou que vento, corrente e nível do mar são dominados por oscilações na banda subinercial de 11-16 dias e 3 dias, com significativa coerência entre os sinais.

Uma desafasagem de 12-24 horas nos dados de vento em relação aos dados de nível do mar também foi encontrada por Castro e Lee (1995), onde as correlações máximas foram obtidas com dados de ventos de estações distanciados entre 100 e $500 \mathrm{~km}$ ao sul.

Resultados de modelagem numérica obtidos por Stech e Lorenzzetti (1992) sugerem que a 
resposta da PCSE do Brasil à passagem de frentes frias é quase-geostrófica e que as flutuações subnerciais devem se mover com as frentes. Além disso, os autores reforçam que parte da variabilidade subnercial das correntes e nível do mar da PCSE não podem ser justificadas somente pelo vento local, e estão associadas as OPC.

Coelho (2007), em seu estudo sobre a resposta da PCSE a ventos sazonais e sinóticos de verão, realizou estudos numéricos utilizando um campo de ventos anteriormente descrito na Seção 1.2, sugerindo que maiores amplitudes de variação do nível do mar em Cananéia podem estar associada à ressonância entre o vento e as OPC, propagando-se com a mesma velocidade do sistema frontal.

Mazzini (2009) observando as correntes subnerciais na PCI entre Peruíbe e São Sebastião, concluiu que tanto na PCI quanto na PCM, as componentes normais à linha de costa são influenciadas diretamente pelo movimento de marés, enquanto que as componentes paralelas à costa são dominadas por forçantes em escalas subnerciais, como vento e os gradientes de densidade, revelando que as correntes subnerciais observadas na PCI e PCM são essencialmente geostróficas.

No estudo de Dottori e Castro (2009) também fica claro que os ventos locais são responsáveis por boa parte dos movimentos subinerciais na região da Plataforma Continental de São Paulo, uma vez que os autores mostraram a existência de uma correlação alta entre o vento local e as correntes paralelas à costa, sugerindo fortemente uma relação de causalidade entre a tensão de cisalhamento do vento e correntes locais. Ainda assim, resta compreender as causas de uma fração considerável, pelo menos $50 \%$, da variabilidade das correntes subinerciais onde as forçantes remotas poderiam desempenhar um papel significativo.

Santos (2009) em estudo sobre a variabilidade das correntes subinerciais ao largo de Cabo Frio-RJ, verificou que os ventos locais têm baixa correlação com as correntes, exceto nos níveis superficiais, revelando a importância das forçantes remotas na dinâmica da região.

Em trabalho recente, ao investigar Ondas Confinadas Costeiras (OCC) na costa brasileira, França (2013) identificou três faixas temporais de maior energia das ondas subinerciais, sendo o período de maior densidade espectral entre 12 e 16 dias, seguido da faixa de 20 e 25 dias, associados à dinâmica da Corrente do Brasil, e por fim a faixa entre 5 e 11 dias, caracterizada por vários picos. A autora diagnosticou um declínio abrupto da velocidade de propagação dessas OCC em $23^{\circ} \mathrm{S}$, relacionado a Cabo Frio e a $18^{\circ} \mathrm{S}$, relacionado a Abrolhos. Em relação à velocidade da onda, os maiores valores foram obtidos no trecho compreendido entre $25^{\circ} \mathrm{S} \mathrm{e}$ $34^{\circ} \mathrm{S}$ com valores de $11.9 \mathrm{~ms}^{-1}$ a $15 \mathrm{~ms}^{-1}$ e tempo médio de 30 horas.

Gregorio (2014) realizou estudos numéricos na PCSE utilizando dados de vento, pressão atmosférica e temperatura atmosférica superficial , abrangendo um período de 30 anos (jan/1982 a dez/2011) e, em relação as oscilações subnerciais, no cenário em que há passagem de uma frente fria apenas na porção sul da plataforma, as oscilações da superficie do mar foram geradas e se propagaram com características semelhantes (com exceção da altura), daquelas geradas por frentes frias que percorreram toda a PCSE, demonstrando que o vento remoto associado 
ao vento local assume perfil construtivo na geração e propagação das oscilações subnerciais, que tiveram características de OPC, principalmente para oscilações com períodos superiores a 7 dias.

\subsection{Hipótese e objetivos}

A hipótese de trabalho deste projeto é que ventos sinóticos, situados ao sul da PCSP, são capazes de excitar ondas subinerciais que se propagam em direção ao equador e são confinadas na plataforma continental, e que diferentes velocidades de propagação dos ventos sinóticos sobre a plataforma resultam em respostas distintas da PCSE e, particularmente, na PCSP.

Assim, o principal objetivo deste trabalho é estudar como os processos remotos subinerciais, gerados ao sul de São Paulo, são capazes de forçar oscilações de correntes e de elevação da superfície do mar na PCSP.

A ferramenta principal para o estudo aqui proposto será a modelagem numérica. Podemos, então, elencar alguns objetivos específicos:

- Estudar a influência dos ventos associados às frentes frias ao sul da PCSE na geração de movimentos nesta última região e consequentemente na PCSP;

- Verificar a correlação entre as variações do nível do mar na costa sul e norte da PCSE;

- Verificar quais as características da tensão de cisalhamento do vento que força eventos extremos (alta elevação da superfície do mar na costa) na PCSE e PCSP;

- Verificar as características de propagação de Ondas de Plataforma Continental na PCSE; 


\section{Capítulo 2}

\section{Metodologia}

\subsection{Modelo numérico e sua implementação}

\subsubsection{Descrição}

O modelo utilizado neste trabalho foi o sECOM (Stevens Institute Estuarine and Coastal Ocean Hydrodynamic Model; Blumberg e Georgas 2008), que é um variante do POM (Princeton Ocean Model, Blumberg e Mellor 1987) e de sua versão para águas rasas ECOMSED (Blumberg, Khan, e John 1999). O sECOM é um modelo hidrodinâmico e de transporte de sedimentos de última geração, hidrostático, de equações primitivas, tridimensional e utiliza coordenadas verticais sigma numa grade $\mathrm{C}$ de Arakawa, que calcula realisticamente a circulação da água, a temperatura, a salinidade, a mistura e transporte, a deposição e ressuspensão de sedimentos coesivos e não coesivos. O modelo numérico completo consiste em vários módulos: módulo hidrodinâmico, módulo de transporte de sedimentos, módulo de onda induzida por vento, módulo de fluxo de calor e módulo de rastreamento de partículas (Blumberg 2010).

Como citado anteriormente, o modelo numérico trabalha com coordenadas verticais sigma $(\sigma)$, que é um sistema de coordenadas de melhor configuração para irregularidades batimétricas, sendo:

$$
\sigma=\frac{z-\eta}{H+\eta}
$$

onde $\eta$ é elevação do nível do mar, $z$ é a coordenada cartesiana vertical e $H$ é a profundidade total da coluna d'água. Assim, em vista da equação 2.1, os níveis sigma representam porcentagens da coluna de água total $(H+\eta)$, como mostra a Figura 2.1. 


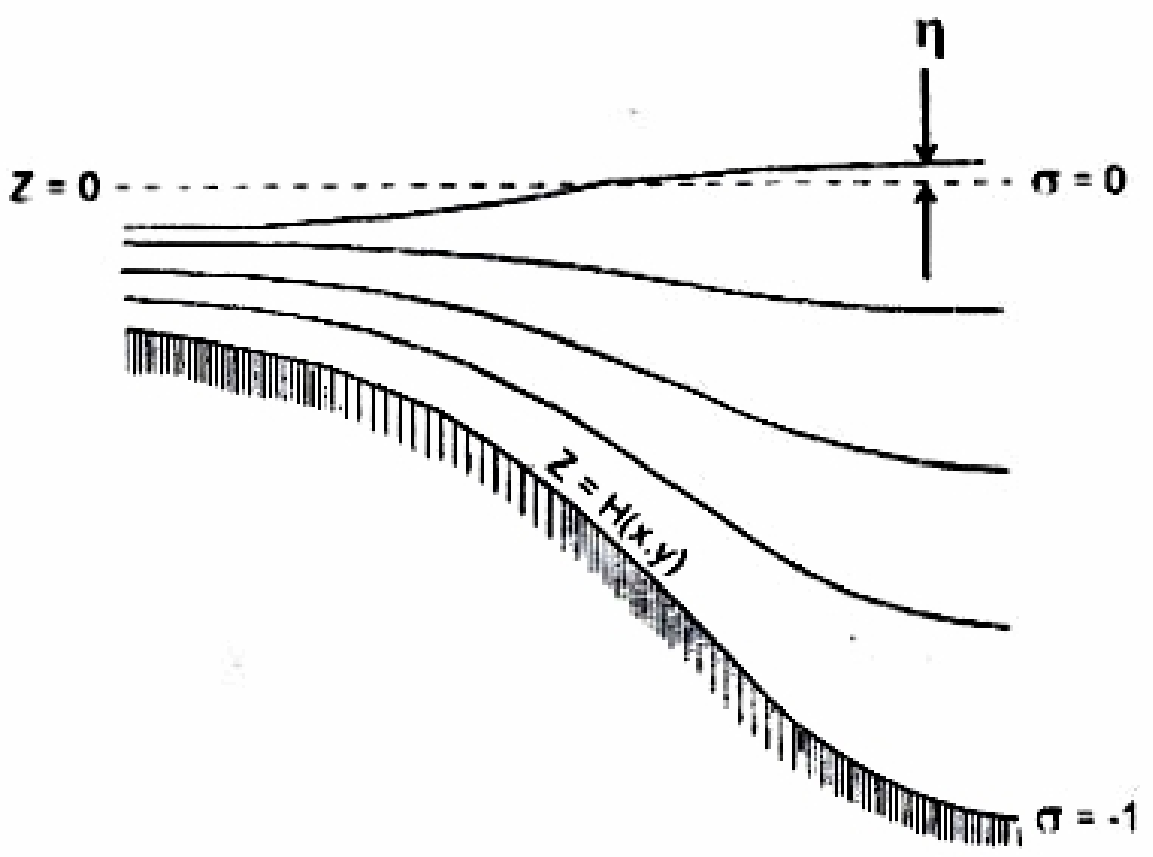

Figura 2.1: Sistema de coordenada sigma $(\sigma)$. Figura extraída de Blumberg (2010).

\subsubsection{Módulo Hidrodinâmico}

Segundo Blumberg (2010), o módulo hidrodinâmico do SECOM é um modelo costeiro tridimensional, incorporando um modelo de fechamento turbulento para fornecer uma parametrização realista dos processos de mistura vertical. As variáveis prognósticas são as três componentes de velocidade $(u, v$, e $w)$, elevação $(\eta)$, temperatura potencial $(\theta)$, salinidade $(S)$ e energia cinética turbulenta. As equações de momentum são não-lineares e incorporam o parâmetro de Coriolis variável com input de latitudes. As equações prognósticas, que regem as quantidades termodinâmicas temperatura e salinidade, são responsáveis pelas variações provocadas por processos de subida / submersão costeira, bem como por processos advectivos horizontais. A elevação da superfície livre também é calculada prognosticamente, com apenas algum sacrifício no tempo computacional para que as marés e os eventos de tempestade também possam ser simulados. Isto é obtido através da utilização de uma técnica de divisão, de modo em que o transporte de volume e a cisalhamento de velocidade vertical sejam resolvidos separadamente. Outras variáveis de computação incluem densidade, viscosidade e difusividade vertical, além de acomodar a geometria de costa realista e topografia de fundo.

\section{Equações Dinâmicas e Termodinâmicas}

As equações que formam a base do modelo de circulação descrevem os campos de velocidade, elevação da superfície e os campos de temperatura e salinidade.

Considerando um sistema de coordenadas cartesianas ortogonais, com x aumentando para 
o leste, y aumentando para o norte e $\mathrm{z}$ aumentando verticalmente para cima, onde a superfície livre está localizada em $z=\eta(x, y, t)$ e o fundo está em $z=-H(x, y)$, temos a equação da continuidade:

$$
\nabla \cdot \vec{V}+\frac{\partial w}{\partial z}=0
$$

onde $\vec{V}$ é o vetor velocidade horizontal, com componentes $u$ e $v$, e $\nabla$ é o operador de gradiente horizontal $\left(\frac{\partial}{\partial x}+\frac{\partial}{\partial y}\right)$. As equações de momentum, discretizadas nas componentes zonal, meridional e vertical são:

$$
\begin{aligned}
\frac{\partial u}{\partial t}+\vec{V} \cdot \nabla u+w \frac{\partial u}{\partial z}-f v & =-\frac{1}{\rho_{o}} \frac{\partial P}{\partial x}+\frac{\partial}{\partial z}\left(K_{m} \frac{\partial u}{\partial z}\right)+F_{x} \\
\frac{\partial v}{\partial t}+\vec{V} \cdot \nabla v+w \frac{\partial v}{\partial z}+f u & =-\frac{1}{\rho_{o}} \frac{\partial P}{\partial y}+\frac{\partial}{\partial z}\left(K_{m} \frac{\partial v}{\partial z}\right)+F_{y} \\
\rho g & =\frac{\partial P}{\partial z}
\end{aligned}
$$

sendo $\rho_{o}$ a densidade de referencia, $\rho$ a densidade local, $g$ a aceleração da gravidade, $P$ a pressão, $K_{m}$ o coeficiente vertical de mistura turbulenta e $f$ é o parâmetro de Coriolis (aproximação do plano $\beta$, detalhes em Pedlosky 1979).

A pressão na profundidade $z$ pode ser obtida através da integração da equação 2.5, do fundo $[z]$ até a superfície livre $\eta[0]$ :

$$
P(x, y, z, t)=P_{a t m}+g \rho_{o} \eta+g \int_{z}^{0} \rho\left(x, y, z^{\prime}, t\right) d z^{\prime}
$$

onde $P_{a t m}$ é a pressão atmosférica.

As equações de conservação da Temperatura e Salinidade podem ser escritas como:

$$
\begin{aligned}
& \frac{\partial \theta}{\partial t}+\vec{V} \cdot \nabla \theta+w \frac{\partial \theta}{\partial z}=\frac{\partial}{\partial z}\left[K_{H} \frac{\partial \theta}{\partial z}\right]+F_{\theta} \\
& \frac{\partial S}{\partial t}+\vec{V} \cdot \nabla S+w \frac{\partial S}{\partial z}=\frac{\partial}{\partial z}\left[K_{H} \frac{\partial S}{\partial z}\right]+F_{S}
\end{aligned}
$$

onde $\theta$ é a temperatura potencial, $S$ é a salinidade, e $K_{H}$ é o coeficiente difusivo de mistura turbulenta de calor e sal. As equações 2.7 e 2.8 são utilizadas para o cálculo da densidade potencial, em função da temperatura potencial $\theta$ e a salinididade $S$, de acordo com Fofonoff (1962): 


$$
\rho=\rho(\theta, S)
$$

Os termos $F_{x}, F_{y}, F_{\theta}$ e $F_{S}$, encontrados nas equações 2.3, 2.4, 2.7 e 2.8 representam parametrizações de mecanismos de mistura horizontal dos movimentos induzidos por processos de pequena escala, que não são diretamente resolvidos pela grade do modelo. Estes termos parametrizados de difusão horizontal são baseados na formulação realizada por Smagorinsky (1963).

\section{Fechamento Turbulento}

A parametrização descrita a seguir para a turbulência no modulo hidrodinâmico do modelo numérico é baseada no trabalho de Mellor e Yamada (1974).

Os coeficientes de mistura vertical, $K_{M}$ e $K_{H}$, que aparecem nas equações 2.3, 2.4, 2.7 e 2.8 são obtidas através de um esquema de fechamento turbulento de segunda ordem, que caracteriza a turbulência por meio de energia cinética turbulenta, $q^{2} / 2$, e macroescala turbulenta, $\varepsilon$, de acordo com:

$$
\frac{\partial q^{2}}{\partial t}+\vec{V} \cdot \nabla q^{2}+w \frac{\partial q^{2}}{\partial z}=\frac{\partial}{\partial z}\left(K_{q} \frac{\partial q^{2}}{\partial z}\right)+2 K_{M}\left[\left(\frac{\partial u}{\partial z}\right)^{2}+\left(\frac{\partial v}{\partial z}\right)^{2}\right]+\frac{2 g}{\rho_{o}} K_{H} \frac{\partial \rho}{\partial z}-\frac{2 q^{3}}{B_{l} \varepsilon}+F_{q}
$$

$\mathrm{e}$

$$
\begin{aligned}
\frac{\partial q^{2} \varepsilon}{\partial t}+\vec{V} \cdot \nabla\left(q^{2} \varepsilon\right)+w \frac{\partial q^{2} \varepsilon}{\partial z}=\frac{\partial}{\partial z} & {\left[K_{q} \frac{\partial}{\partial z}\left(q^{2} \varepsilon\right)\right] } \\
& +\varepsilon E_{l} K_{M}\left[\left(\frac{\partial u}{\partial z}\right)^{2}+\left(\frac{\partial v}{\partial z}\right)^{2}\right]+\frac{\varepsilon E_{l} g}{\rho_{o}} K_{H} \frac{\partial \rho}{\partial z}-\frac{q^{3}}{B_{l}}+F_{\varepsilon}
\end{aligned}
$$

onde $F_{q}$ e $F_{\varepsilon}$ são os termos de mistura horizontal e são parametrizados analogamente como a temperatura e salinidade, $\nabla$ é o operador de gradiente horizontal e é a função de proximidade da parede, que relaciona a escala de turbulência em questão à macroescala e assegura comportamento logarítmico próximo aos contornos sólidos (Coelho 2007), é definida por:

$$
\equiv 1+E_{2}\left(\frac{\varepsilon}{\kappa L}\right)^{2}
$$

onde

$$
(L)^{-1} \equiv(\eta-z)^{-1}+(H+z)^{-1}
$$

com $\kappa=0.4$ sendo a constante von Karman (Blumberg 2010) e, embora os detalhes do mó- 
dulo de fechamento turbulento estejam bastante trabalhados, é possível reduzir a prescrição dos coeficientes de mistura $K_{M}, K_{H}$ e $K_{q}$ através das seguintes equações:

$$
\begin{gathered}
K_{M} \equiv \varepsilon . q S_{M} \\
K_{H} \equiv \varepsilon . q S_{H} \\
K_{q} \equiv \varepsilon . q S_{q}
\end{gathered}
$$

As funções de $S_{M}, S_{H}$ e $S_{q}$ são analiticamente derivadas e são dependentes de $\partial u / \partial z, \partial v / \partial z$, $g \rho_{o}^{-1} \partial \rho / \partial z, q$ e $\varepsilon$. Detalhe dos cálculos podem ser encontrados em Mellor e Yamada (1982).

\subsubsection{Condições de Contorno}

\section{Superfície livre}

Segundo Blumberg (2010), as condições de contorno do modelo numérico, na superfície livre $z=\eta(x, y)$ são:

$$
\begin{gathered}
\rho_{o} K_{M}\left(\frac{\partial u}{\partial z}, \frac{\partial u}{\partial z}\right)=\left(\tau_{o x}, \tau_{o y}\right) \\
\rho_{o} K_{H}\left(\frac{\partial \theta}{\partial z}, \frac{\partial S}{\partial z}\right)=(\phi, S S) \\
q^{2}=B_{l}^{2 / 3} u_{\tau s}^{2} \\
q^{2} \varepsilon=0 \\
w=u \frac{\partial \eta}{\partial x}+v \frac{\partial \eta}{\partial y}+\frac{\partial \eta}{\partial t}
\end{gathered}
$$

onde $\left(\tau_{o x}, \tau_{o y}\right)$ correspondem ao vetor tensão de cisalhamento do vento nas componentes $u$ e $v$, e $u_{\tau s}$ corresponde a magnitude deste vetor. A quantidade $B_{l}^{2 / 3}$ é uma constante empírica adimensional obtida das relações de fechamento turbulento, $\phi$ é o fluxo de calor do oceano, $S S \equiv$ $S(0)[E v-P r] / \rho_{o}$, onde $[E v-P r]$ é a diferença entre a taxa de evaporação e de precipitação, e $S(0)$ é a salinidade da superfície. 


\section{Camada de fundo e Contorno lateral fechado}

Nos contornos fechados (lateral e no fundo), os gradientes de $\theta$ e $S$ são nulos para que não exista nenhum fluxo de calor ou salinidade através destes contornos. Na camada de fundo, as condições de contorno são:

$$
\begin{gathered}
\rho_{o} K_{M}\left(\frac{\partial u}{\partial z}, \frac{\partial v}{\partial z}\right)=\left(\tau_{b x}, \tau_{b y}\right) \\
q^{2}=B_{l}^{2 / 3} u_{\tau b}^{2} \\
q^{2} \varepsilon=0 \\
w_{b}=-u_{b} \frac{\partial H}{\partial x}-v_{b} \frac{\partial H}{\partial y}
\end{gathered}
$$

onde $H(x, y)$ é a topografia de fundo e $u_{\tau b}$ é o cisalhamento da corrente associada aos componentes de atrito de fundo $\left(\tau_{b x}, \tau_{b y}\right)$, descrito como:

$$
\vec{\tau}_{b}=\rho_{o} C_{D}\left|\vec{V}_{b}\right| \vec{V}_{b}
$$

cujo coeficiente de arrasto $C_{D}$ é dado por:

$$
C_{D}=\left[\frac{1}{\kappa} \ln \left(H+z_{b}\right) / z_{o}\right]^{-2}
$$

onde $z_{b}$ e $V_{b}$ estão localizados no ponto de grade próximo ao fundo e $\kappa$ é a constante de von Karman. Em situações em que o contorno de fundo não é bem resolvido, é mais apropriado espefificar $C_{D}=25 \times 10^{-4}$. O parametro $z_{o}$ depende da rugosidade de fundo local, e em ausência de informações específicas utiliza-se $z_{o}=1 \mathrm{~cm}$ (Blumberg 2010).

\section{Contorno lateral aberto}

Nos contornos laterais abertos, existem dois tipos de condições: de entrada (inflow) e de saída (outflow). Os valores de temperatura e salinidade são prescritos através de dados como condição de entrada. Entretanto, para a condição de saída do contorno lateral,

$$
\frac{\partial}{\partial t}(\theta, S)+u_{n} \frac{\partial}{\partial n}(\theta, S)=0
$$


é utilizada, considerando que $n$ é a coordenada normal ao contorno. A energia cinética turbulenta e macroescala turbulenta são calculadas no contorno lateral negligenciando os termos de advecção em comparação aos outros termos da equação.

A velocidade nos contornos laterais podem ser computadas através do uso de dados em conjunto com um simples modelo diagnóstico, e uma descrição específica é dada em Kantha, Mellor, e Blumberg (1982). Uma vez que a componente de velocidade normal ao contorno é especificada, uma condição de livre-escorregamento é usada para a componente tangencial.

Em relação a elevação do nível do mar, o modelo sECOM possui uma gama de condições que permitem a entrada/saída de energia de onda longa através dos contornos abertos para o interior do domínio do modelo. Nas simulações realizadas para este trabalho, utilizou-se a condição de contorno desenvolvida por Reid e Bodine (1968), na forma:

$$
\eta=\eta_{o}+\lambda_{t} u_{n}\left[\frac{g}{D}\right]^{-1 / 2}
$$

onde $\eta$ é a elevação do mar no contorno aberto, $\eta_{o}$ é a elevação relacionada a maré ou variações de baixa frequência na célula da grade, $u_{n}$ é a velocidade perpendicular ao contorno aberto calculada pelo modelo, $g$ é a aceleração da gravidade e $D$ é a profundidade associada a célula da grade. O multiplicador $\lambda_{t}$ é calculado a cada passo de tempo, permitindo modificações na elevação do mar derivada da radiação de ondas longas.

\subsubsection{Grade do modelo}

A grade usada nas simulações foi idealizada no trabalho de Pereira et al. (2007) e utilizada em estudo numérico de Morais (2016). Configurada em um modo ortogonal e curvilínea, a grade (Figura 2.2) possui 110 pontos orientados perpendicularmente à costa, e 137 pontos orientados paralelos à costa, com resolução horizontal irregular, variando de $0.2 \mathrm{~km}$ a $5 \mathrm{~km}$ na direção $X$ (perpendicular), para a porção que contempla a plataforma continental, e com espaçamento de até $35 \mathrm{~km}$ para profundidades maiores do que $2.100 \mathrm{~m}$. Para a direção y (paralela), a resolução varia de $0.5 \mathrm{~km}$, na porção mais central da grade, a $35 \mathrm{~km}$ próximo aos contornos.

Nas simulações realizadas, o domínio foi verticalmente dividido em 37 níveis sigma, da superfície $\sigma=0$ ao fundo $\sigma=-1$, sendo $\sigma=(-1,-0.9,-0.75,-0.6,-0.5,-0.4,-0.35,0.325,-0.3$, $-0.275,-0.25,-0.225,-0.2,-0.175,-0.15,-0.125,-0.1,-0.095,-0.09,-0.085,-0.08,-0.075,-0.07$, $-0.065,-0.06,-0.055,-0.05,-0.045,-0.04,-0.035,-0.03,-0.025,-0.02,-0.015,-0.01,-0.005,0)$. Essa configuração proporcionou maior resolução na região da plataforma continental e talude, e baixa resolução em regiões de oceano profundo, e nas camadas mais profundas da coluna d'água.

A escolha de 37 níveis se deu através de testes durante a implementação da grade numérica, visando diminuir as instabilidades geradas na região do talude continental. 


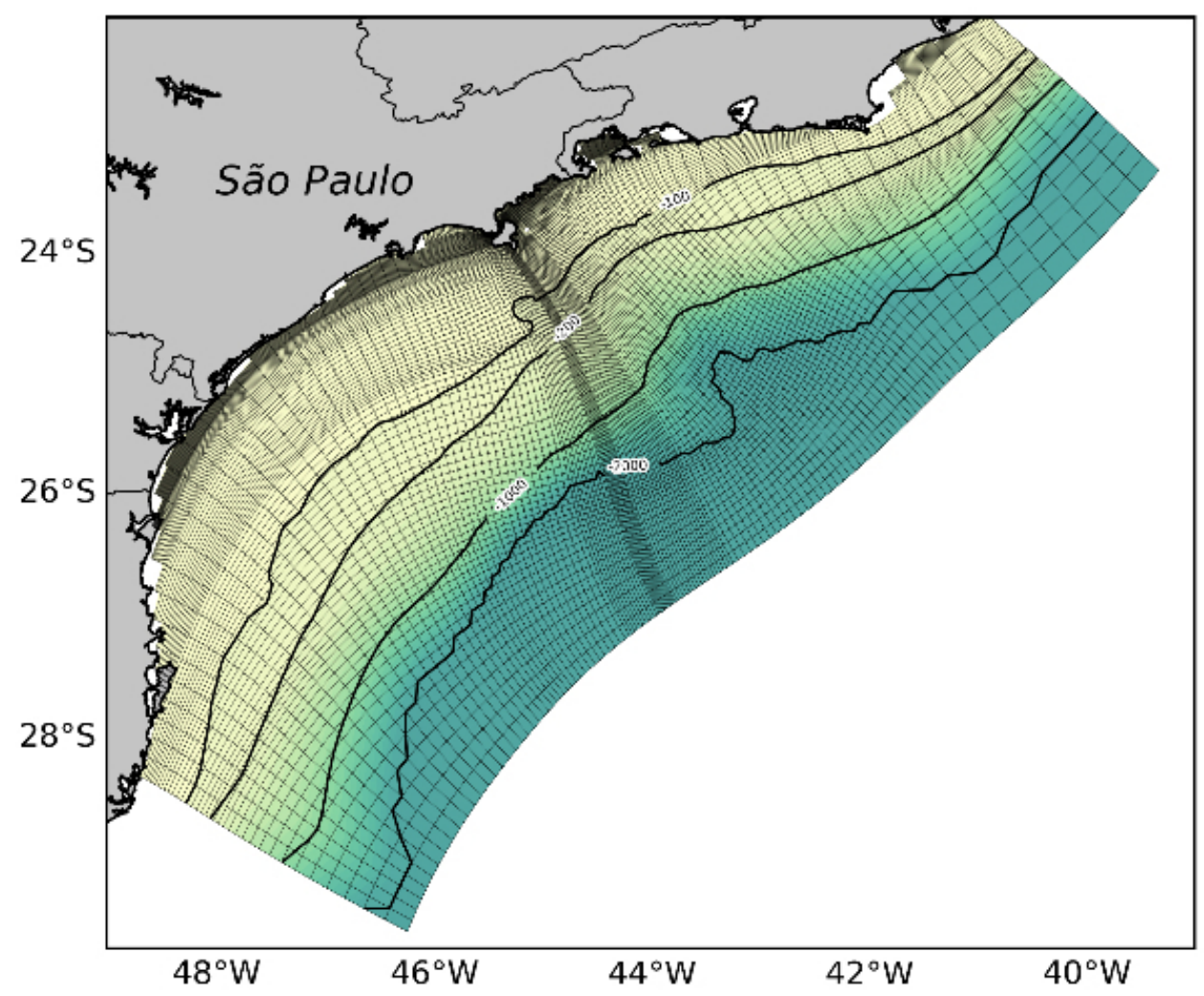

Figura 2.2: Grade curvilínea e ortogonal utilizada nas simulações adaptada de Pereira et al. (2007). Figura extraída de Morais (2016).

\subsection{Validação do modelo numérico}

Em seu trabalho sobre a hidrodinâmica da plataforma continental interna do estado de São Paulo, Morais (2016) validou o modelo númerico para as regiões da PCI e PCM da grade da Plataforma Continental Sudeste utilizada nesse trabalho, através de dados de corrente, vento, marés e descarga fluvial média dos sistemas estuarinos de Santos e Cananéia. Os dados de corrente foram obtidos de fundeios específicos dos projetos Influência do Complexo Estuarino da Baixada Santista sobre o Ecossistema da Plataforma Adjacente (ECOSAN) e Dinâmica do Ecossitema de Plataforma da Região Oeste do Atlântico Sul (DEPROAS), como mostra a tabela abaixo, com dados de vento para o período provenientes do National Centers for Envirommental \begin{tabular}{|l|l|}
\hline Prediction (NCEP) Climate Forecast System Reanalysis (CFSR). \\
\hline
\end{tabular}

Tabela 2.1: Relação dos fundeios selecionados por Morais (2016) para a validação do modelo númerico na PCSE.

\begin{tabular}{c|c|c|c|c|c}
\hline \hline Simulação & Projeto & Identificação & Prof. local & Prof. equip. & Período \\
\hline \hline S1 & ECOSAN & ES0202 & $20 \mathrm{~m}$ & $12 \mathrm{~m}$ & $28 / 06 / 2005$ a 28/07/2005 \\
\hline S2 & DEPROAS & FUB110030 & $50 \mathrm{~m}$ & $30 \mathrm{~m}$ & $11 / 12 / 2001$ a 10/01/2002 \\
\hline S3 & ECOSAN & ES0802 & $100 \mathrm{~m}$ & $56 \mathrm{~m}$ & $06 / 01 / 2006$ a 05/02/2006 \\
\hline \hline
\end{tabular}


A validação foi obtida de análise comparada utilizando o parâmetro skill, estabelecido por Willmott (1981), e formulada por:

$$
S_{k i l l}=1-\frac{\sum_{i=1}^{N}\left(\left|P_{i}-O_{i}\right|\right)^{2}}{\sum_{i=1}^{N}\left(\left|P_{i}-\mu_{O}\right|+\left|O_{i}-\mu_{O}\right|\right)^{2}}
$$

onde $N$ é a quantidade de amostragens, $P_{i}$ é a série temporal de uma variável calculada pelo modelo, $O_{i}$ é a variável observada e $\mu_{O}$ é a média dos dados observacionais. O valor de $S_{k i l l}$ varia no intervalo $\left[0 \leq S_{k i l l} \leq 1\right]$, sendo que 0 representa a discordância e 1 , o perfeito ajuste entre os resultados modelados e observados.

Morais (2016) obteve no geral valores de $S_{\text {kill }}$ mais significativos para a componente paralela da velocidade do que para a componente perpendicular. A componente perpendicular apresentou valores de $S_{\text {kill }}$ de $0.25,0.45$ e 0.36 para simulações S1, S2 e S3, respectivamente, ao passo que a componente paralela da velocidade apresentou valores de $0.74,0.56$ e 0.70 , concluindo que a ausência de disparidades para as variáveis avaliadas valida o modelo para a região, pois contempla satisfatoriamente as correntes paralelas em sentidos e intensidade.

\subsection{Simulações}

Com o objetivo de analisar a resposta da $\mathrm{PCSP}$ em relação a propagação e duração de frentes frias, foram realizadas 16 simulações, sendo:

- Duas simulações-controle, uma com campo homogêneo e outra com campo estratificado de temperatura e salinidade;

- Quatro simulações com a forçante do vento atuando apenas na porção sul da grade do modelo (até a divisa de Santa Catarina e São Paulo), com a ação de quatro frentes frias cada, em um campo estratificado de temperatura e salinidade, com a finalidade de avaliar apenas a contribuição do vento remoto proveniente de sul;

- Dez simulações com a forçante do vento atuando em toda a grade do modelo, com a passagem de de quatro frentes frias cada, em um campo estratificado de temperatura e salinidade, com o intuito de analisar o efeito combinado do vento local e vento remoto.

A única forçante do modelo foi a tensão de cisalhamento do vento na superfície, desconsiderandose os fluxos de água doce e calor. Portanto, variações das propriedades hidrográficas foram possíveis, apenas, através de advecção e difusão.

Todos os experimentos foram rodados em modo prognóstico. Com a finalidade de minimizar a excitação de oscilações espúrias em decorrência do ajuste ao equilíbrio devido a ação das forçantes nos instantes iniciais de integração, foi ativado a função $R A M P$, de forma que as 
variáveis só assumam seu valor integral após decorridos três dias. Um RAMP com esse valor permite que tanto as oscilações inerciais quanto as subnerciais não sejam filtradas dos resultados finais.

As condições iniciais climatológicas de temperatura e salinidade, ventos e o modelo de frente fria utilizado nas simulações estão descritas nas Seções 2.3.1, 2.3.2 e 2.3.3, respectivamente. As especificações das simulações estão descritas nas Seções 2.3.4 2.3.5 e 2.3.6.

\subsubsection{Climatologia de temperatura e salinidade}

Para as simulações com campos estratificados de temperatura e salinidade, foi utilizada uma climatologia regional de verão idealizada por Rezende (2003) e interpolada tridimensionalmente para a grade da PCSE Para a simulação de campo homogêneo, a temperatura e salinidade foram fixadas em $25^{\circ} \mathrm{C}$ e 35 , respectivamente.

\subsubsection{Condição inicial de vento}

O modelo foi inicializado com ventos de nordeste característicos da Alta Subtropical do Atlântico Sul, e aquecido por 3 dias, para ajuste dos campos de temperatura e salinidade. O campo de ventos escolhido foi do dia 17/03/2000 hora sinótica 12H, como mostra a Figura 2.3 .

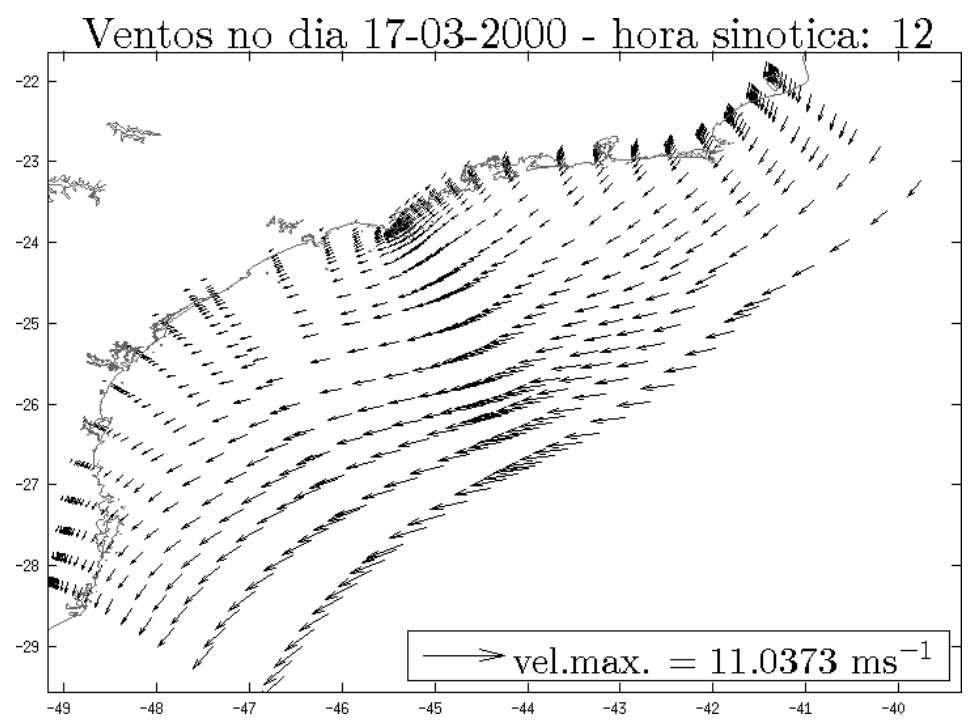

Figura 2.3: Vento característico da ASAS, elaborado a partir de dados do dia 17/03/2000-12H.

\subsubsection{Modelo de frente fria}

Com base no trabalho de Coelho (2007), foi selecionada, a partir do banco de dados do NCEP. CFSR, a frente fria que cruzou a região sudeste da plataforma continental brasileira entre 17/03/2000-18H e 19/03/2003-12H. A escolha dessa frente em específico foi baseada nos valo- 


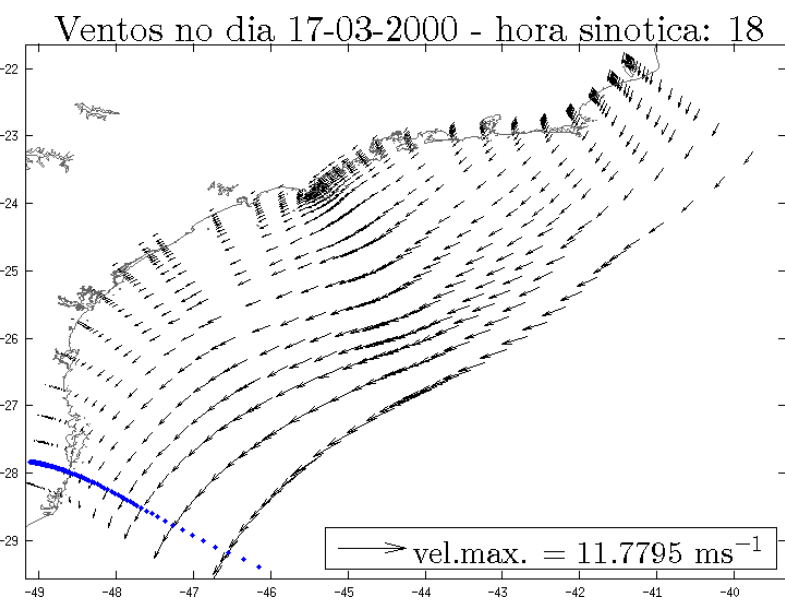

(a)

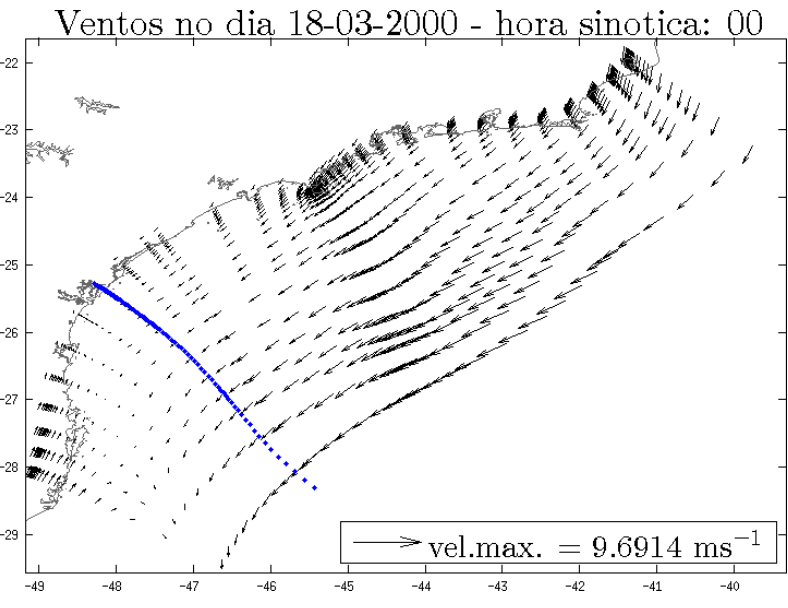

(b)

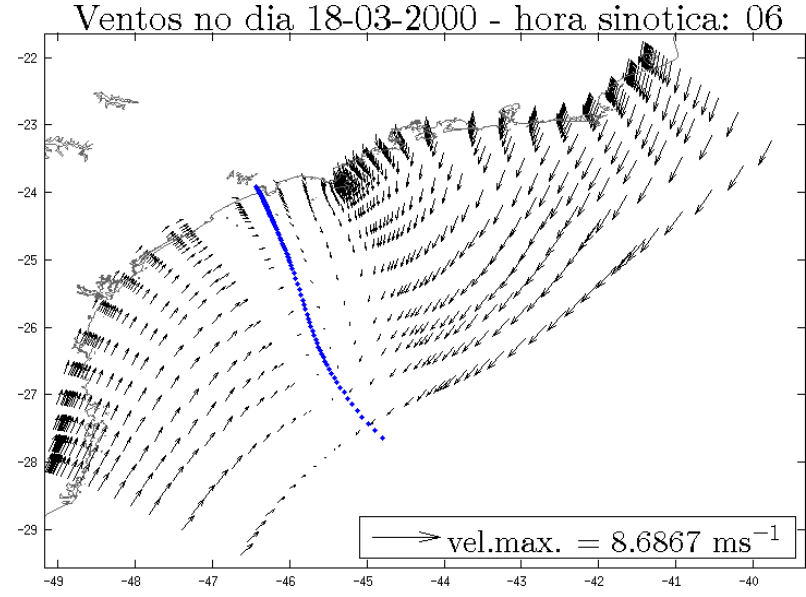

(c)

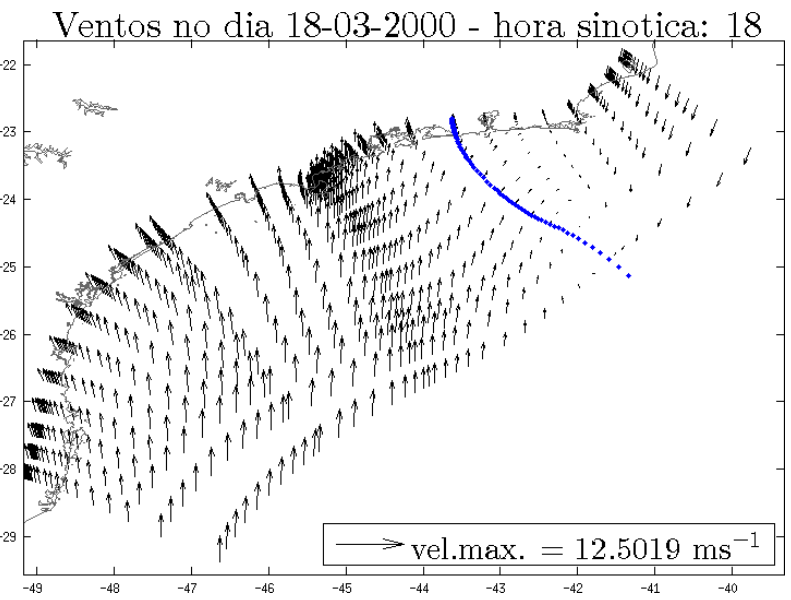

(d)

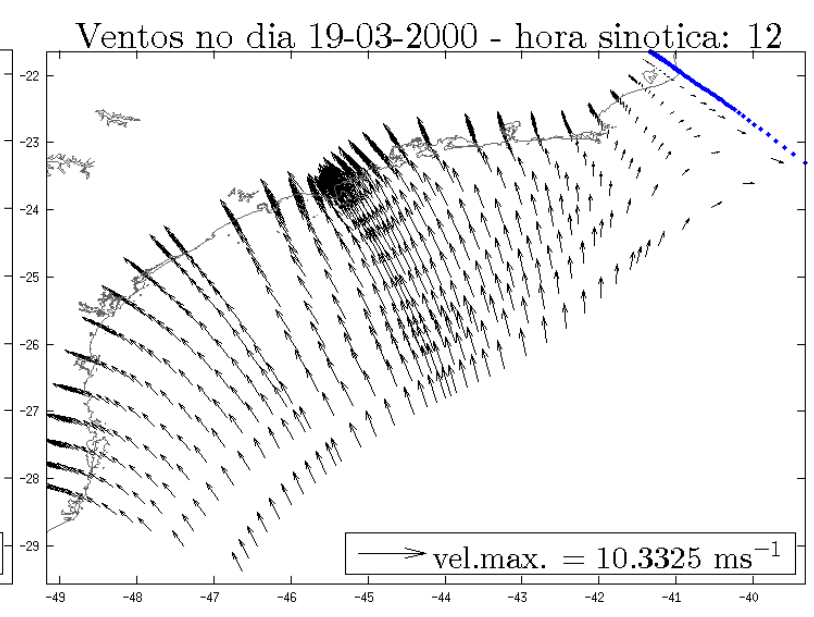

(f)

Figura 2.4: Modelo de frente fria: frente (a) no Cabo de Santa Marta-SC; (b) em Cananéia-SP; (c) em Santos-SP; (d) em Ilha Grande-RJ; (e) em Cabo Frio-RJ; e (f) após Cabo Frio-RJ. 
res de velocidade média e desvio padrão obtidos por Coelho (2007) para frentes frias durante o verão, como mostra a Tabela 2.2 .

Assim, o modelo de frente fria proposto nesse trabalho e apresentado na Figura 2.4 consiste em seis quadros: frente fria no Cabo de Santa Marta-SC, frente fria até Cananéia-SP, frente até Santos-SP, frente até Ilha Grande-RJ, frente até Cabo Frio-RJ e frente após Cabo Frio-RJ.

Tabela 2.2: Velocidade de propagação média e desvio padrão da média para as frentes frias que se deslocam desde Cabo de Santa Marta a Cabo de São Tomé, durante o verão.

\begin{tabular}{|c|c|c|}
\hline & Velocidade média $\left(m s^{-1}\right)$ & Desvio Padrão $\left(m s^{-1}\right)$ \\
\hline Frente fria (verão, segundo Coelho 2007) & 9,1 & 2,3 \\
\hline Frente fria (17 a 21/03/2000) & 9,2 & 2,3 \\
\hline
\end{tabular}

\subsubsection{Simulações de controle}

As duas simulações controle, denominadas SC1 e SC2, foram forçadas apenas com vento caracteristíco da ASAS, como descrito na Seção 2.3.2. em toda a extensão da grade do modelo, por 10 dias, em modo prognóstico sendo que SC1 possui um campo homogêneo de temperatura e salinidade (T/S), e SC2 possui um campo estratificado, como descrito na Seção 2.3.1.

\subsubsection{Simulações Vento Remoto Sul}

As quatro simulações de vento remoto sul, denominadas RS1, RS2, RS3 e RS4, possuem campo T/S estratificado, e forçadas por ventos característicos da ASAS nos 3 dias iniciais, a cargo de ajuste hidrodinâmico, e forçadas em seguida pela frente fria descrita na Seção 2.3.3. Em todas as simulações, os ventos tanto típicos da ASAS quanto de frente fria, foram inseridos apenas na parte sul da grade, em modo prognóstico, como mostra a Figura 2.5 .

Todas as simulações de vento remoto de sul foram forçadas por 4 frentes cada, intercaladas com 3 dias de vento típico da ASAS de nordeste, e diferem entre si no que se refere ao tempo de permanência das frentes frias, como mostra a Tabela 2.3

Tabela 2.3: Características das Simulações de Vento Remoto Sul, onde Tempo de Permanência é o tempo de ação da frente na região sul da PCSE.

\begin{tabular}{c|c|c}
\hline \hline Simulação & Campo T/S & Tempo de Permanência \\
\hline \hline RS1 & estratificado & 18 horas \\
\hline RS2 & estratificado & 36 horas \\
\hline RS3 & estratificado & 54 horas \\
\hline RS4 & estratificado & 72 horas \\
\hline \hline
\end{tabular}




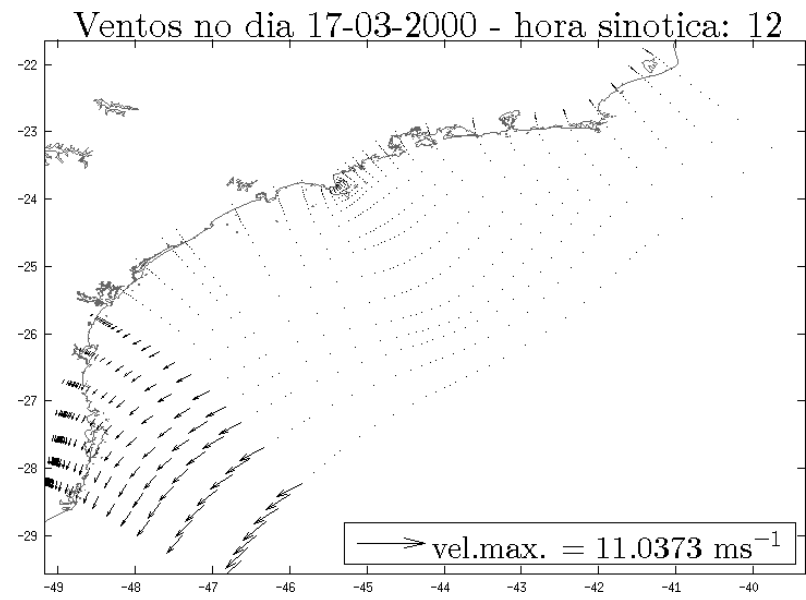

(a)
Ventos no dia 18-03-2000 - hora sinotica: 06

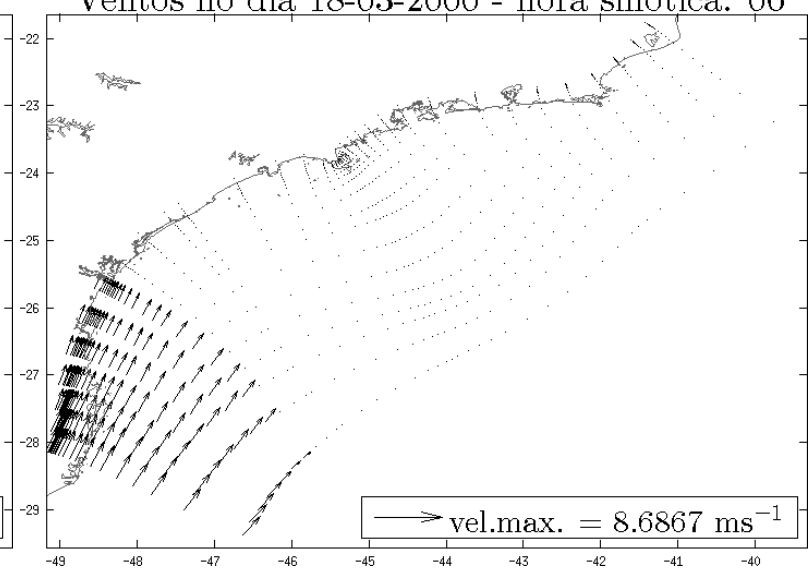

(b)

Figura 2.5: Ventos forçados na porção sul da PCSE: (a) ventos de nordeste típicos da ASAS e (b) ventos de sudoeste típicos de frente fria.

\subsubsection{Simulações Vento Total na PCSE}

As últimas dez simulações deste trabalho, de prefixo SVT, possuem campo T/S estratificado de acordo com a Seção 2.3.1, forçados em toda grade do modelo por ventos típicos da ASAS nos 3 dias iniciais e, em seguida, pelo modelo de frente fria estabelecido na Seção 2.3.3. Assim como nas simulações vento remoto sul, cada experimento foi forçado por 4 frentes intecaladas por 3 dias de ventos de nordeste, em modo prognóstico. As principais características das simulações de vento na PCSE estão descritas na Tabela 2.4

Tabela 2.4: Características das Simulações de Vento Total na PCSE, onde Vel Prop. é a velocidade de propagação de cada frente fria, e Tempo de Permanência é o tempo total da frente na PCSE.

\begin{tabular}{c|c|c|c}
\hline \hline Simulação & Campo T/S & Vel Prop. $\left(\mathrm{ms}^{-1}\right)$ & Tempo de Permanência \\
\hline \hline SVT1 & estratificado & 18.9 & 18 horas \\
\hline SVT2 & estratificado & 14.2 & 24 horas \\
\hline SVT3 & estratificado & 11.4 & 30 horas \\
\hline SVT4 & estratificado & 9.5 & 36 horas \\
\hline SVT5 & estratificado & 8.1 & 42 horas \\
\hline SVT6 & estratificado & 7.1 & 48 horas \\
\hline SVT7 & estratificado & 6.3 & 54 horas \\
\hline SVT8 & estratificado & 5.7 & 60 horas \\
\hline SVT9 & estratificado & 5.2 & 66 horas \\
\hline SVT10 & estratificado & 4.7 & 72 horas \\
\hline \hline
\end{tabular}




\section{Capítulo 3}

\section{Resultados e Discussão}

Este capítulo está dividido em três seções, sendo que a primeira contempla os resultados obtidos nas simulações controle, a segunda se refere aos resultados obtidos nas simulações de vento remoto, e a terceira apresenta os resultados das simulações de vento em toda a grade do modelo, como apresentado no capítulo anterior, Seção 2.3 .

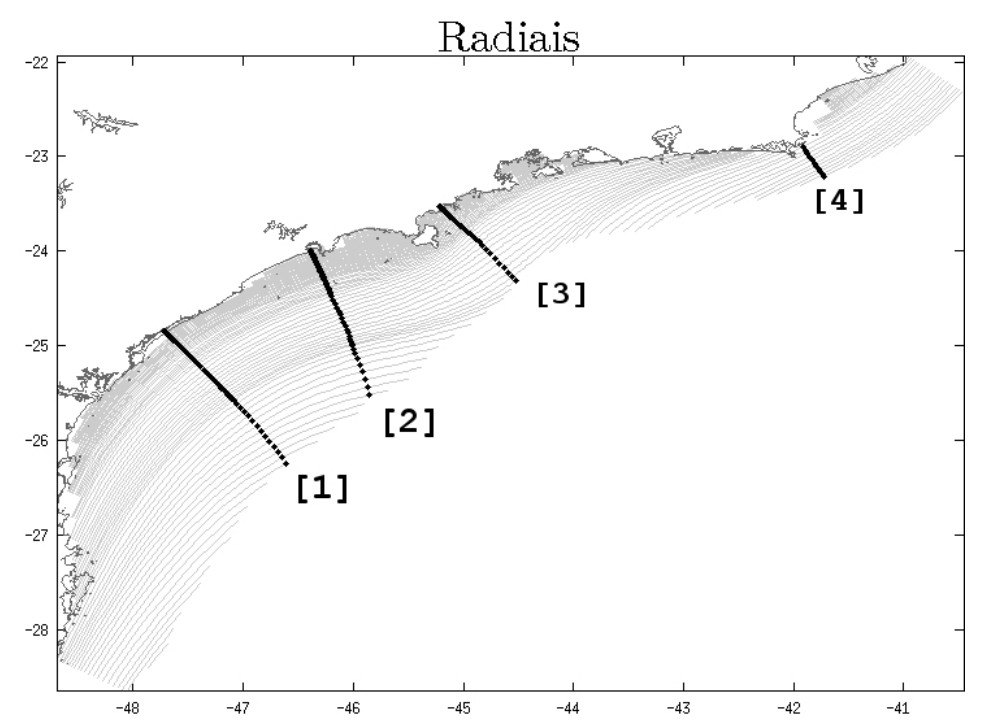

Figura 3.1: Localização das radiais na grade do modelo. [1] Radial Cananéia, [2] Radial Santos, [3] Radial Ubatuba e [4] Radial Cabo Frio.

Os resultados são apresentados até a isóbata de 200 metros, embora as simulações incluam a região do talude e parte do oceano profundo, possibilitando melhor visualização dos resultados na plataforma continental.

Ainda serão focados as seguintes radiais para a apresentação dos resultados: radial Cananéia, localizada em frente a cidade de Cananéia-SP; radial Santos, localizada em frente a Baía de Santos-SP; radial Ubatuba, em frente a cidade de Ubatuba-SP; e radial Cabo Frio, localizada em frente a cidade de Cabo Frio-RJ, como mostra a Figura 3.1 .

Os resultados serão referenciados de acordo com a compartimentação apresentada na Seção 1.1 e estabelecida por Castro (1996) para a o norte da Plataforma Continental de São Paulo. Uma vez utilizada a climatologia de verão, serão adotados os seguintes limites: 
- Plataforma Continental Interna (PCI): da linha de costa até a isóbata de 40 metros;

- Plataforma Continental Média (PCM): entre as isóbatas de 40 e 90 metros;

- Plataforma Continental Externa (PCE): entre a isóbata de 90 metros e a quebra da plataforma.

Para melhor caracterizar os períodos dos movimentos analisados, será adotada a terminologia inercial para movimentos com períodos iguais ao período de rotação da Terra, suprainercial para movimentos com períodos inferiores ao período de rotação da Terra, e subinercial para movimentos com períodos superiores ao período de rotação terrestre.

\subsection{Simulações Controle}

Como descrito na Seção 2.3.4 os experimentos denominados SC1 e SC2 foram forçados em toda a grade do modelo por ventos de nordeste característicos da Alta Subtropical do Atlântico Sul.

Os resultados apresentados na Figura 3.1 mostram que, após 10 dias de simulação, há um rebaixamento do nível do mar, com desnível máximo de -0.1 m no experimento $\mathrm{SC} 1 \mathrm{e}$, com a inclusão dos campos estratificados de temperatura e salinidade, desníveis da ordem de $-0.2 \mathrm{~m}$ no experimento SC2. Estes resultados são compatíveis com os estudos analíticos desenvolvidos por Csanady (1976) e Scott e Csanady (1976), que descrevem a resposta da plataforma continental com fluido homogêneo à ação do cisalhamento do vento paralelo à costa, que promovem transporte de água ortogonal à costa nas camadas mais superficiais, e é defletido pela força de Coriolis. Mudanças no nível do mar na região costeira surgem, devido a imposição de limite lateral costeiro e conforme o campo de pressão se ajusta em balanço geostrófico às velocidades paralelas à costa do interior da coluna d'água. No Hemisfério Sul, onde os movimentos em meso a larga escala são defletidos pela força de Coriolis para a esquerda, um vento de nordeste acarreta em correntes com o mesmo sentido e transporte de água da costa para o oceano, rebaixando o nível do mar na plataforma continental. Segundo Castro et al. (2006) o intervalo de tempo necessário para que o ajuste geostrófico ocorra é de 10 a 20 horas.

As menores elevações se concentraram ao norte do domínio, próximo a Cabo Frio, onde a plataforma continental é mais estreita. O grande rebaixamento do nível do mar ao norte de Cabo Frio também pode estar associados a intensidade do cisalhamento do vento local de nordeste, uma vez que Coelho (2007) mostrou que os maiores valores desta forçante ocorrem próximo a Cabo Frio, na região mais ao norte da PCSE, e os menores valores de cisalhamento na $\overline{\text { PCI }}$ do estado de São Paulo. Observando a orientação das isolinhas de elevação, o experimento SC1 apresenta isolinhas orientadas paralelamente a costa ao norte da Ilha de São Sebastião, de E-NE. Ao sul da Ilha, a orientação das isolinhas é perpendicular a linha de costa, também de E-NE. No 


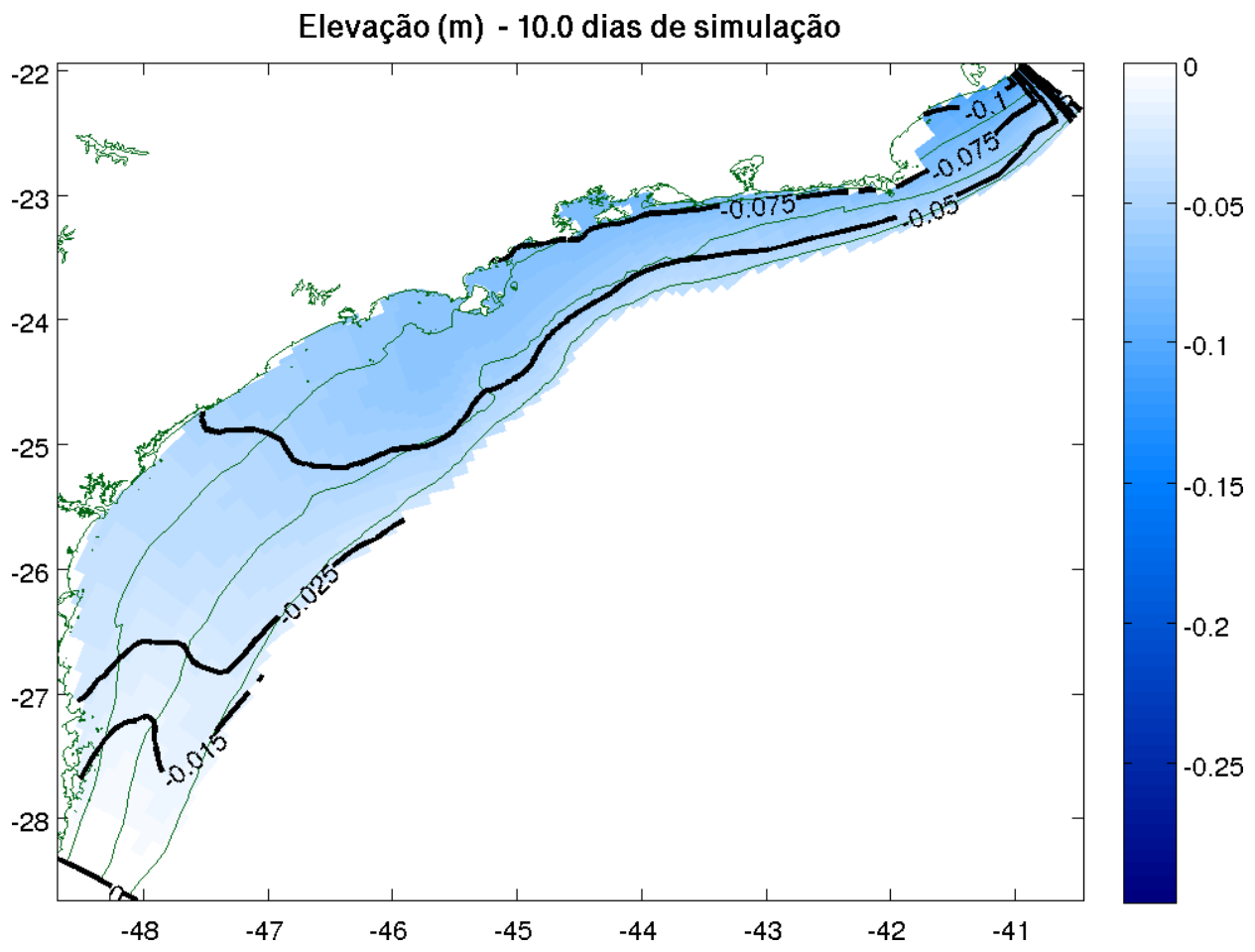

(a)

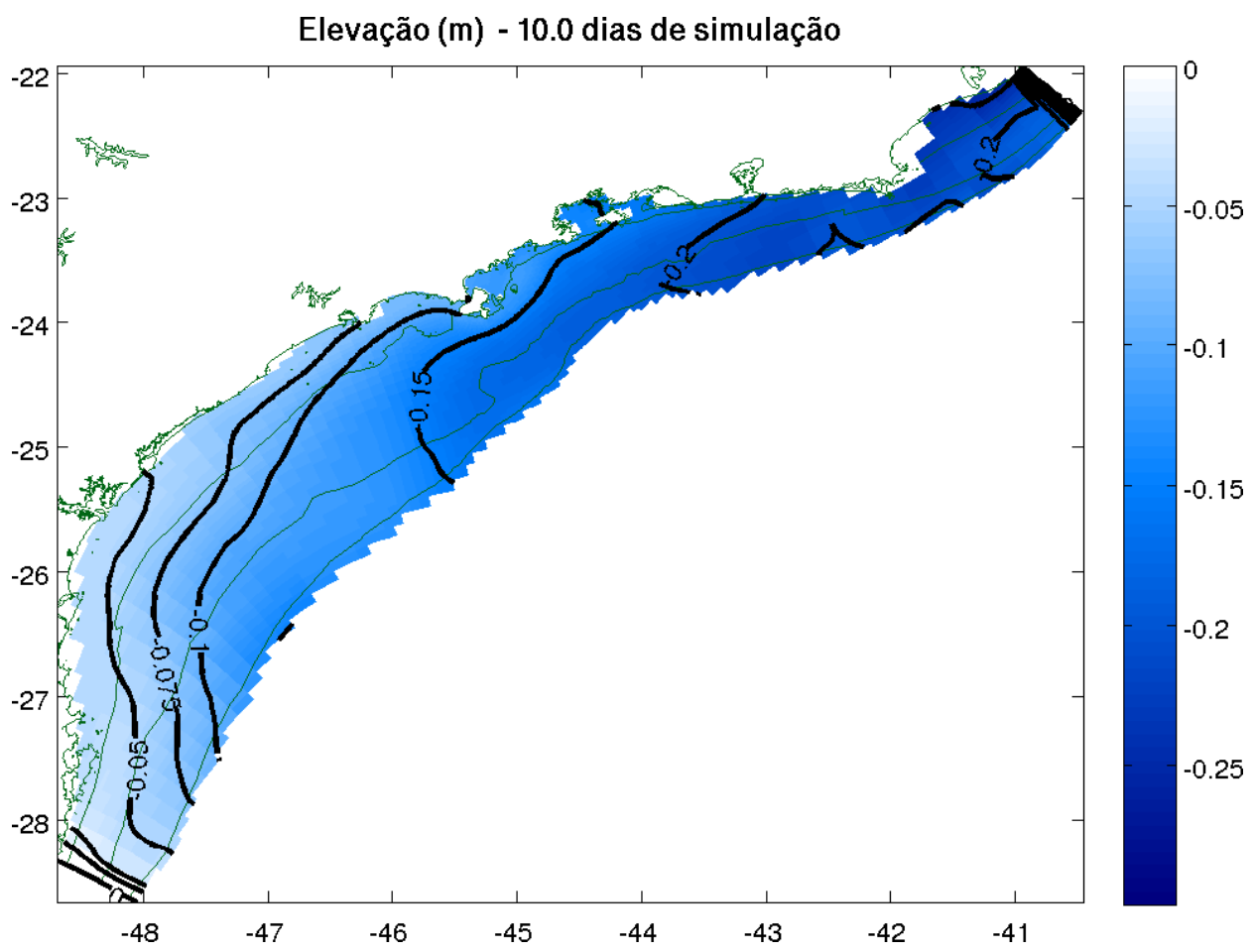

(b)

Figura 3.2: Mapas de elevação da superfície do mar nos experimentos (a) SC1 e (b) SC2. 
experimento SC2, a orientação das isolinhas é paralela na região sul da PCSE, com orientação S-SW, e o norte da PCSE as isolinhas são perpendiculares à costa, de SW.

Analisando a variabilidade temporal da elevação do nível do mar, o experimento SC1 (Figura 3.3 a e Figura 3.3 p) alcançou valores quase constantes após 4,5 dias de simulação, sendo possível observar um decaimento da elevação do oceano aberto para a costa, onde as regiões mais ao sul apresentaram menores desníveis entre a $\mathrm{PCI}, \mathrm{PCM}] \mathrm{PCE}$, quando comparadas com as regiões mais ao norte do domínio. Por exemplo, na radial de Cananéia, na PCI e na PCM o desnível foi de $-0.043 \mathrm{~m}$ e, na PCE, de $-0.038 \mathrm{~m}$. Na radial Cabo Frio encontram-se os menores valores de elevação e os maiores desníveis entre a PCI-PCM e a PCE, sendo cerca de $-0.075 \mathrm{~m} \mathrm{e}-0.055 \mathrm{~m}$, respectivamente.

Considerando as séries temporais de elevação do nível da superfície, no experimento SC2 (Figura 3.3 ), nota-se uma oscilação de alta frequência nas radiais Cananéia, Santos e Ubatuba. Comparado com o experimento anterior, o experimento SC2 apresentou maiores valores de rebaixamento do nível do mar, contudo os desníveis na $\mathrm{PCI}$ e na PCM foram menores do que na PCE em todas as radiais exceto a radial Cabo Frio (Figura $3.3 \mathrm{~d}$ ). A radial Cananéia apresentou valores de cerca de $-0.05 \mathrm{~m}$ na PCI, -0.053 na $\mathrm{PCM} \mathrm{e}-0.1 \mathrm{~m}$ na PCE. A radial de Cabo Frio não apresentou as oscilações de alta frequência observadas nas demais radiais, com menores desníveis entre PCI, PCM e PCE. Ao final de 10 dias de simulação os desníveis entre PCI, PCM e PCE praticamente desaparecem.

A Figura 3.4 apresenta os mapas de velocidades superficiais e velocidades médias na coluna d'água nas simulações controle. No mapa de velocidade máxima na superfície do experimento SC1 (Figura 3.4a), nota-se que as maiores velocidades são observadas ao norte de Cabo Frio$\mathrm{RJ}$, alcançando valores acima de $0.4 \mathrm{~ms}^{-1}$. Contudo, na maior parte do domínio, a velocidade máxima foi de cerca de $0.2 \mathrm{~ms}^{-1}$, principalmente em regiões com profundidades maiores que 30 metros, correspondendo a região da $\mathrm{PCM}$ e $\mathrm{PCE}$. Na $\mathrm{PCI}$ do estado de São Paulo, até as regiões mais rasas de Ilha Grande, no estado do Rio de Janeiro (profundidade < 30 metros), as velocidades foram de $0.1 \mathrm{~ms}^{-1}$, com direção da corrente superficial dominantemente para sudoeste em toda a região de estudo, obedecendo o regime de ventos. Sob o aspecto de velocidade média (Figura 3.4b), exceto a porção norte do domínio, que apresentou velocidade superior a $0.2 \mathrm{~ms}^{-1}$, o experimento $\mathrm{SC} 1$ apresentou valores próximos a $0.1 \mathrm{~ms}^{-1}$.

O experimento SC2 apresentou resultados distintos do SC1 no que se refere a intensidade máxima das correntes superficiais (Figura 3.4 c), onde valores acima de $0.45 \mathrm{~ms}^{-1}$ ocorreram ao norte de Cabo Frio, ao largo de Cananéia e Santos, após a isóbata de 100 metros, e na face sudeste da Ilha de São Sebastião. Diferente do experimento anterior, onde toda a $\mathrm{PCI}$ apresentou velocidade uniforme, a PCI no experimento SC2 apresentou valores de $0.1 \mathrm{~ms}^{-1}$ na região mais rasa de Cananéia, e ao norte de Santos até Ilha Grande. Nas demais regiões da PCI, os valores variaram de 0.2 a $0.3 \mathrm{~ms}^{-1}$. Em relação à direção da corrente, na PCI a partir de $25^{\circ} \mathrm{S}$ a direção foi preferencialmente para nordeste e na PCM e $\mathrm{PCE}$ o fluxo fluiu para sudoeste. $\mathrm{Na}$ superfície, em regiões mais próxima da $\overline{\mathrm{PCI}}$, os campos de densidade promoveram um fluxo de 

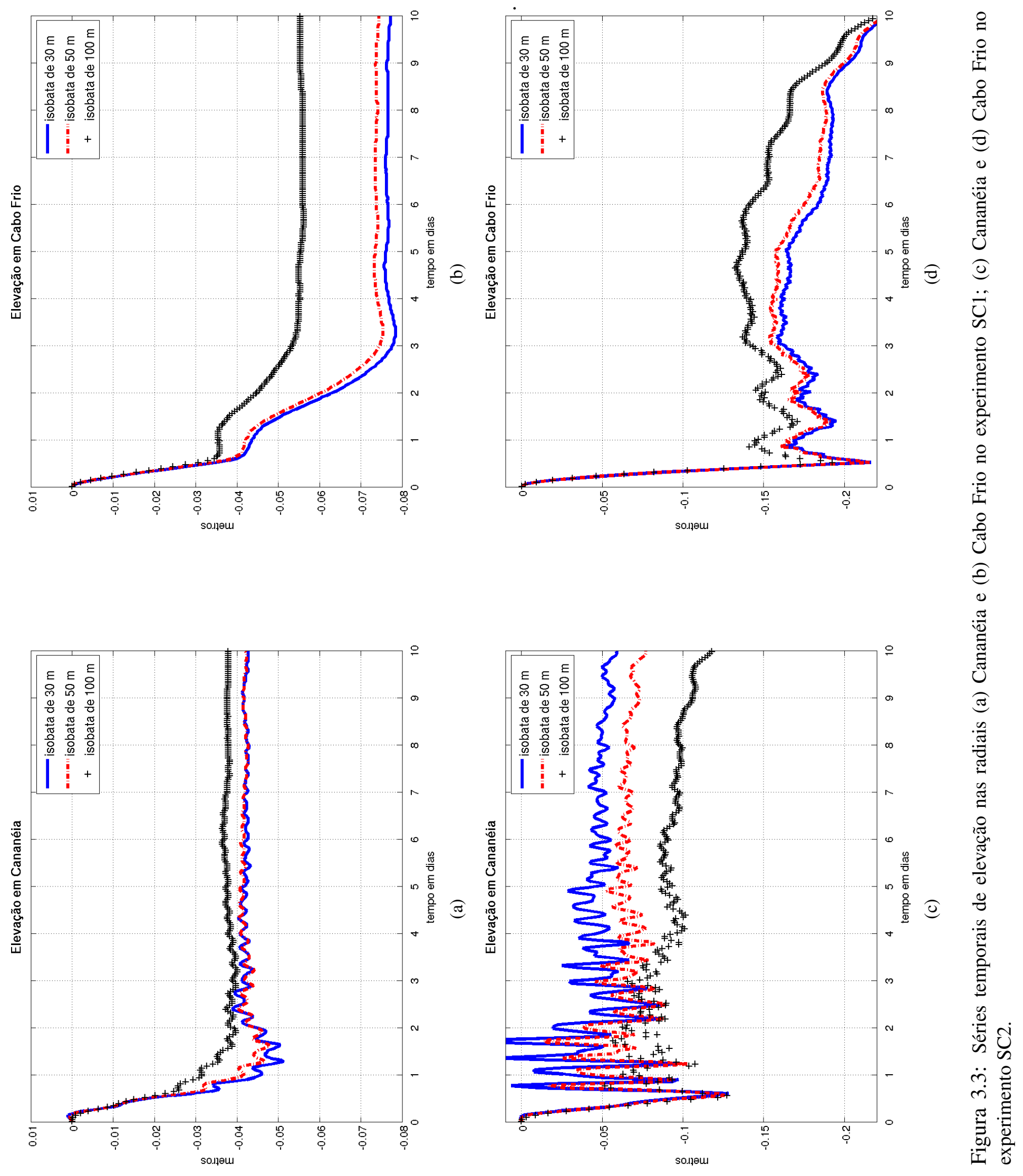

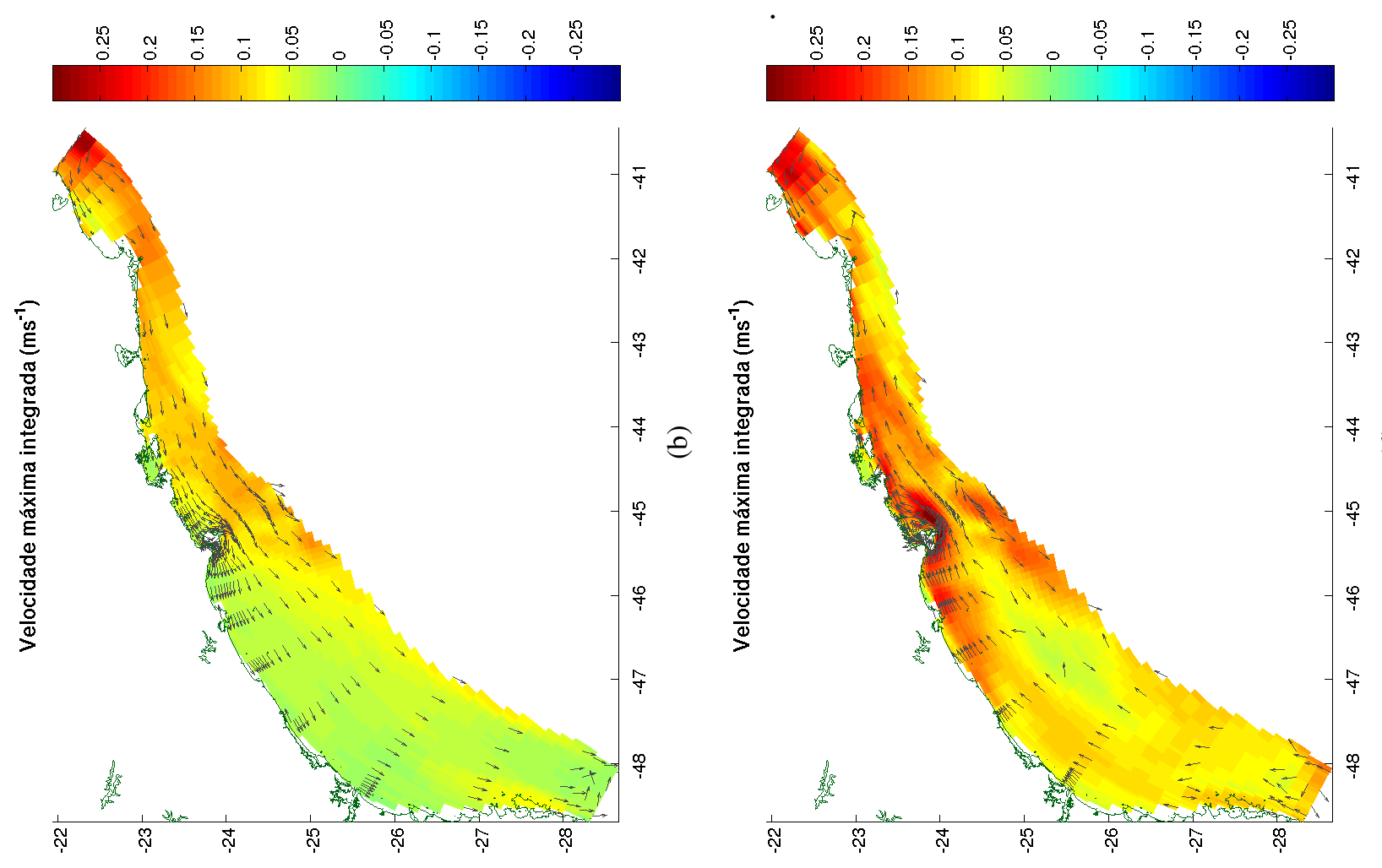

0
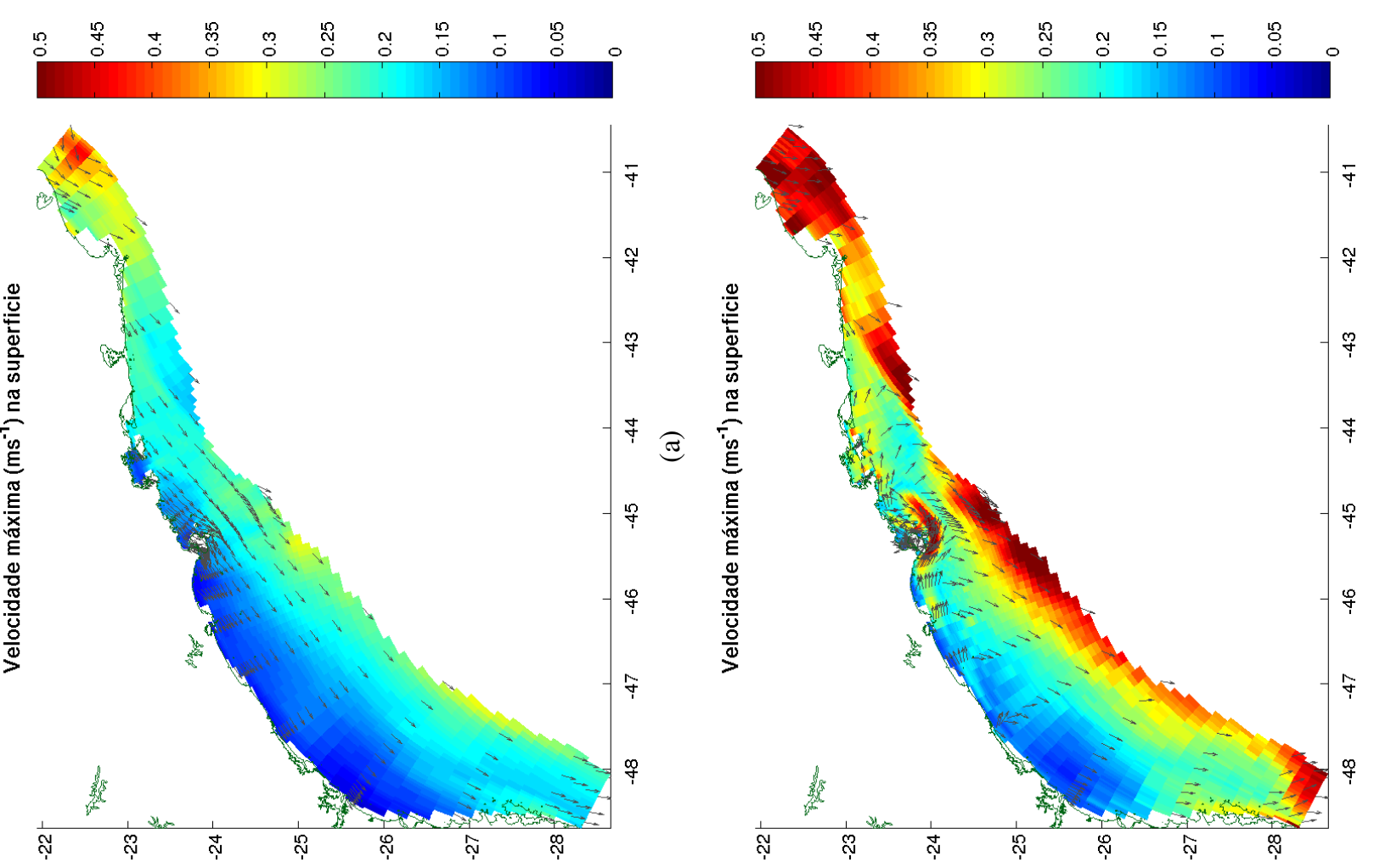

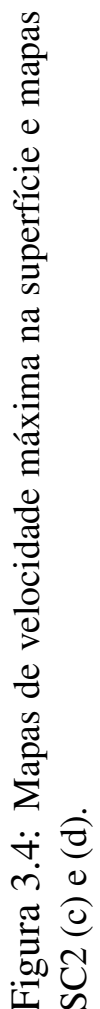


flutuabilidade intenso o suficiente para se sobrepor a forçante de vento. Este resultado corrobora com os trabalhos de Castro (1996), Valente (1999) e Mazzini (2009), que indicam que as correntes na PCI ao sul da Ilha de São Sebastião são preferencialmente para nordeste devido ao fluxo de flutuabilidade durante o verão. Este condicionamento também foi obtido por Morais (2016), ao realizar estudos numéricos na PCI da PCSP.

No experimento SC2, (Figura 3.4d), os maiores valores de velocidade média estão associados a Ilha de São Sebastião, com $0.3 \mathrm{~ms}^{-1}$ e direção para nordeste e, as regiões ao largo da Ilha de São Sebastião (isóbata de 100 metros), ao largo de Ilha Comprida e norte de Cabo Frio, com $0.2 \mathrm{~ms}^{-1}$ e direção sudoeste, nordeste e sudoeste respectivamente. Nessa simulação os vetores de velocidade média apresentaram direção preferencial para nordeste, sentido oposto ao vento na $\mathrm{PCI}$. Isso se deve provavelmente ao perfil estratificado de densidade da simulação $\mathrm{SC} 2$, que promoveu nas camadas de água mais profundas fluxos mais intensos para nordeste. O condicionamento das correntes sobre a PCI e parte da $\overline{\text { PCM }}$ preferencialmente para nordeste foi observado no estudo numérico na PCSE desenvolvido por Morais (2016), em que a ação dos ventos climatológicos de verão não foi capaz de se sobrepor ao fluxo de flutuabilidade promovido pelo campo estratificado de densidade. Em trabalho numérico anterior, Ruffato (2011) deduz que os campos estratificados de temperatura e salinidade na PCSE condicionam as correntes para nordeste na PCI, principalmente pela ação do fluxo de futuabilidade e a uma feição anti-ciclônica entre a PCM e a PCE ao sul da Ilha de São Sebastião.

Em relação as séries temporais de velocidade na superfície, o experimento $\mathrm{SC} 1$ apresentou, para todas as radiais, as maiores velocidades em regiões da PCE, sobre a isóbata de $100 \mathrm{~m}$, com cerca de $0.2 \mathrm{~ms}^{-1}$, sendo excessão a radial Cabo Frio, que em toda a sua extensão apresentou velocidades acima de $0.2 \mathrm{~ms}^{-1}$. Ruffato (2011) justifica a maior intensidade das correntes no norte da PCSE aos maiores valores de tensão de cisalhamento do vento na região entre Cabo de São Tomé e Cabo Frio. No restante da PCSE, o autor percebeu uma tendência da tensão de cisalhamento do vento aumentar em direção ao largo, onde as regiões de $\mathrm{PCI}$ de Cabo de Santa Marta até a Baía de Guanabara apresentam os menores valores de tensão de cisalhamento do vento se comparado com as regiões ao norte da PCSE. A Figura 3.5 apresenta as séries temporais de velocidade superficial de Santos e Cabo Frio de forma a representar os padrões encontrados durante simulação.

Já no experimento SC2, as séries temporais de velocidade superficial apresentadas na Figura 3.6 indicam que a inclusão de um campo estratificado de densidade ocasionou oscilações da velocidade superficial, assim como observado nas séries temporais de elevação, principalmente na isóbata de 100 metros da radial Cabo Frio. Após o quarto dia de simulação, a radial Santos apresentou inversões na direção da corrente na PCI. Na PCE de Santos foram observadas oscilações com períodos de cerca de 28.6 horas. Na radial Cabo Frio foram encontradas oscilações da corrente na $\mathrm{PCM}$ e na PCE, no entanto não há inversões de direção da corrente superficial.

Em relação a estrutura vertical da velocidade, as maiores velocidades foram encontradas na superfície no experimento SC1. No sul do domínio as velocidades foram de cerca de $0.1 \mathrm{~ms}^{-1}$ 

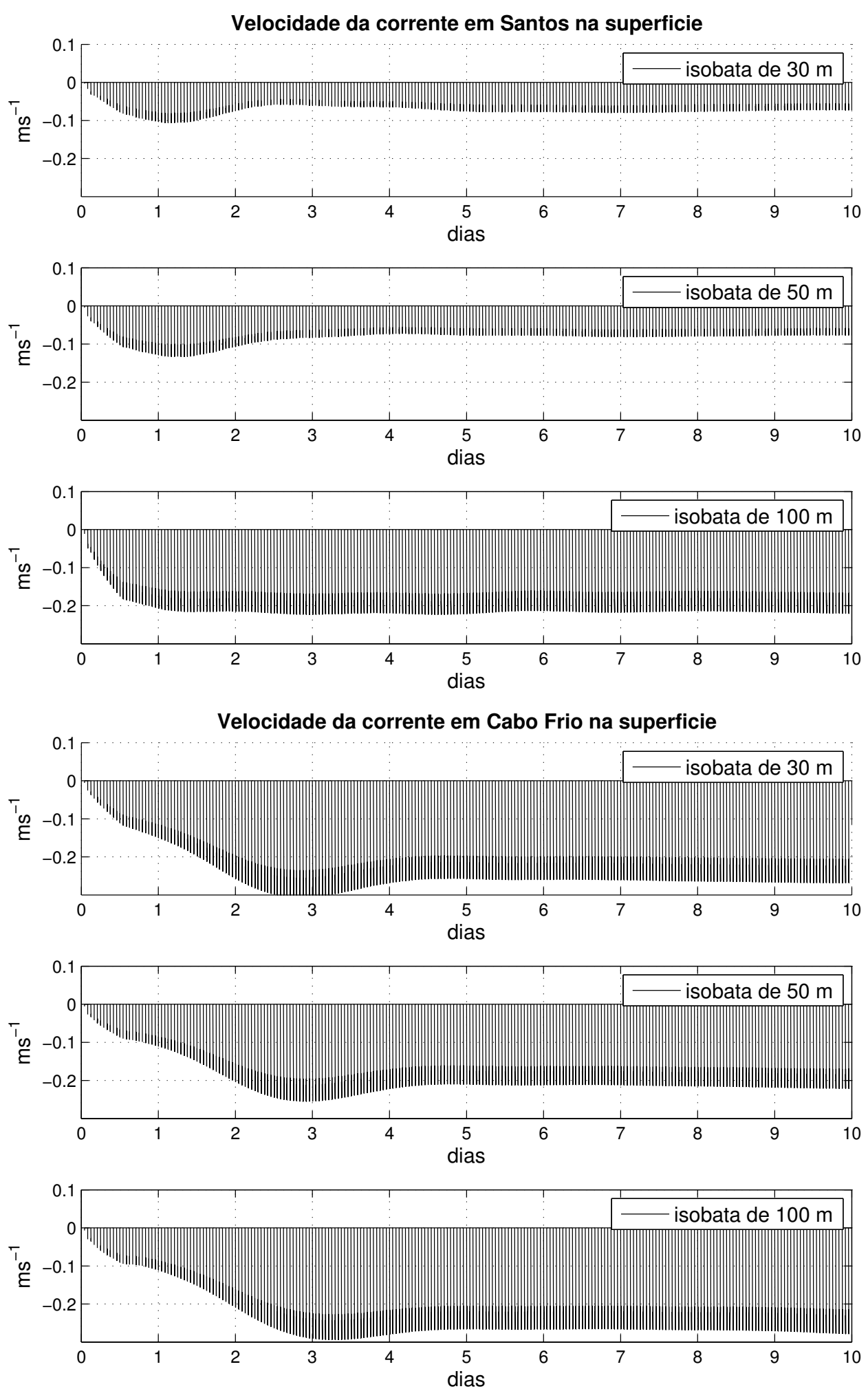

Figura 3.5: Séries temporais de velocidade na superfície, das radiais Santos e Cabo Frio, simulação SC1. 

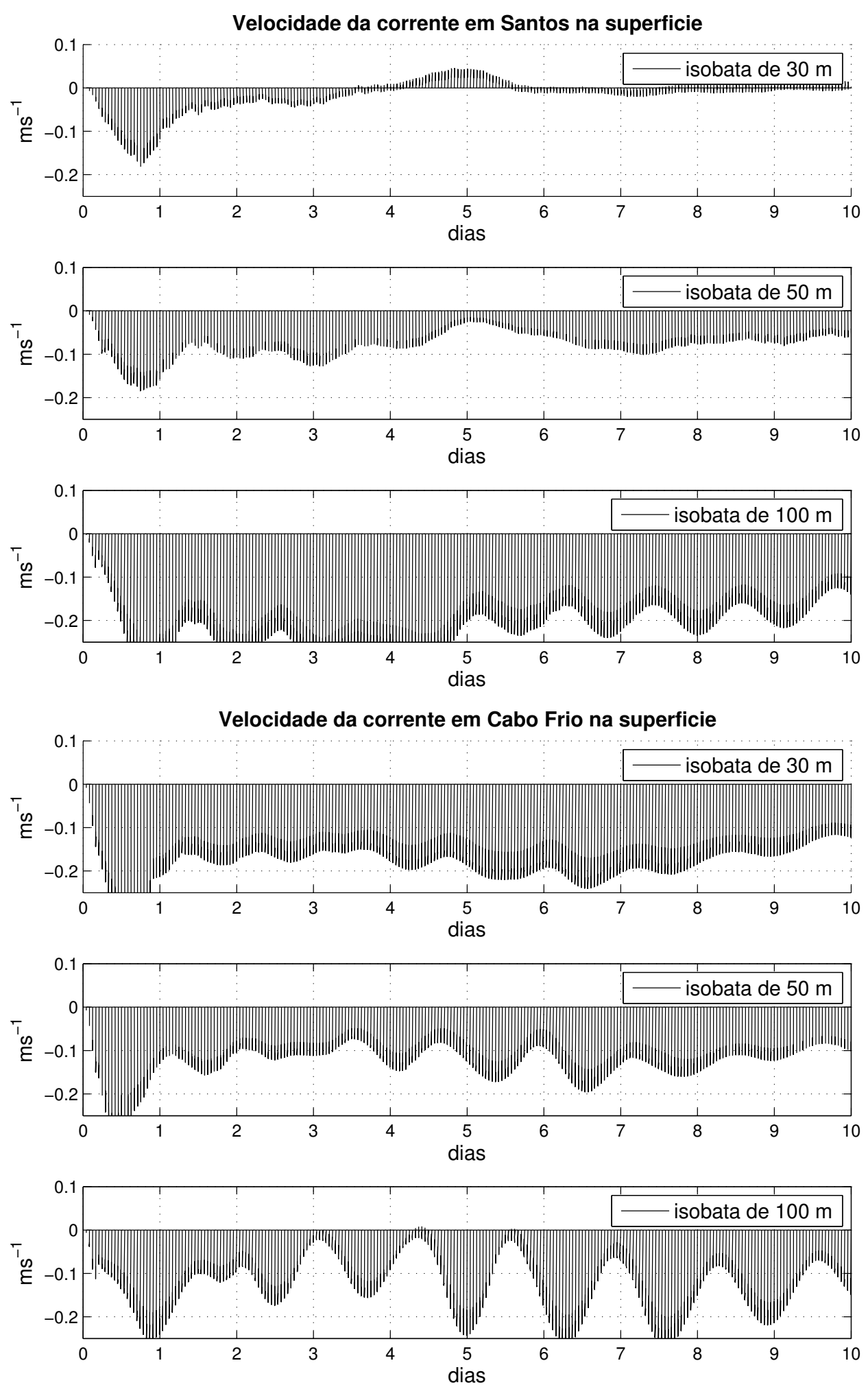

Figura 3.6: Séries temporais de velocidade na superfície das radiais Santos e Cabo Frio, simulação SC2. 

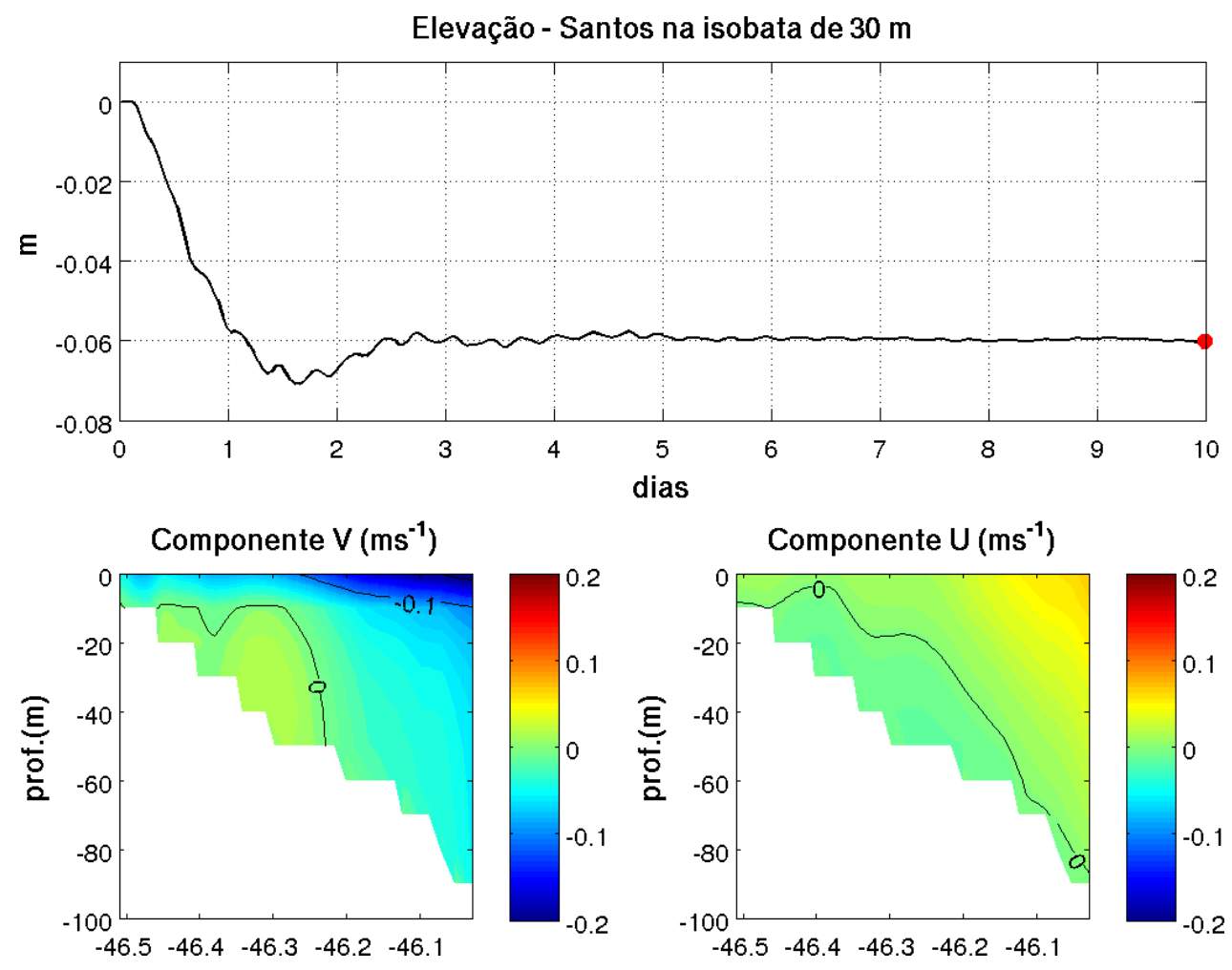

(a)
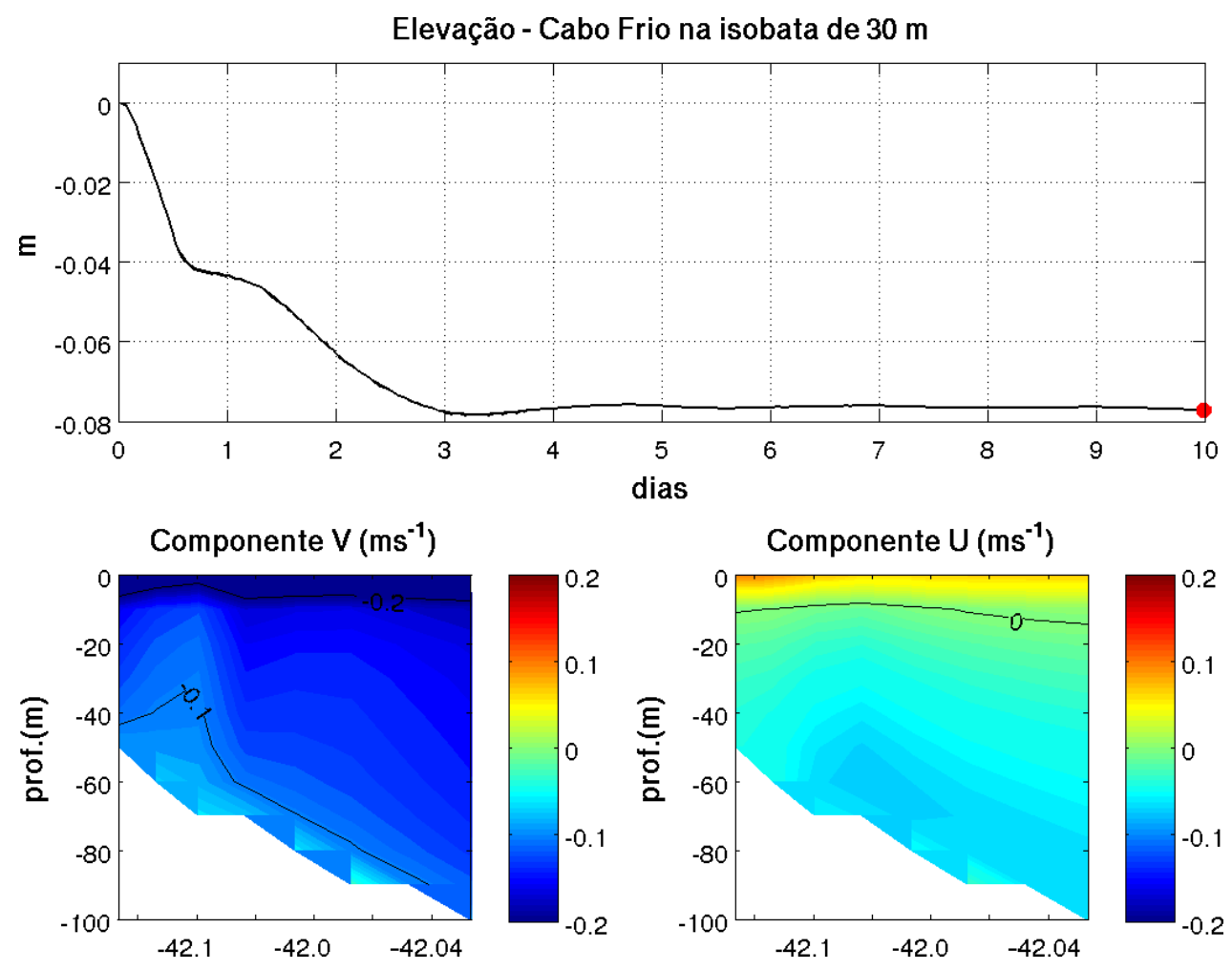

(b)

Figura 3.7: Série temporal de elevação e perfis verticais de velocidade perpendicular (U) e paralela (V) após 10 dias de simulação, experimento SC1. (a) radial Santos e (b) radial Cabo Frio. 

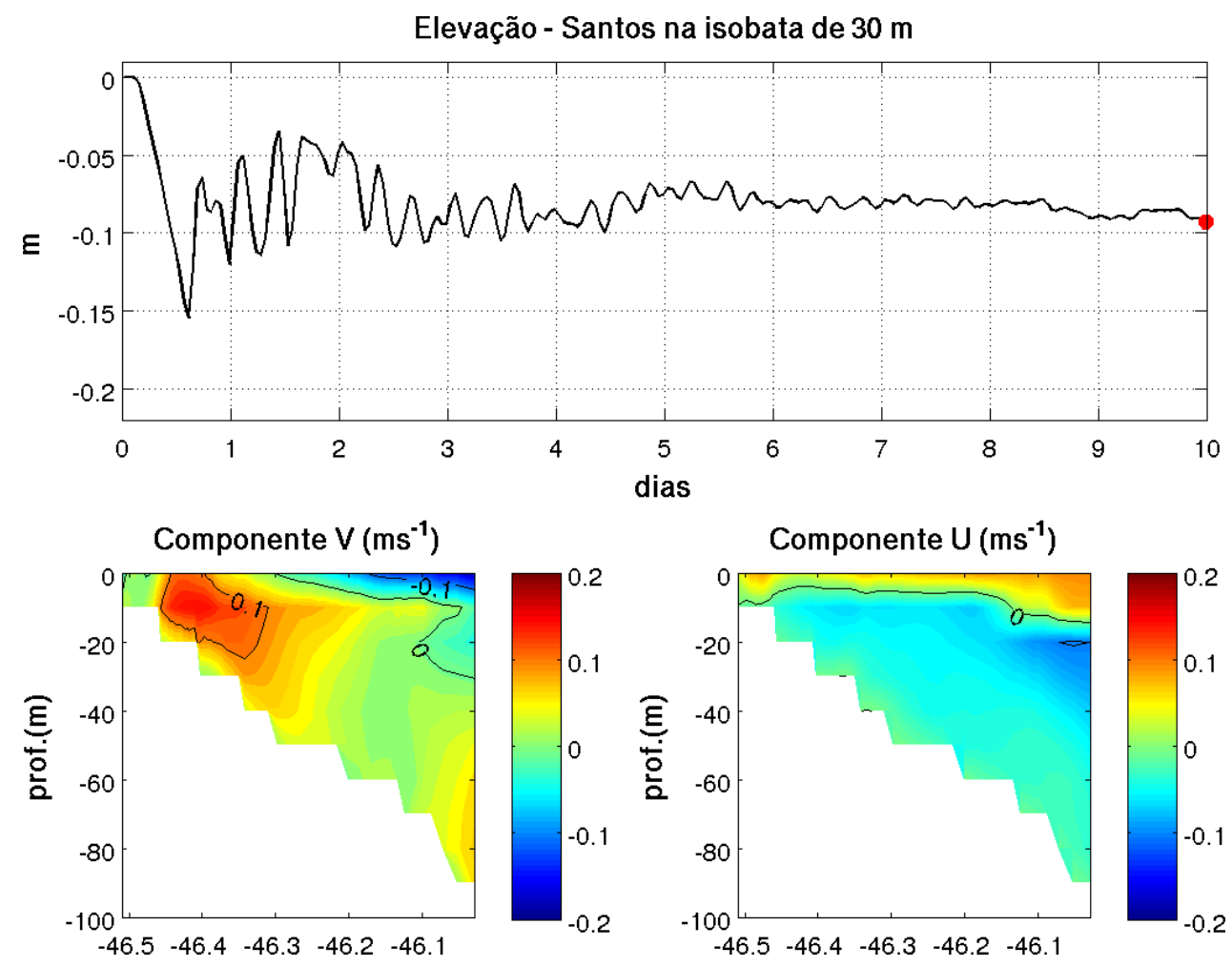

(a)
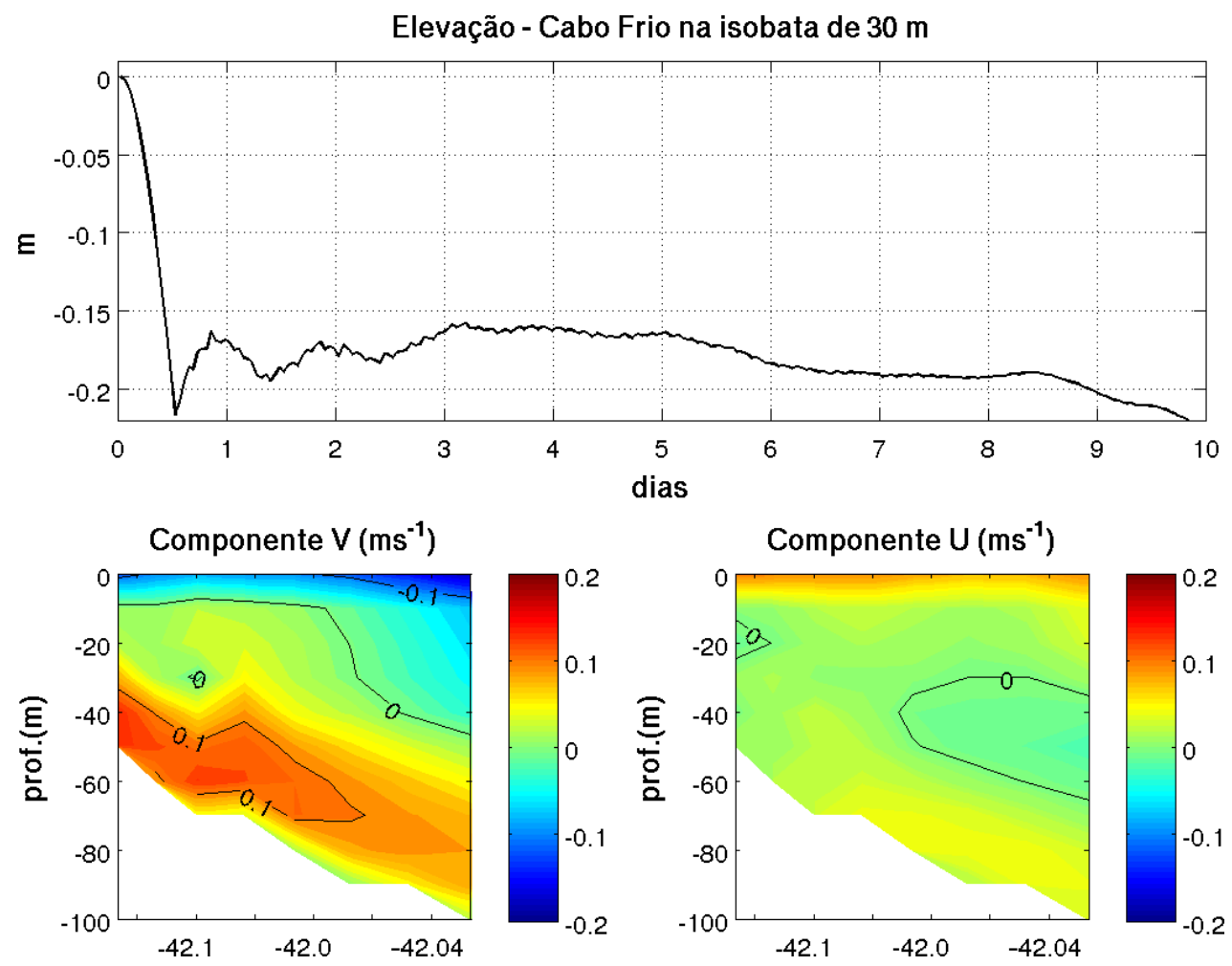

(b)

Figura 3.8: Série temporal de elevação e perfis verticais de velocidade perpendicular (U) e paralela (V) após 10 dias de simulação, experimento SC2. (a) radial Santos e (b) radial Cabo Frio. 
na componente paralela. A direção das componentes são dadas de acordo com a convenção adotada ${ }^{2}$ e $\operatorname{logo}$ as correntes paralelas apresentaram direção predominante para sudoeste e perpendicular para o largo.

De modo geral, as correntes tornaram-se mais intensas em menores latitudes, tanto pelo maior cisalhamento do vento ao norte da PCSE quanto pela orientação da costa, principalmente em Ubatuba e Cabo Frio. Com a finalidade de representar a estrutura vertical típica das correntes da região sul e da região norte do domínio, a Figura 3.7 apresenta a estrutura vertical da corrente em ambas as componentes da velocidade, associadas a elevação em Santos (Figura 3.7 A) e Cabo Frio (Figura $3.7 \mathrm{p}$ ), onde os valores da componente paralela foram maiores que a perpendicular, alcançando $0.2 \mathrm{~ms}^{-1}$.

As estruturas verticais de velocidade do experimento SC2 diferem do experimento SC1, e em Santos (Figura 3.8 a) o campo de densidade na região permitiu uma fraca corrente paralela (componente $\mathrm{V}$ ) de $0.1 \mathrm{~ms}^{-1}$ que flui para nordeste na $\mathrm{PCI}$ na superfície até a profundidade de 20 metros. Na PCE a corrente paralela superficial foi de $0.1 \mathrm{~ms}^{-1}$ para sudoeste. Na superfície da radial Cabo Frio, a corrente paralela fluiu para sudoeste com intensidade de $0.1 \mathrm{~ms}^{-1}$ e uma corrente de mesma intensidade para nordeste foi observada entre 40 metros de profundidade e o fundo na PCI e $\mathrm{PCM}$ (Figura $3.8 \mathrm{~b}$ ).

\subsection{Simulações de Vento Remoto}

A seguir serão apresentados os resultados das simulações numéricas forçadas apenas com vento remoto na parte sul do domínio, denominados experimentos RS1, RS2, RS3 e RS4, descritos na Seção 2.3.5.

Com o intuito de observar o alcance da pertubação do nível do mar gerada pelo sinal remoto do vento, foram elaborados mapas de elevação máxima do nível do mar na PCSE nos experimentos, apresentados na Figura 3.9. Nos mapas, as maiores elevações ocorreram no sul da PCSE, aréa de atuação dos ventos, delimitada pela linha pontilhada, e com isso não representam elevações associadas apenas ao sinal remoto do vento, mas a ação combinada de vento remoto e vento local.

No experimento RS1 (Figura 3.9 a), com frentes frias com 18 horas de permanência no sul da PCSE, as elevações máximas da superfície foram de $0.2 \mathrm{~m}$ próximo à costa, na divisa dos estados do Paraná e São Paulo. No experimento RS2 (Figura 3.9p), com 36 horas de pemanência das frentes frias, a superfície do mar atingiu valor máximo de $0.3 \mathrm{~m}$. As maiores diferenças entre essas duas simulações foram as elevações na parte norte da PCSE, onde em RS1 as elevações na PCM e na PCE foram de até $0.1 \mathrm{~m}$, e em RS2, a PCE e ao norte de Cabo Frio as elevações foram abaixo de zero.

\footnotetext{
${ }^{2}$ componente paralela-v [-]: para sul-sudoeste; componente paralela-v [+]: para norte-nordeste; componente perpendicular-u [-]: para a costa; e componente perpendicular-u $[+]$ : para a quebra da plataforma
} 

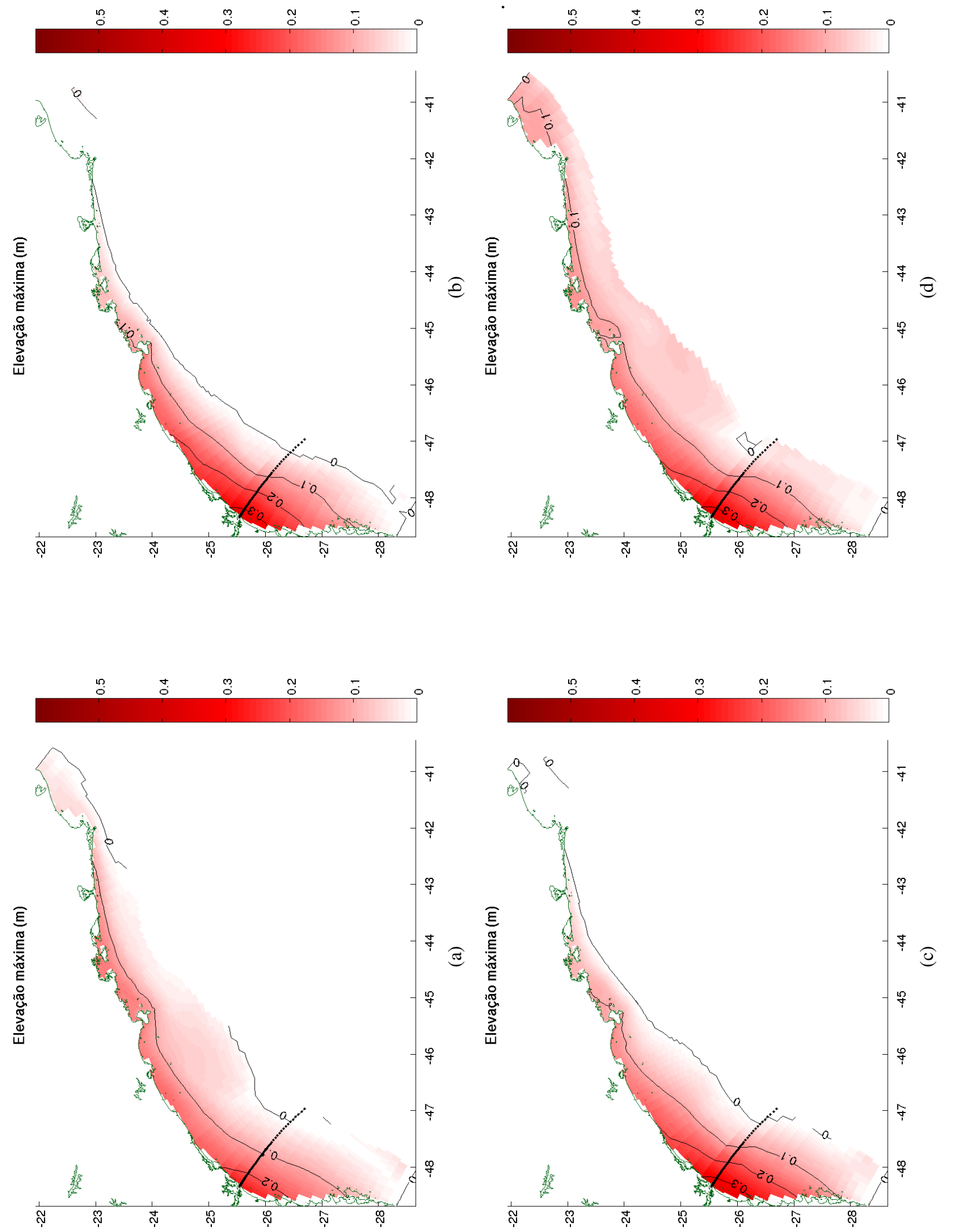

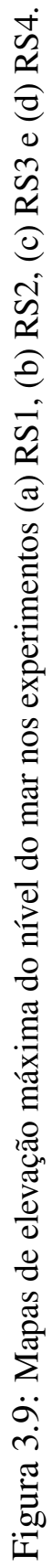


Contudo, a Figura 3.9c indica que o experimento RS3, com 54 horas de permanência da frente fria remota, apresentou elevação máxima de $0.3 \mathrm{~m}$ na $\mathrm{PCI}$ nas proximidades da Baía de Paranaguá-PR. Entre a PCI de São Paulo até a Ilha de São Sebastião as elevações máximas foram entre 0.1 e $0.2 \mathrm{~m}$. Já o experimento RS4 (Figura 3.9d), com 72 horas de frente fria remota, apresentou elevações positivas em todo o domínio da PCSE, como o ocorrido no experimento RS1, sendo que na região norte de Cabo Frio o nível do mar com a passagem da OPC atingiu $0.1 \mathrm{~m}$.

Analisando as séries temporais de elevação no experimentos RS1, os picos de elevações coincidem com o momento de inversão dos ventos remotos e, deste modo, estão associados a crista de uma onda de plataforma continental (OPC). As frentes com 18 horas de permanência geraram as maiores amplitudes na PCI das radiais de Cananéia e Santos, de cerca de $0.18 \mathrm{~m}$ e de $0.15 \mathrm{~m}$, respectivamente, e estão associados principalmente com a proximidade das radiais ao local de ação dos ventos. Na radial Ubatuba a elevação do nível do mar alcançou valor positivo apenas após as passagens remota das frentes fria, atingindo $0.02 \mathrm{~m}$ na passagem das três primeiras frentes e $0.12 \mathrm{~m}$ na última. Por estar afastada mais de $600 \mathrm{~km}$ de distância da área de atuação dos ventos, a radial Cabo Frio preservou o nível do mar rebaixado, e as cristas das OPCs observadas mais ao sul da radial não foram observadas nesta radial, exceto na passagem da última frente no dia 16, que elevou a superfície até $0.08 \mathrm{~m}$.

As crista das $\mathrm{OPC} \beta$ alcançaram maiores valores no experimento RS2, visto que apresenta frentes frias com maior tempo de permanência. Em Cananéia o valor máximo de elevação foi de $0.21 \mathrm{~m}, 0.15 \mathrm{~m}$ em Santos, e $0.1 \mathrm{~m}$ em Ubatuba, todas durante a passagem da terceira frente remota, na região da PCI. Em Cabo Frio o nível do mar permaneceu abaixo de zero durante toda a simulação. Em relação aos valores de elevação na $\mathrm{PCE}$, na isóbata de 100 metros, apenas em Cananéia houve elevações positivas, com cerca de $0.01 \mathrm{~m}$, marcando a passagem da OPC nessa região.

$\mathrm{O}$ aumento para 54 horas de tempo de permanência da frente no experimento RS3 gerou amplitudes da altura da onda da OPC um pouco menores do que os observados em RS2, mas preservou o padrão de maiores valores nas radiais mais próximas da ação do vento. A PCI ao largo de Cananéia registrou $0.2 \mathrm{~m}$ de altura da OPC, e em Santos e Ubatuba cerca de $0.1 \mathrm{~m}$. Durante o experimento RS4 as elevações do nível do mar na PCI foram similares as observadas no experimento RS3, com 0.2 m em Cananéia, 0.13 m em Santos, 0.1 m em Ubatuba.

Observando as séries temporais de elevação nos quatro experimentos de vento remoto, percebe-se que, no experimento RS1 as séries temporais de elevação apresentam oscilações entre as $\mathrm{OPC} \beta$, principalmente nas radiais mais próximas da ação do vento, não sendo perceptíveis em Cabo Frio. Nos demais experimentos, essas oscilações não apresentam magninute significativas. A Figura 3.10a apresenta as séries temporais de elevação na radial Cananéia durante o experimento RS1, e nas imagens seguintes nota-se a atenuação dessa oscilação com o aumento do tempo de permanência das frentes, nos experimentos RS2 (Figura $3.10 \mathrm{p}$ ), experimento RS3 (Figura 3.10c) e RS4 (Figura 3.10d). 

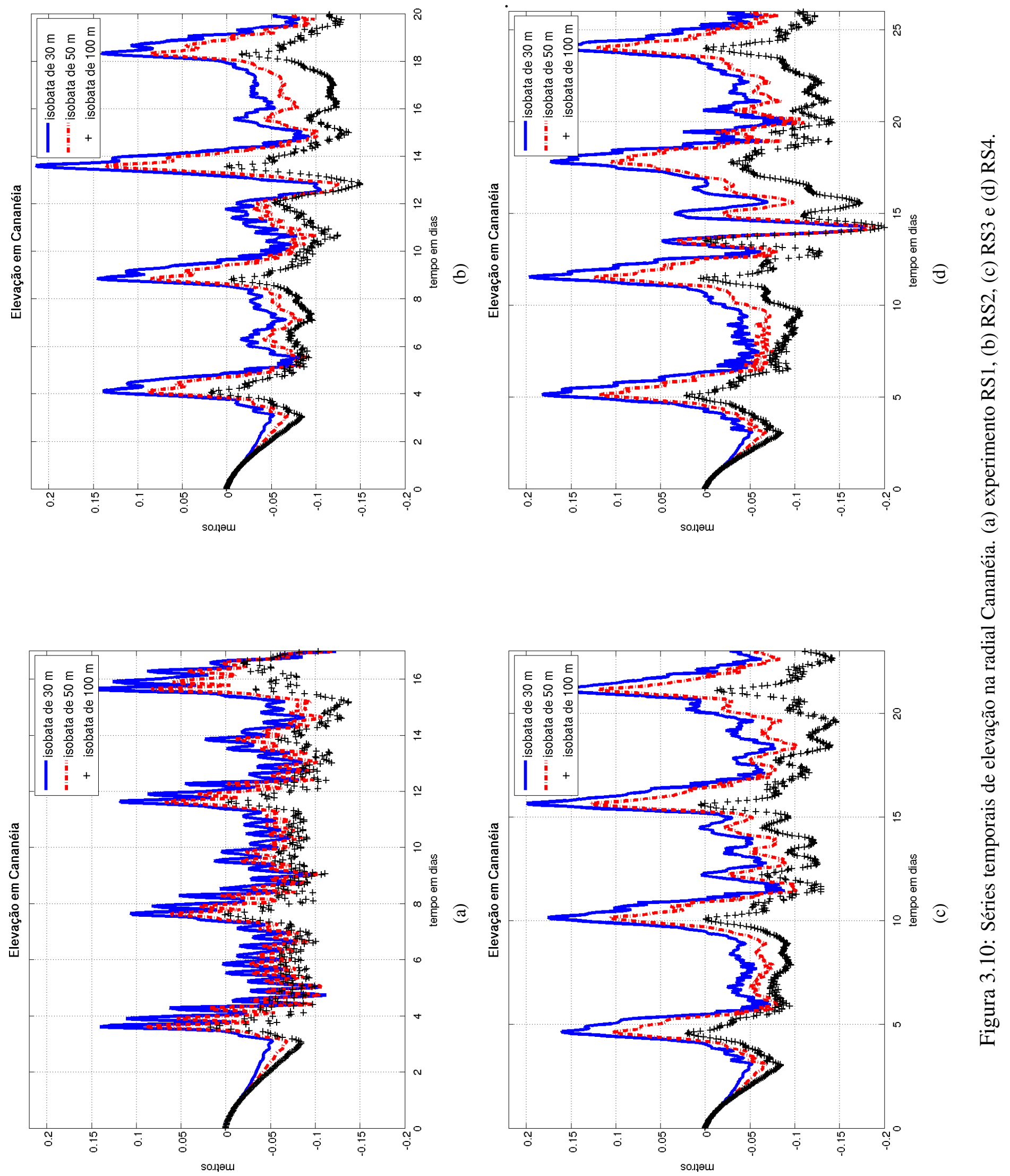

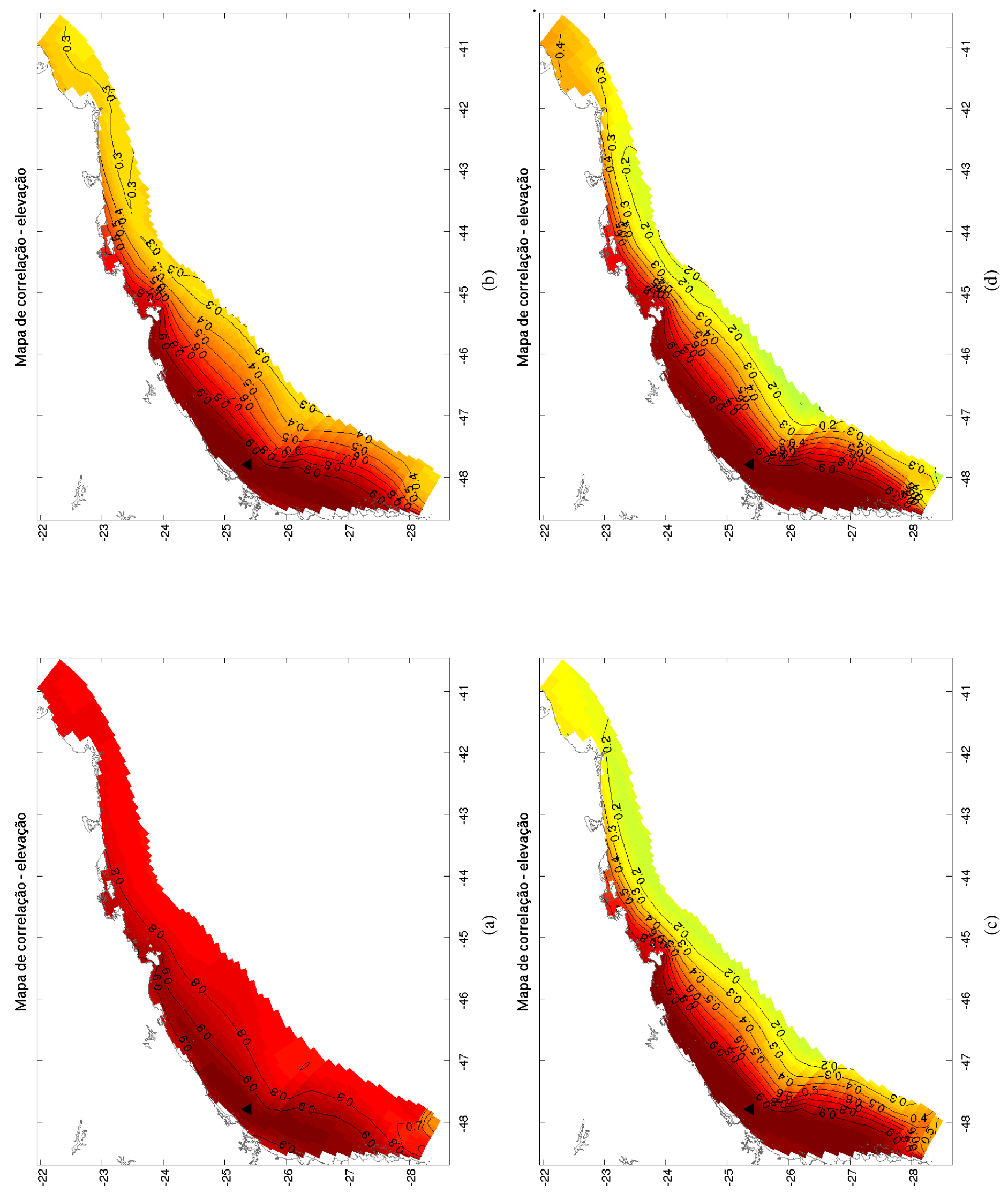
A Figura 3.11 exibe os mapas de correlação da elevação do nível do mar em relação ao ponto de referência ( $\mathbf{\Lambda})$. Os mapas indicam que os experimentos apresentaram uniformidade de correlação de elevação, com valores acima de 0.9 na $\mathrm{PCI}$ de Santa Catarina, ao sul do domínio, até o sul da Ilha de São Sebastião $\left(24^{\circ} \mathrm{S}-45.5^{\circ} \mathrm{W}\right)$. Valores de 0.8 foram obtidos na $\mathrm{PCM}$ de Santa Catarina até a região da PCI de Ilha Grande-RJ $\left(23.5^{\circ} \mathrm{S}-44^{\circ} \mathrm{W}\right)$. Apesar de exibir valores insignificantes, a região ao norte da PCSE apresentou maior variabilidade nos valores de correlação, onde no experimento RS2 (Figura 3.11 p) apresentou correlaçao de 0.3 , diminuindo para para 0.2 no experimento RS3 (Figura 3.11), e aumentando para 0.4 no experimento RS4 (Figura 3.11d).

De forma a estimar o comprimento das OPC $\$$ nos experimentos, a Figura 3.12 apresenta diagramas de Hovmöller relacionando as elevações do nível do mar na costa da PCSE (aproximadamente $1050 \mathrm{~km}$ de extensão) durante os experimentos. Os dados de elevação foram previamente filtrados em 40 horas para a eliminação das oscilações de alta frequência, exibindo as cristas das OPCs com valores abaixo dos apresentados nos mapas de elevação máxima. As estimativas dos comprimentos das OPCs foram feitas através dos comprimentos das cristas (isolinhas de elevação positiva) e das cavas (isolinhas de elevação negativa). Considerando que a cidade de São Franscisco do Sul-SC está a 150 km do limite sul da PCSE; a Baía de ParanaguáPR a cerca de 193 km; a cidade de Cananéia-SP a cerca de 221 km; a cidade de Santos-SP a 481.5 km; a cidade de São Sebastião-SP a 574 km; a cidade de Ubatuba-SP a 636.7 km; a Baía da Guanabara-RJ a 838.3; e a cidade de Cabo Frio-RJ a 949.7 km, as três primeiras OPC experimento RS1 (Figura 3.12 a) atingiram a região de Ubatuba, e a última alcançou a região de Cabo Frio.

A exemplo de medição, as cristas das OPCs atingiram Ubatuba e a cava passou por São Francisco do Sul algumas horas depois, indicando um comprimento médio de cerca de 1250 km no experimento RS1. Durante o experimento RS2 (Figura 3.12 p), as duas primeiras OPCs alcançaram Ubatuba, com comprimento estimado em $1450 \mathrm{~km}$ e as duas últimas alcançaram a região da Baía de Guanabara, com cerca de 1550 km e 1700 km de comprimento. Os valores da crista das OPC frente fria dissipativa (que não percorre toda a extensão) na PCSE durante o verão, encontrou maiores valores nas regiões de Cananéia e Paranaguá, entre 0.1 e $0.2 \mathrm{~m}$.

O aumento do tempo de ação dos ventos de frente fria remota nos experimentos subsequentes acarretaram no progressivo aumento do comprimento das OPCs, sendo que no experimento RS3 (Figura 3.12 $\mathrm{k}$ ), o comprimento médio das OPC $\$$ foi de $1650 \mathrm{~km}$ e no experimento RS4 (Figura $3.12 \mathrm{~d}$ ) foi de $1700 \mathrm{~km}$.

Em relação ao deslocamento da onda na PCSE, a Tabela 3.1 apresenta os valores de velocidade de propagação da OPC calculada a partir dos valores de atraso da correlação e da distância das radiais de estudo em relação ao ponto de referência. Entre os experimento RS1 e RS2 há um aumento na velocidade de propagação da onda em todas as radiais, resultando na região sul da PCSE um aumento de $6.1 \mathrm{~ms}^{-1}$ para $9.2 \mathrm{~ms}^{-1}$. O experimento RS3 apresentou atraso superior 


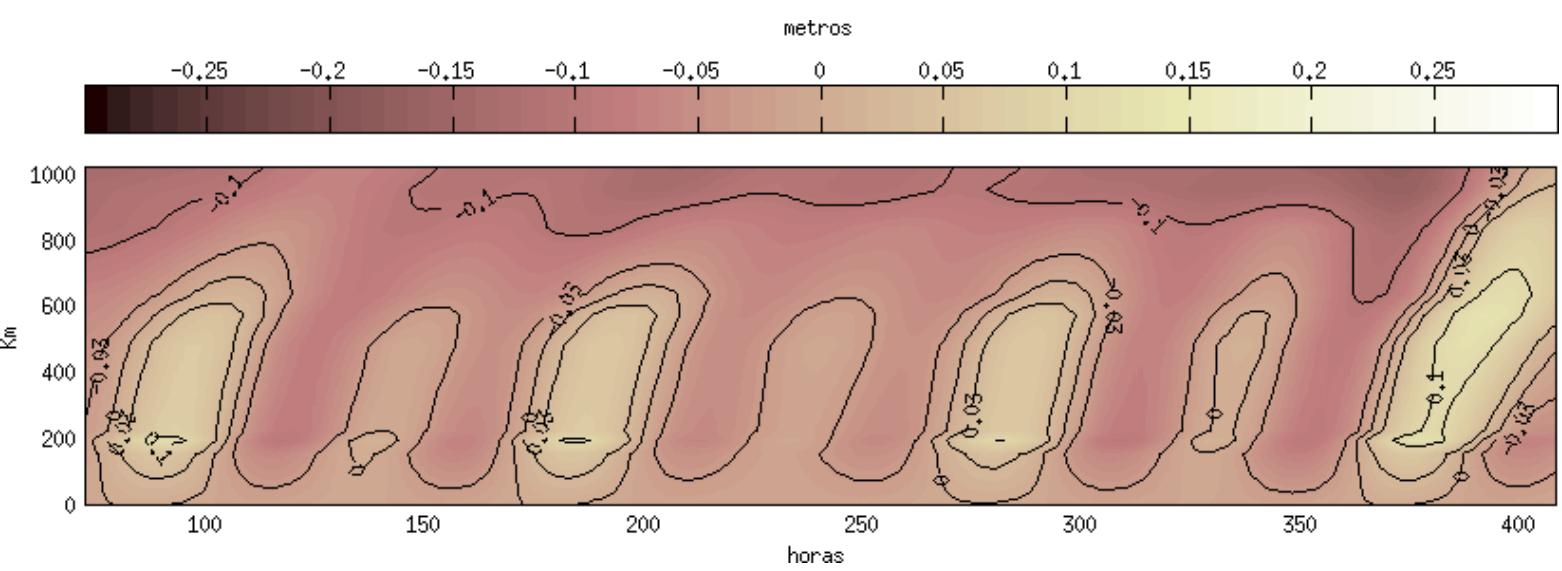

(a)

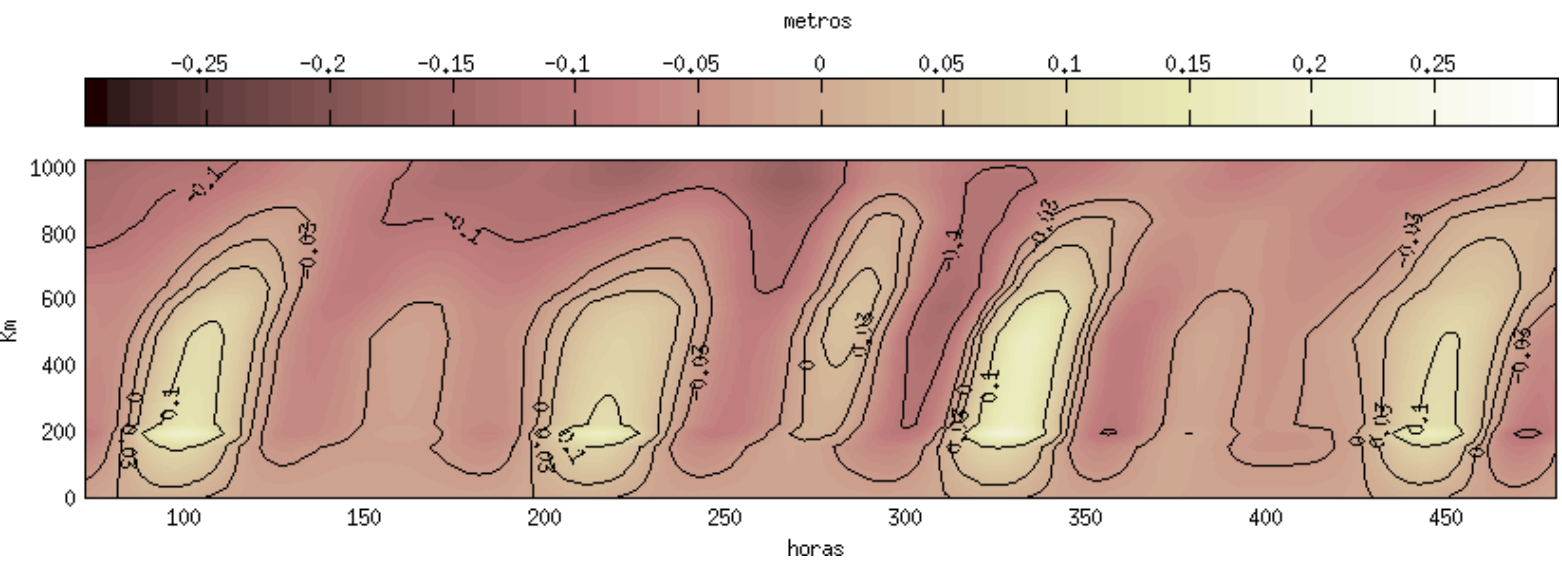

(b)
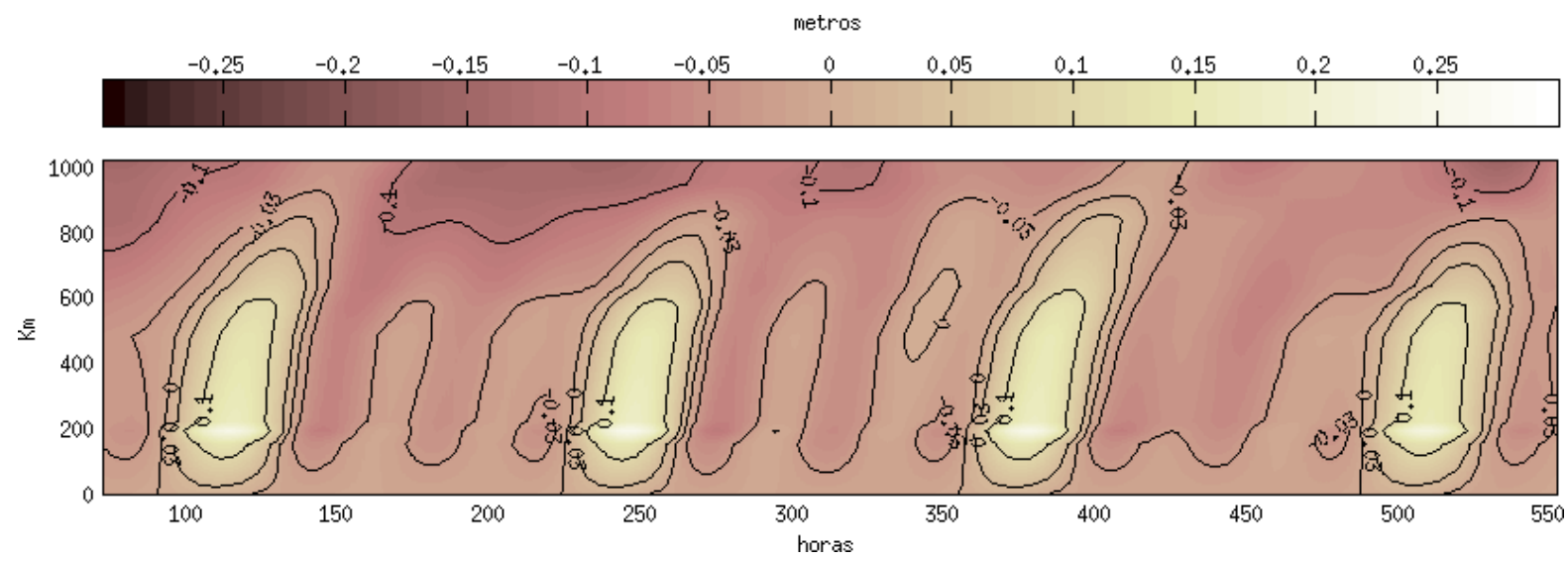

(c)
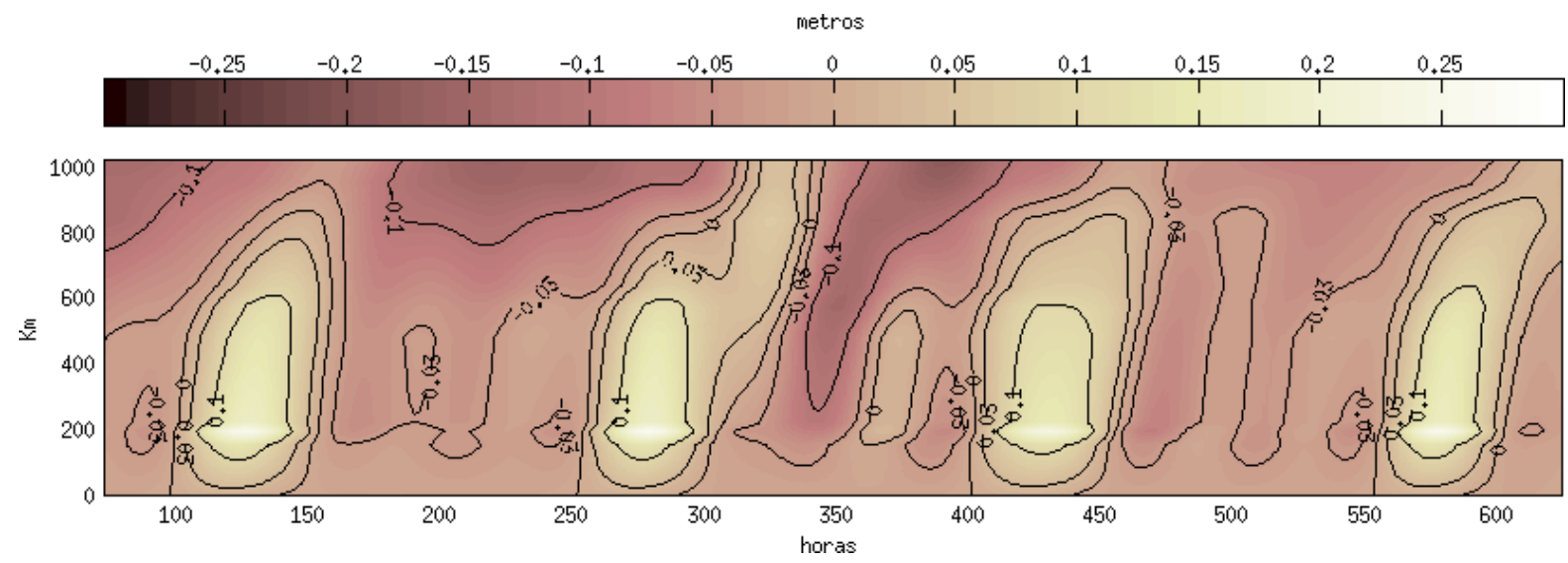

(d)

Figura 3.12: Isopletas de elevação da Onda de Plataforma Continental, nos experimentos (a) RS1 , (b) RS2, (c) RS3 e (d) RS4. Dados filtrados em 40 horas. 
Tabela 3.1: Relação dos valores de atraso e velocidade de propagação da Onda de Plataforma Continental, nos experimentos remotos de Sul.

\begin{tabular}{|c|c|c|c|c|c|}
\hline & & RS1 & RS2 & RS3 & RS4 \\
\hline $\begin{array}{l}\text { Radial Cananéia } \\
(66.9 \mathrm{~km} \text { da referência } \mathbf{\Delta})\end{array}$ & $\begin{array}{l}\text { Atraso (lag) } \\
\text { Vel.OPC }\end{array}$ & $\begin{array}{c}03 \mathrm{~h} \\
6.2 \mathrm{~ms}^{-1}\end{array}$ & $\begin{array}{c}02 \mathrm{~h} \\
9.3 \mathrm{~ms}^{-1}\end{array}$ & $\begin{array}{c}02 \mathrm{~h} \\
9.3 \mathrm{~ms}^{-1}\end{array}$ & $\begin{array}{c}02 \mathrm{~h} \\
9.3 \mathrm{~ms}^{-1}\end{array}$ \\
\hline $\begin{array}{l}\text { Radial Santos } \\
(227.4 \mathrm{~km} \text { da referência } \mathbf{\Delta})\end{array}$ & $\begin{array}{l}\text { Atraso (lag) } \\
\text { Vel.OPC }\end{array}$ & $\begin{array}{c}09 \mathrm{~h} \\
7.0 \mathrm{~ms}^{-1}\end{array}$ & $\begin{array}{c}06 \mathrm{~h} \\
10.5 \mathrm{~ms}^{-1}\end{array}$ & $\begin{array}{c}06 \\
10.5 \mathrm{~ms}^{-1}\end{array}$ & $\begin{array}{c}07 \\
9.0 \mathrm{~ms}^{-1}\end{array}$ \\
\hline $\begin{array}{l}\text { Radial Ubatuba } \\
(380.3 \mathrm{~km} \text { da referência } \mathbf{\Delta})\end{array}$ & $\begin{array}{l}\text { Atraso (lag) } \\
\text { Vel.OPC }\end{array}$ & $\begin{array}{c}18 \mathrm{~h} \\
5.9 \mathrm{~ms}^{-1}\end{array}$ & $\begin{array}{c}15 \mathrm{~h} \\
7.0 \mathrm{~ms}^{-1}\end{array}$ & $\begin{array}{c}13 \mathrm{~h} \\
8.1 \mathrm{~ms}^{-1}\end{array}$ & $\begin{array}{c}14 \mathrm{~h} \\
7.5 \mathrm{~ms}^{-1}\end{array}$ \\
\hline $\begin{array}{l}\text { Radial Cabo Frio } \\
(693.8 \mathrm{~km} \text { da referência } \mathbf{\Delta})\end{array}$ & $\begin{array}{l}\text { Atraso (lag) } \\
\text { Vel.OPC }\end{array}$ & $\begin{array}{c}35 \mathrm{~h} \\
5.5 \mathrm{~ms}^{-1}\end{array}$ & $\begin{array}{c}33 \mathrm{~h} \\
5.8 \mathrm{~ms}^{-1}\end{array}$ & $\begin{array}{c}51 \mathrm{~h} \\
3.8 \mathrm{~ms}^{-1}\end{array}$ & $\begin{array}{c}40 \mathrm{~h} \\
4.8 \mathrm{~ms}^{-1}\end{array}$ \\
\hline $\begin{array}{l}\text { PCSE - sul até São Sebastião } \\
(331 \mathrm{~km} \text { da referência } \mathbf{\Delta})\end{array}$ & $\begin{array}{l}\text { Atraso (lag) } \\
\text { Vel.OPC }\end{array}$ & $\begin{array}{c}15 \mathrm{~h} \\
6.1 \mathrm{~ms}^{-1}\end{array}$ & $\begin{array}{c}10 \mathrm{~h} \\
9.2 \mathrm{~ms}^{-1}\end{array}$ & $\begin{array}{c}09 \mathrm{~h} \\
10.2 \mathrm{~ms}^{-1}\end{array}$ & $\begin{array}{c}09 \mathrm{~h} \\
10.2 \mathrm{~ms}^{-1}\end{array}$ \\
\hline $\begin{array}{l}\text { PCSE-norte até Cabo Frio } \\
\text { (362.8 km de São Sebastião ) }\end{array}$ & $\begin{array}{l}\text { Atraso (lag) } \\
\text { Vel.OPC }\end{array}$ & $\begin{array}{c}20 \mathrm{~h} \\
5.0 \mathrm{~ms}^{-1}\end{array}$ & $\begin{array}{c}23 \mathrm{~h} \\
4.4 \mathrm{~ms}^{-1}\end{array}$ & $\begin{array}{c}42 \mathrm{~h} \\
2.4 \mathrm{~ms}^{-1}\end{array}$ & $\begin{array}{c}31 \mathrm{~h} \\
3.2 \mathrm{~ms}^{-1}\end{array}$ \\
\hline
\end{tabular}

a 50 horas em Cabo Frio, fazendo esta a única radial que apresentou redução para $3.8 \mathrm{~ms}^{-1}$ na velocidade de propagação da onda. No experimento RS4, o atraso em Cabo Frio retornou a faixa das 40 horas, promovendo um aumento para $4.8 \mathrm{~ms}^{-1}$ na velocidade da OPC. Analisando localmente, as radiais Cananéia, Santos e Ubatuba apresentaram maiores velocidades de propagação de onda durante o experimento RS3, e a radial Cabo Frio no experimento RS2, mas de modo geral, a região sul da PCSE até a Ilha de São Sebastião apresentou maior velocidade no experimento RS3, e a região norte da PCSE no experimento RS1, onde o atraso entre São Sebastião e Cabo Frio foi menor, com 20 horas.

As velocidades de propagação da onda nos experimentos remotos estão abaixo dos estimados para o sul da PCSE por França (2013), de cerca de $12 \mathrm{~ms}^{-1}$, mas estão próximos aos encontrados por Castro e Lee (1995), entre 9 e $10 \mathrm{~ms}^{-1}$. Contudo, deve-se considerar que essas OPC $\$$ foram geradas apenas pela ação do vento remoto e, provavelmente a ação de uma frente fria que percorra toda a extensão da PCSE promova ondas mais rápidas, ou a ação dos ventos de nordeste atenuem as velocidades de propagação.

A Figura 3.13 mostra que, em todos os experimentos os maiores valores de velocidade máxima na superfície ocorreram na porção sul do domínio, na área sob influência direta da ação do vento. Considerando o efeito remoto do vento, velocidades de $1.0 \mathrm{~ms}^{-1}$ foram encontradas na face externa da Ilha de São Sebastião $\left(24^{\circ} \mathrm{S}\right)$, e na $\mathrm{PCE}$ ao norte de Cabo Frio $\left(22.5^{\circ} \mathrm{S}-\right.$ $41^{\circ} \mathrm{W}$ ) nos experimentos RS2 (Figura 3.13b), RS3 (Figura 3.13 c) e RS4 (Figura 3.13d).

Comparando os quatro experimentos, a região sul do domínio até a Ilha de São Sebastião 


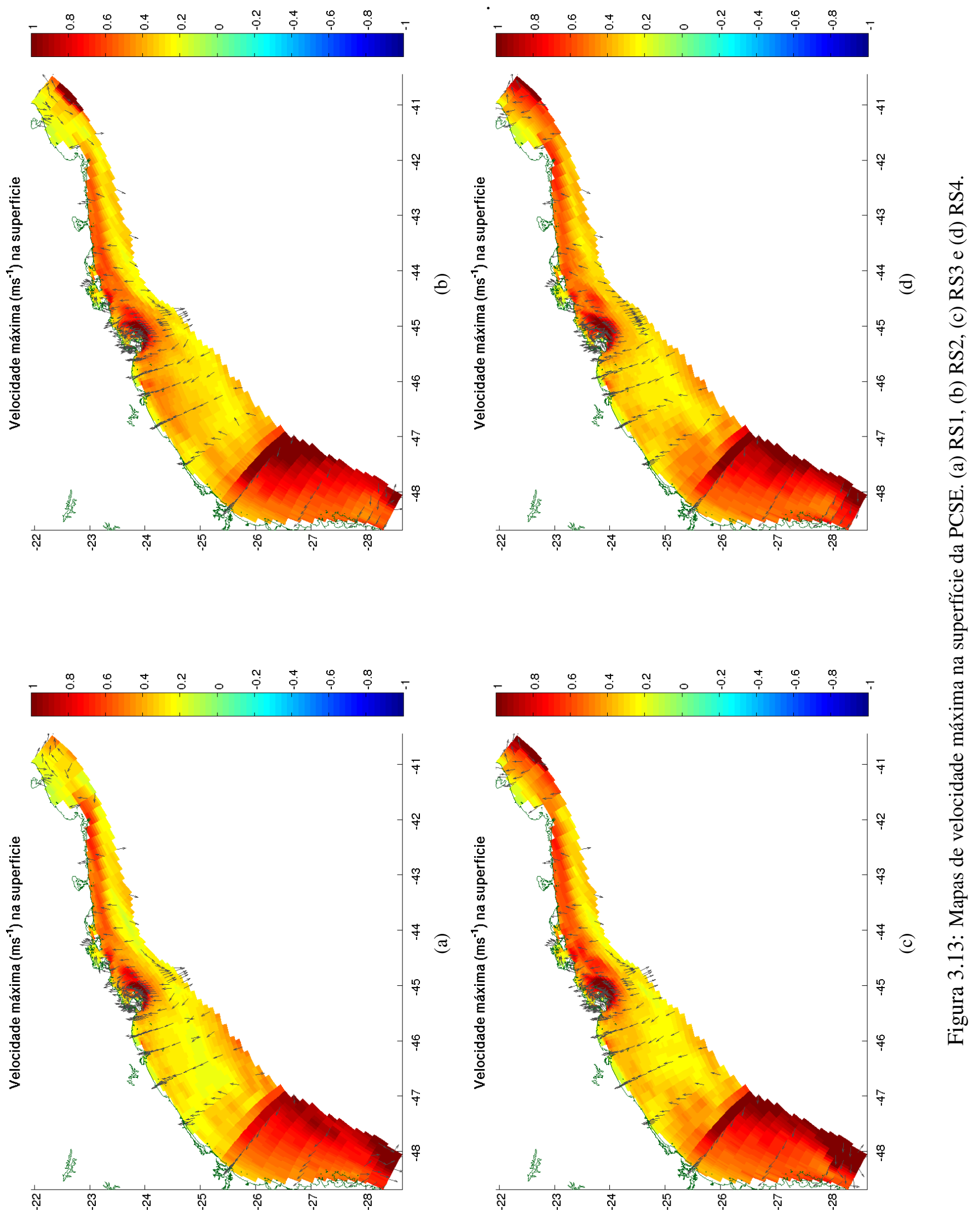


$\left(24^{\circ} \mathrm{S}\right)$ atingiu maiores velocidades na simulação com as frentes frias com ação de 36 horas (experimento RS2), onde a $\mathrm{PCI}-\mathrm{PCM}$ apresentou valores de $0.4 \mathrm{a} 0.5 \mathrm{~ms}^{-1}$. Na parte norte do domínio as maiores velocidades ocorreram na simulação com frentes com ação de 54 horas (experimento RS3), com corrente superficial variando entre 0.6 e $0.7 \mathrm{~ms}^{-1}$ na PCI.

Em relação a direção da corrente, em todos os experimentos as velocidades máximas superficiais apresentaram direção nordeste, indicando que as maiores velocidades foram alcançadas durante a permanência da frente fria no sul do domínio, exceto ao largo da Ilha de São Sebastião, onde a corrente apresentou direção sudoeste, que pode estar relacionada tanto com a proximidade da região com a Corrente do Brasil (incluida na simulação através dos campos de densidade) quanto a ação de ventos mais intensos de nordeste, associdada ao sistema de alta pressão atmosférica.

Na Figura 3.14, assim como observado nos mapas de velocidade superficial, o sul do domínio apresentou velocidade média máxima entre 0.25 e $0.35 \mathrm{~ms}^{-1}$ na PCI-PCM na simulação RS2 (Figura 3.14b) e o norte do domínio alcançou valores máximos de cerca de $0.45 \mathrm{~ms}^{-1}$ na PCI de Ubatuba até Cabo Frio na simulação RS3 (Figura 3.14p). Diferente dos mapas de velocidades superficiais, na porção sul do domínio as velocidades médias não foram altas, demostrando que a ação remota dos ventos é limitada as camadas mais superficiais da plataforma. Nos quatro experimentos a direção da corrente média foi preferencialmente para nordeste em todo o domínio.

Em relação as séries temporais das velocidades superficiais, no experimento RS1 em Cananéia as velocidades na PCI apresentaram picos positivos de cerca de $0.15 \mathrm{~ms}^{-1}$, relacionadas com o sinal remoto das frentes frias. Na PCM e na PCE esses picos não foram proeminentes, mascarados por oscilações de cerca de 24 horas, como mostra a Figura 3.15. Em Santos as oscilações não foram aparentes. $\mathrm{Na} / \mathrm{PCI} / \mathrm{PCM}$ a corrente superficial para nordeste foi intensificada pelo sinal remoto da frente fria e, na PCE, a corrente teve inicialmente direção para sudoeste, apresentou inversões de corrente durante a passagem dos mesmos. Em Ubatuba e Cabo Frio o efeito das frentes frias foi tênue do que nas radiais anteriores, e logo não foram perceptíveis inversões relacionadas a elas. A PCM da região de Ubatuba apresentou as maiores velocidades, chegando a $1.0 \mathrm{~ms}^{-1}$, podendo estar relacionadas com a forçante baroclínica que, sem a ação dos ventos locais, foi provavelmente intensificada pelo sinal da corrente gerada na face externa da Ilha de São Sebastião. Em Cabo Frio as velocidades são mais baixas do que em Ubatuba, alcançando valor máximo de $0.2 \mathrm{~ms}^{-1}$ na PCI ao fim da simulação.

No experimento RS2, as maiores velocidades na radial Cananéia ocorreram na $\mathrm{PCI}$, com $0.25 \mathrm{~ms}^{-1}$ durante a ação das frentes frias(Figura 3.16). A PCE de Cananéia apresentou menores inversões de corrente comparada a PCI e PCM, sendo que após ação da frente fria a corrente retornou para a direção sudoeste com cerca de $0.25 \mathrm{~ms}^{-1}$ entre os dias 10 e 13 . Em Santos, tanto na PCI quanto na PCM, as correntes mantiveram direção para nordeste, apresentando velocidade máxima de $0.3 \mathrm{~ms}^{-1}$ na PCI, e $0.25 \mathrm{~ms}^{-1}$ na PCM. Na radial Ubatuba foram observados os maiores valores de corrente superficial, acima de $1.0 \mathrm{~ms}^{-1}$ para nordeste na PCI, e em Cabo 


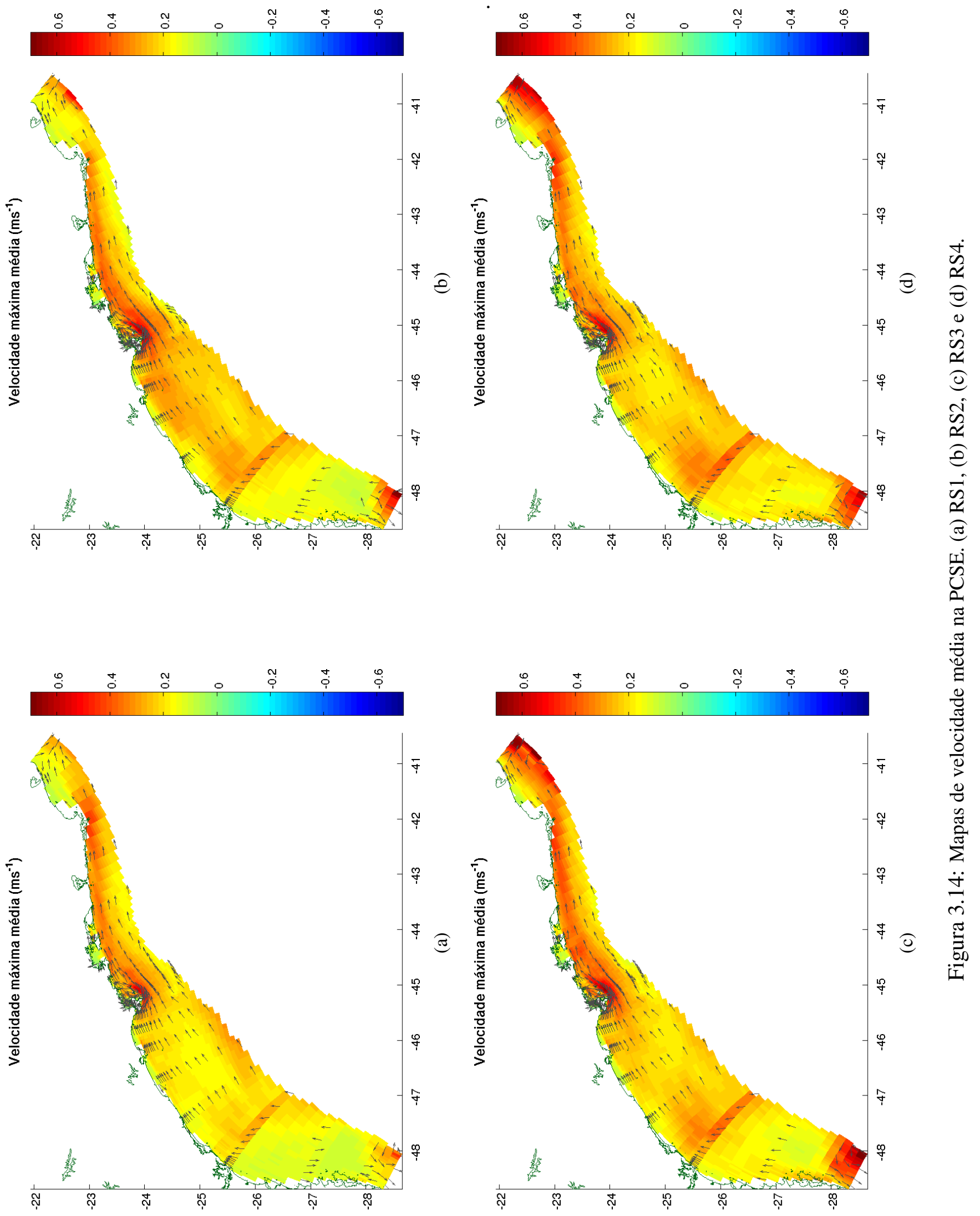



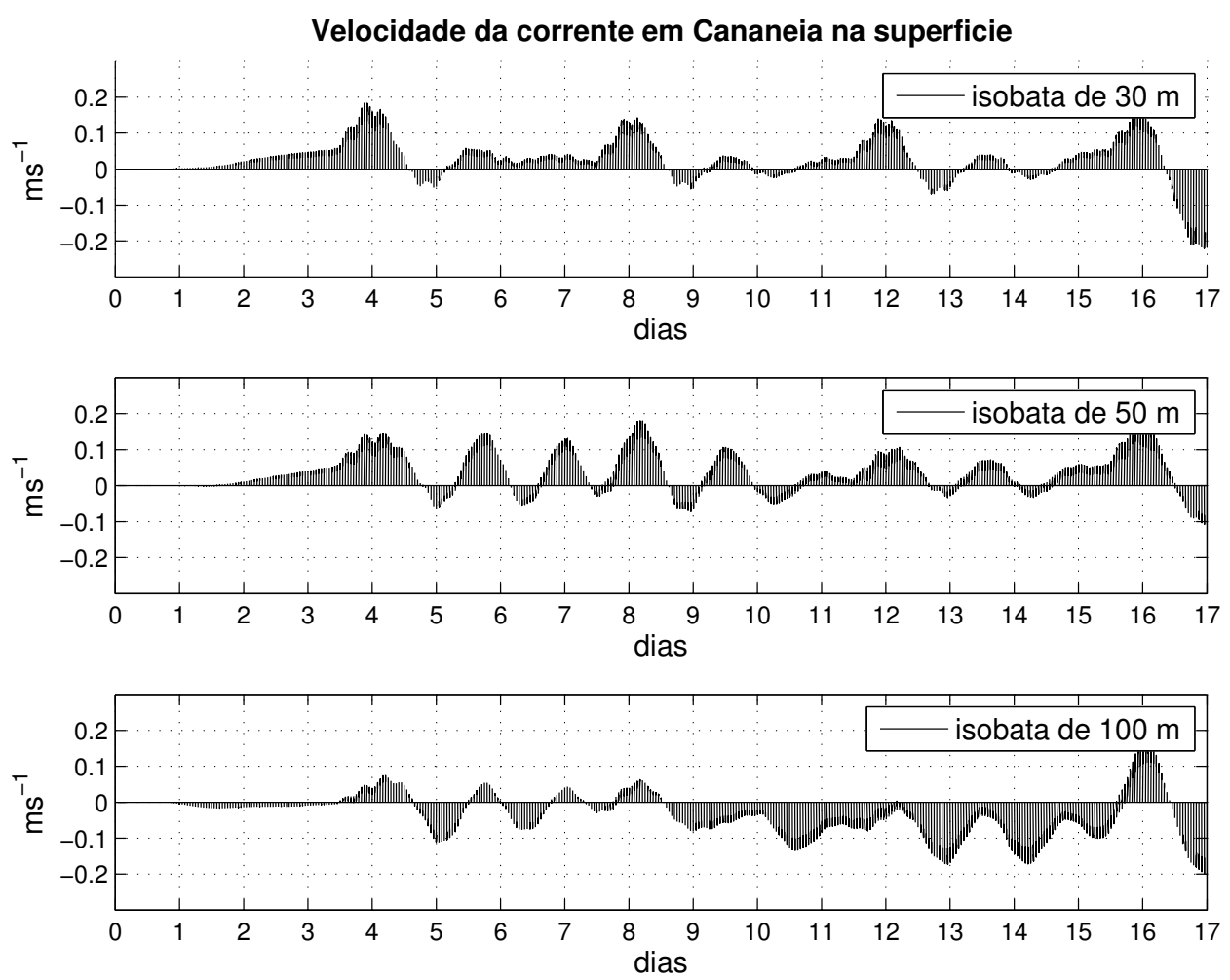

Figura 3.15: Séries temporais de velocidade na superfície na radial Cananéia, simulação RS1.
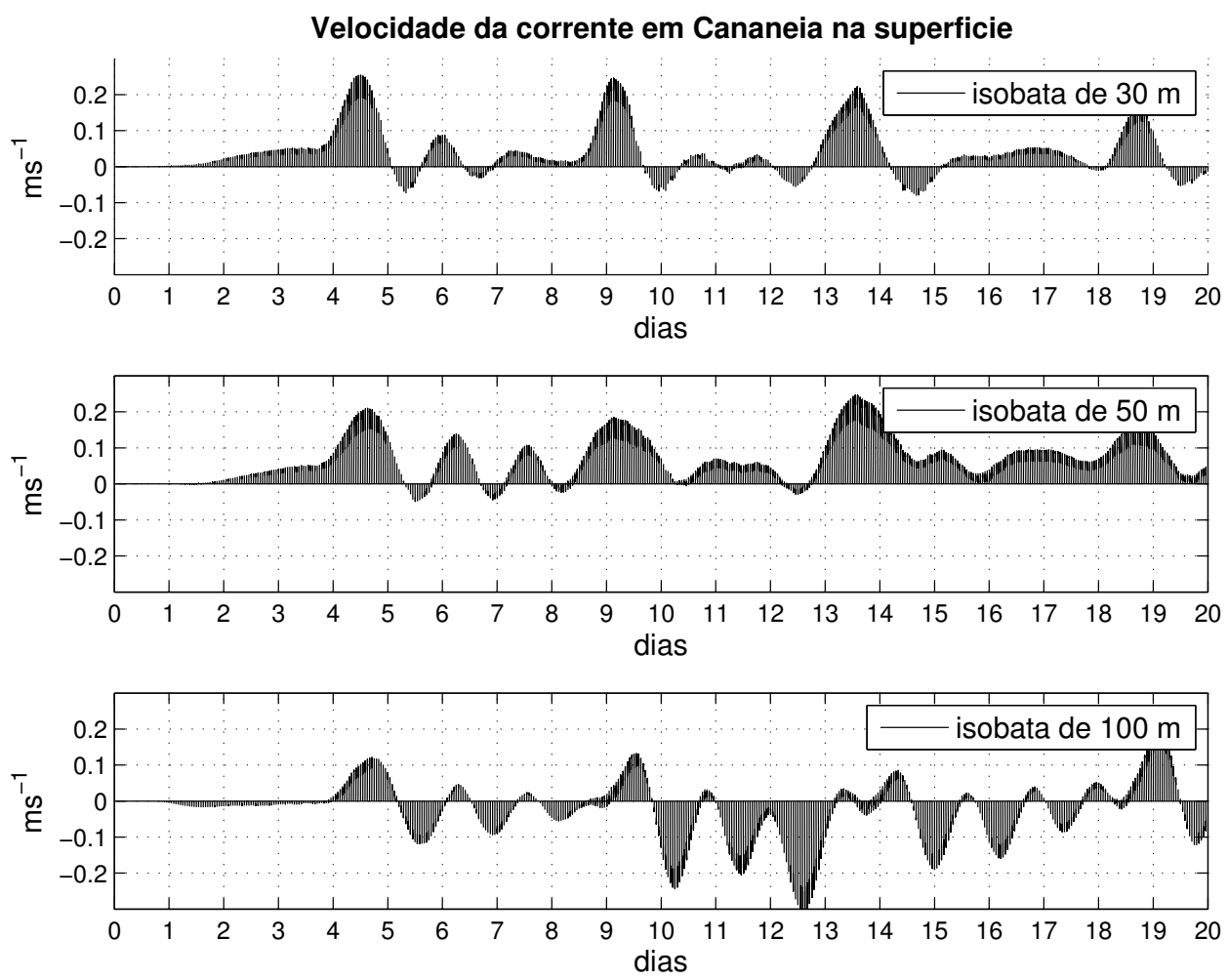

Figura 3.16: Séries temporais de velocidade na superfície na radial Cananéia, simulação RS2. 
Frio não houve inversões aparentes que possam ser diretamente associados o sinal remoto das frentes frias, onde na PCI e na PCM as velocidades se mantiveram praticamente constantes em $0.2 \mathrm{~ms}^{-1}$.

As séries de velocidade no experimento RS3 de Cananéia, devido a sua proximidade com a área de ação dos ventos, apresentaram velocidade de $0.35 \mathrm{~ms}^{-1}$ na PCI, gradualmente perdendo intensidade a medida que aumentou a profundidade, com 0.25 e $0.2 \mathrm{~ms}^{-1}$ na PCM e PCE, respectivamente. Em Santos, as correntes para nordeste na PCI foram intensificadas pelo sinal do vento remoto de frente fria, atingindo $0.25 \mathrm{~ms}^{-1}$ e $0.2 \mathrm{~ms}^{-1}$ na PCM. Na PCE, onde as correntes exibiram velocidade de $0.05 \mathrm{~ms}^{-1}$ e direção sudoeste, atingiram $0.2 \mathrm{~ms}^{-1}$ e direção nordeste durante a passagem das frentes. Em Ubatuba a PCM alcançou maior valor da corrente, com $1.0 \mathrm{~ms}^{-1}$, associado ao sinal remoto do vento de sudoeste. Em Cabo Frio, a PCE exibiu os menores valores de velocidade da corrente superficial para nordeste do experimento, com 0.2 $\mathrm{ms}^{-1}$.

Analisando os resultados de velocidade superficial do experimento RS4 percebeu-se que em Cananéia o sinal remoto da primeira frente foi responsável por uma corrente de acima de 0.3 $\mathrm{ms}^{-1}$ na $\mathrm{PCI}, 0.25 \mathrm{~ms}^{-1}$ na $\mathrm{PCM}$ e na PCE. Além disso, a região da PCE de Cananéia exibiu oscilações de alta frequência, com período de 30 horas entre os dias 19 e 24 (Figura 3.17). Em Santos essa oscilação também foi observada na PCE no mesmo intervalo de tempo, contudo as correntes possuíram velocidades mais baixas do que as observadas em Cananéia, com máxima de $0.23 \mathrm{~ms}^{-1}$ na PCI, $0.2 \mathrm{~ms}^{-1}$ na PCM e $0.1 \mathrm{~ms}^{-1}$ na PCE. Em Ubatuba as velocidades de corrente superficial foram menores do que no experimento RS3, com valor máximo de $0.9 \mathrm{~ms}^{-1}$ na PCM. Na PCE a corrente máxima observada foi de $0.25 \mathrm{~ms}^{-1}$. Na radial Cabo Frio a PCI apresentou correntes de $0.22 \mathrm{~ms}^{-1}$ e $0.15 \mathrm{~ms}^{-1}$ na PCM.

Analisando a estrutura vertical das componentes perpendicular (U) e paralela (V) nas radiais, onde os valores positivos e negativos indicam a direção da corrente de acordo com a convenção adotada ${ }^{3}$ foi possível constatar que, a radial Cananéia, quando sob influência da frente remota, apresentou valores da componente paralela (componente V) na PCI mais intensa que a perpendicular, de $0.2 \mathrm{~ms}^{-1}$ em superfície para nordeste durante a passagem da frente. Por exemplo, a Figura 3.18 apresenta as componentes paralelas e perpendiculares associados a passagem da primeira frente fria no experimento RS2. A resposta ao vento remoto na radial Cananéia se manteve a mesma em todos os experimentos, mostrando que tanto a componente paralela quanto a perpendicular à costa atingem um valor máximo independente do tempo de ação dos ventos remotos.

$\mathrm{Na}$ radial Santos as magnitudes das componentes paralela foram superiores a perpendicular em todos os experimentos, com o valor acima de $0.2 \mathrm{~ms}^{-1}$ entre a $\mathrm{PCI}$ e a $\mathrm{PCM}$ durante a ação da frente remota em toda a coluna d'água, fluindo para nordeste (Figura 3.19a). Após a influência do sinal remoto dos sistemas frontais, mesmo sob ação remota de ventos de nordeste,

\footnotetext{
${ }^{3}$ corrente paralela-v [-]: para sul; corrente paralela-v [+]: para norte; corrente perpendicular-u [-]: para a costa; e corrente perpendicular-u[+]: para a quebra da plataforma.
} 

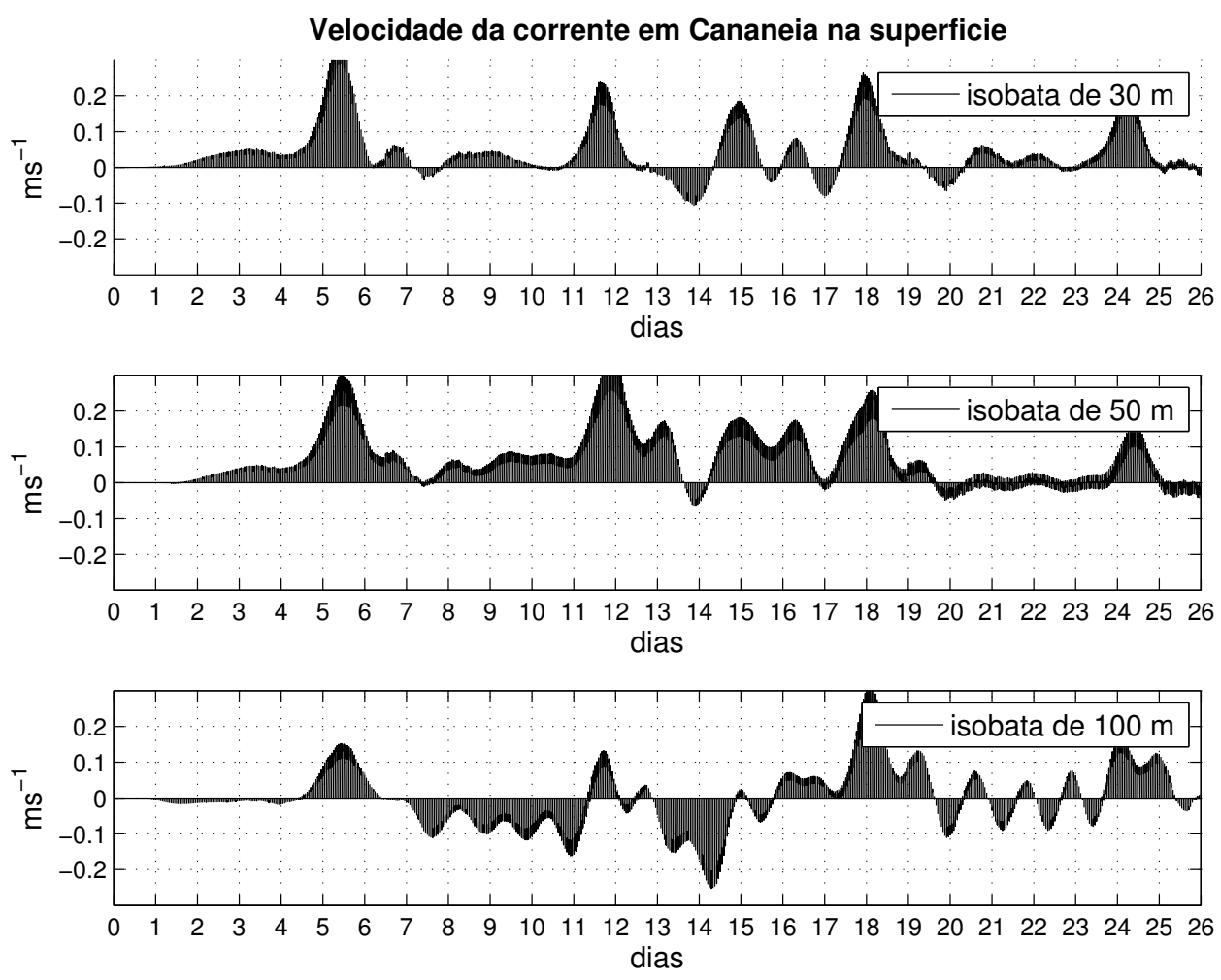

Figura 3.17: Séries temporais de velocidade na superfície na radial Cananéia, simulação RS4.

a corrente paralela na PCI preservou sentido para nordeste, com intensidade média de $0.1 \mathrm{~ms}^{-1}$, como mostra a Figura $3.19 \mathrm{~b}$.

A estrutura vertical da corrente na radial Ubatuba apresentou dois núcleos estruturados da componente paralela: um que desce a costa na $\overline{\mathrm{PCI}}$, próximo à isóbata de 40 metros, e um que sobe a costa na PCM entre as isóbatas de 40 e de 60 metros. Um escoamento barotrópico a 60 km de distância da costa de Ubatuba também foi observado nos estudos numéricos de Ruffato (2011), com núcleo estruturado se estendendo até 25 metros de profundidade. Segundo o autor, esse fluxo para nordeste na PCM de Ubatuba pode ser fruto do escoamento induzido pelo fluxo de flutuabilidade observado na PCI ao sul da Ilha de São Sebastião. Em todos os experimentos, a componente paralela pra sudoeste exibiu magnitude entre 0.1 a $0.2 \mathrm{~ms}^{-1} \mathrm{e}$, a paralela para nordeste, de 0.4 a $0.5 \mathrm{~ms}^{-1}$, ambas durante a passagem da frente remota. No experimento RS3 a componente paralela nordeste exibiu velocidade acima de $0.8 \mathrm{~ms}^{-1}$ durante a ação da segunda frente fria remota, como mostra a Figura 3.20 a. De maneira geral, após a ação remota da frente, a corrente paralela nordeste foi atenuada, atingindo valor de até $0.4 \mathrm{~ms}^{-1}$ (Figura $3.20 \mathrm{p}$ ).

A radial Cabo Frio, mais afastada da região de ação dos ventos, não exibiu alteração visível do nível do mar pela passagem da OPC, contudo, o sinal remoto das correntes geradas em regiões mais ao sul alteram de forma significante a estrutura vertical das componentes da velocidade. Como exemplo, temos a Figura 3.21 a, que apresenta a radial Cabo Frio sem a influência do sinal remoto da corrente, mas em Figura $3.21 \mathrm{~b}$ exibe a mudança da estrutura vertical com a passagem do sinal remoto das correntes vindas das radiais mais ao sul, exibindo perfis de 

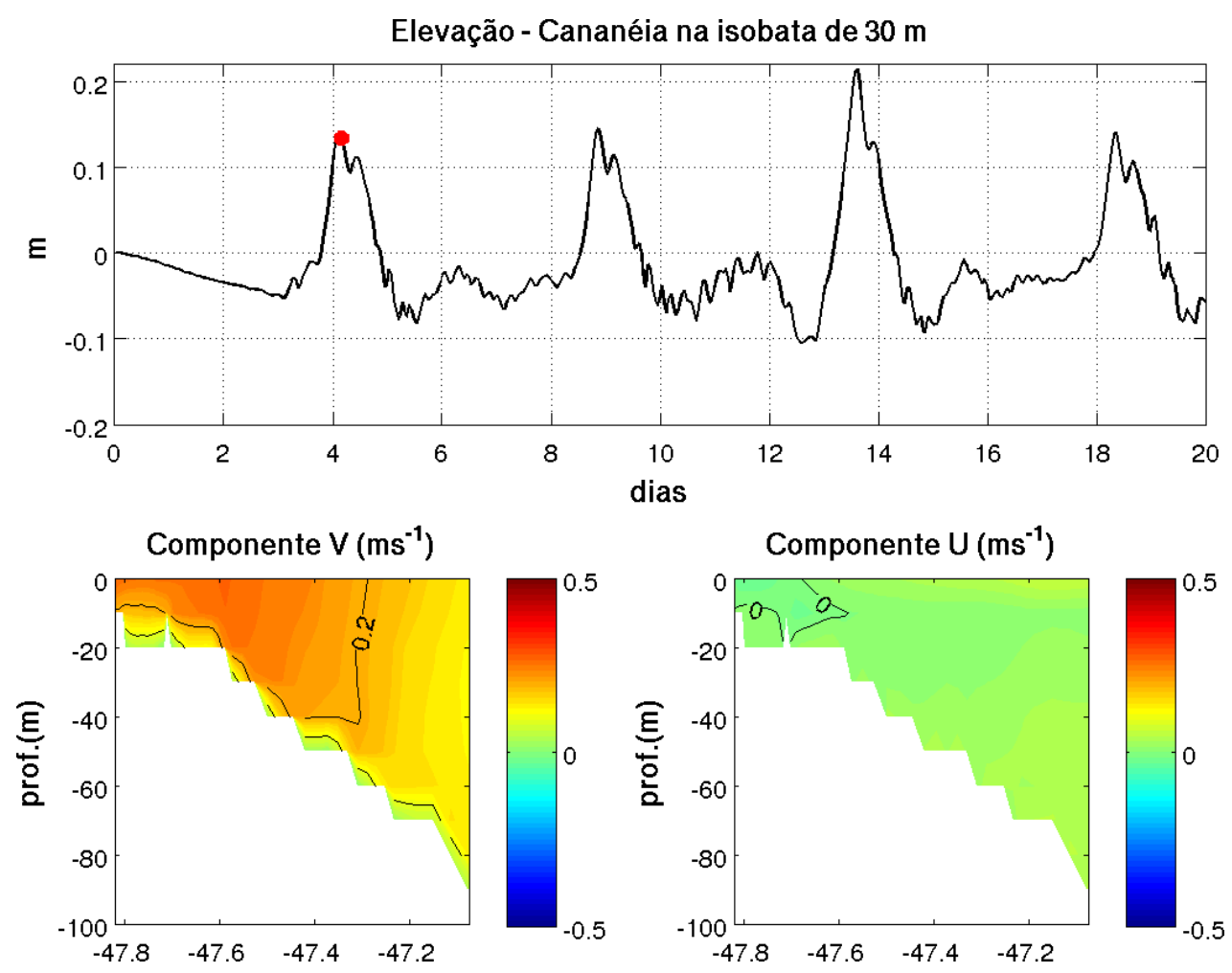

Figura 3.18: Série temporal de elevação e perfis verticais de velocidade perpendicular (U) e paralela (V) em Cananéia, simulação RS2.

correntes paralela com velocidade de $0.4 \mathrm{~ms}^{-1}$ na PCI durante o experimento RS3.

De modo geral, os quatro experimentos apontaram que as frentes frias com tempo de permanência menor que 40 horas (experimentos RS1 e RS2) geraram nas radiais mais ao sul, Cananéia e Santos, correntes para nordeste menos intensas, e o aumento do tempo de ação das frentes acima de 40 horas (experimentos RS3 e RS4) promoveu um aumento na magnitude da componente paralela em cerca de 0.1 a $0.2 \mathrm{~ms}^{-1}$ para nordeste. Nas radiais ao norte, Ubatuba e Cabo Frio, o incremento na velocidade da corrente paralela foi maior, de 0.2 a $0.4 \mathrm{~ms}^{-1}$ de aumento se comparado aos experimentos RS1 e RS2. Além disso, as radiais Santos, Ubatuba e Cabo Frio apresentaram correntes paralelas mais intensas para nordeste, associadas ao sinal remoto dos ventos de frente fria (e consequentemente com a passagem das ondas de plataforma) somado ao fluxo de flutuabilidade local, derivado dos campos climatológicos de densidade impostos nas simulações.

Se compararmos os resultados obtidos nos experimentos SC1 e SC2, descritos na Seção 3.1. pode-se sugerir que a ausência de cisalhamento do vento sobre o restante do domínio foi responsável pela baixa variabilidade da direção da corrente, sendo que o sinal remoto do vento de nordeste e da corrente gerada pelo mesmo não foi capaz de sobrepujar de forma efetiva as correntes geradas pelo vento remoto de sudoeste somados ao fluxo de flutuabilidade. 

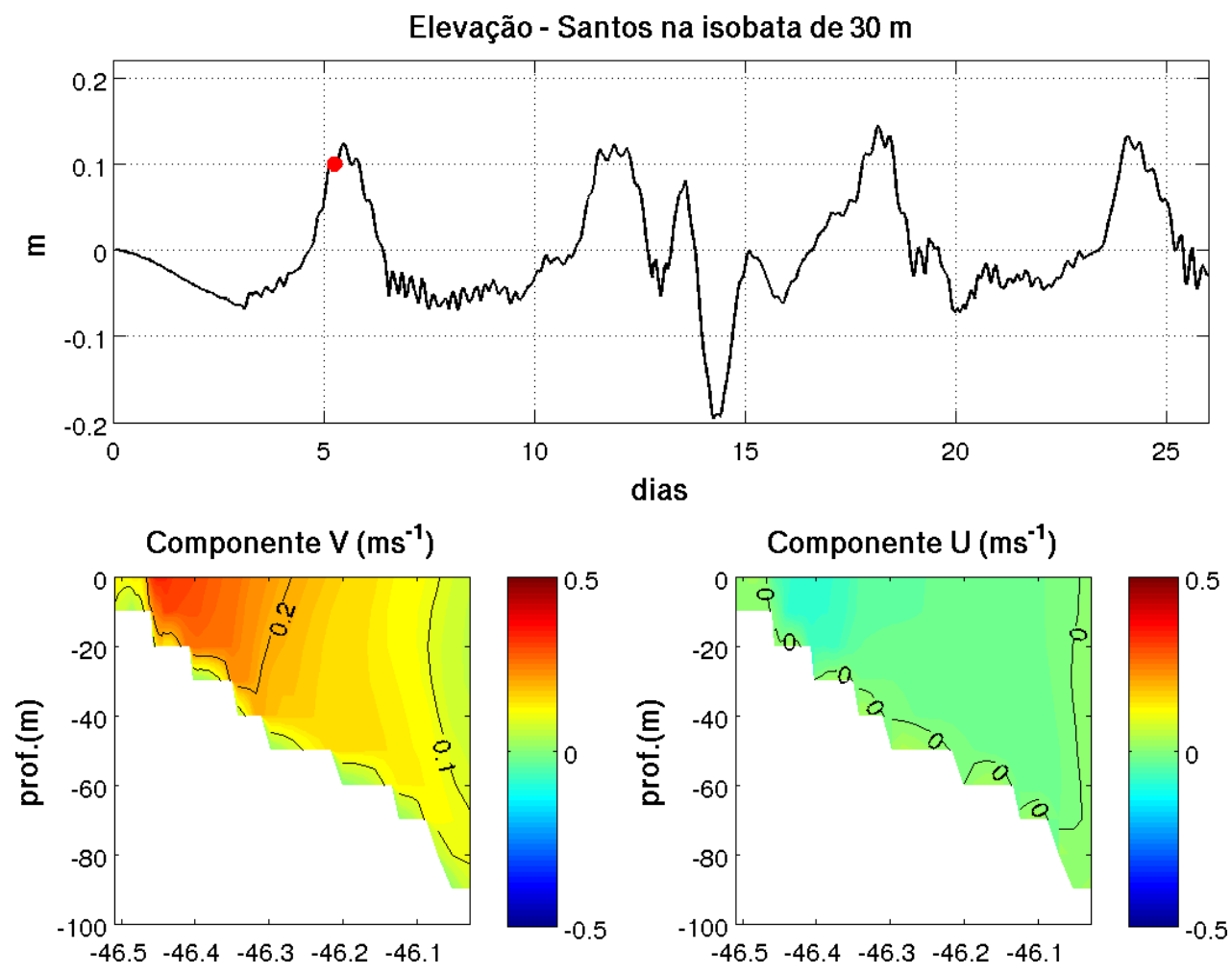

(a)
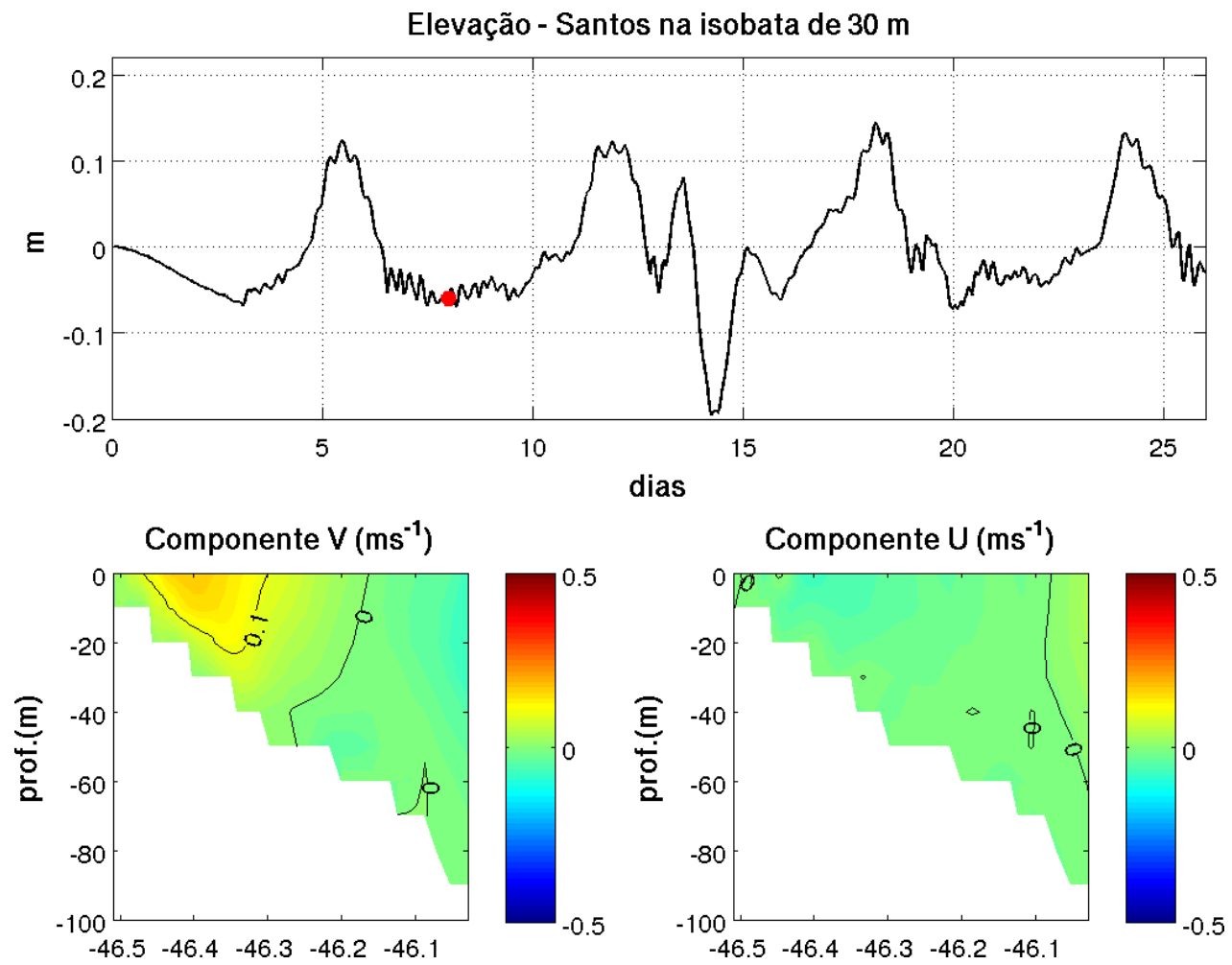

(b)

Figura 3.19: Série temporal de elevação e perfis verticais de velocidade perpendicular (U) e paralela (V) em Santos, simulação RS4. 

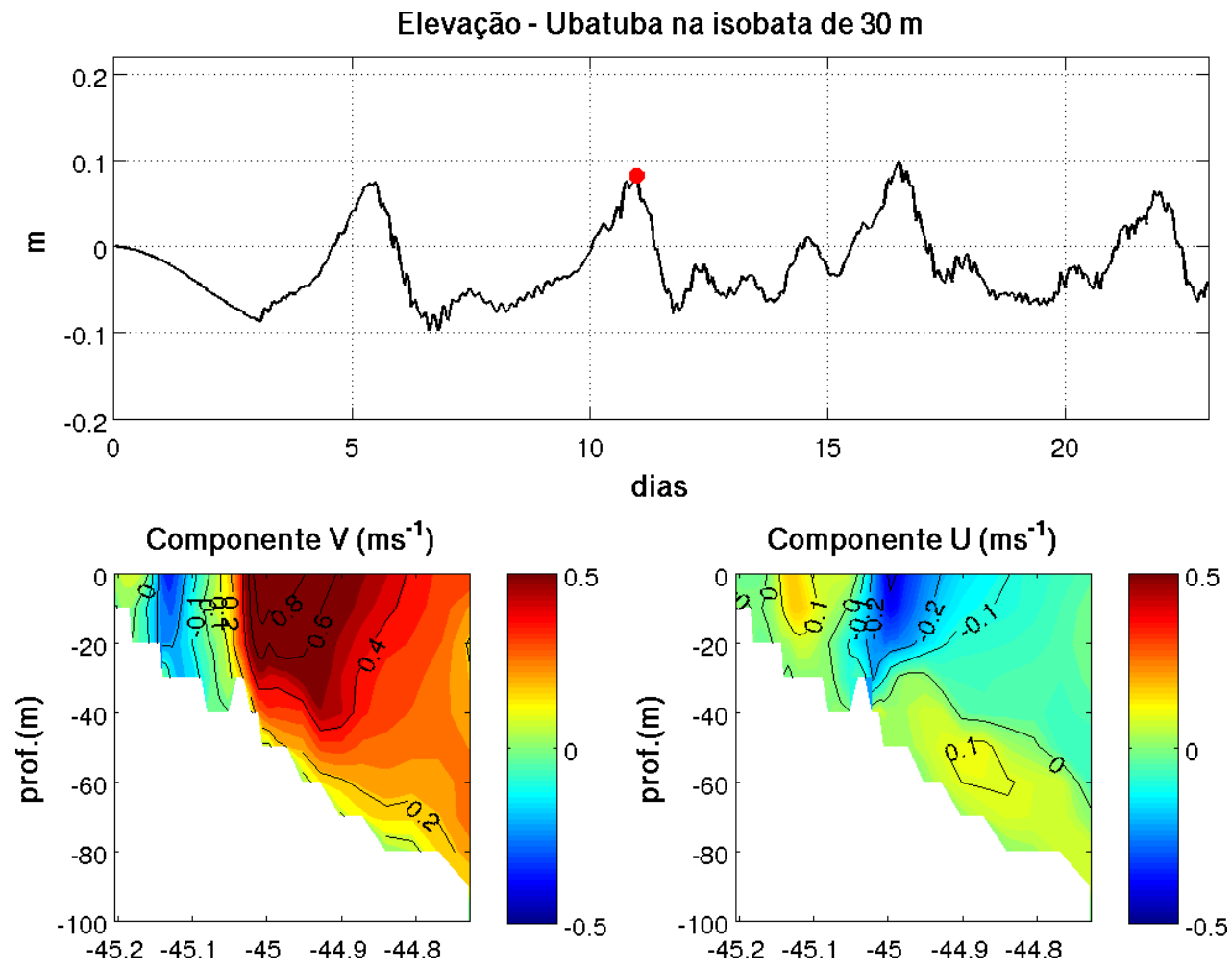

(a)
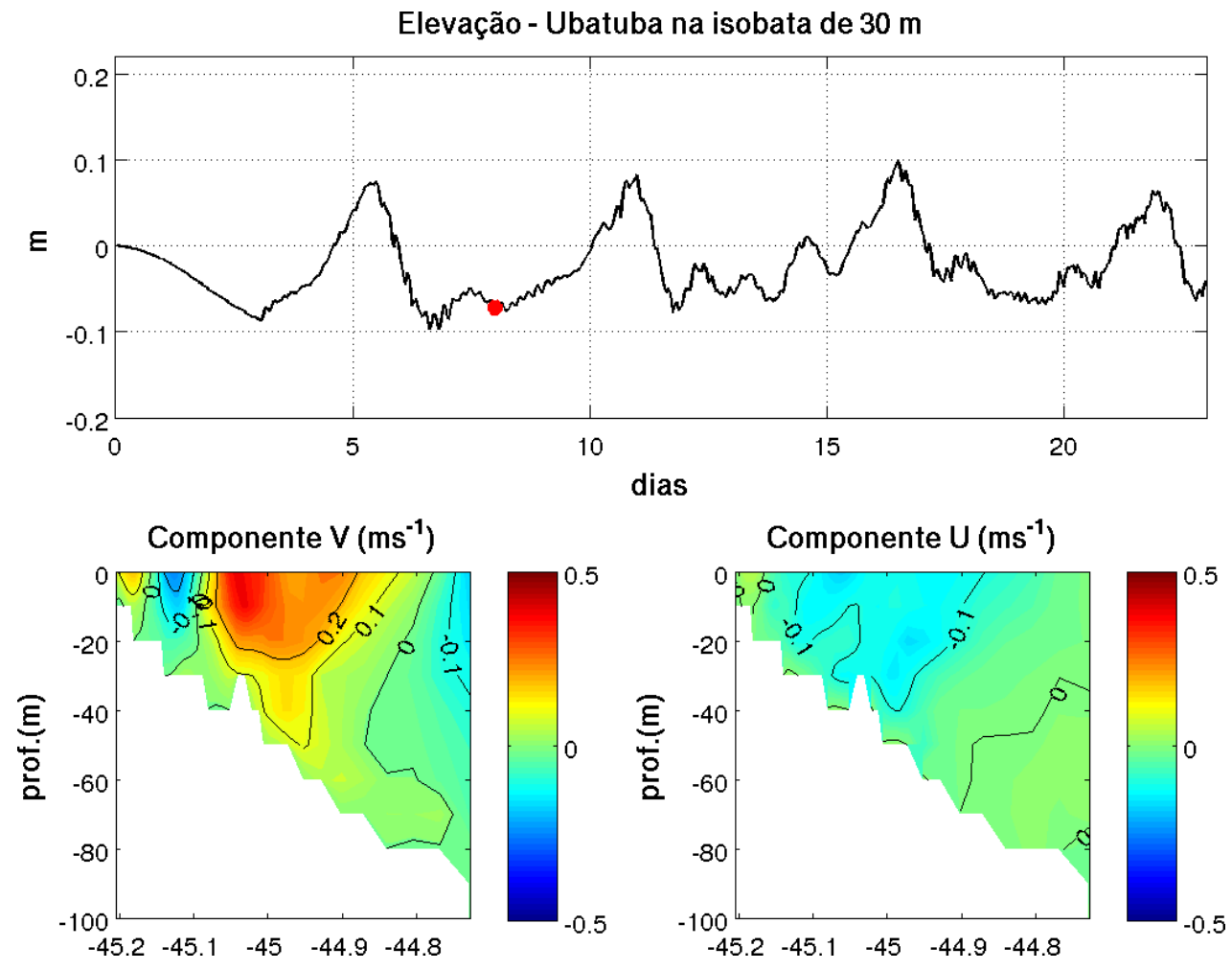

(b)

Figura 3.20: Série temporal de elevação e perfis verticais de velocidade perpendicular (U) e paralela (V) em Ubatuba, simulação RS3. 

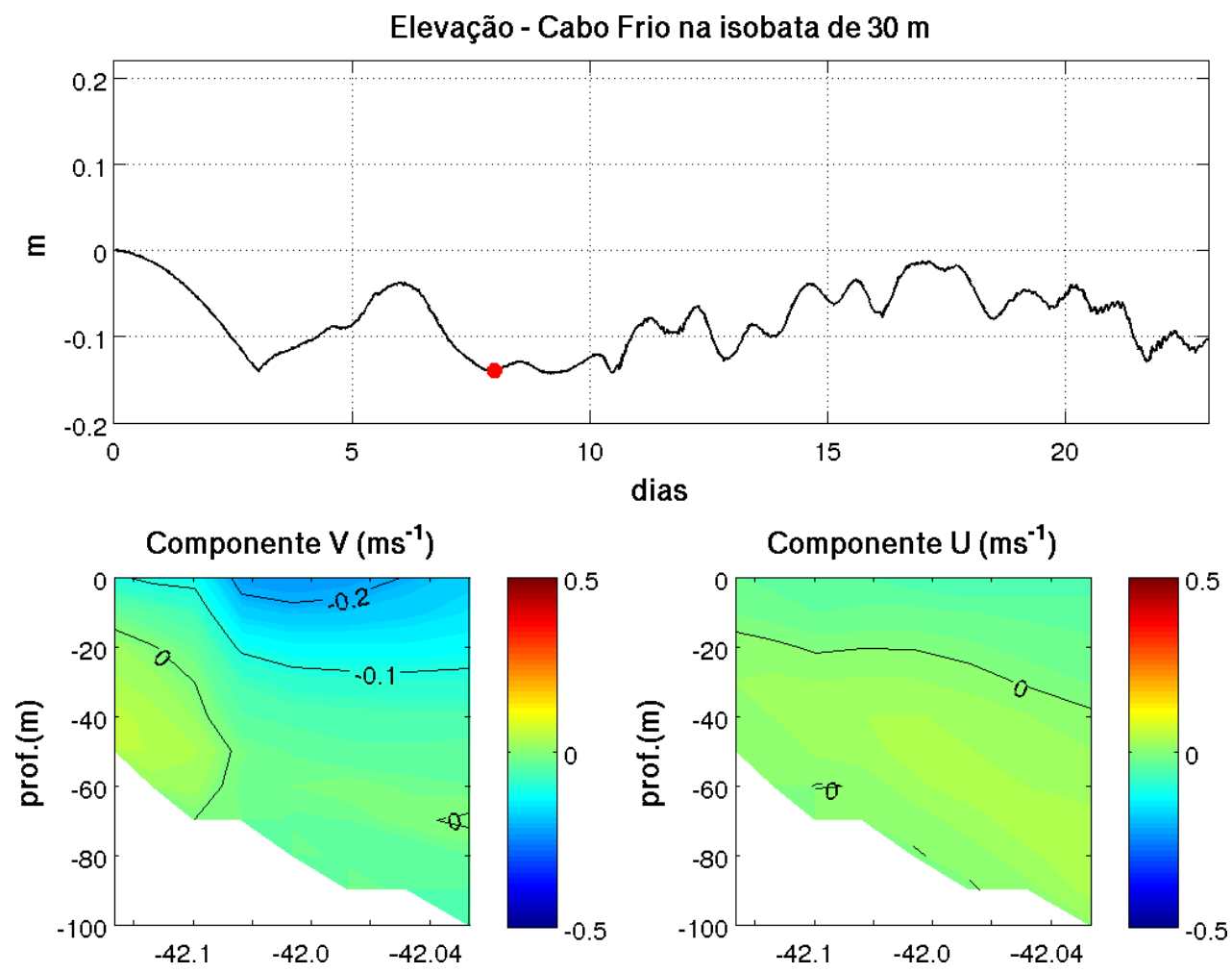

(a)
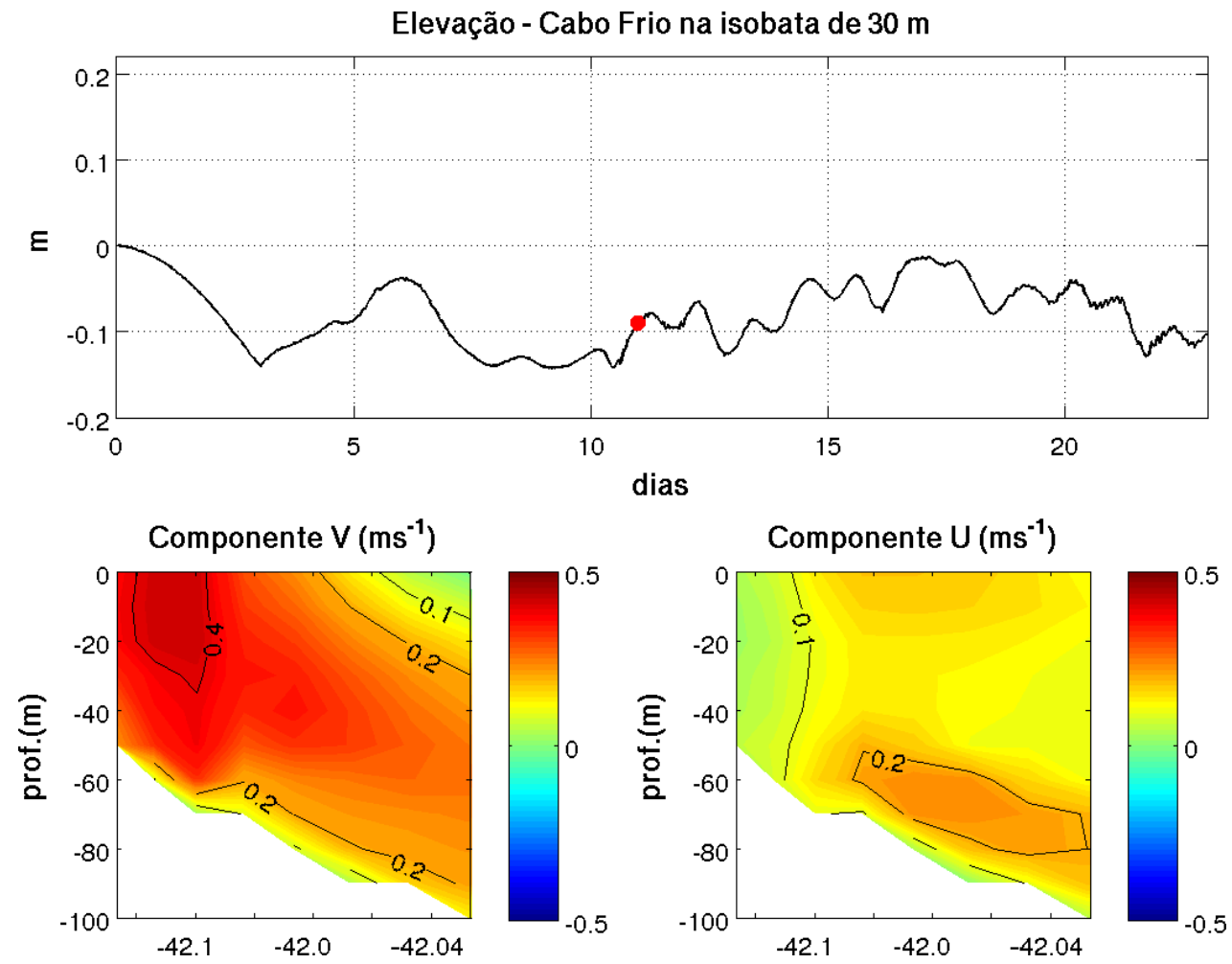

(b)

Figura 3.21: Série temporal de elevação e perfis verticais de velocidade perpendicular (U) e paralela (V) em Cabo Frio, simulação RS3. 


\subsection{Simulações de Vento em toda a grade}

A seguir são apresentados os resultados das simulações forçadas com vento em toda a PCSE, como previamente descritas na Seção 2.3.6 Na Seção 3.3.1 são apresentados e discutidos os resultados dos experimentos SVT1, SVT2, SVT3 e SVT4; na Seção 3.3.2 são abordados os resultados dos experimentos SVT5, SVT6, SVT7 e SVT8; e por fim na Seção 3.3 .3 são apresentados os resultados e a discussão dos experimentos SVT9 e SVT10.

\subsubsection{Frentes com tempo de permanência inferior a 40 horas na PCSE}

A Figura 3.22 mostra que o experimento SVT1, com frente fria de 18 horas e velocidade de propagação de $18.9 \mathrm{~ms}^{-1}$, apresentou elevação máxima acima de $0.4 \mathrm{~m}$ na $\mathrm{PCI}$ de Cananéia, $0.3 \mathrm{~m}$ na PCM de Cananéia e na região costeira de Ilha Comprida até Santos. Valores de $0.2 \mathrm{~m}$ foram observados até Ubatuba, e após a Baía de Guanabara as elevações ficaram abaixo de zero. Com a redução da velocidade de propagação da frente nos experimentos SVT2 para $14.2 \mathrm{~ms}^{-1}$ (frente de 24 horas), elevações de 0.4 m foram observadas da Baía de Paranaguá, no Paraná, até o sul de Santos. Na PCI de Santos até o norte da Ilha de São Sebastião a elevação máxima foi de $0.3 \mathrm{~m}$. Em SVT3, com frentes com $11.4 \mathrm{~ms}^{-1}$ de velocidade de propagação (frentes de 30 horas), pouca diferença foi percebida em relação ao experimento SVT2, com exceção a região da Baía de Guanabara, no Rio de Janeiro, que apresentou elevações acima de zero, assim como observado em SVT4, com velocidade de propagação das frentes de $9.5 \mathrm{~ms}^{-1}$ (frentes de 36 horas).

Ao comparar os resultados de elevações dos experimentos SVT1 e SVT4 com os obtidos nos experimentos RS1 e RS2, apresentados na seção anterior (Seção 3.2), e que correspondem apenas a ação de frentes remotas na plataforma, com 18 e 36 horas de ação, percebeu-se que parte das elevações observadas na PCSE durante as simulações de vento total podem ser associadas ao sinal remoto do vento. No experimento RS1 a PCI apresentou elevações de até $0.1 \mathrm{~m}$ e em RS2 de até $0.2 \mathrm{~m}$. Apesar dos resultados obtidos nos experimentos de vento remoto corresponderem menos da metade da elevação obtida com a ação de um vento sobre toda a área de estudo, essas elevações são superestimadas para um cenário mais realístico, pois são resultados de simulações que não foram consideradas perdas de energia pelo cisalhamento do vento oposto a propagação da OPC, sendo que apenas a região sul da PCSE esteve sob ação dos ventos.

As diferenças de elevações do nível do mar entre os experimentos podem ser melhor vizualidadas na Figura 3.23. No experimento SVT1 (Figura 3.23 a), as elevações da PCI em Cananéia foram de $0.33 \mathrm{~m}$ durante a passagem da primeira frente, na PCM, de $0.23 \mathrm{~m}$ e na PCE, de 0.1 m. Com o aumento do tempo de evolução da frente, no experimento SVT4 (Figura 3.23 c) as elevações foram as mesmas durante a primeira frente, mas com a passagem do terceiro sistema frontal, as elevações alcançaram $0.39 \mathrm{~m}$ na PCI, $0.29 \mathrm{~m}$ na PCM e $0.9 \mathrm{~m}$ na PCE. Na radial Ubatuba, durante o experimento SVT1 (Figura 3.23b), a PCI atingiu $0.2 \mathrm{~m}$ e a PCM $0.1 \mathrm{~m}$ durante a passagem da terceira frente fria. A PCE apresentou valores abaixo de zero durante 

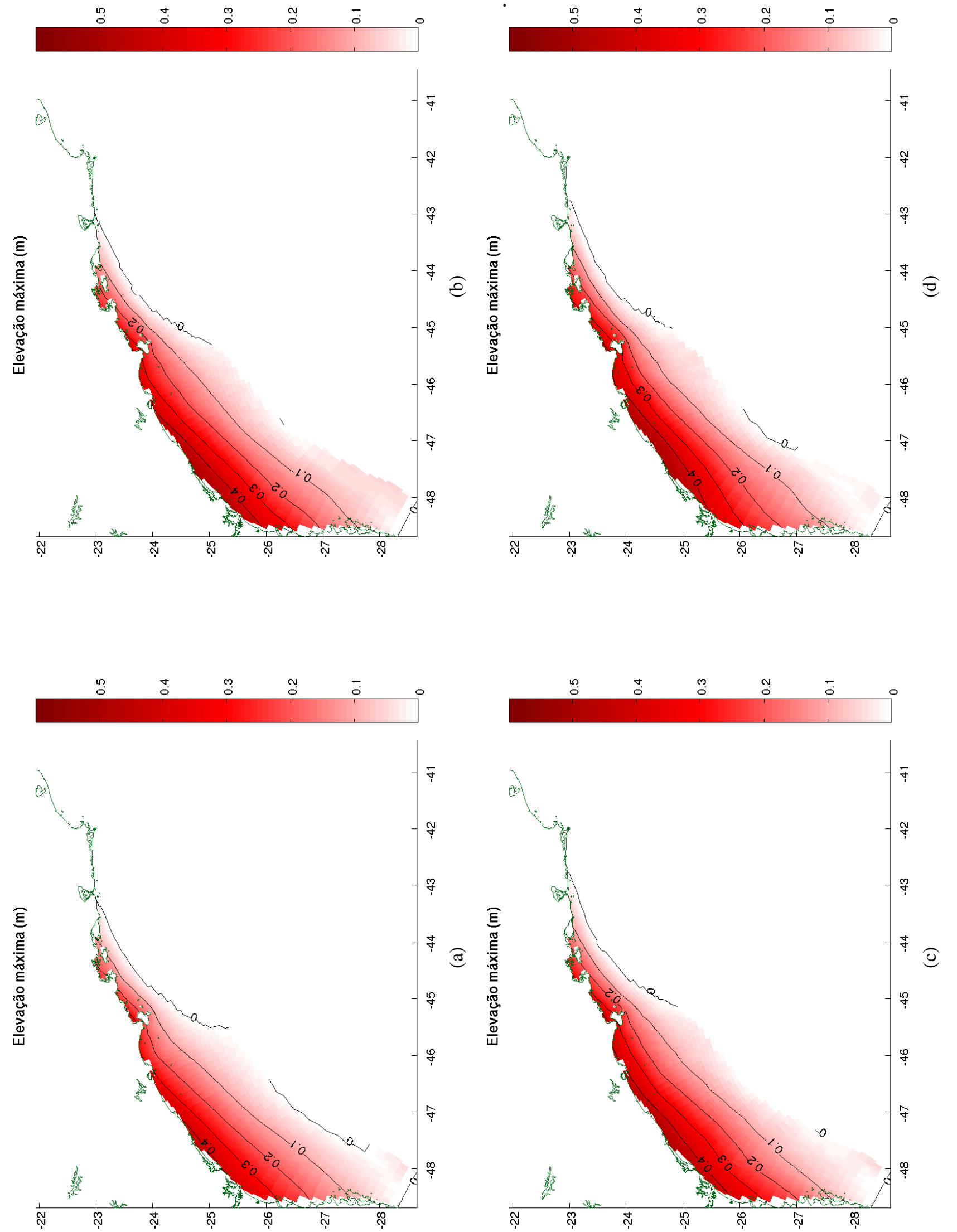

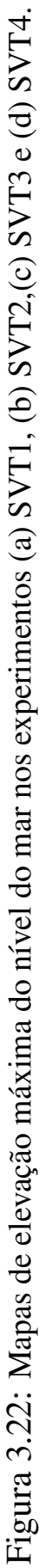



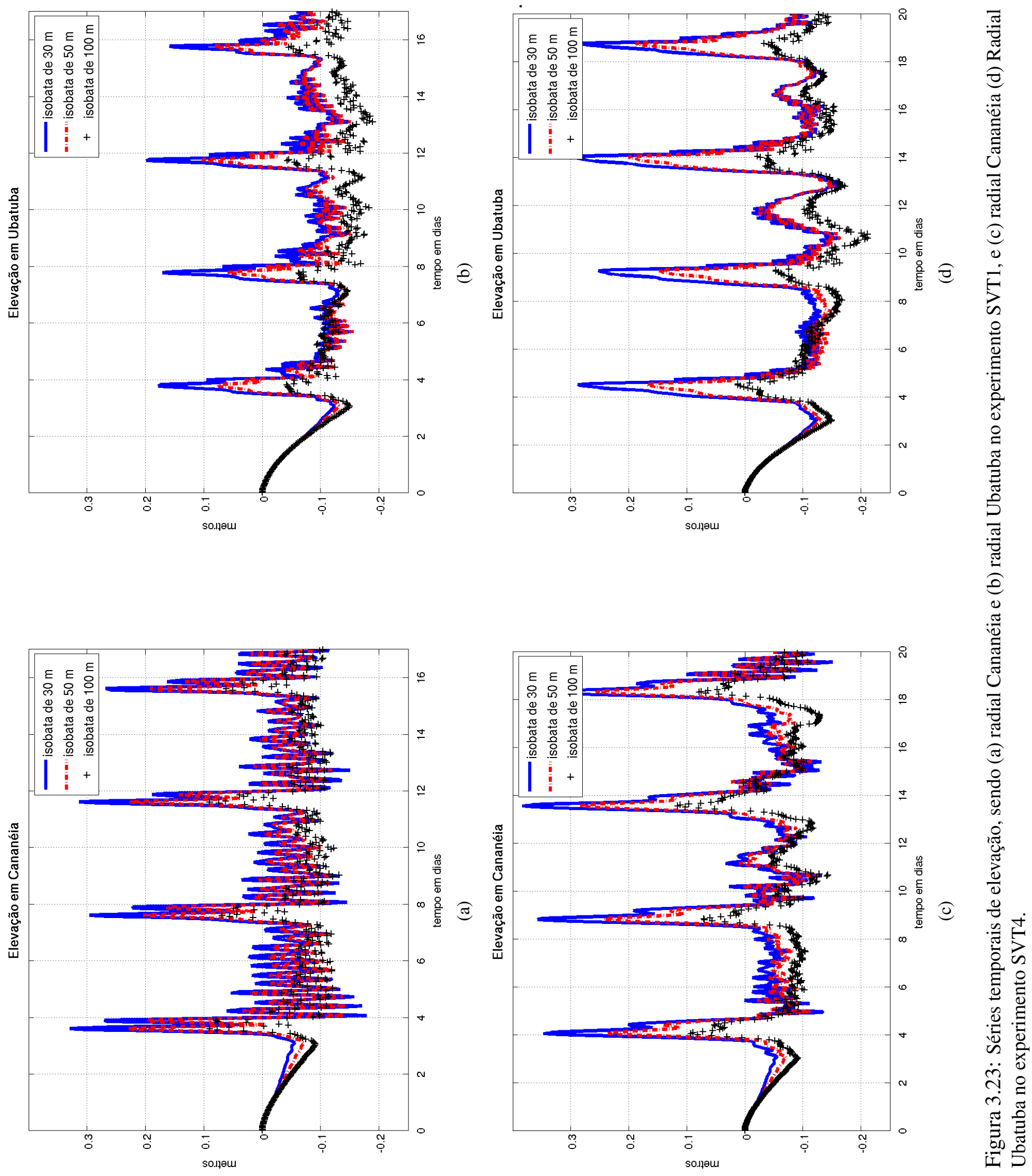

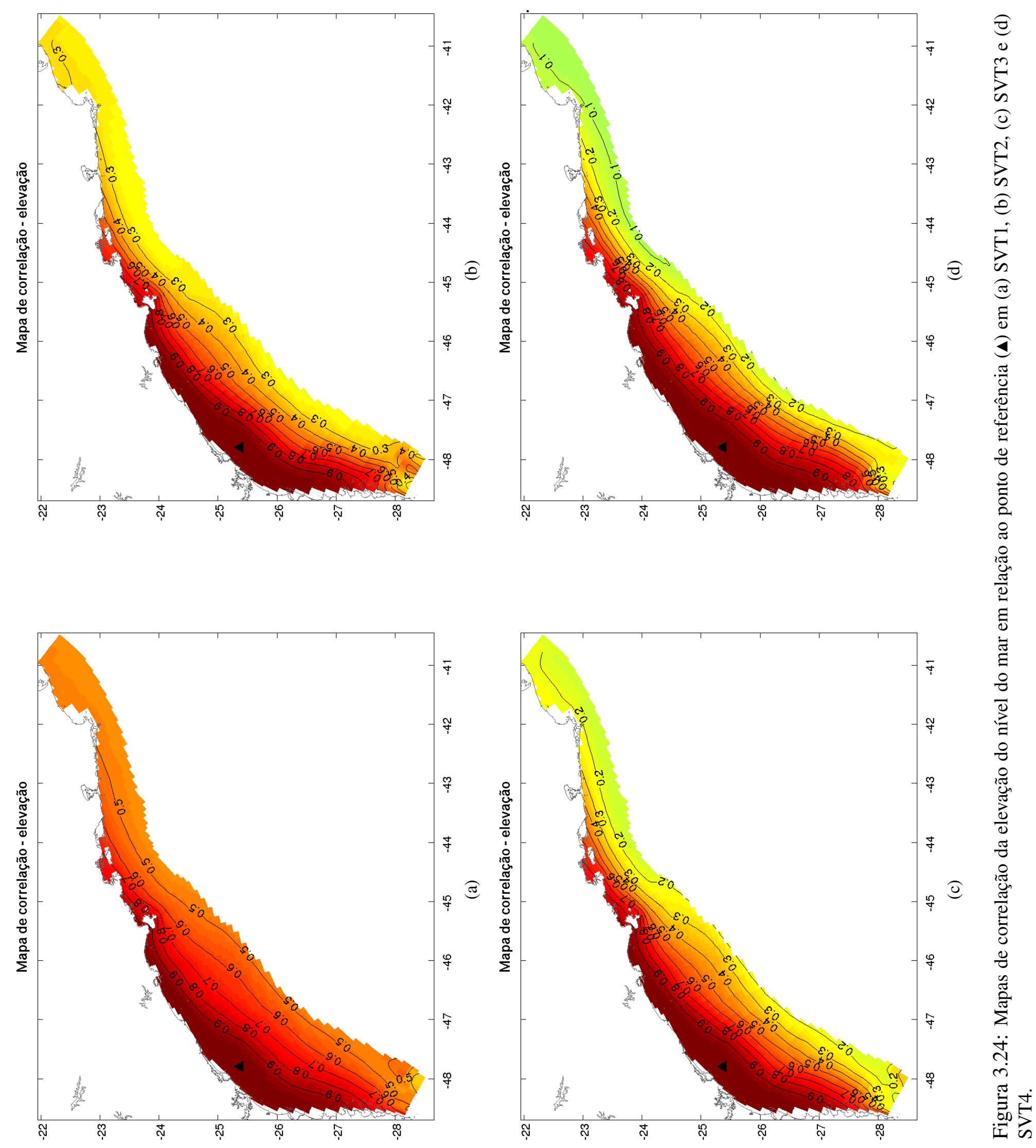
todo o período de simulação, com amplitude de $0.09 \mathrm{~m}$. No experimento SVT4 as elevações em Ubatuba alcançaram $0.3 \mathrm{~m}$ na PCI e $0.2 \mathrm{~m}$ na PCM (Figura $3.23 \mathrm{~d}$ ).

A Figura 3.24 apresenta os valores de correlação da elevação na PCSE, e indica que a elevação no ponto de referência (ム) tem correlação muito alta com as elevações observadas na PCI nas regiões ao sul da Ilha de São Sebastião, e a redução da velocidade de propagação da frente fria entre os experimentos pouco alterou os resultados na PCI e $\overline{\text { PCM }}$ no sul da PCSE. Contudo, a região ao norte da Ilha de São Sebastião gradativamente apresentou uma redução na correlação. Em em SVT1 (Figura 3.24a) a correlação na região norte da PCSE foi de 0.5 e, em SVT4 (Figura 3.24d), a correlação baixou para 0.1. Com base nestas informações de correlação há indícios que: a região sul, possuindo uma costa menos acidentada e plataforma continental com batimetria suave, é capaz de propagar ondas de plataforma continental com baixa perda de energia, preservando por mais tempo as características da onda gerada em regiões mais ao sul; a região ao norte de São Sebastião, com mais irregularidades na linha de costa, como ilhas e baías, além de exibir uma plataforma continental mais estreita e profunda, está sob intensa influência de ventos de nordeste oriundos da ASAS, o que promove maior dissipação da energia da onda. A correlação no norte da PCSE consequentemente tende a ser mais baixa se comparada com uma onda na região sul.

Além disso, o maior tempo de permanência de ventos de sudoeste sobre a região fez com que as elevações registradas no norte tenham mais relação com a ação do vento local do que com o sinal remoto das elevações geradas no sul, o que explicaria a diminuição da correlação no norte. Este fato fica mais claro ao se comparar os resultados de correlação dos experimentos SVT1 e SVT4 com os experimentos de vento remoto correspondentes, RS1 e RS2 (Figura 3.11a-b da Seção 3.2. No experimento RS1, a correlação da elevação, foi de 0.8 em Ubatuba e 0.7 ao norte de Cabo Frio. Com a inclusão do cisalhamento do vento em toda a região de estudo em SVT1 (Figura 3.24a), a correlação diminuiu para 0.7 e 0.5, respectivamente. Com aumento do tempo de ação da frente remota em RS2, a correlação baixou para 0.7 em Ubatuba e 0.3 no norte de Cabo Frio, e em SVT4, quando a PCSE submetida ao cisalhamento do vento em toda a sua extensão, Ubatuba manteve correlação de 0.7, mas Cabo Frio apresentou cerca de 0.1 (Figura $3.24 \mathrm{~d}$ ).

Considerando que o comprimento médio da PCSE é de cerca de $1020 \mathrm{~km}$, a Figura 3.25 apresenta os diagramas Hovmöller com os valores de altura da OPC na costa ao longo da PCSE, durante as simulações. Investigando o alcance das OPC na PCSE, a Figura 3.25 apresenta que durante o experimento SVT1 as cristas da onda atingiram uma distância de cerca de $750 \mathrm{~km}$ costa acima, cruzando a costa da cidade de Ubatuba, distante cerca de $636 \mathrm{~km}$ do limite sul da PCSE. A cava da onda foi visível horas depois, próxima da cidade de São Fransico do Sul-SC, distante cerca de $100 \mathrm{~km}$ do limite sul da PCSE. Os comprimentos das OPCs no experimento SVT1 foram em média de $1350 \mathrm{~km}$ (Figura 3.25a). No experimentos SVT2 a última crista da OPC atingiu 820 km costa acima, próximo da região da Baía de Guanabara, no estado do Rio de Janeiro, e o comprimento médio das primeiras ondas foi em torno de $1450 \mathrm{~km}$ (Figura 3.25b). 


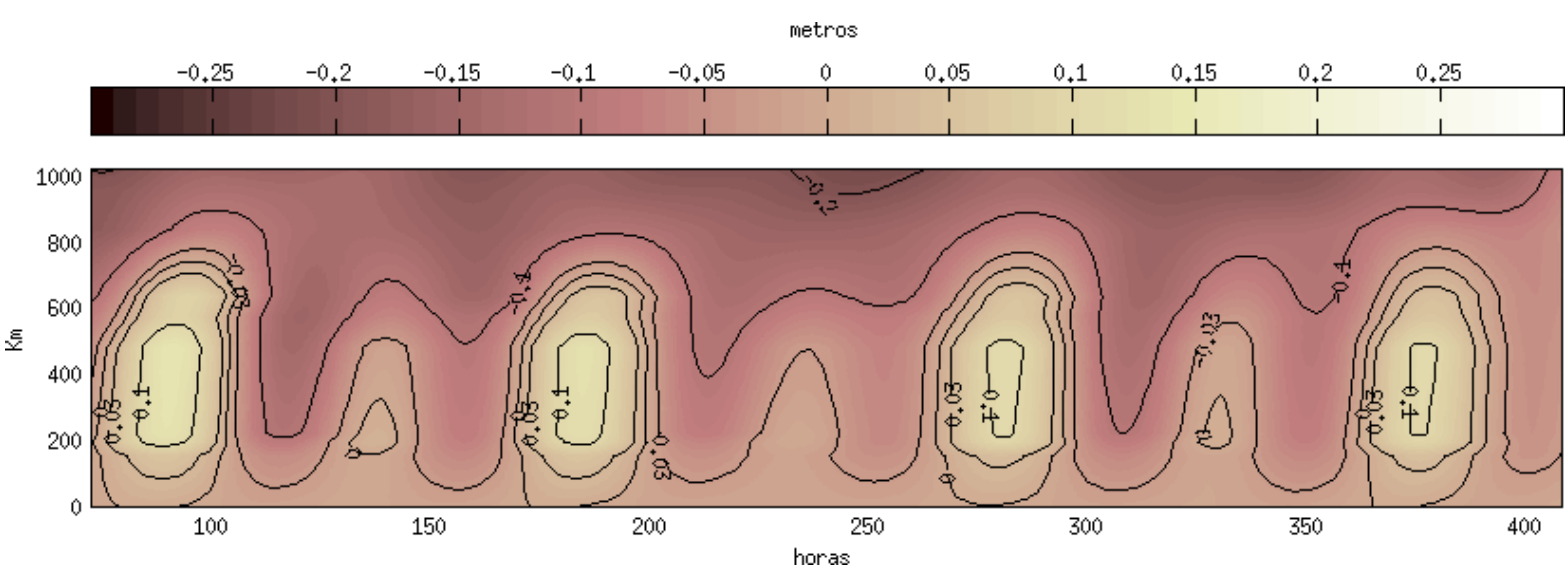

(a)

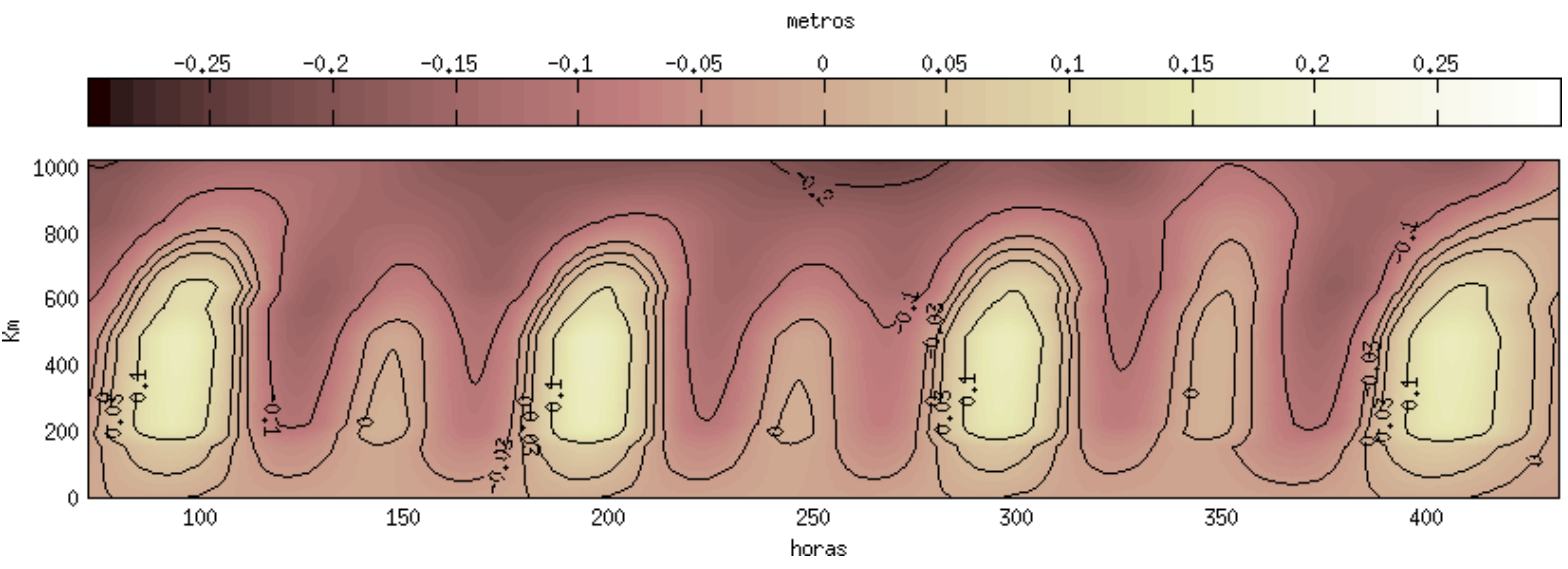

(b)
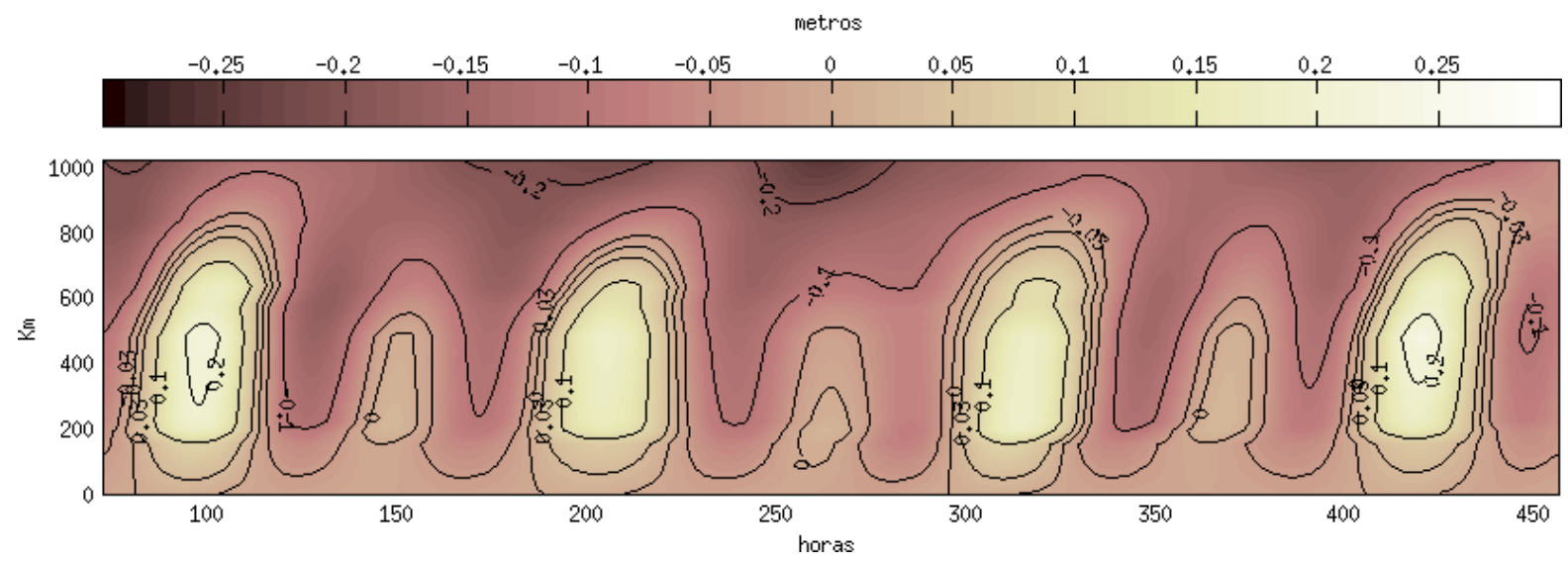

(c)
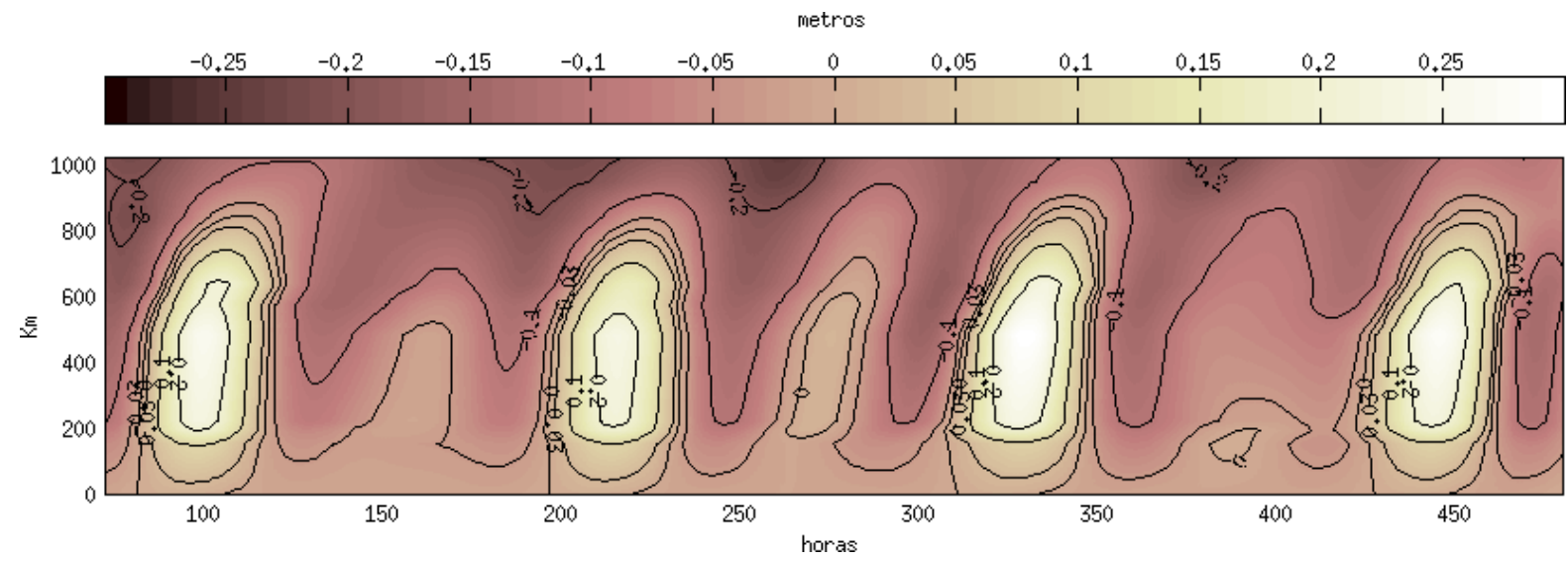

(d)

Figura 3.25: Isopletas de elevação da Onda de Plataforma Continental, nos experimentos (a) SVT1, (b) SVT2, (c) SVT3 e (d) SVT4. Dados filtrados em 40 horas. 
Tabela 3.2: Relação dos valores de atraso da correlação e velocidade de propagação da Onda de Plataforma Continental, nos experimentos SVT1, SVT2, SVT3 e SVT4.

\begin{tabular}{|c|c|c|c|c|c|}
\hline & & SVT1 & SVT2 & SVT3 & SVT4 \\
\hline $\begin{array}{l}\text { Radial Cananéia } \\
\text { (66.9 km da referência } \mathbf{\Delta})\end{array}$ & $\begin{array}{l}\text { Atraso (lag) } \\
\text { Vel.OPC }\end{array}$ & $\begin{array}{c}02 \mathrm{~h} \\
9.3 \mathrm{~ms}^{-1}\end{array}$ & $\begin{array}{c}02 \mathrm{~h} \\
9.3 \mathrm{~ms}^{-1}\end{array}$ & $\begin{array}{c}02 \mathrm{~h} \\
9.3 \mathrm{~ms}^{-1}\end{array}$ & $\begin{array}{c}02 \mathrm{~h} \\
9.3 \mathrm{~ms}^{-1}\end{array}$ \\
\hline $\begin{array}{l}\text { Radial Santos } \\
(227.4 \text { km da referência } \mathbf{\Delta})\end{array}$ & $\begin{array}{l}\text { Atraso (lag) } \\
\text { Vel.OPC }\end{array}$ & $\begin{array}{c}03 \mathrm{~h} \\
21.0 \mathrm{~ms}^{-1}\end{array}$ & $\begin{array}{c}04 \mathrm{~h} \\
15.8 \mathrm{~ms}^{-1}\end{array}$ & $\begin{array}{c}03 \\
21.0 \mathrm{~ms}^{-1}\end{array}$ & $\begin{array}{c}03 \\
21.0 \mathrm{~ms}^{-1}\end{array}$ \\
\hline $\begin{array}{l}\text { Radial Ubatuba } \\
(380.3 \mathrm{~km} \text { da referência } \mathbf{\Delta})\end{array}$ & $\begin{array}{l}\text { Atraso (lag) } \\
\text { Vel.OPC }\end{array}$ & $\begin{array}{c}07 \mathrm{~h} \\
15.1 \mathrm{~ms}^{-1}\end{array}$ & $\begin{array}{c}09 \mathrm{~h} \\
11.7 \mathrm{~ms}^{-1}\end{array}$ & $\begin{array}{c}08 \mathrm{~h} \\
13.2 \mathrm{~ms}^{-1}\end{array}$ & $\begin{array}{c}08 \mathrm{~h} \\
13.2 \mathrm{~ms}^{-1}\end{array}$ \\
\hline $\begin{array}{l}\text { Radial Cabo Frio } \\
(693.8 \text { km da referência } \Delta)\end{array}$ & $\begin{array}{l}\text { Atraso (lag) } \\
\text { Vel.OPC }\end{array}$ & $\begin{array}{c}22 \mathrm{~h} \\
8.8 \mathrm{~ms}^{-1}\end{array}$ & $\begin{array}{c}34 \mathrm{~h} \\
5.6 \mathrm{~ms}^{-1}\end{array}$ & $\begin{array}{c}30 \mathrm{~h} \\
6.4 \mathrm{~ms}^{-1}\end{array}$ & $\begin{array}{c}20 \mathrm{~h} \\
9.6 \mathrm{~ms}^{-1}\end{array}$ \\
\hline $\begin{array}{l}\text { PCSE - sul até São Sebastião } \\
(331 \mathrm{~km} \text { da referência } \mathbf{\Delta})\end{array}$ & $\begin{array}{l}\text { Atraso (lag) } \\
\text { Vel.OPC } \\
\end{array}$ & $\begin{array}{c}06 \mathrm{~h} \\
15.3 \mathrm{~ms}^{-1} \\
\end{array}$ & $\begin{array}{c}06 \mathrm{~h} \\
15.3 \mathrm{~ms}^{-1} \\
\end{array}$ & $\begin{array}{c}06 \mathrm{~h} \\
15.3 \mathrm{~ms}^{-1} \\
\end{array}$ & $\begin{array}{c}06 \mathrm{~h} \\
15.3 \mathrm{~ms}^{-1} \\
\end{array}$ \\
\hline $\begin{array}{l}\text { PCSE-norte até Cabo Frio } \\
\text { (362.8 km de São Sebastião ) }\end{array}$ & $\begin{array}{l}\text { Atraso (lag) } \\
\text { Vel.OPC }\end{array}$ & $\begin{array}{c}16 \mathrm{~h} \\
6.3 \mathrm{~ms}^{-1}\end{array}$ & $\begin{array}{c}28 \mathrm{~h} \\
3.6 \mathrm{~ms}^{-1}\end{array}$ & $\begin{array}{c}24 \mathrm{~h} \\
4.2 \mathrm{~ms}^{-1}\end{array}$ & $\begin{array}{c}14 \mathrm{~h} \\
7.2 \mathrm{~ms}^{-1}\end{array}$ \\
\hline
\end{tabular}

Os experimentos SVT3 (Figura 3.25 c) e SVT4 (Figura 3.25d) apresentaram comprimentos de onda de $1510 \mathrm{~km}$ e $1550 \mathrm{~km}$, respectivamente e as últimas ondas de ambos os experimentos alcançaram a região da Baía de Guanabara, atingindo cerca de $830 \mathrm{~km}$ da costa da PCSE.

As velocidades de propagação da OPC foram calculadas utilizando o tempo de atraso das correlações máximas de elevação do nível do mar e a distância das radiais em relação ao ponto de referência, e são apresentadas na Tabela 3.2. Os valores de velocidade obtidos indicam que o aumento do tempo de permanência das frentes não provocou mudanças na velocidade de propagação da onda nas radiais mais ao sul da PCSE. A radial Cananéia apresentou valores de atraso da onda iguais em todos os experimentos, o que resultou em uma velocidade de propagação da OPC de $9.3 \mathrm{~ms}^{-1}$. O mesmo padrão é observado para a radial Santos, com exceção o experimento SVT2, que o atraso da onda foi uma hora a mais em relação aos demais experimentos, resultando em uma onda mais rápida. Nas radiais ao norte da PCSE, Ubatuba e Cabo Frio, o aumento do tempo de ação das frentes frias geraram um aumento no tempo de atraso entre os experimentos SVT1 e SVT2, e as ondas diminuíram sua velocidade de propagação. A partir do experimento SVT3 as velocidades aumentaram novamente. Avaliando as velocidades nas duas regiões da PCSE, de maneira geral, a parte norte da PCSE (da Ilha de São Sebastião até Cabo Frio) apresentou maior variabilidade na velocidade de propagação da OPC com as mudanças do regime de frentes se comparado a parte sul da PCSE(de Santa Catarina até o sul da Ilha de São Sebastião).

No que se refere a velocidade da corrente superficial, a Figura 3.26 indica que as regiões mais ao sul do domínio até a Ilha de São Sebastião apresentaram as maiores valores, relacionadas com a passagem dos sistemas frontais, uma vez que a direção das correntes máximas estão 

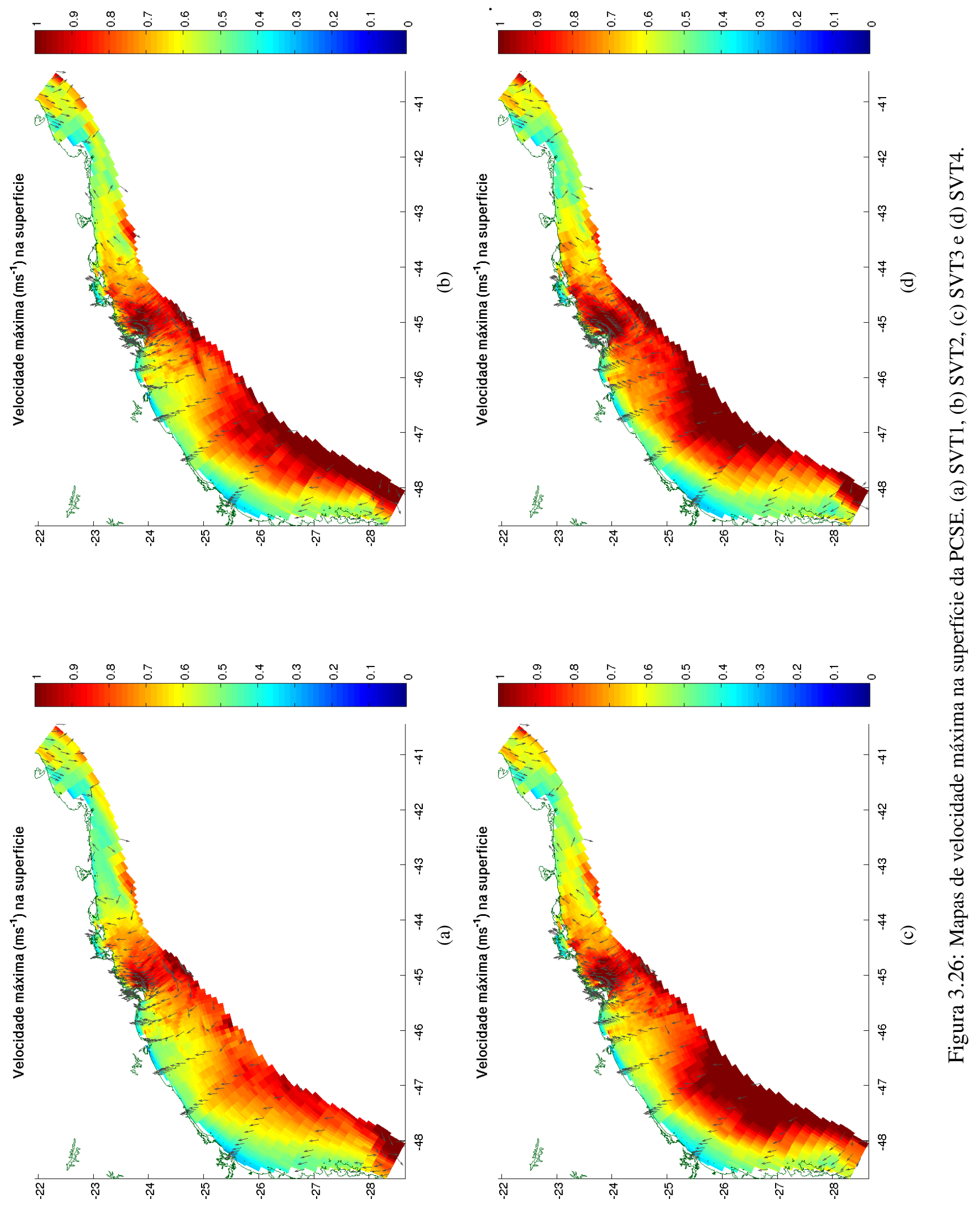
cerca de $45^{\circ}$ dos ventos de sudoeste. A região ao norte de Cabo Frio, entretanto, apresentou direção da corrente máxima para sudoeste, sendo uma corrente gerada pelo cisalhamento dos ventos de nordeste, típicos da Alta Subtropical do Atlântico Sul. Segundo Santos (2009), o condicionamento das correntes para sudoeste na região de Cafo Frio está associado a formação vortical provocada pela proximidade da Corrente do Brasil ao largo da região, imposta nas simulações através dos campos climatológicos de densidade.

O experimento SVT1 (Figura 3.26a) apresentou as maiores velocidades na face externa da ilha e ao largo de São Sebastião, na isóbata de 200 metros, com $1.0 \mathrm{~ms}^{-1}$. De forma geral, a PCI da porção sul do domínio apresentou velocidade superficial de $0.4 \mathrm{~ms}^{-1}$, a PCM de $0.6 \mathrm{~ms}^{-1} \mathrm{e} \mathrm{a}$ PCE de $0.75 \mathrm{~ms}^{-1}$. A porção norte, mais especificamente em Cabo Frio, tanto PCI (até a isóbata de 40 metros) quanto a PCM (até a isobata de 90 metros) apresentaram velocidade superficial máxima de $0.4 \mathrm{~ms}^{-1}$. Com o aumento do tempo de ação da frente, e consequentemente a diminuição de sua velocidade de propagação, a PCM da região sul do domínio apresentou maiores áreas com velocidades acima de $0.8 \mathrm{~ms}^{-1}$, principalmente na região de Santos. Valores acima de $1.0 \mathrm{~ms}^{-1}$ foram observados na PCM e na PCE ao largo de Cananéia, como visto na Figura 3.26d para o experimento SVT4, com frentes frias se propagando a $9.5 \mathrm{~ms}^{-1}$. Deste modo é possível estabelecer uma relação entre o aumento da velocidade da corrente superficial na região sul com a velocidade de propagação da frente, uma vez que a velocidade da corrente possui valor muito próximo da velocidade de propagação da frente fria.

Analisando as séries temporais de velocidade superficial da radial de Cananéia no experimento SVT4, a Figura 3.27 mostra que o início da simulação com ventos de nordeste promoveram correntes para sudoeste em toda a radial, sendo que a PCE apresentou correntes mais intensas, de $0.2 \mathrm{~ms}^{-1}$. No dia 4 , com a mudança do regime dos ventos, a corrente inverteu sua direção, fluindo para nordeste com intensidade de $0.5 \mathrm{~ms}^{-1}$ na PCI, $0.6 \mathrm{~ms}^{-1}$ na PCM e 0.9 $\mathrm{ms}^{-1}$ na PCE. Após a passagem do primeiro sistema frontal, os valores de velocidade assumem característica oscilatória, com período de cerca de 26.5 horas na PCM e na PCE. Esse perfil oscilatório também ocorreu nos experimentos SVT1, SVT2 e SVT3, com período pouco alterado, demonstrando que a mudança da velocidade de propagação da frente entre as simulações não interfere no período de oscilação natural da corrente.

$\mathrm{Na}$ PCM $\mathrm{e}$ na $\mathrm{PCE}$ de Cananéia foram observadas as maiores amplitudes de inversão derivada dessa oscilação natural e, na isóbata de 50 metros, a corrente máxima para sudoeste foi de $0.3 \mathrm{~ms}^{-1}$ e, na isóbata de 100 metros, de $0.49 \mathrm{~ms}^{-1}$, ambos no dia 5 .

Se observarmos as séries temporais de Ubatuba no experimento SVT4 (Figura 3.28), vemos que a isóbata de 100 metros também apresentou oscilações com período de 26.1 horas, período próximo ao período inercial efetivo calculado por Leite (2014) para Ubatuba e Arraial do CaboRJ, de 26.5 horas. Na isóbata de 50 metros foram observadas as maiores velocidades superficiais no dia 9 e dia 14 , com correntes superiores a $1.0 \mathrm{~ms}^{-1}$. 

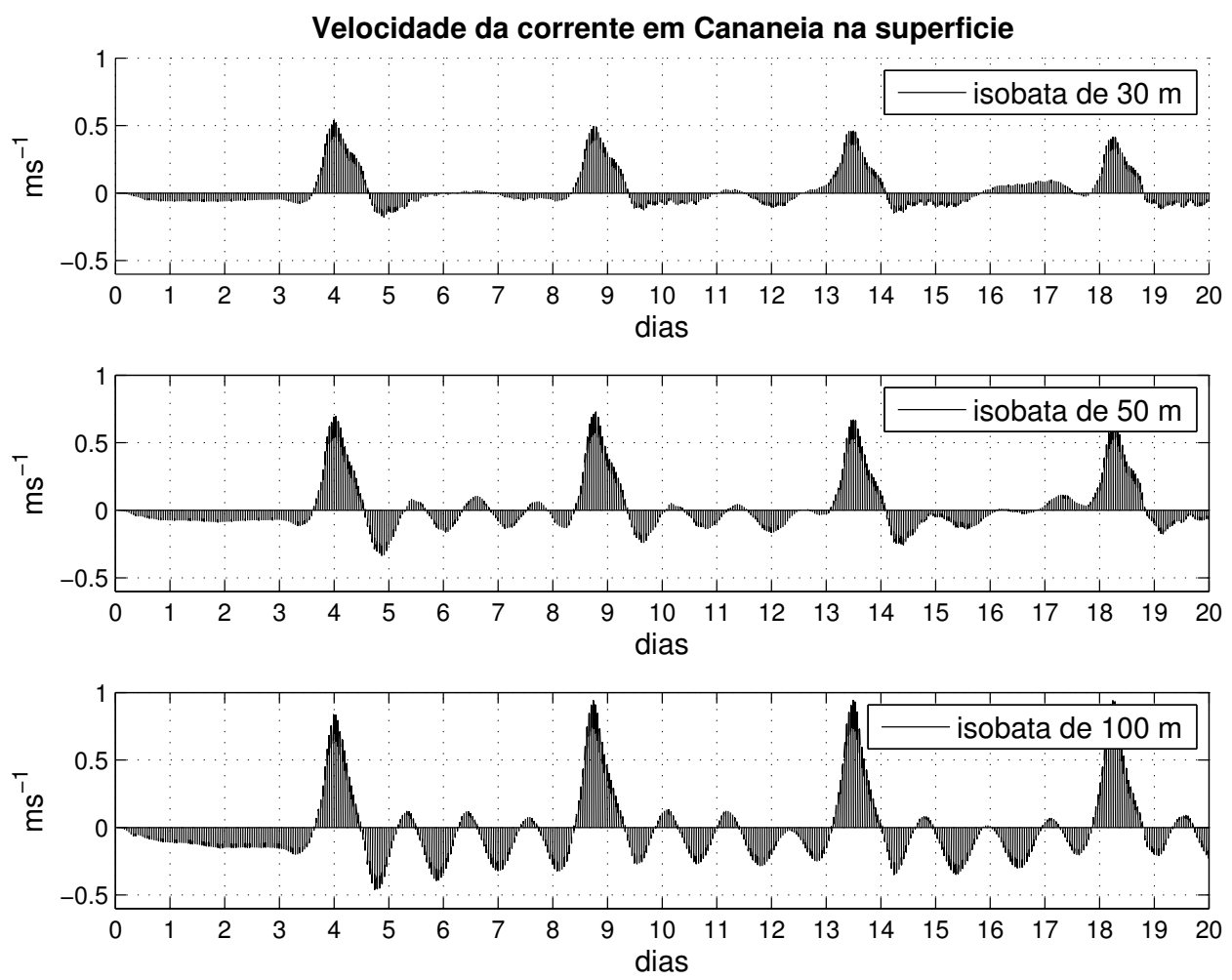

Figura 3.27: Séries temporais de velocidade na superfície na radial Cananéia, na simulação SVT4.
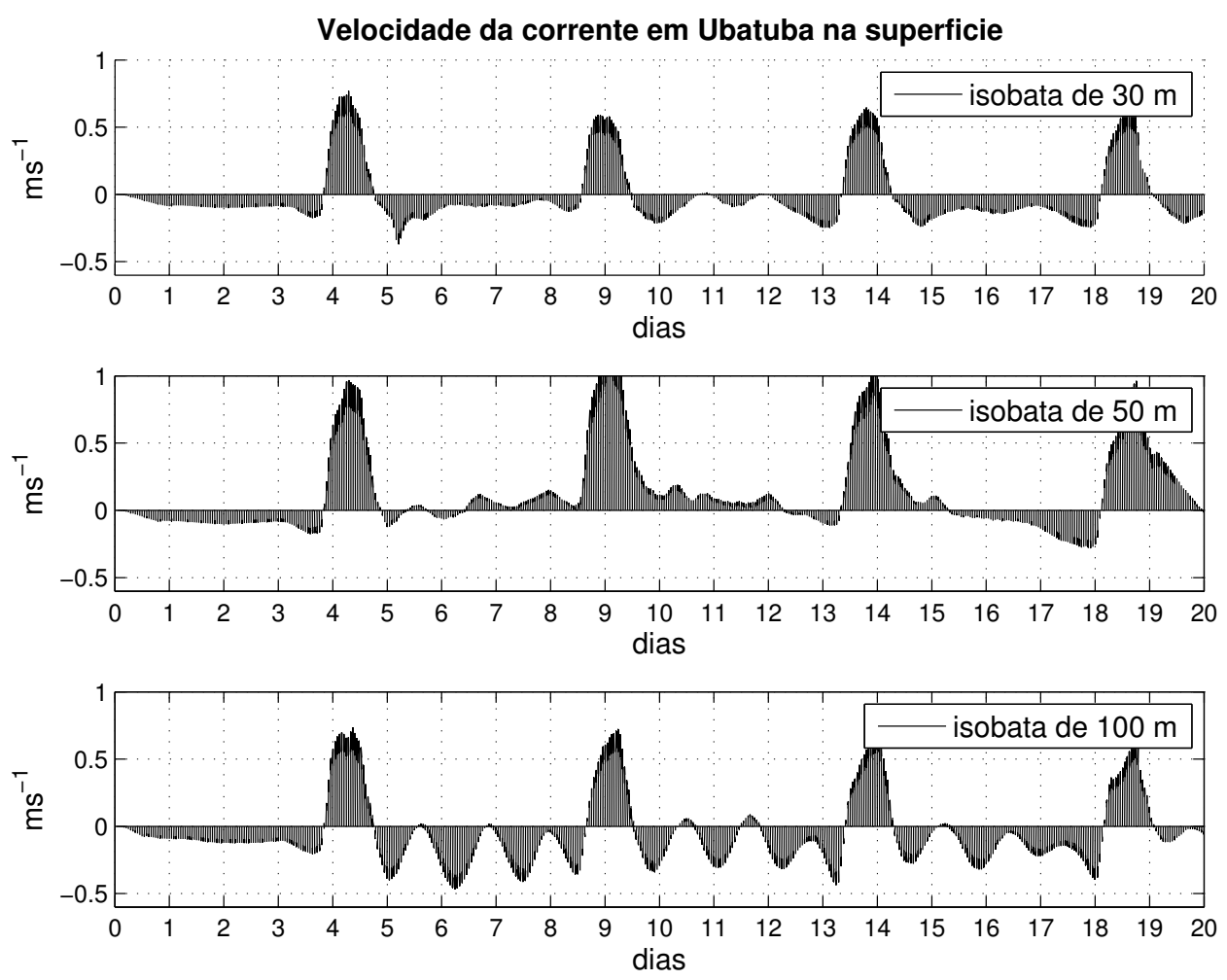

Figura 3.28: Séries temporais de velocidade na superfície na radial Ubatuba, na simulação SVT4. 

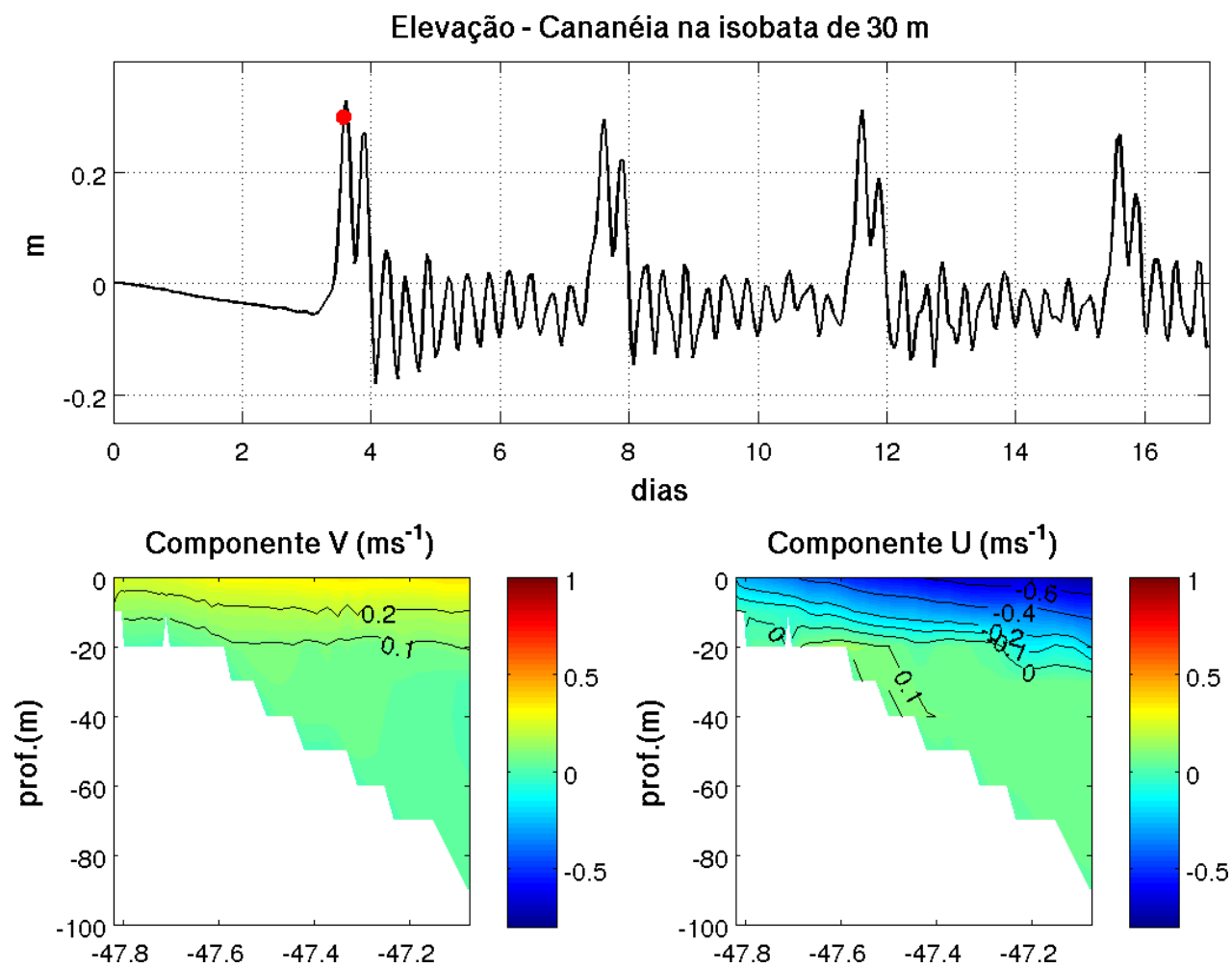

Figura 3.29: Série temporal de elevação e perfis verticais de velocidade perpendicular (U) e paralela (V) durante a passagem da primeira frente fria na radial Cananéia no experimento SVT1.
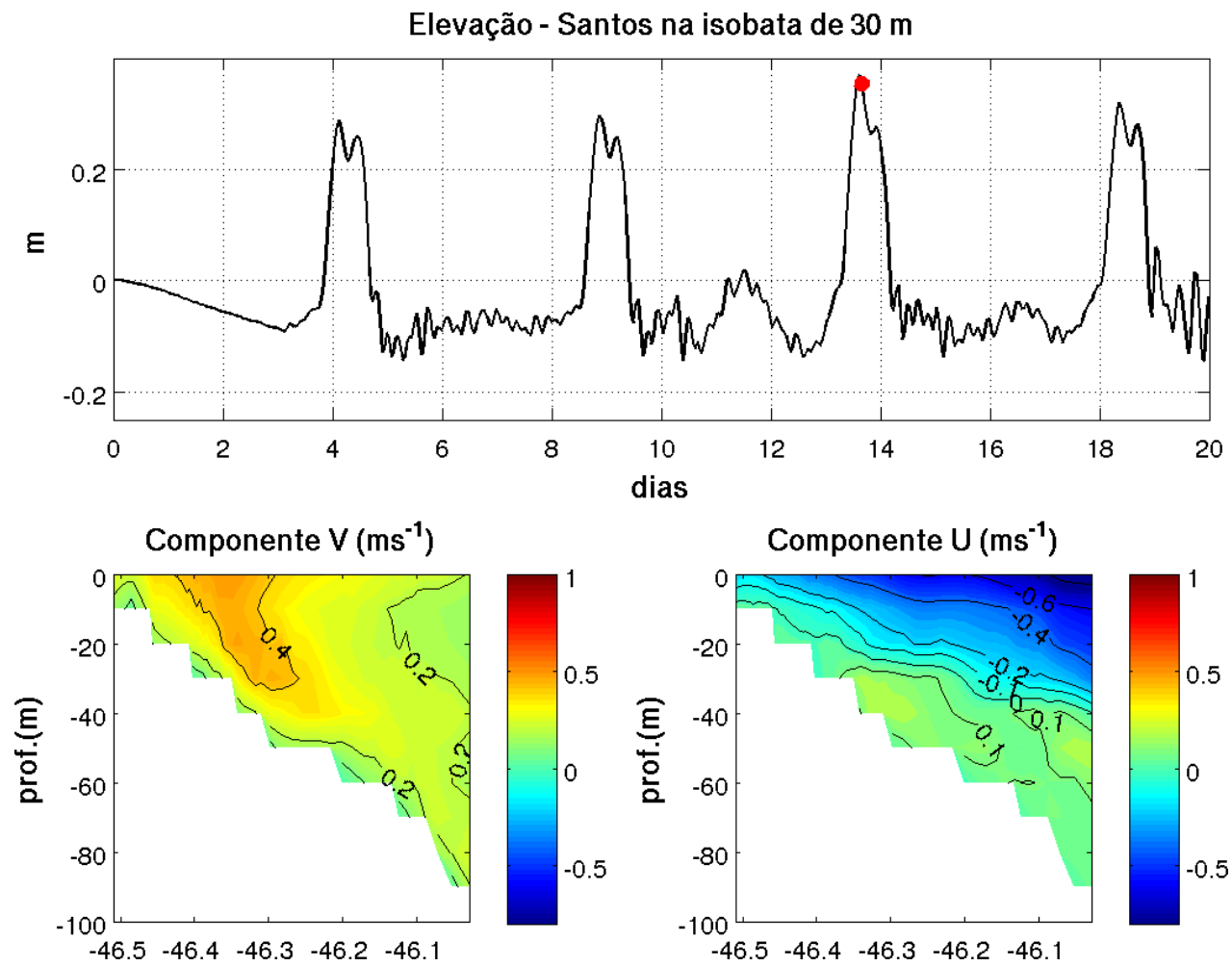

Figura 3.30: Série temporal de elevação e perfis verticais de velocidade perpendicular (U) e paralela (V) durante a passagem da terceira frente fria na radial Santos no experimento SVT4. 


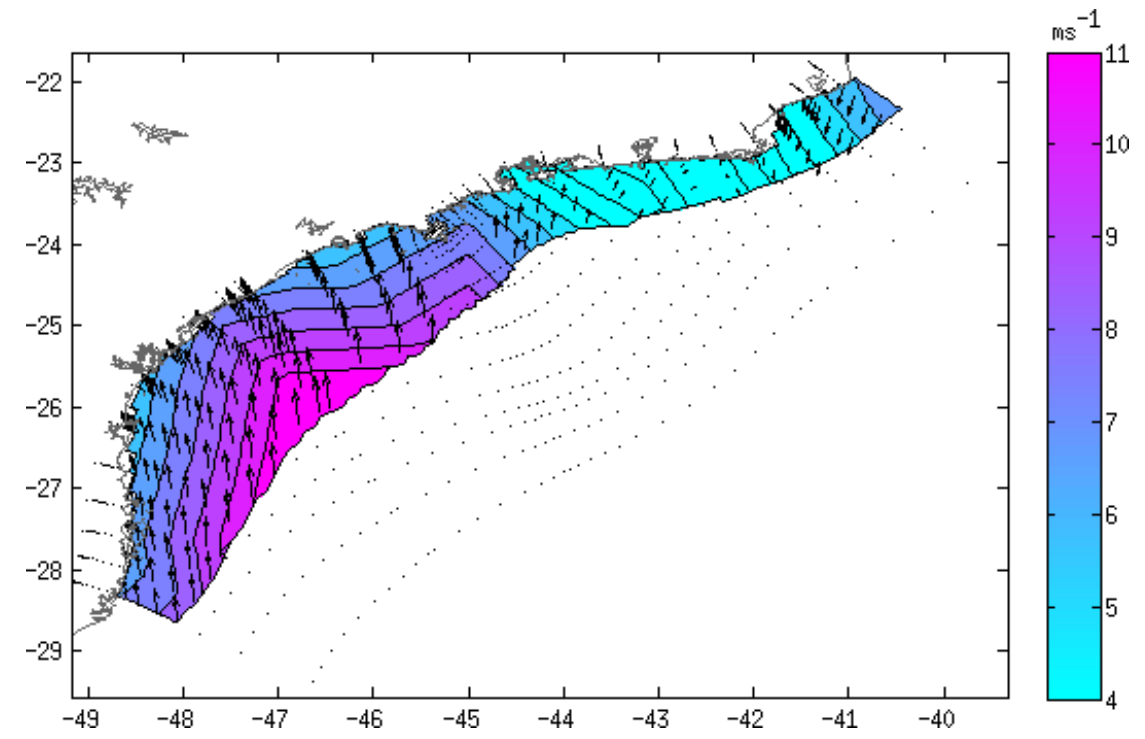

Figura 3.31: Intensidade dos ventos de frente fria sobre sul da PCSE.

Sob o aspecto da estrutura vertical da corrente na coluna d'água, na radial Cananéia durante a passagem da primeira frente, comparando os resultados dos experimentos SVT1 e SVT4, notase que a estrutura da componente paralela da corrente (componente $\mathrm{V}$ da velocidade) pouco foi alterada, sendo que o cisalhamento do vento de sudoeste promoveu um valor máximo de 0.2 $\mathrm{ms}^{-1}$ em superfície para nordeste. Essa velocidade foi atenuada nas camadas mais profundas até que, em cerca de 20 metros de profundidade, a velocidade da componente paralela foi cerca de $0.1 \mathrm{~ms}^{-1}$. Nesta radial, a componente perpendicular (componente $U$ ) foi maior que a componente paralela, exibindo na PCE valores acima de $0.6 \mathrm{~ms}^{-1}$, como mostra a Figura 3.29 . O sentido da corrente perpendicular durante a passagem dos sistemas frontais foi em direção à costa, acompanhando o sentido do cisalhamento do vento de frente fria na região. Nos demais experimentos, a estrutura vertical das correntes mantiveram o mesmo padrão, com a componente perpendicular maior que a paralela, principalmente na $\mathrm{PCM}$ e na PCE, durante a ação dos ventos de nordeste, e intensificadas a medida em que se reduziu o tempo de propagação das frentes entre os experimentos.

Na radial Santos, Figura 3.30, a redução da velocidade de propagação da frente também acarretou no aumento da componente perpendicular da corrente, como pode ser visto na Figura 3.30, que apresenta a estrutura vertical da corrente durante a passagem da terceira frente fria e, consequentemente, da terceira OPC no experimento SVT4. O aumento da componente perpendicular que flui sentido à costa nas camadas mais superficiais está associado ao sentido predominante dos ventos de frente fria na região, assim como ocorreu na radial Cananéia. O mapa apresentado na Figura 3.3.1 apresenta a intensidade e sentido dos ventos sobre as radiais, de forma a elucidar a maior intensidade da componente perpendicular da corrente nas radiais mais ao sul do domínio. A Figura 3.32 mostra que, em Ubatuba, as componentes paralela e perpendicular são intensificadas pela maior permanência da frente fria na região, sendo que no experimento SVT4 (Figura 3.32 p) a passagem da primeira OPC na região está associada a com- 

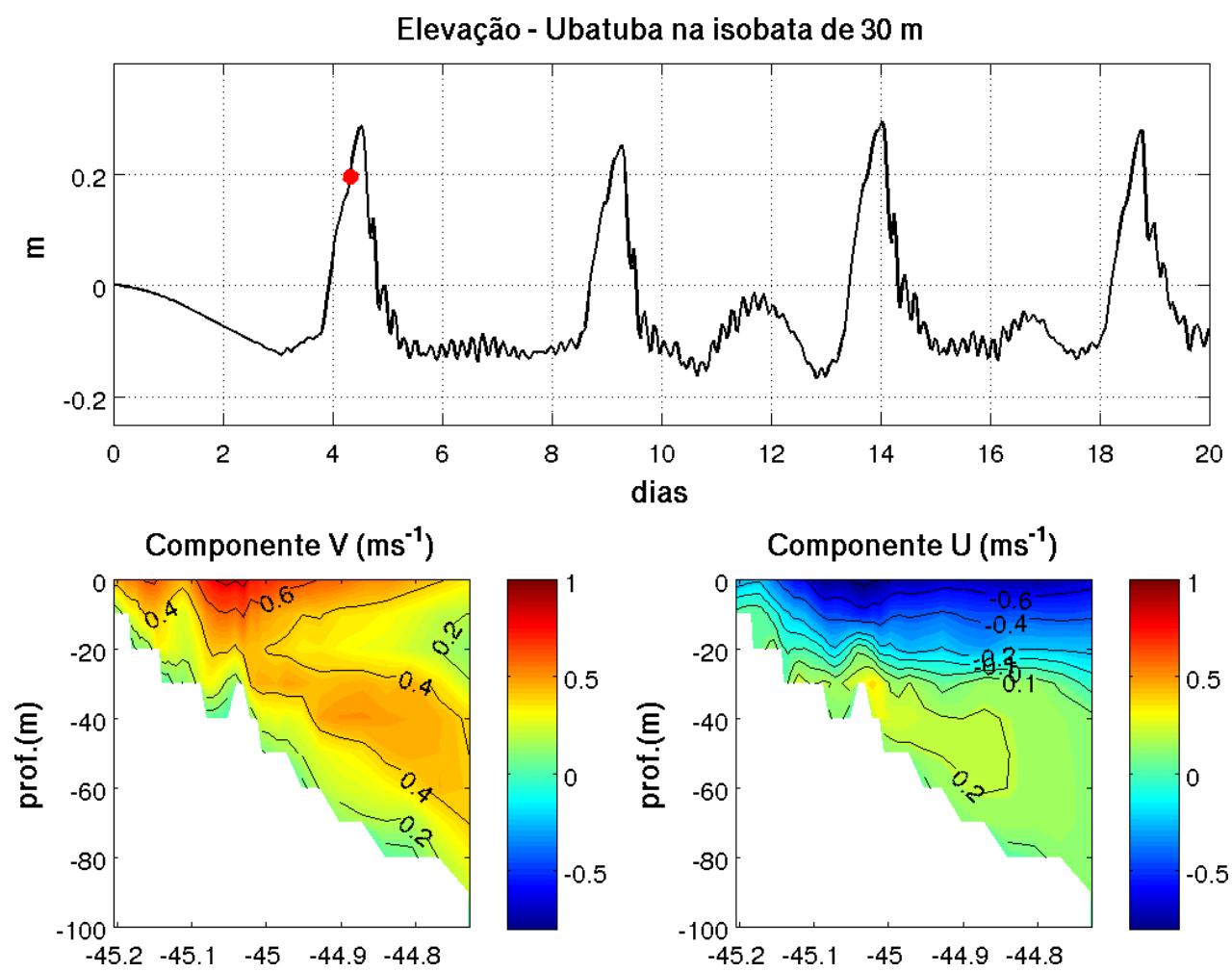

Figura 3.32: Série temporal de elevação e perfis verticais de velocidade perpendicular (U) e paralela (V) durante a passagem da primeira frente fria na radial Ubatuba no experimento SVT4.

ponentes paralela e perpendicular na ordem de $0.6 \mathrm{~ms}^{-1}$, resultando em correntes para nordeste durante a passagem da frente fria.

\subsubsection{Frentes com tempo de permanência entre 40 a 60 horas na PCSE}

A Figura 3.33 revela que as maiores elevações do nível do mar ocorreram na parte sul do domínio, na $\mathrm{PCI}$ de Cananéia até Santos, com elevações acima de $0.4 \mathrm{~m}$. A região norte da PCSE, ao norte da Ilha de São Sebastião, apresentou pequenas variações de elevação com a alteração da velocidade das frentes, onde o experimento SVT5 (Figura 3.33 a), com 42 horas de permanência das frentes frias e velocidade de propagação de $8.1 \mathrm{~ms}^{-1}$, exibiu elevações acima de $0.3 \mathrm{~m}$ na PCI de Ubatuba e entre 0.2 e $0.1 \mathrm{~m}$ na PCI de Ilha Grande e Baía de Guanabara, no estado do Rio de Janeiro. Com a redução da velocidade de propagação da frente para $7.1 \mathrm{~ms}^{-1}$ no experimento SVT6 (Figura 3.33 b, com 48 horas de permanência), o padrão de amplitudes manteve-se praticamente inalterado. No experimento SVT7 (Figura 3.33 ), com frentes com 54 horas de permanência e $6.3 \mathrm{~ms}^{-1}$ de velocidade de propagação, regiões ao norte da Baía de Guanabara apresentaram elevações positivas, e o aumento da ação da frente para 60 horas no experimento SVT8 (Figura $3.33 \mathrm{~d}$ ), com $5.7 \mathrm{~ms}^{-1}$ de velocidade de deslocamento da frente, promoveu amplitudes positivas ao norte de Cabo Frio.

O aumento da elevação do nível do mar na região norte da PCSE podem ser melhor analisados na Figura 3.34, que apresenta as séries temporais de elevação do nível do mar de Ubatuba 

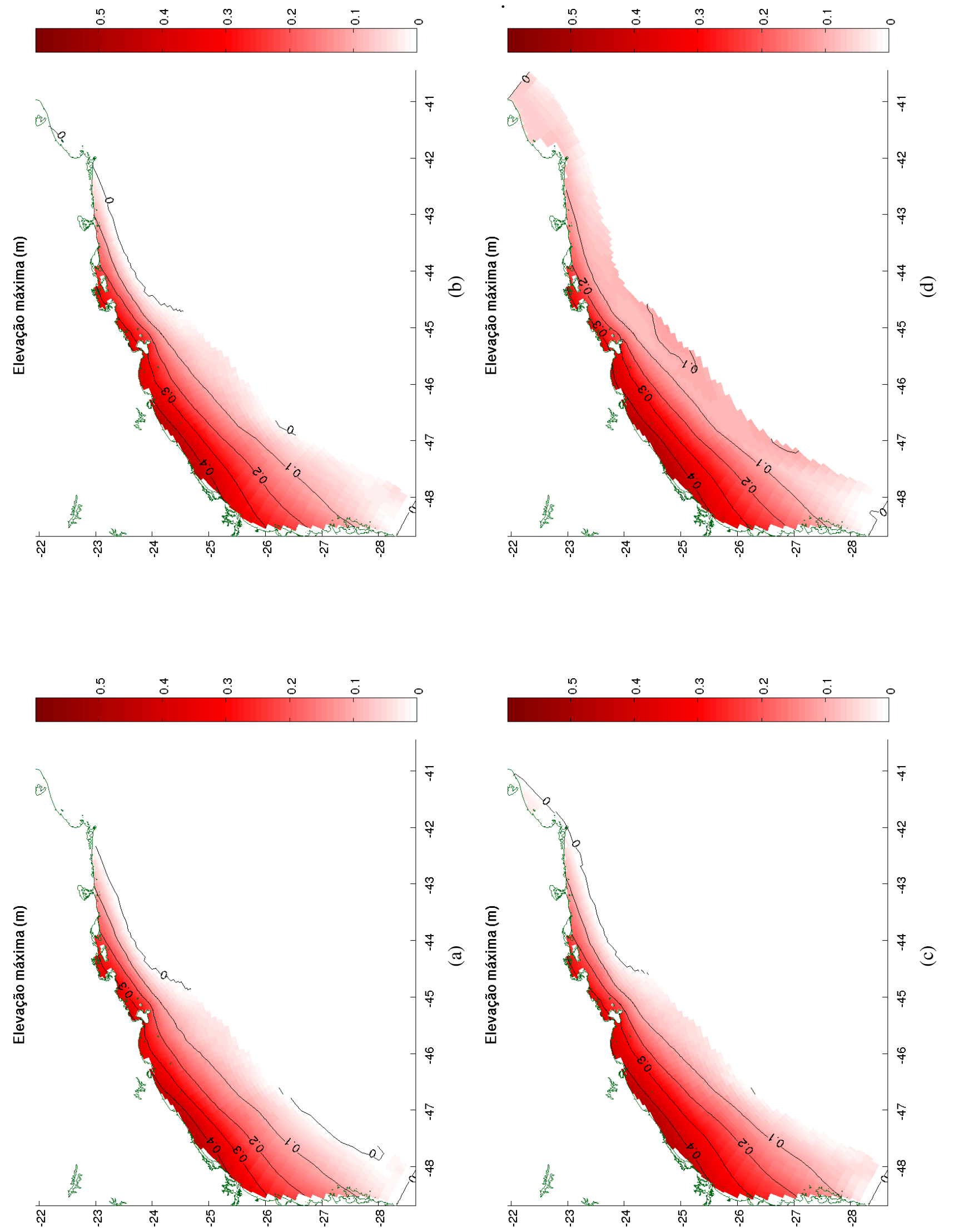

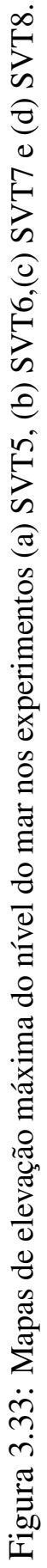



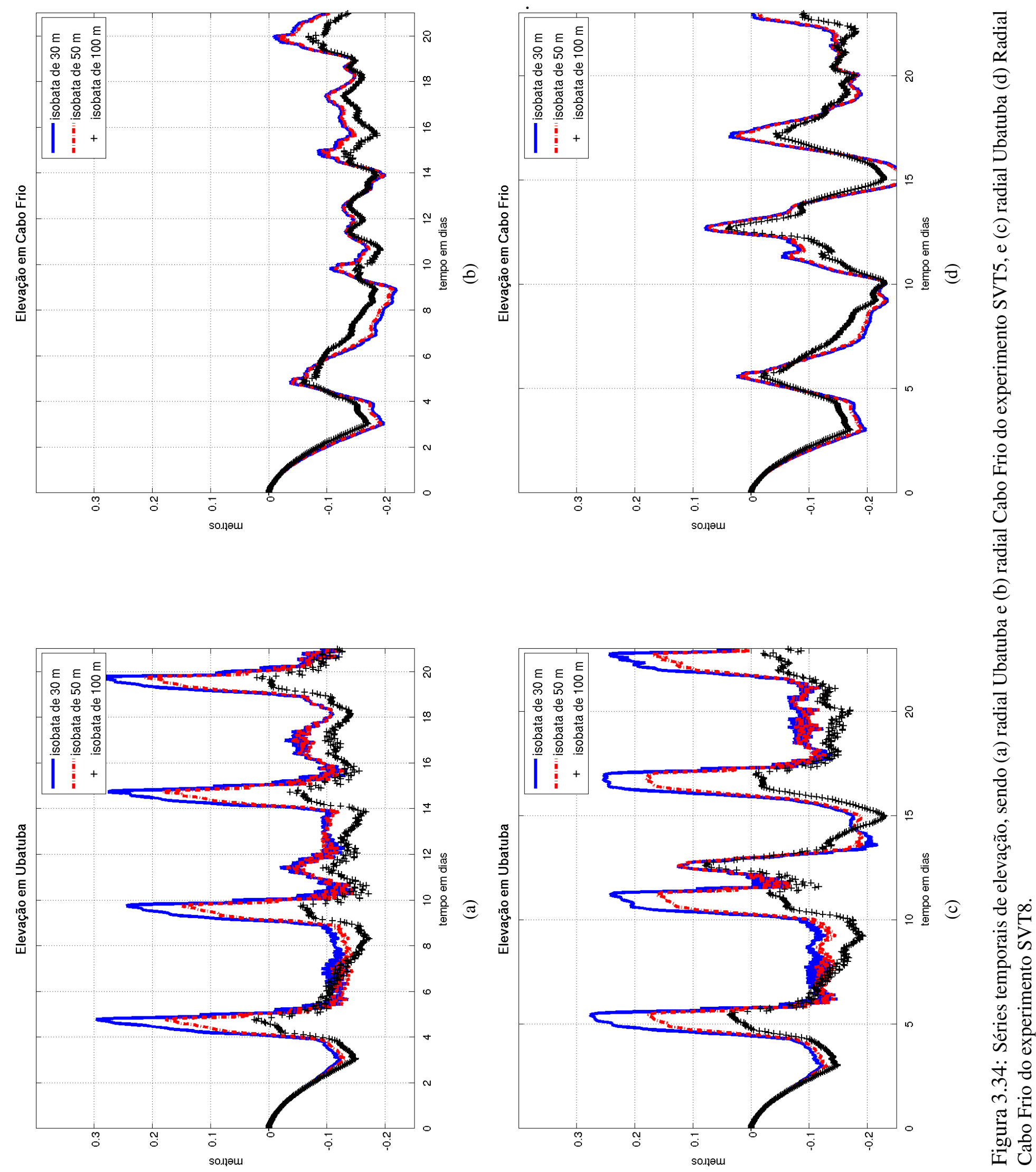

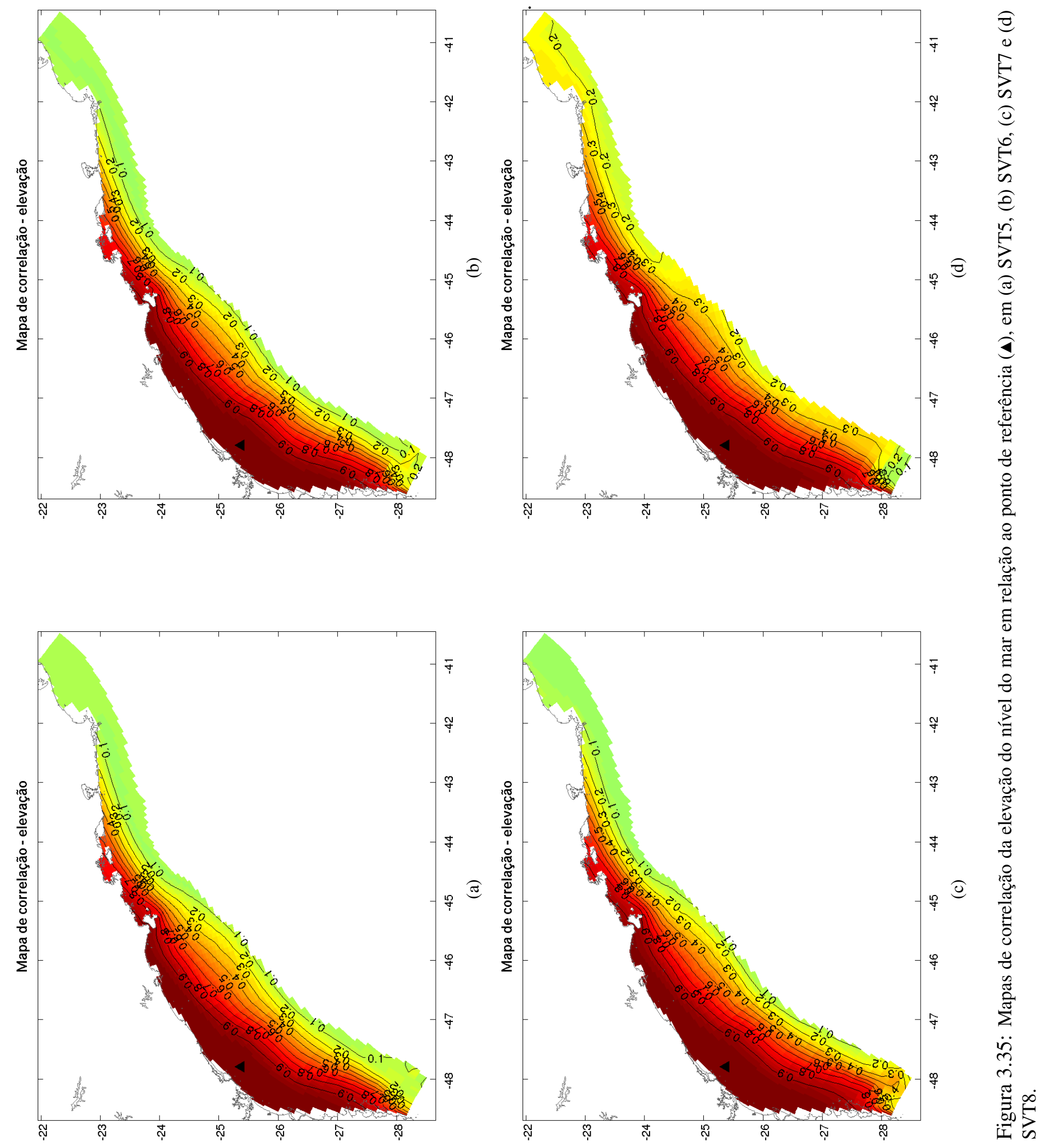
e Cabo Frio. Observando a Figura 3.34 a, percebe-se que a PCI da região de Ubatuba alcançou $0.3 \mathrm{~m}$ de altura durante a passagem da primeira frente fria no experimento SVT5, e a redução da velocidade de deslocamento da frente fria causou a diminuição do nível do mar para 0.28 $\mathrm{m}$ no experimento SVT8, Figura 3.34c. A série temporal de elevação da radial de Cabo Frio no experimento SVT5 (Figura 3.34p) apresentou nível do mar abaixo de zero durante todos os experimentos, mas foram percebidos picos entre os dias 4 e 6,8 e 10, 14 e 16, e 18 e 20, onde a maior aplitude absoluta foi de cerca de $0.15 \mathrm{~m}$ entre os dias 4 e 6 . O aumento do tempo de permanência da frente para 60 horas promoveu na região de Cabo Frio elevações positivas de até $0.08 \mathrm{~m}$ durante a passagem da terceira frente fria.

Em relação as oscilações do nível do mar, após a passagem da frente fria, tanto o período quanto a amplitude dessas ondulações diminuíram com o aumento do tempo de permanência da frente, principalmente nas radiais ao sul do domínio, além de serem observadas oscilações de alta frequência em Cananéia.

A Figura 3.35 revela que as maiores correlações do nível do mar obtidas nos experimentos foram encontradas na $\mathrm{PCI}$ PCM ao sul da Ilha de São Sebastião, sendo máxima na costa e atingindo valor de 0.6 na PCM. Esse padrão de distribuição da correlação no sul da PCSE pouco se alterou com a alteração da velocidade de propagação das frentes frias. As menores correlações são observadas na região norte da PCSE, onde a redução da velocidade de propagação da frente entre os experimentos preservou a correlação próxima a zero ao norte de Cabo Frio, entre os experimentos SVT5, SVT6 e SVT7.

Contudo o aumento do tempo de permanência da frente fria na região por 60 horas no experimento SVT8 acarretou no aumento da correlação, mesmo que insignificante, no norte da PCSE, que foi entre 0.2 e 0.3 .

Comparando os resultados de correlação do experimento SVT8 com o experimento RS3 (frente fria remota com 54 horas de ação), apresentado anteriormente na Seção 3.2 (Figura 3.11), temos uma idéia da contribuição do sinal remoto da frente fria na região norte. No experimento RS3 os valores de correlação ao norte de Cabo Frio foram entre 0.3 e 0.2 e a similaridade dos valores de correlação entre os dois experimentos no norte propõe que as variações do nível do mar ao norte de Cabo Frio são relacionadas, mesmo que fracamente, a pertubação gerada pelo sinal remoto do vento.

A Figura 3.36 apresenta os diagramas de Hovmöller de elevação na costa da PCSE, o que torna possível identificar o alcance e comprimento das OPC primento das cristas (isolinhas positivas) e cavas (isolinhas negativas) da onda. O experimento SVT5 apresentou ondas com comprimento de $1640 \mathrm{~km}$, sendo que a crista subiu a costa da PCSE até cerca de $840 \mathrm{~km}$ do limite sul da PCSE, próximo a região da Baía de Guanabara, e as cavas das ondas foram observadas horas depois, a partir de $100 \mathrm{~km}$ do limite sul, próximo da cidade de São Francisco do Sul em Santa Catarina (Figura 3.36). O aumento do tempo da frente em SVT6 promoveu ondas com comprimento médio de cerca de $1690 \mathrm{~km}$ (Figura 3.36b), e as últimas ondas geradas atingiram a região sul de Cabo Frio, a cerca de $900 \mathrm{~km}$ do limite sul 


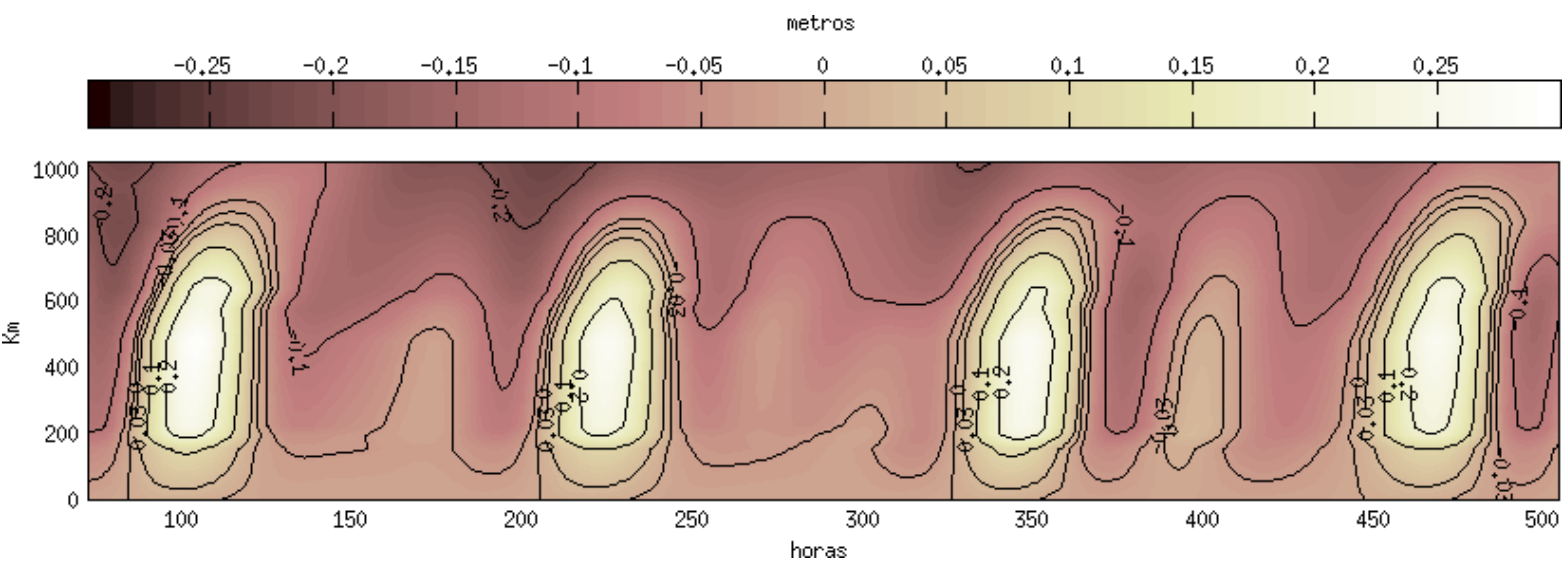

(a)
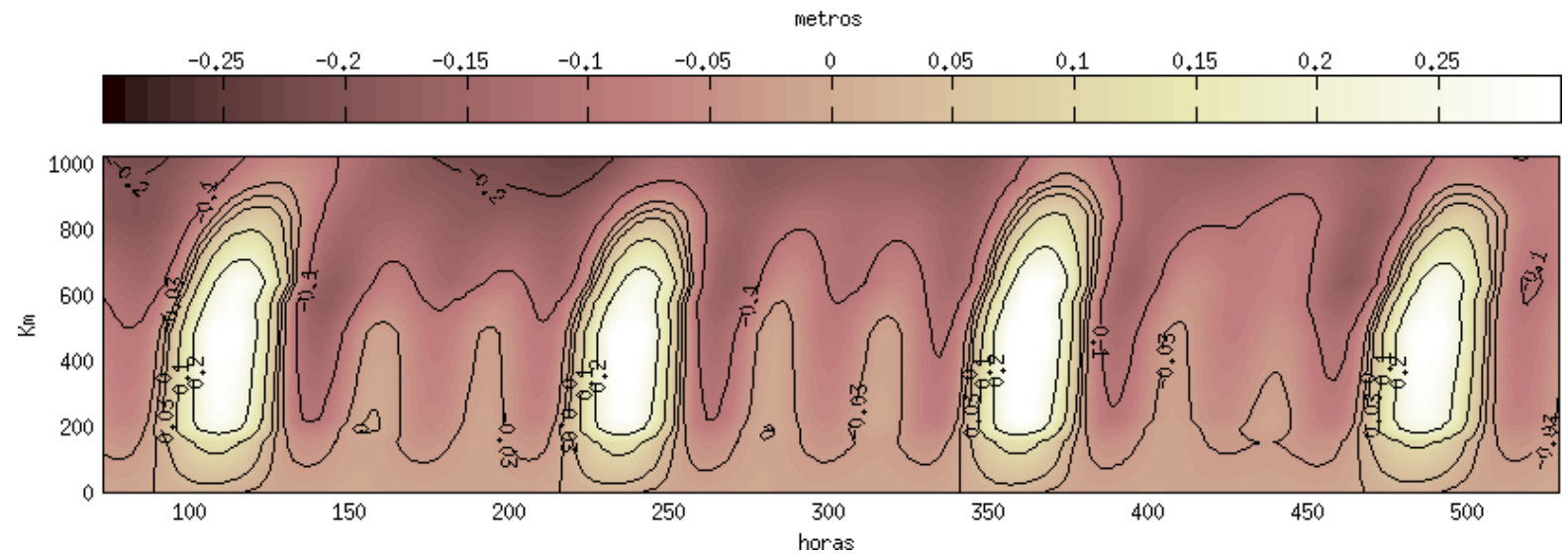

(b)
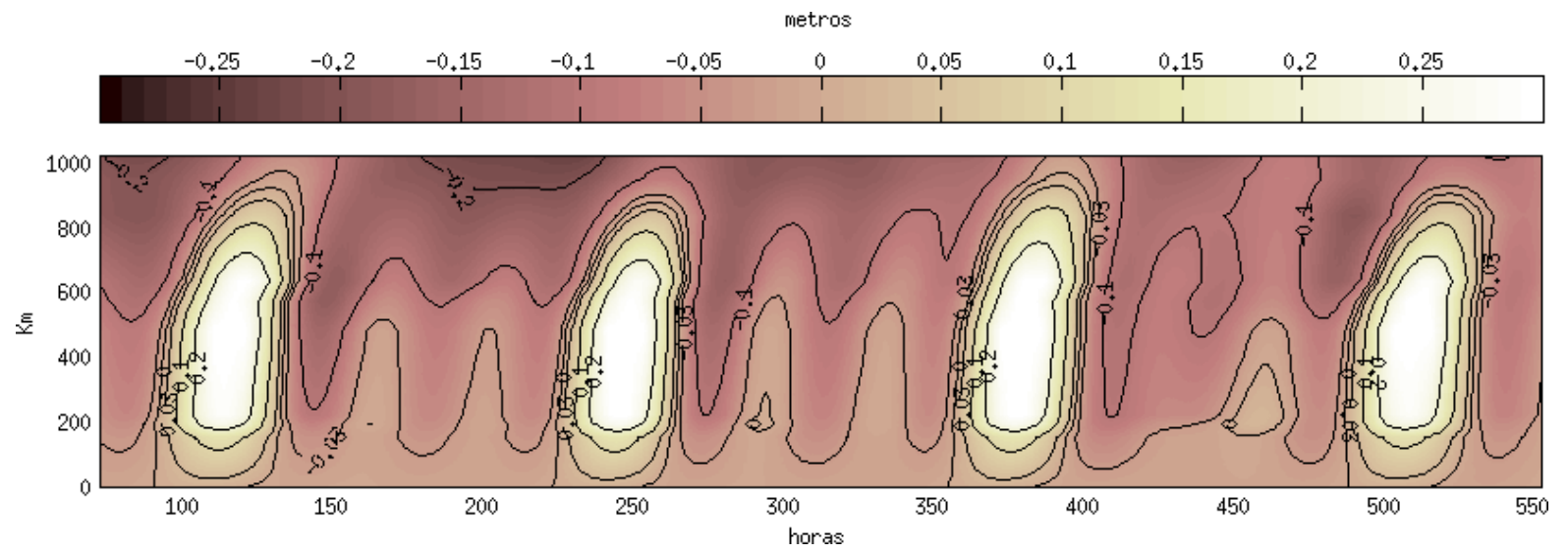

(c)
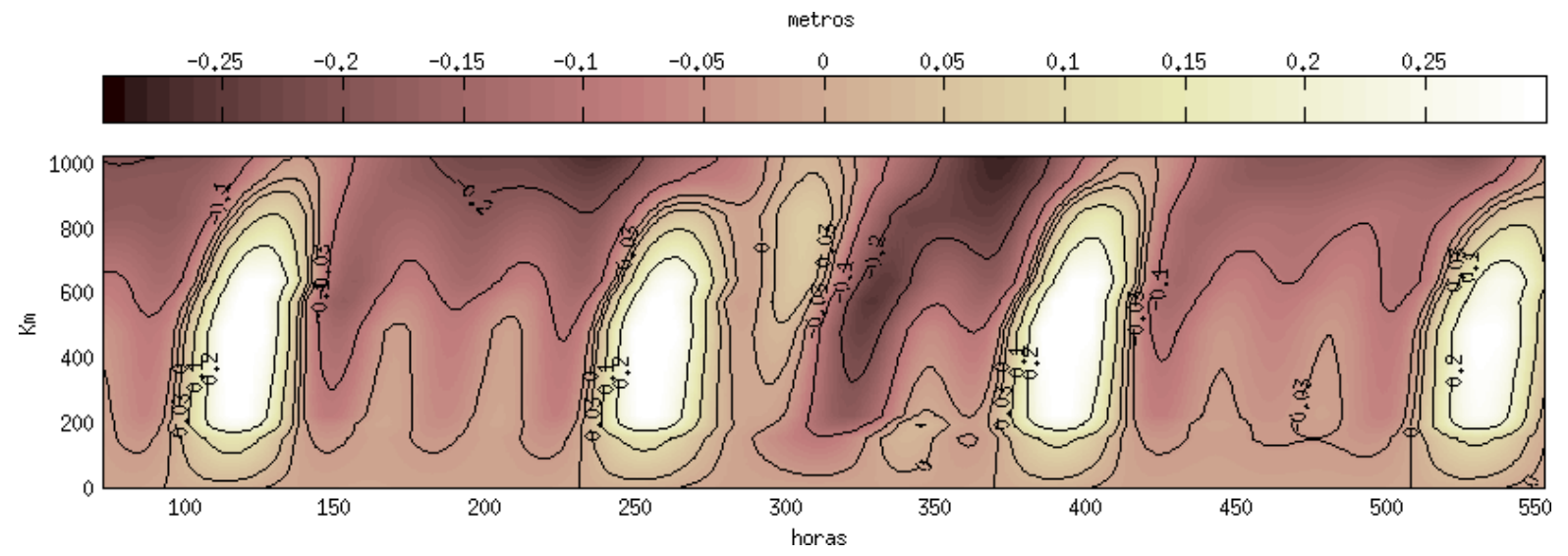

(d)

Figura 3.36: Isopletas de elevação da Onda de Plataforma Continental, nos experimentos (a) SVT5, (b) SVT6, (c) SVT7 e (d) SVT8. Dados filtrados em 40 horas. 
Tabela 3.3: Relação dos valores de atraso da correlação e velocidade de propagação da Onda de Plataforma Continental, nos experimentos SVT5, SVT6, SVT7 e SVT8.

\begin{tabular}{|c|c|c|c|c|c|}
\hline & & SVT5 & SVT6 & SVT7 & SVT8 \\
\hline $\begin{array}{l}\text { Radial Cananéia } \\
\text { (66.9 km da referência } \mathbf{\Delta})\end{array}$ & $\begin{array}{l}\text { Atraso (lag) } \\
\text { Vel.OPC }\end{array}$ & $\begin{array}{c}01 \mathrm{~h} \\
18.6 \mathrm{~ms}^{-1}\end{array}$ & $\begin{array}{c}01 \mathrm{~h} \\
18.6 \mathrm{~ms}^{-1}\end{array}$ & $\begin{array}{c}02 \mathrm{~h} \\
9.3 \mathrm{~ms}^{-1}\end{array}$ & $\begin{array}{c}02 \mathrm{~h} \\
9.3 \mathrm{~ms}^{-1}\end{array}$ \\
\hline $\begin{array}{l}\text { Radial Santos } \\
(227.4 \text { km da referência } \mathbf{\Delta})\end{array}$ & $\begin{array}{l}\text { Atraso (lag) } \\
\text { Vel.OPC }\end{array}$ & $\begin{array}{c}02 \mathrm{~h} \\
31.6 \mathrm{~ms}^{-1}\end{array}$ & $\begin{array}{c}03 \mathrm{~h} \\
21.0 \mathrm{~ms}^{-1}\end{array}$ & $\begin{array}{c}03 \\
21.0 \mathrm{~ms}^{-1}\end{array}$ & $\begin{array}{c}06 \\
10.5 \mathrm{~ms}^{-1}\end{array}$ \\
\hline $\begin{array}{l}\text { Radial Ubatuba } \\
(380.3 \mathrm{~km} \text { da referência } \mathbf{\Delta})\end{array}$ & $\begin{array}{l}\text { Atraso (lag) } \\
\text { Vel.OPC }\end{array}$ & $\begin{array}{c}06 \mathrm{~h} \\
17.6 \mathrm{~ms}^{-1}\end{array}$ & $\begin{array}{c}08 \mathrm{~h} \\
13.2 \mathrm{~ms}^{-1}\end{array}$ & $\begin{array}{c}08 \mathrm{~h} \\
13.2 \mathrm{~ms}^{-1}\end{array}$ & $\begin{array}{c}10 \mathrm{~h} \\
10.5 \mathrm{~ms}^{-1}\end{array}$ \\
\hline $\begin{array}{l}\text { Radial Cabo Frio } \\
(693.8 \text { km da referência } \Delta)\end{array}$ & $\begin{array}{l}\text { Atraso (lag) } \\
\text { Vel.OPC }\end{array}$ & $\begin{array}{c}23 \mathrm{~h} \\
8.4 \mathrm{~ms}^{-1}\end{array}$ & $\begin{array}{c}24 \mathrm{~h} \\
8.0 \mathrm{~ms}^{-1}\end{array}$ & $\begin{array}{c}20 \mathrm{~h} \\
9.6 \mathrm{~ms}^{-1}\end{array}$ & $\begin{array}{c}32 \mathrm{~h} \\
6.0 \mathrm{~ms}^{-1}\end{array}$ \\
\hline $\begin{array}{l}\text { PCSE - sul até São Sebastião } \\
(331 \mathrm{~km} \text { da referência } \mathbf{\Delta})\end{array}$ & $\begin{array}{l}\text { Atraso (lag) } \\
\text { Vel.OPC } \\
\end{array}$ & $\begin{array}{c}05 \mathrm{~h} \\
18.4 \mathrm{~ms}^{-1} \\
\end{array}$ & $\begin{array}{c}05 \mathrm{~h} \\
18.4 \mathrm{~ms}^{-1} \\
\end{array}$ & $\begin{array}{c}06 \mathrm{~h} \\
15.3 \mathrm{~ms}^{-1} \\
\end{array}$ & $\begin{array}{c}09 \mathrm{~h} \\
10.2 \mathrm{~ms}^{-1} \\
\end{array}$ \\
\hline $\begin{array}{l}\text { PCSE-norte até Cabo Frio } \\
\text { (362.8 km de São Sebastião ) }\end{array}$ & $\begin{array}{l}\text { Atraso (lag) } \\
\text { Vel.OPC }\end{array}$ & $\begin{array}{c}18 \mathrm{~h} \\
5.6 \mathrm{~ms}^{-1}\end{array}$ & $\begin{array}{c}19 \mathrm{~h} \\
5.3 \mathrm{~ms}^{-1}\end{array}$ & $\begin{array}{c}14 \mathrm{~h} \\
7.2 \mathrm{~ms}^{-1}\end{array}$ & $\begin{array}{c}23 \mathrm{~h} \\
4.9 \mathrm{~ms}^{-1}\end{array}$ \\
\hline
\end{tabular}

da PCSE. No experimento SVT7 (Figura 3.36c) o comprimento médio da onda foi de cerca de $1680 \mathrm{~km}$ e no experimento SVT8 (Figura 3.36 d) de $1810 \mathrm{~km}$, sendo que as OPCs atingiram o sul de Cabo Frio.

Os valores de velocidade de propagação das $\mathrm{OPC} \beta$, presentes na Tabela 3.3 , indicam que as velocidades foram maiores nas radiais ao sul da $\mathrm{PCSE}$ do que as calculadas para o norte. De maneira geral, os maiores valores ocorreram no experimento SVT5 para as radiais Cananéia, Santos e Ubatuba. A radial Cabo Frio apresentou maior velocidade de propagação de onda no experimento SVT7. Avaliando as velocidades de forma setorizada, o sul da PCSE exibiu diminuição da velocidade de propagação a medida em que se aumentou o tempo de permanência das frentes frias na PCSE; a região norte apresentou maior variabilidade nos valores de velocidade, sendo que no experimento SVT7 exibiu velocidade de $7.2 \mathrm{~ms}^{-1}$. Os valores de velocidade de propagação observados no sul da PCSE nos experimentos SVT7 e SVT8 foram próximos dos encontrados por França (2013), de 15 a $11.9 \mathrm{~ms}^{-1}$, dos obtidos por Castro e Lee (1995), de 9 a $10 \mathrm{~ms}^{-1}$ e por Filippo (2003), de $10.9 \mathrm{~ms}^{-1}$.

Com relação a velocidade máxima superficial, a Figura 3.37 indica que a diminuição da velocidade de propagação das frentes frias intensificaram progressivamente as velocidades superficiais ao norte da Ilha de São Sebastião. No experimento SVT5 (Figura 3.37a), as velocidades superficiais ao largo de Cananéia e Santos foram intensificadas e, com a diminuição da velocidade de propagação, a área com velocidades acima de $0.8 \mathrm{~ms}^{-1}$ foi menor nos experimentos seguintes. Em SVT8 (Figura 3.37d) a velocidade máxima alcancada ao largo de Santos foi de cerca de $0.7 \mathrm{~ms}^{-1}$. Contudo a região norte após a Ilha de São Sebastião respondeu positivamente a diminuição da velocidade da frente, sendo que em SVT5 a região da $\mathrm{PCI}] \mathrm{e}$ da $\mathrm{PCM}$ de 

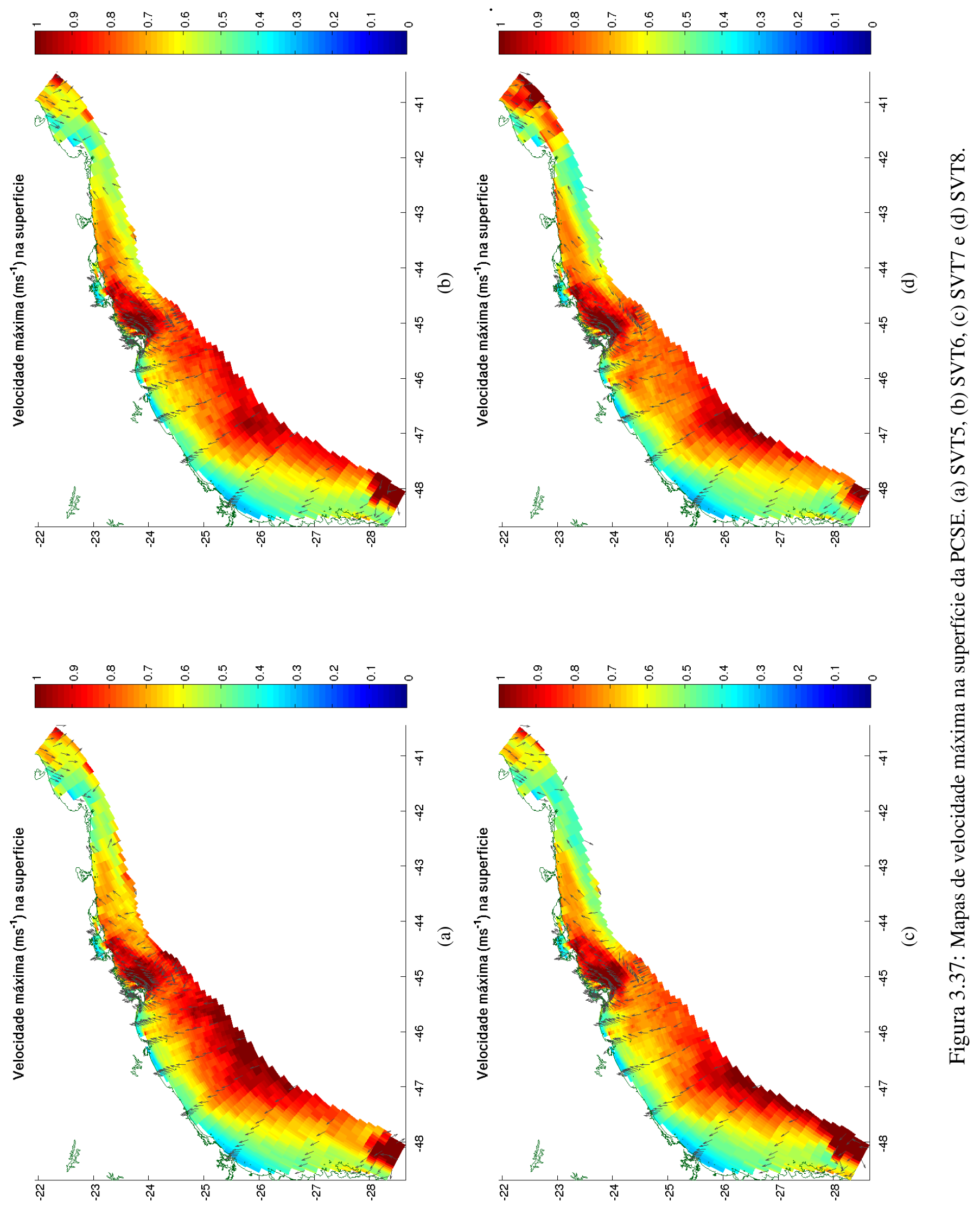
Ilha Grande-RJ apresentou correntes superficiais entre 0.6 a $0.7 \mathrm{~ms}^{-1}$, e em SVT8 o aumento do tempo de permanência das frentes frias promoveram correntes superiores a $0.7 \mathrm{~ms}^{-1}$ até a região da Baía da Guanabara-RJ. Velocidades acima de $0.9 \mathrm{~ms}^{-1}$ foram encontradas ao norte de Cabo Frio no experimento SVT8, contudo a direção da corrente para sudoeste indica que esses valores estão associados as correntes geradas pelos ventos de nordeste oriundos da ASAS

As diferenças da resposta das correntes superficiais à mudança da velocidade de propagação dos ventos entre as regiões sul e norte são melhor visualizadas nas séries temporais das radiais de Santos (Figura 3.38) e Ubatuba (Figura 3.39), nos experimentos SVT5 e SVT8.

Na radial Santos, pouca diferença foi notada nas velocidades da corrente superficial na PCI, onde as inversões do vento promovida pela passagem das frentes frias inverteram a direção da corrente para nordeste, com valores máximos de $0.5 \mathrm{~ms}^{-1}$ tanto em SVT5 (Figura 3.38a) quanto em SVT8 (Figura 3.38p). Na PCM a velocidade máxima foi de $0.6 \mathrm{~ms}^{-1}$ durante a passagem da segunda frente fria no experimento SVT5, enquanto que no experimento SVT8 foi de 0.7 $\mathrm{ms}^{-1}$. Mas foi na PCE que as maiores diferenças foram notadas, onde a frente com propagação de $8.1 \mathrm{~ms}^{-1}$ acarretou correntes superficiais de $0.9 \mathrm{~ms}^{-1}$ durante a passagem da segunda frente, enquanto que frentes se propagando a $5.7 \mathrm{~ms}^{-1}$ no experimento SVT8 acarretaram em correntes de até $0.6 \mathrm{~ms}^{-1}$.

Na radial Ubatuba, a redução da velocidade de propagação da frente em SVT8 (Figura 3.39 ) preservou correntes superficiais acima de $1.0 \mathrm{~ms}^{-1}$ na PCM, embora a PCE tenha mostrado ligeira redução de $0.7 \mathrm{~ms}^{-1}$ no experimento SVT5 (Figura 3.39 a) para $0.65 \mathrm{~ms}^{-1}$ durante a terceira frente no experimento SVT8.

As corrente superficiais apresentaram característica oscilatória após passagem da frente fria, e na Figura 3.38 observa-se que, na radial Santos, as séries temporais da PCM e da PCE apresentaram ondulações com período entre 27 horas, assim como a PCE de Ubatuba (Figura 3.39).

No que se refere as mudanças causadas pela diferença do tempo de propagação da frente fria na estrutura vertical da velocidade, em Santos a estrutura da corrente pouco se alterou, e a componente perpendicular à costa (componente $U$ ) preservou velocidades acima de $0.6 \mathrm{~ms}^{-1}$ na superfície da PCE, decrescendo em intensidade até atingir $0.2 \mathrm{~ms}^{-1}$ na profundidade de 30 metros, como pode ser visto na Figura 3.40.

Considerando que nos experimentos descritos na Seção 3.3.1 as velocidades na radial Santos aumentaram progressivamente até que em SVT4, com $9.5 \mathrm{~ms}^{-1}$ de velocidade de propagação de frente, foram encontrados valores de velocidade perpendicular superiores a $0.8 \mathrm{~ms}^{-1}$ na PCE, na isóbata de 100 metros. A diminuição da velocidade de propagação da frente entre os experimentos SVT5 e SVT6 reduziram a velocidade da componente perpendicular para $0.6 \mathrm{~ms}^{-1}$. A partir do experimento SVT6 os valores de velocidade perpendicular se manteram praticamente inalterados, indicando que a transferência de energia pelo cisalhamento do vento possui um limite, não aumentando mais independentemente do aumento do tempo de permanência da frente.

Segundo Coelho (2007), a velocidade média do vento de um sistema frontal no verão é 

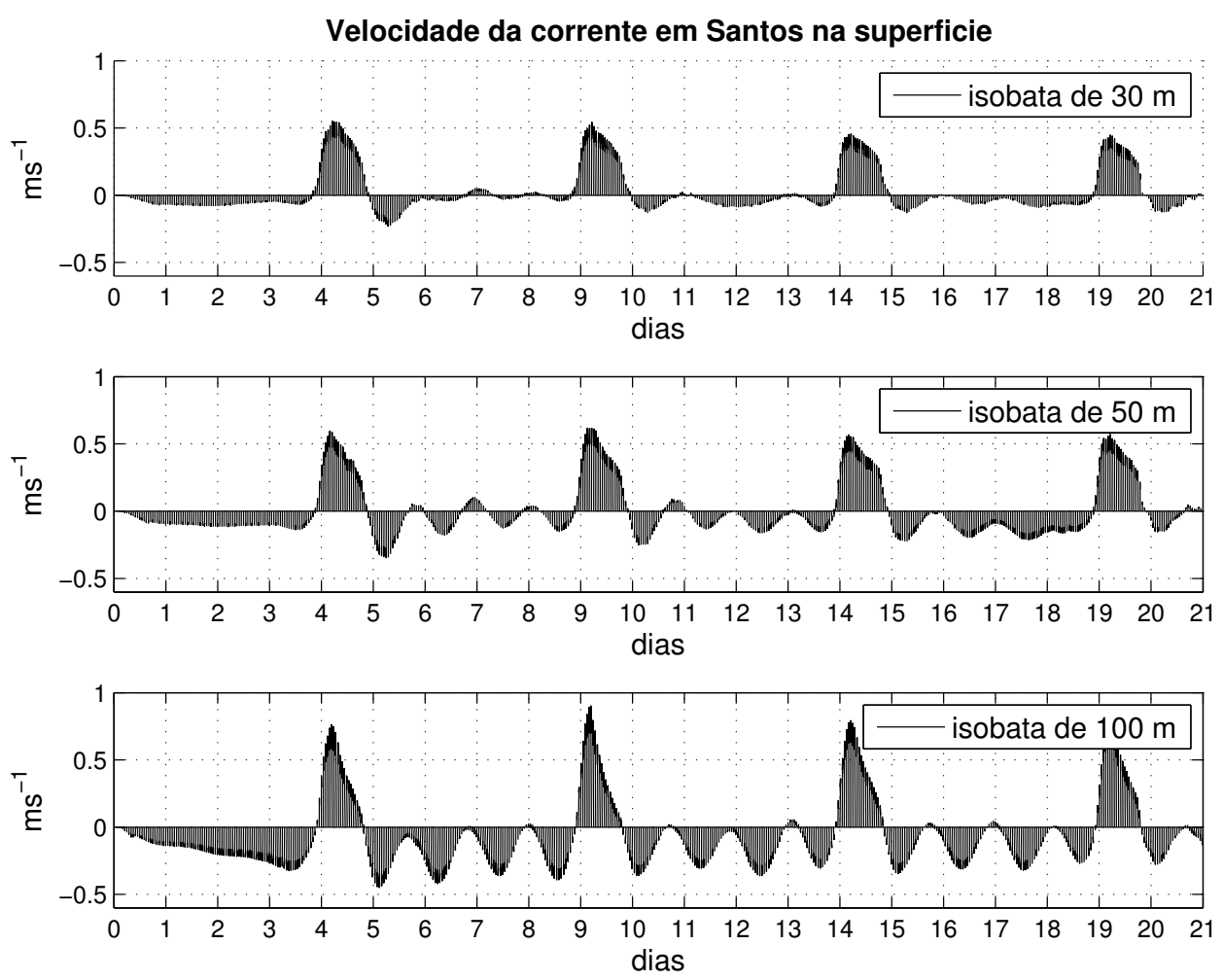

(a)
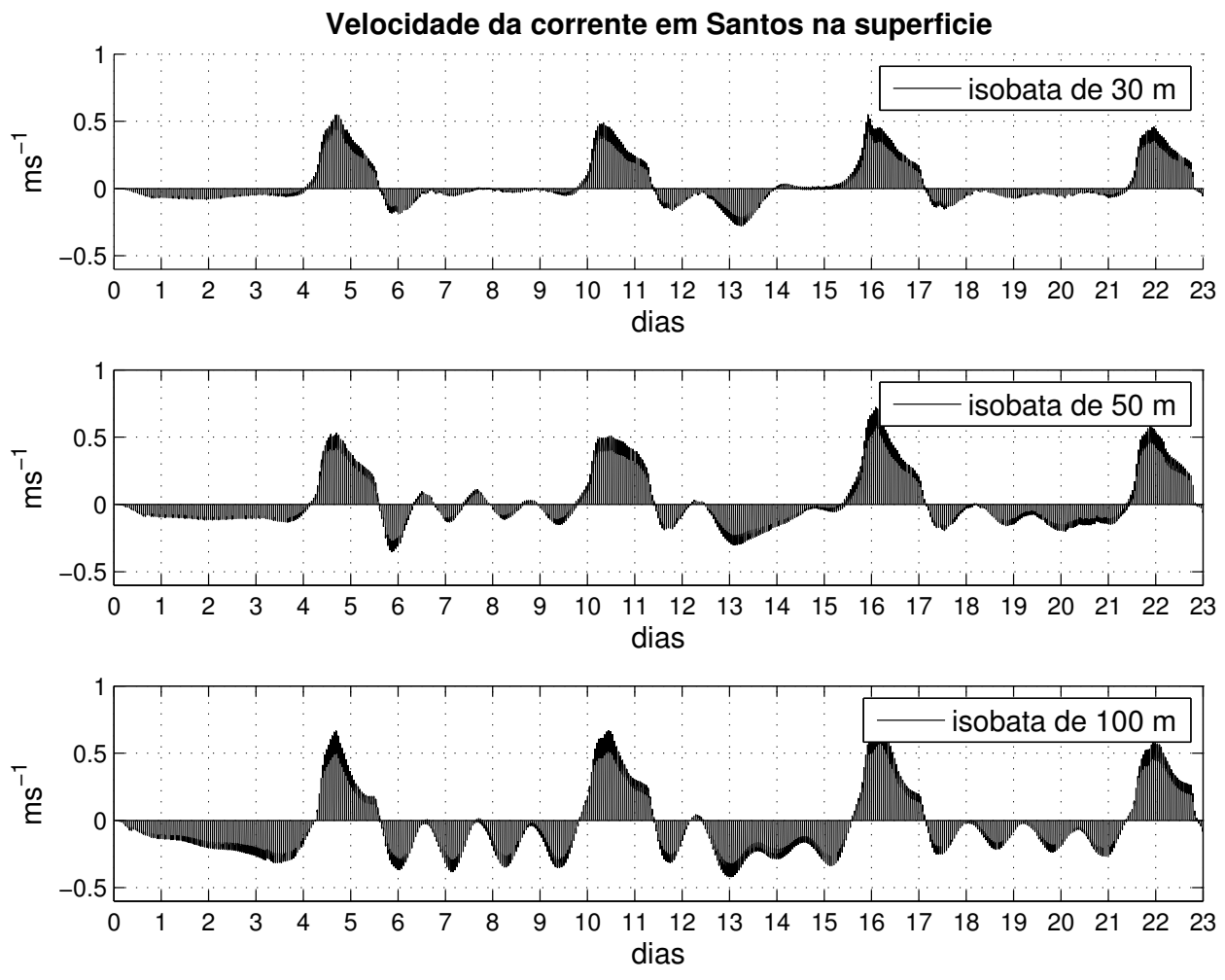

(b)

Figura 3.38: Séries temporais de velocidade na superfície na radial Santos nos experimentos (a) SVT5 e (b) SVT8. 

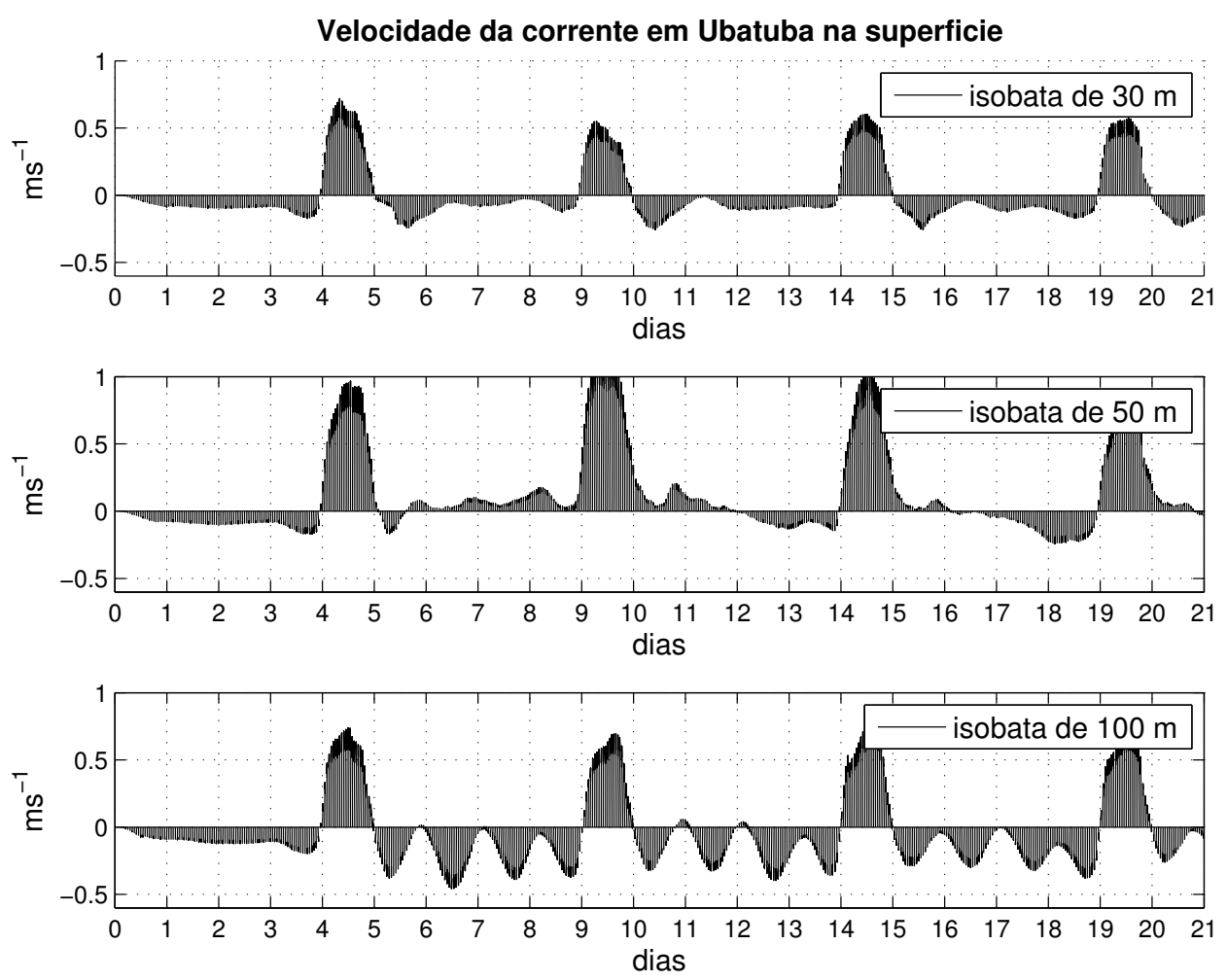

(a)
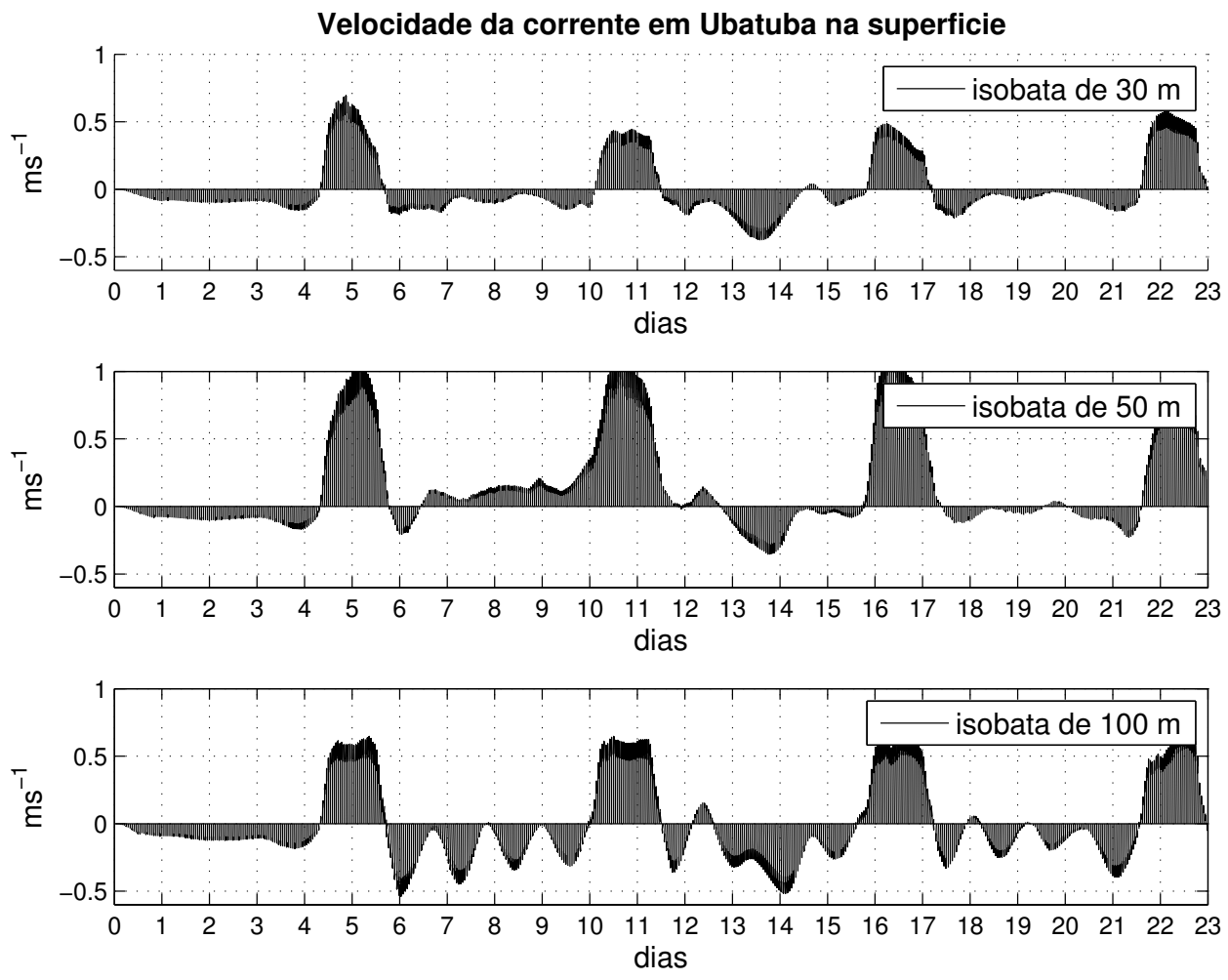

(b)

Figura 3.39: Séries temporais de velocidade na superfície na radial Ubatuba nos experimentos (a) SVT5 e (b) SVT8. 

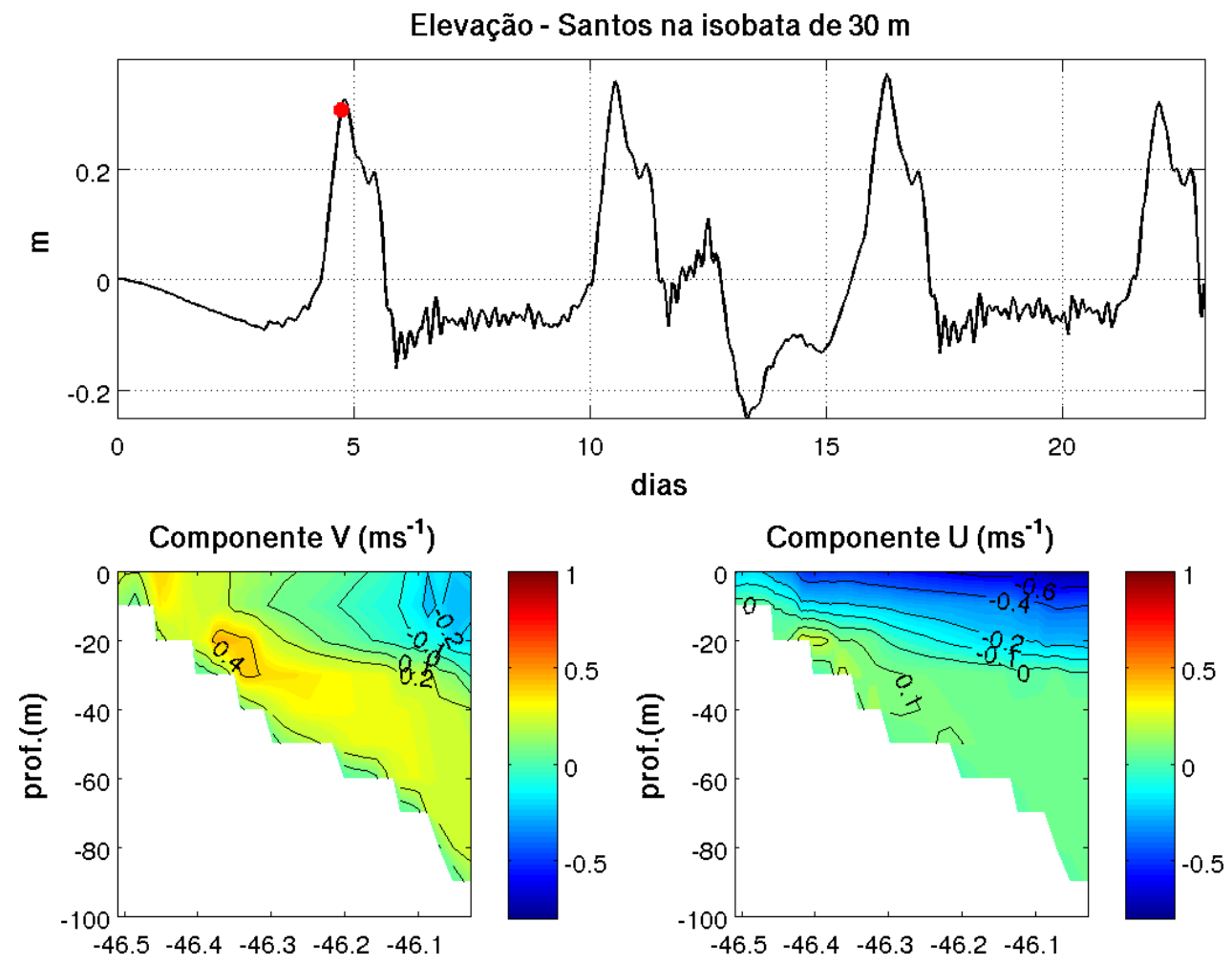

Figura 3.40: Série temporal de elevação e perfis verticais de velocidade perpendicular (U) e paralela (V) na radial Santos no experimentos SVT8.
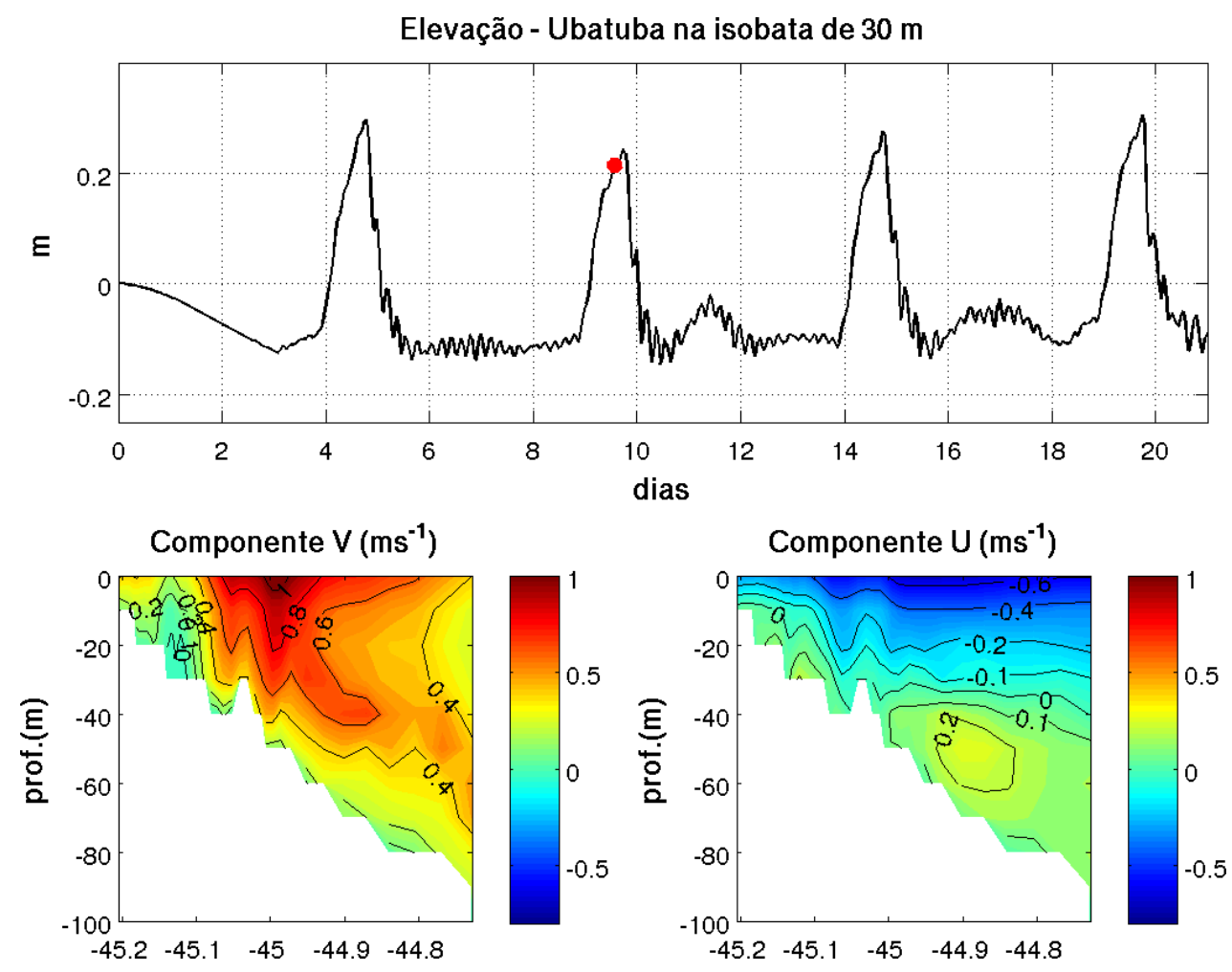

Figura 3.41: Série temporal de elevação e perfis verticais de velocidade perpendicular (U) e paralela (V) na radial Ubatuba no experimentos SVT5. 
cerca de $9 \mathrm{~ms}^{-1}$, próxima a velocidade de propagação dos sistemas frontais em SVT4, e a ação combinada desses dois fatores promoveram a ampliação máxima da corrente na região, apresentando ressonância com frentes com velocidade de propagação nesse intervalo.

Em Ubatuba as estruturas verticais da corrente pouco alteraram entre experimentos de STV5 e SVT8. Contudo, no experimento SVT5 a radial Ubatuba apresentou componente paralela acima de $1.0 \mathrm{~ms}^{-1}$ durante a passagem da segunda frente fria (Figura 3.41), e nos demais experimentos a componente paralela ficou em $0.6 \mathrm{~ms}^{-1}$, sugerindo que as correntes da região de Ubatuba foram ressonantes com as frentes frias do experimento SVT5, com velocidade de propagação de $8.1 \mathrm{~ms}^{-1}$.

\subsubsection{Frentes com tempo de permanência superior a 60 horas na PCSE}

Na Figura 3.42 observa-se que no experimento SVT9, com 66 horas de permanência das frentes e velocidade de propagação de $5.2 \mathrm{~ms}^{-1}$, a elevação máxima observada na PCI de Cananéia foi da ordem dos $0.5 \mathrm{~m}$ na $\mathrm{PCI}, 0.4 \mathrm{~m}$ em Santos e $0.3 \mathrm{em}$ Ubatuba. Na região da Baía de Guanabara-RJ as elevações foram entre 0.2 e $0.1 \mathrm{~m}$ e em Cabo Frio acima de zero. No experimento SVT10, com 72 horas de frente e propagação de cerca de $4.7 \mathrm{~ms}^{-1}$, as elevações diminuíram na PCI de Cananéia para $0.4 \mathrm{~m}$, e as demais localidades preservaram as elevações do experimento anterior.

Comparando as elevações máximas encontradas em SVT10 com o seu experimento correspondente de vento remoto RS4 (Figura 3.9d da Seção 3.2), com 72 horas de permanência da frente no sul da PCSE, foi notado que o vento remoto elevou a superfície do mar entre 0.1 a 0.2 $\mathrm{m}$ de Cananéia até Cabo Frio. Isso pode indicar que as elevações observadas no experimento SVT10 são respostas da combinação do vento remoto e vento local.

Observando as séries temporais de elevação nos experimentos SVT9 e SVT10, apesar das elevações terem diminuído na radial Cananéia e radial Santos, essa última apresentando $0.4 \mathrm{~m}$ em SVT9 e 0.37 m em SVT10 (Figura $3.43 \mathrm{a}-\mathrm{c}$ ), a radial Cabo Frio apresentou um aumento de mesma proporção, antes de $0.05 \mathrm{~m}$ em SVT9 para $0.08 \mathrm{~m}$ em SVT10 (Figura $3.43 \mathrm{~b}-\mathrm{d}$ ).

Em linhas gerais, os resultados de elevação do nível do mar dos experimentos SVT1 ao experimento SVT10 indicaram que a alteração do tempo de ação das frentes aumentou as elevações do nível do mar, e as mudanças mais expressivas são observadas na parte norte do domínio. Contudo, a região da PCI de Cananéia apresentou aumentos progressivos durante os experimentos até que atingiu valor máximo no experimento SVT9, acima de $0.5 \mathrm{~m}$, mas no experimento SVT10 as elevações diminuíram. Esse declínio observado no experimento SVT10 indica que o experimento SVT9 apresentou empilhamento máximo de água em Cananéia, e o nível do mar não aumentou mais mesmo com o aumento do tempo de permanência da frente para 72 horas.

Analisando os mapas de correlação do nível do mar apresentados na Figura 3.44, a diminuição da velocidade de propagação entre os experimentos SVT9 e SVT10 não alterou os valores 


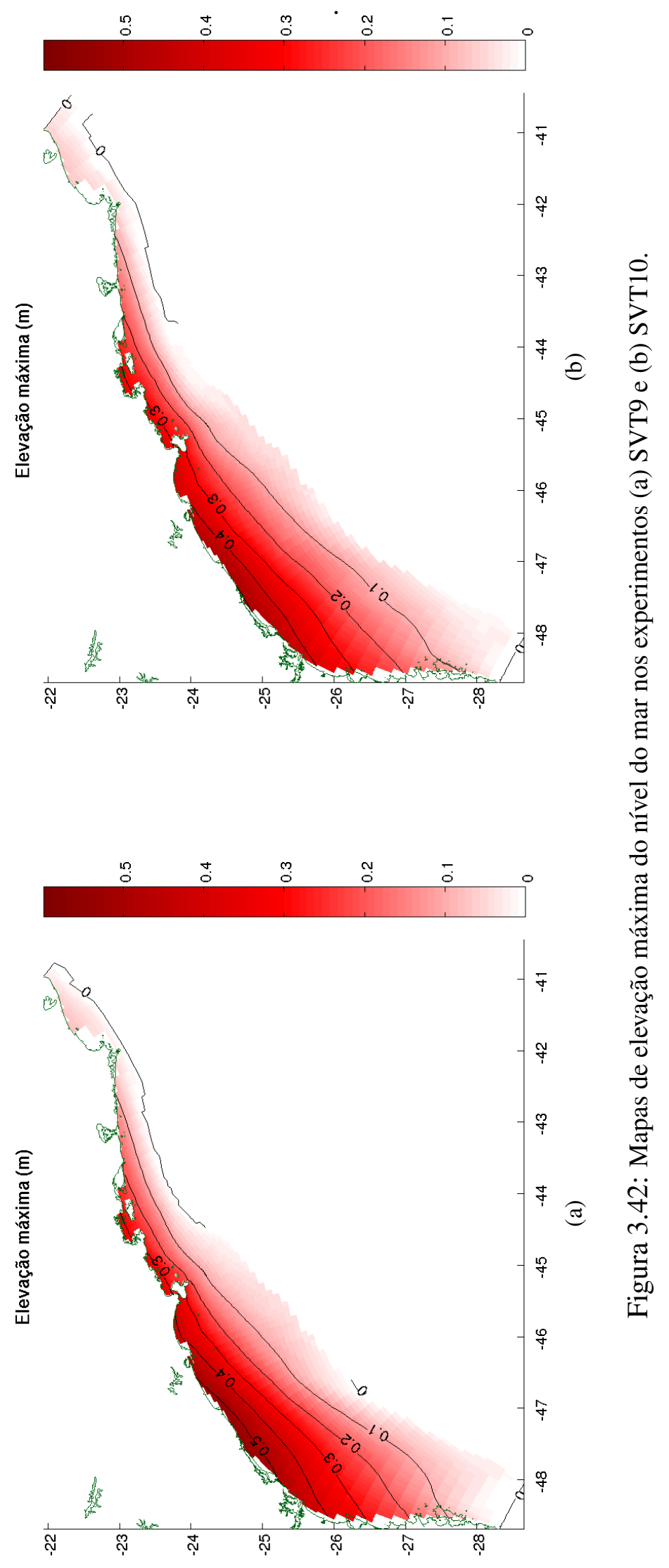



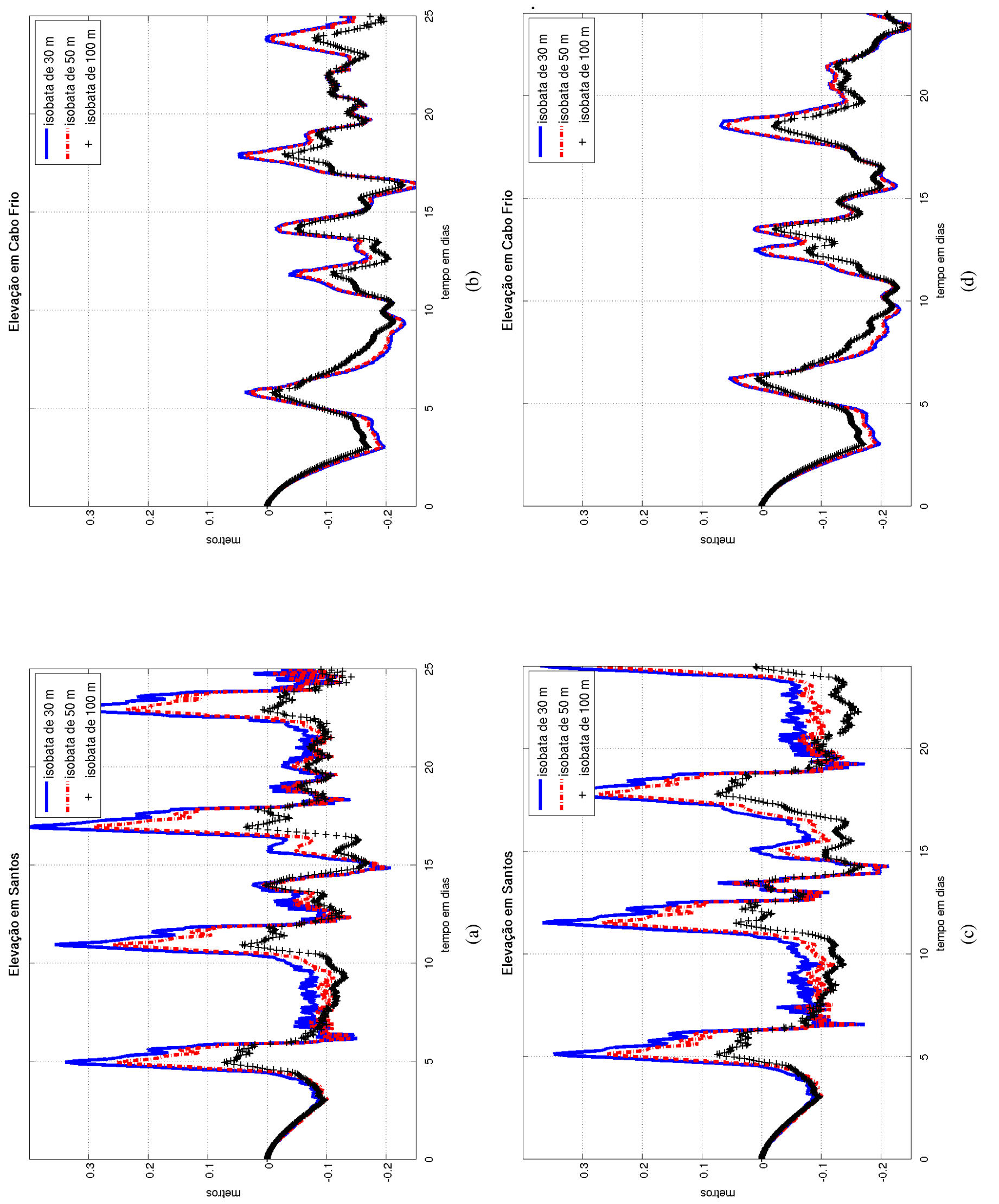

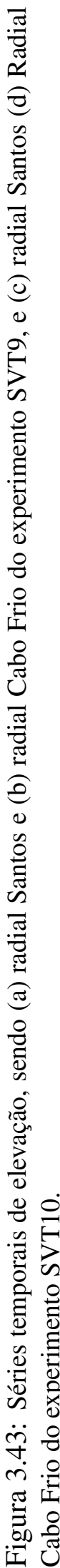




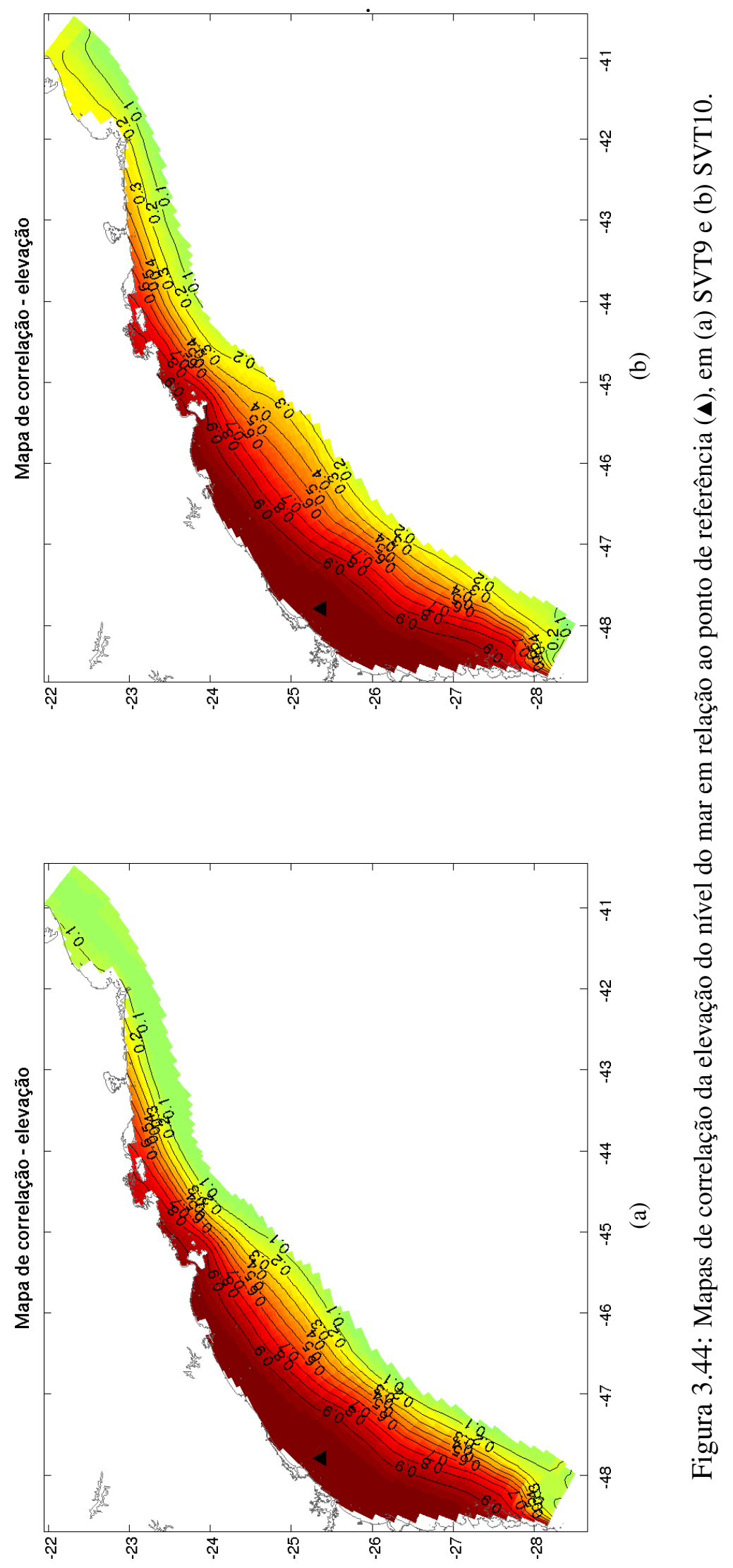


de correlação na PCI e $\overline{\mathrm{PCM}}$ ao sul da Ilha de São Sebastião. Um pequeno aumento da correlação na $\overline{\mathrm{PCI}}$ de Cabo Frio, mesmo que insignificante, foi observada, de 0.1 para 0.2. A correlação obtida em SVT10 é menor que a obtida em RS4 para Cabo Frio, que foi de 0.3 (Figura 3.11d da Seção 3.2. Considerando que em RS4 a correlação é para a variação do nível do mar frente a um vento remoto, pode-se sugerir que a diminuição da correlação ao norte de Cabo Frio pode estar associada a ação do vento local associada ao sinal remoto do vento.

Em relação a correlação de elevação dos experimentos anteriores, o experimento SVT1 foi o que apresentou maiores valores de correlação em toda a PCSE principalmente na região norte do domínio computacional e, apesar da correlação ter ligeiramente aumentado no experimento SVT8, apresentando valores entre 0.3 e 0.2 na região de Cabo Frio, não foi possível estabelecer uma relação clara entre a variação do tempo de permanência da frente da região e o aumento/redução dos valores de correlação.

Entretanto, os maiores valores de correlação em SVT1 coincidem com as maiores oscilações de alta frequência observadas em Cananéia após a passagem da frente fria. A amplitude das oscilações diminuíram a medida que a OPC atingiu latitudes menores e a medida que se aumentou o tempo de permanência das frentes frias nos experimentos subsequentes, principalmente na região sul da PCSE.

Analisando as OPCs quanto ao comprimento e velocidade de propagação, a Figura 3.45 apresenta o diagrama Hovmöller de altura do nível do mar na costa da PCSE durante os experimentos SVT9 e SVT10. Os valores de elevação foram filtrados para a eliminação das elevações suprainerciais, e por isso os diagramas exibem valores de altura do nível do mar bem abaixo dos apresentados nos mapas de elevação máxima e nas séries temporais de elevação.

É possível observar que no experimento SVT9 a crista da primeira OPC atingiu uma distância de 910 km do limite sul da PCSE, surgindo nas proximidades da região de Cabo Frio. A cava da onda surgiu horas depois, a $110 \mathrm{~km}$ do limite sul da PCSE, sendo possível calcular um comprimento de onda de cerca de $1710 \mathrm{~km}$. No experimento SVT10 (Figura 3.45b), comprimento médio da OPC foi de cerca $1750 \mathrm{~km}$, atingindo a região de Cabo Frio.

Considerando a velocidade de propagação da OPC de forma discriminada, a Tabela 3.4 apresenta os valores de atraso da correlação do nível do mar e a velocidade de propagação da onda em cada uma das radiais. Com base nos diagramas de Hovmöller de elevação do nível do mar e da tabela de velocidades de propagação, pode-se atribuir que o aumento do tempo de permanência das frentes frias entre o experimentos SVT9 e SVT10 acarretou no aumento do comprimento da OPC, enquanto que as velocidades de propagação aumentaram ligeiramente ao norte da $\mathrm{PCSE}$, onde a OPC percorreu a distância entre o ponto de referência até Cabo Frio com velocidade de propagação de 8.0 para $8.4 \mathrm{~ms}^{-1}$.

A Figura 3.46 apresenta os resultados de velocidade superficial máxima nos experimentos SVT9 e SVT10, onde é possível observar que ao norte da Ilha de São Sebastião as correntes superficiais se intensificaram em SVT10, ficando acima de $0.8 \mathrm{~ms}^{-1}$ na PCI e PCM de Ubatuba a Ilha Grande, no Rio de Janeiro. Ao largo da Baía de Guanabara e na PCI de Cabo Frio as 

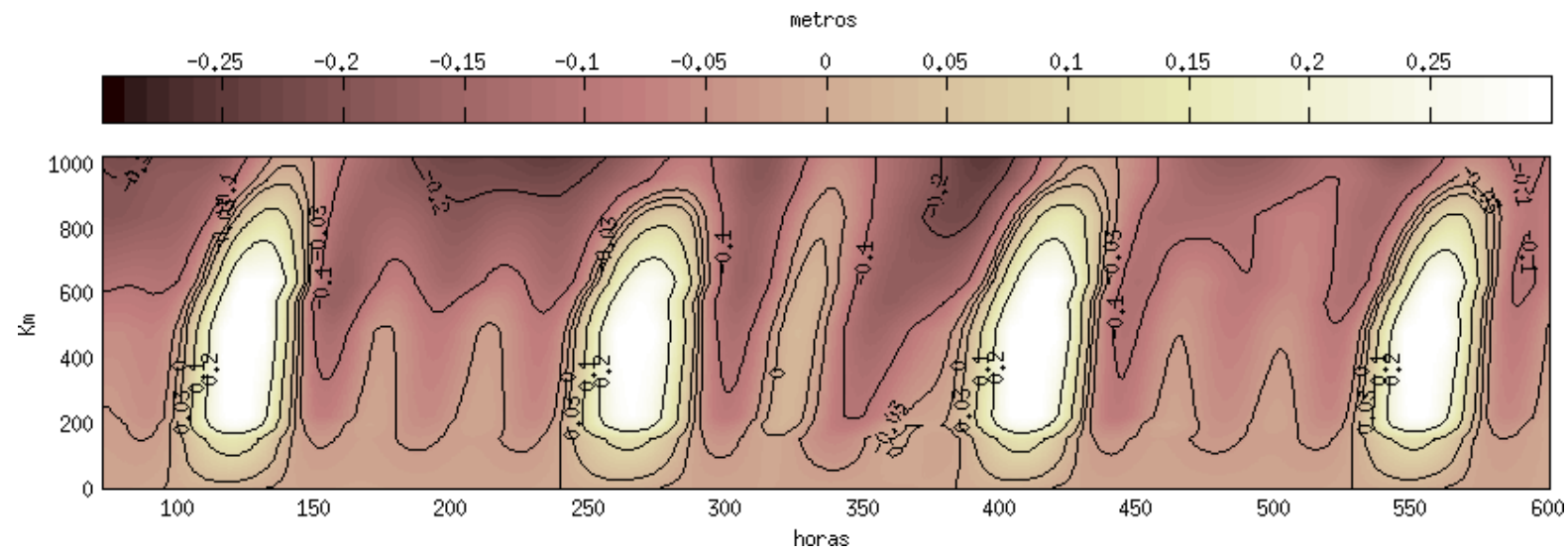

(a)

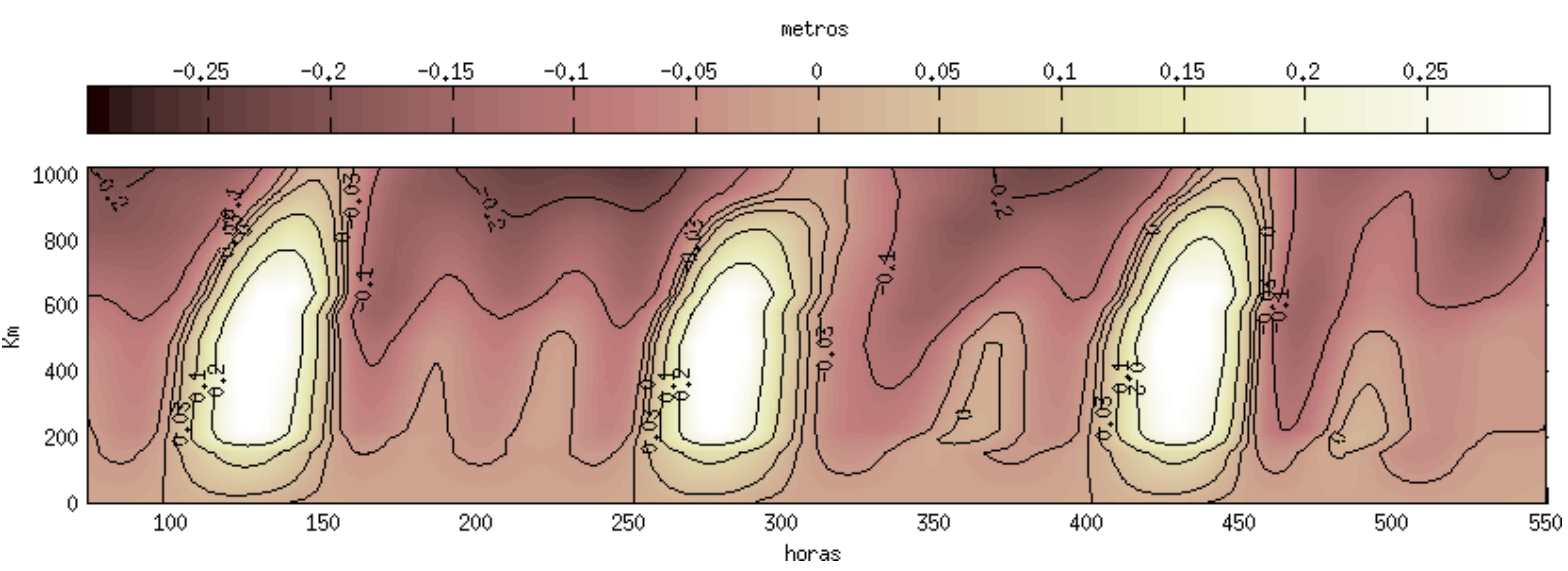

(b)

Figura 3.45: Isopletas de elevação da Onda de Plataforma Continental, nos experimentos (a) SVT9 e (b) SVT10. Dados filtrados em 40 horas.

Tabela 3.4: Relação dos valores de atraso da correlação e velocidade de propagação da Onda de Plataforma Continental, nos experimentos SVT9 e SVT10.

\begin{tabular}{|c|c|c|c|}
\hline & & SVT9 & SVT10 \\
\hline $\begin{array}{l}\text { Radial Cananéia } \\
\text { (66.9 km da referência } \mathbf{\Delta})\end{array}$ & $\begin{array}{l}\text { Atraso (lag) } \\
\text { Vel.OPC }\end{array}$ & $\begin{array}{c}02 \mathrm{~h} \\
9.3 \mathrm{~ms}^{-1}\end{array}$ & $\begin{array}{c}02 \mathrm{~h} \\
9.3 \mathrm{~ms}^{-1}\end{array}$ \\
\hline $\begin{array}{l}\text { Radial Santos } \\
(227.4 \mathrm{~km} \text { da referência } \Delta)\end{array}$ & $\begin{array}{l}\text { Atraso (lag) } \\
\text { Vel.OPC }\end{array}$ & $\begin{array}{c}04 \\
15.8 \mathrm{~ms}^{-1}\end{array}$ & $\begin{array}{c}04 \\
15.8 \mathrm{~ms}^{-1}\end{array}$ \\
\hline $\begin{array}{l}\text { Radial Ubatuba } \\
\text { (380.3 km da referência } \Lambda \text { ) }\end{array}$ & $\begin{array}{l}\text { Atraso (lag) } \\
\text { Vel.OPC }\end{array}$ & $\begin{array}{c}09 \mathrm{~h} \\
11.7 \mathrm{~ms}^{-1}\end{array}$ & $\begin{array}{c}09 \mathrm{~h} \\
11.7 \mathrm{~ms}^{-1}\end{array}$ \\
\hline $\begin{array}{l}\text { Radial Cabo Frio } \\
\text { (693.8 km da referência } \Delta \text { ) }\end{array}$ & $\begin{array}{l}\text { Atraso (lag) } \\
\text { Vel.OPC }\end{array}$ & $\begin{array}{c}24 \mathrm{~h} \\
8.0 \mathrm{~ms}^{-1} \\
\end{array}$ & $\begin{array}{c}23 \mathrm{~h} \\
8.4 \mathrm{~ms}^{-1}\end{array}$ \\
\hline $\begin{array}{l}\text { PCSE - sul até São Sebastião } \\
(331 \mathrm{~km} \text { da referência } \mathbf{\Delta})\end{array}$ & $\begin{array}{l}\text { Atraso (lag) } \\
\text { Vel.OPC }\end{array}$ & $\begin{array}{c}06 \mathrm{~h} \\
15.3 \mathrm{~ms}^{-1} \\
\end{array}$ & $\begin{array}{c}06 \mathrm{~h} \\
15.3 \mathrm{~ms}^{-1} \\
\end{array}$ \\
\hline $\begin{array}{l}\text { PCSE-norte até Cabo Frio } \\
\text { (362.8 km de São Sebastião ) }\end{array}$ & $\begin{array}{l}\text { Atraso (lag) } \\
\text { Vel.OPC }\end{array}$ & $\begin{array}{c}18 \mathrm{~h} \\
5.6 \mathrm{~ms}^{-1}\end{array}$ & $\begin{array}{c}17 \mathrm{~h} \\
5.9 \mathrm{~ms}^{-1}\end{array}$ \\
\hline
\end{tabular}


correntes superficiais foram de $0.7 \mathrm{~ms}^{-1}$. Valores de corrente superficial acima de $1.0 \mathrm{~ms}^{-1}$ foram observados em ambos os experimentos na face externa da Ilha de São Sebastião e na PCE ao norte de Cabo Frio. Em SVT10 a região da PCE ao largo da Ilha de São Sebastião também apresentou valores acima de $1.0 \mathrm{~ms}^{-1}$.

No que se refere a direção da corrente superficial máxima a região sul da PCSE, do Paraná a São Sebastião, em ambos os experimentos a direção predominante das correntes máximas foi norte-nordeste, indicando que a corrente máxima apresentada está relacionada com os ventos de sul-sudoeste típicos de frentes frias. Já na região norte da PCSE as maiores velocidades superficiais ao largo da Ilha de São Sebastião estão associadas as frentes frias, mas ao norte de Cabo Frio as correntes mais energéticas foram para sudoeste, estando relacionadas com as correntes geradas pelo cisalhamento dos ventos da Alta Subtropical do Atlântico Sul. Devido a imposição climatógica de verão na PCSE de temperatura e salinidade nos experimentos, é possível que os campos de densidade representem a estrutura baroclínica da Corrente do Brasil, podendo influenciar no movimento e intensificação de correntes, de superfície e subsuperfície, para sudoeste nesta região.

$\mathrm{Na}$ PCE ao largo de São Sebastião no experimento SVT10, as correntes superficiais máximas apresentaram direção para sudoeste, podendo estar associadas tanto ao sinal da Corrente do Brasil e o cisalhamento do ventos da ASAS quanto ao ajuste oscilatório da corrente após a passagem da frente fria, como observado nos experimentos anteriores.

As Figura 3.47 e Figura 3.48 apresentam as séries temporais de velocidade superficial em Ubatuba nos experimento SVT9 e SVT10, respectivamente, radial mais próxima da região de São Sebastião, e podem elucidar a questão das correntes mais energéticas possuírem sentido oposto ao vento de frente fria ao largo da Ilha de São Sebastião.

Analisando os dois experimentos foi notado, assim como a maioria dos experimentos analisados anteriormente, que na PCM (isóbata de 50 metros) a corrente superficial alcançou velocidade acima de $1.0 \mathrm{~ms}^{-1}$ no experimento SVT9 (Figura 3.47). Na PCE, isóbata de 100 metros, após a passagem da primeira frente fria no dia 5, e consequente mudança na direção da corrente, a mesma apresentou oscilação natural com período inercial e velocidade de $0.51 \mathrm{~ms}^{-1}$ para sudoeste, valor muito próximo do observado durante a passagem da OPC de $0.55 \mathrm{~ms}^{-1}$. Logo pode-se verificar que há momentos em que, a após a inversão da corrente devido a passagem do sistema frontal na região, as oscilações inerciais podem promover uma corrente com igual intensidade, mas em sentido oposto.

Cabe salientar que durante a passagem da segunda frente fria, no dia 11, coincidiu com uma crista da oscilação inercial, o que fez a corrente aumentar para $0.6 \mathrm{~ms}^{-1}$. Essa característica oscilatória exibida pela corrente também foi observada na passagem da terceira e quarta frente fria, e em todas é possível observar o aumento da velocidade da corrente durante a passagem da frente fria devido a passagem das oscilações inerciais.

O experimento SVT10 (Figura 3.48) exibiu maiores velocidades superficiais do que as observadas no experimento SVT9, sendo que na isobata de 100 metros a passagem da primeira 


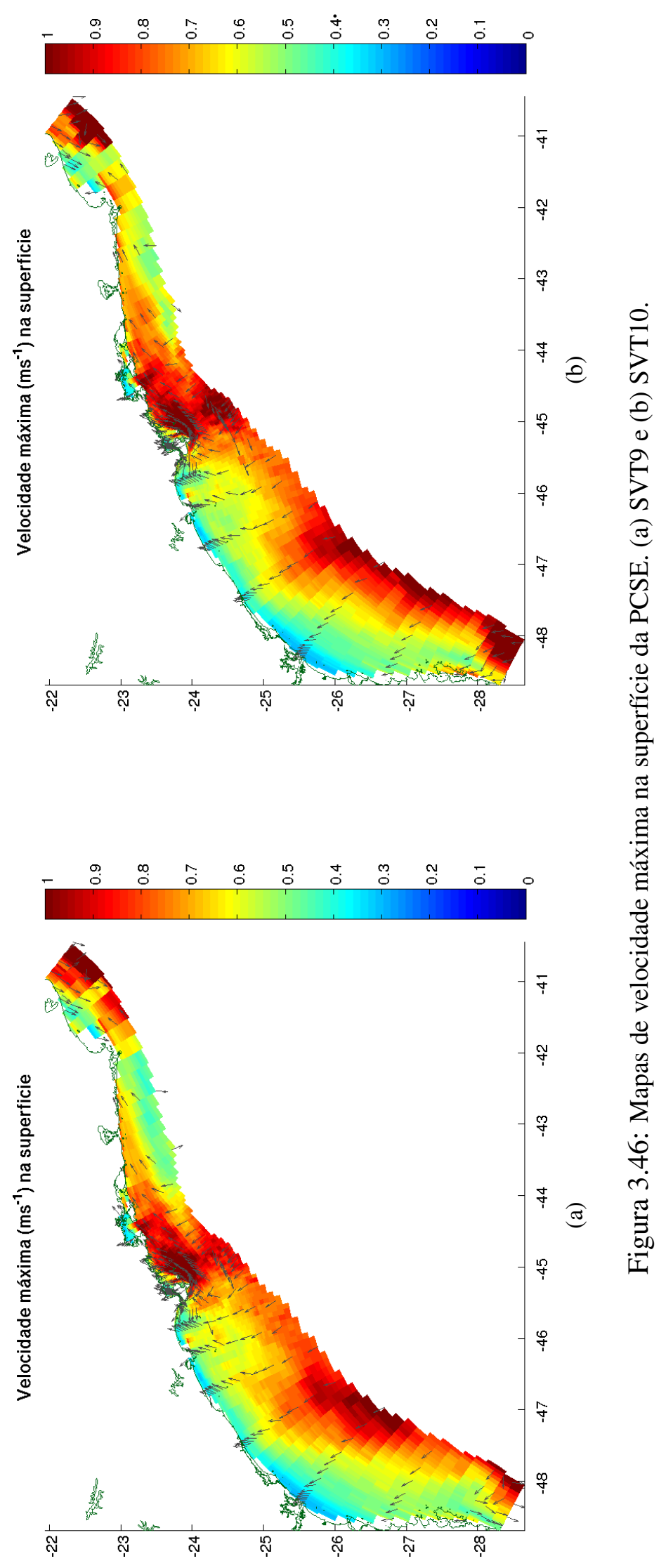



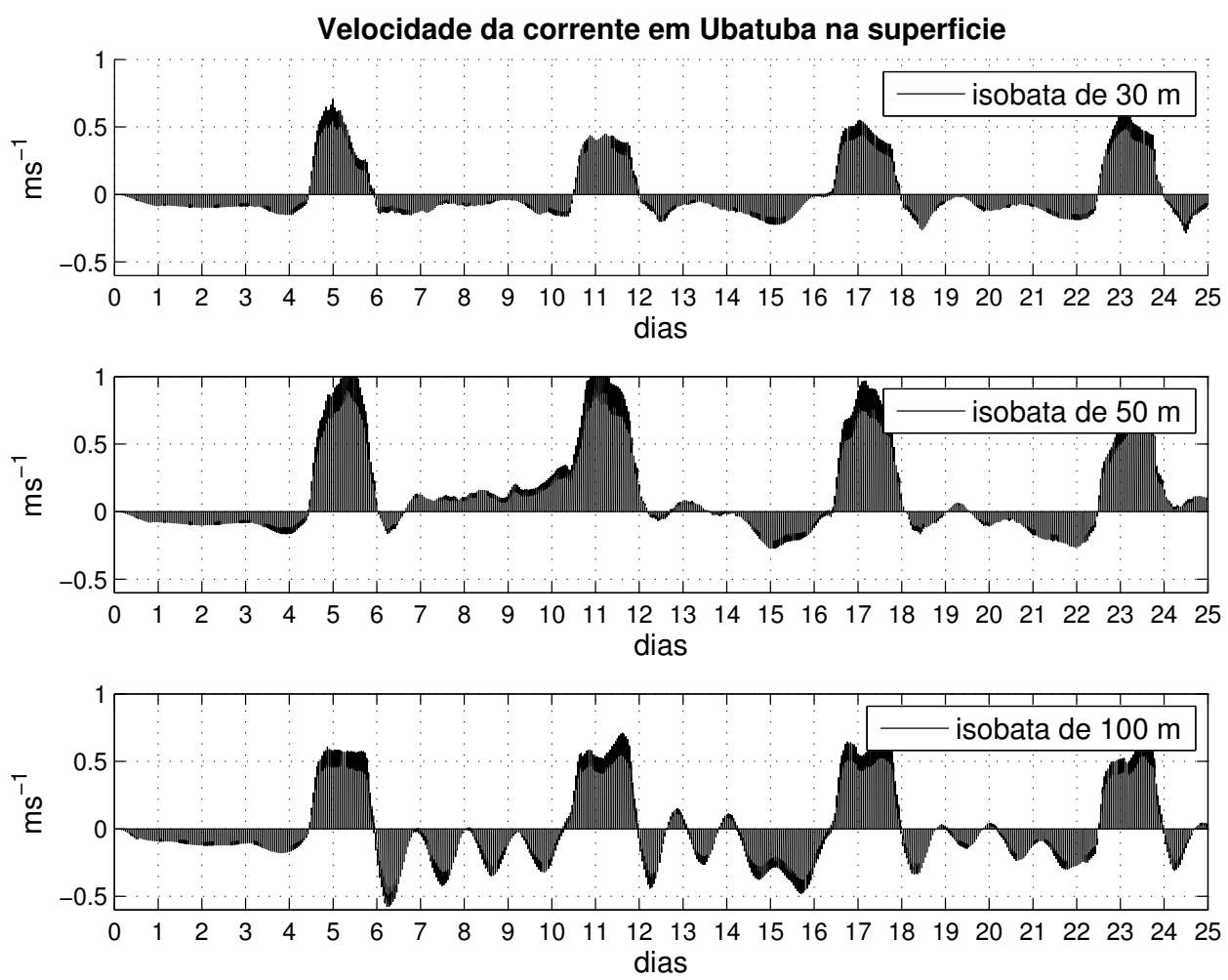

Figura 3.47: Séries temporais de velocidade na superfície na radial Ubatuba, experimento SVT9.
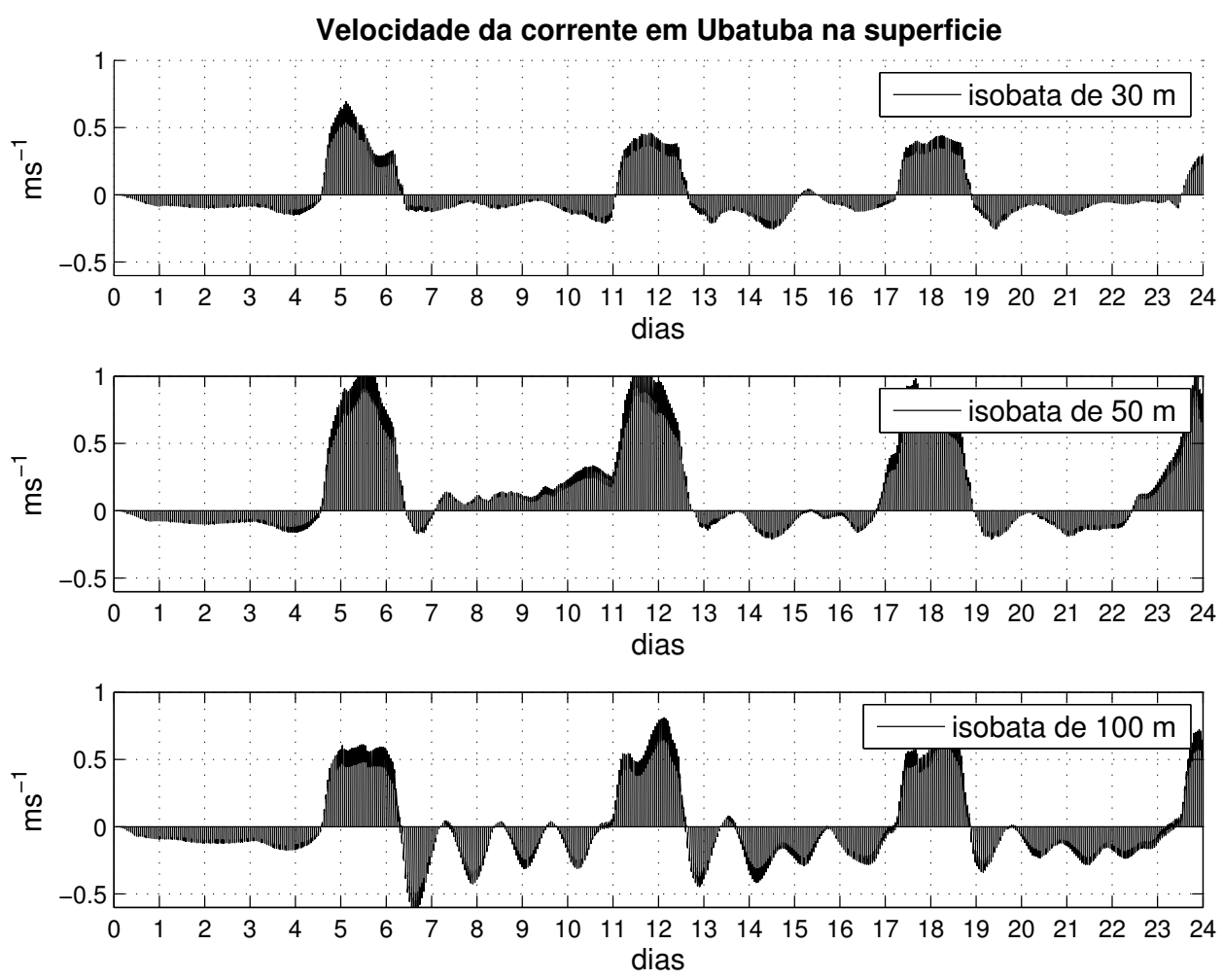

Figura 3.48: Séries temporais de velocidade na superfície na radial Ubatuba, experimento SVT10. 

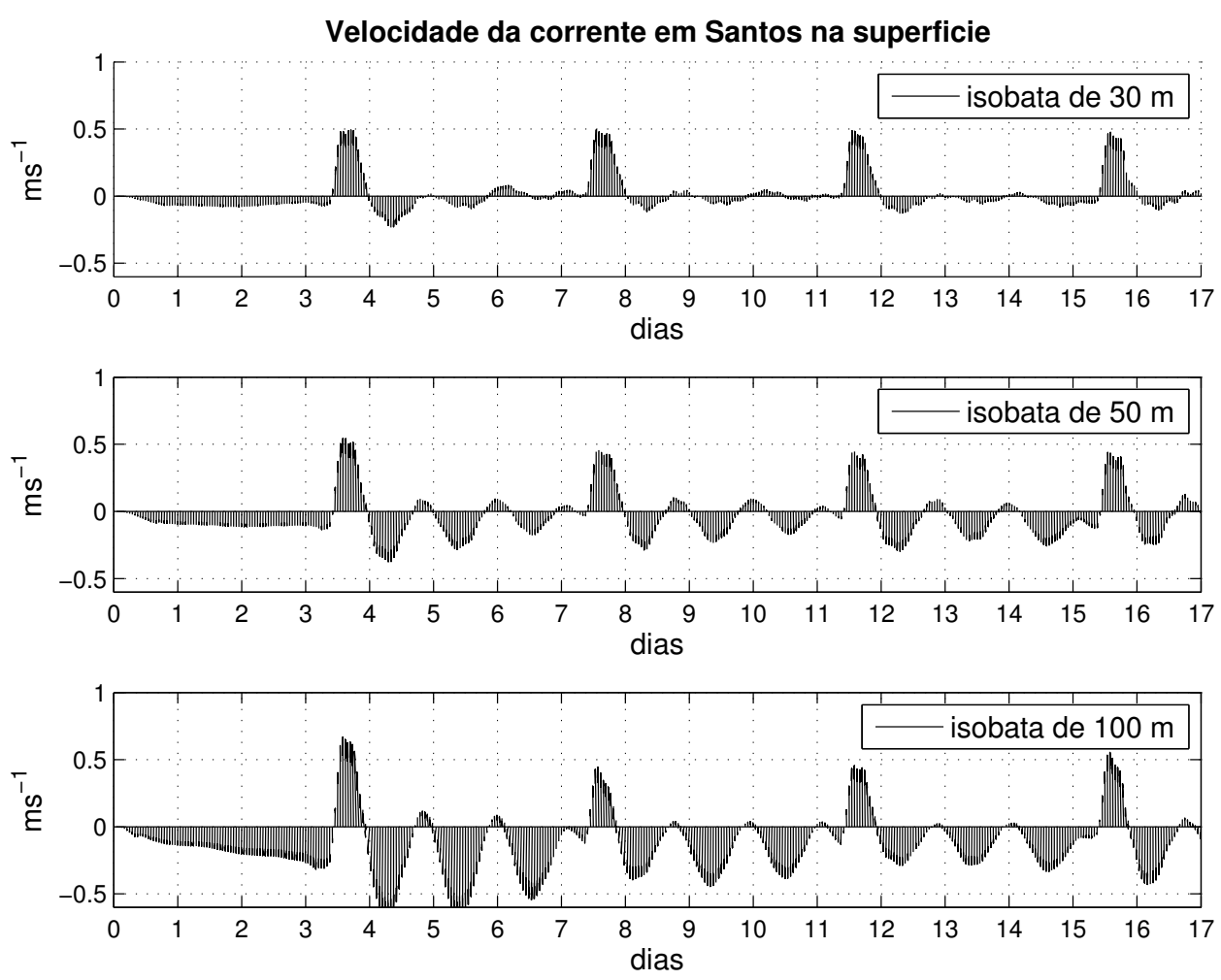

Figura 3.49: Séries temporais de velocidade na superfície na radial Ubatuba, experimento SVT1.

frente fria acarretou em uma corrente de sudoeste de $0.52 \mathrm{~ms}^{-1}$ e as oscilações inerciais subsequentes com corrente máxima de nordeste de cerca de $0.6 \mathrm{~ms}^{-1}$ entre os dias 6 e 7 . Aqui vemos um exemplo da oscilação inercial ser maior que a inversão da corrente devido a passagem da frente fria. Tal fato pode justificar as correntes mais intensas para sudoeste ao largo de São Sebastião, que podem estar associadas às oscilações inerciais da corrente mais intensas.

Assim como observado no experimento SVT9, a corrente superficial na PCEdo experimento SVT10 exibiu oscilações com período de 30.4 horas.

Do experimento SVT1 ao experimento SVT10 foram observadas que as oscilações naturais da corrente variaram entre as radiais de Cananéia, Santos, Ubatuba e Cabo Frio em período e amplitude, esta última possuindo maior variabilidade entre os experimentos. Foi constatado que a oscilação, considerada como oscilação inercial, foi capaz de aumentar ou reduzir a velocidade da corrente gerada pelo vento subnercial.

Um exemplo de redução da amplitude da velocidade corrente de sudoeste pode ser observada na Figura 3.49, que apresenta a série temporal da radial de Santos no experimento SVT1. $\mathrm{Na}$ isóbata de 100 metros, a primeira inversão da corrente entre os dias 3 e 4 alcançou amplitude de $0.65 \mathrm{~ms}^{-1}$ e a segunda inversão, entre os dias 7 e 8 , que coincidiu com o início da cava da oscilação inercial antecedente, com período de 28.8 horas, atingiu valor próximo a $0.4 \mathrm{~ms}^{-1}$. A terceira inversão, entre os dias 11 e 12, também coincidiu com uma cava de uma oscilação inercial e apresentou resultados abaixo do calculado na primeira inversão da corrente, que não foi influenciada com oscilações anteriores. 
Tabela 3.5: Dados de período inercial médio, variância e desvio padrão calculados para a PCI, PCM e PCE, em horas, nas radiais Cananéia, Santos, Ubatuba e Cabo Frio.

\begin{tabular}{ll|c|c|c}
\hline \hline & & média $[\bar{x}]$ & variância $\left[\sigma^{2}\right]$ & desvio padrão $[\operatorname{std}(x)]$ \\
\hline \hline \multirow{4}{*}{ Radial Cananéia } & PCI & 28.3 & 0.011 & 0.11 \\
& PCM & 27.8 & 0.017 & 0.13 \\
& PCE & 27.3 & 0.022 & 0.15 \\
\hline \multirow{3}{*}{ Radial Santos } & PCI & 29.2 & 0.013 & 0.11 \\
& PCM & 28.6 & 0.059 & 0.24 \\
& PCE & 27.9 & 0.022 & 0.15 \\
\hline \multirow{3}{*}{ Radial Ubatuba } & PCI & 29.9 & 0.005 & 0.07 \\
& PCM & 29.6 & 0.014 & 0.12 \\
& PCE & 29.2 & 0.007 & 0.08 \\
\hline \multirow{2}{*}{ Radial Cabo Frio } & PCI & 30.7 & 0.003 & 0.05 \\
& PCE & 30.7 & 0.003 & 0.05 \\
\hline \hline
\end{tabular}

Analisando os períodos das oscilações derivadas das inversões da corrente, a Tabela 3.5 apresenta os valores de período inercial médio, variância e o desvio padrão calculados para a PCI, PCM e PCE nas radiais de estudo, e a Tabela 3.6 os períodos médios das oscilações secundárias de velocidade em cada radial em todos os experimentos de vento com ação em toda a PCSE,

Com base nessas duas tabelas, percebe-se que a corrente superficial na $\mathrm{PCM}$ e na $\mathrm{PCE}$ nas quatro radiais de estudo apresentaram, de modo geral, oscilação natural a passagem da frente fria com período próximo ao período inercial.

Entretanto na $\mathrm{PCI}$ de Cananéia, Ubatuba e Cabo Frio foram poucos os períodos estimados, uma vez que a identificação das cristas e cavas das amplitudes de velocidade foram prejudicadas pela baixa variabilidade da corrente nestas regiões. A Tabela 3.6 exibe as estimativas de período natural das corrente superficial nos experimentos realizados.

No que diz respeito a estrutura vertical da corrente, os experimentos SVT9 e SVT10 apresentaram padrão de distribuição similares, tanto em estratificação das maiores velocidades quanto na intensidade das componentes da velocidade propriamente dita, a exemplo a Figura 3.50, que apresenta a radial Ubatuba no experimento SVT10 durante a passagem da primeira frente fria, que apresentou a mesma estrutura de corrente observada em SVT9.

As demais radiais apresentaram estrutura vertical da corrente muito semelhantes as observadas nos experimentos anteriores, e a radial Cabo Frio apresentou componente paralela máxima de $0.6 \mathrm{~ms}^{-1}$ para nordeste durante a passagem da terceira frente fria (Figura 3.51).

Investigando os maiores valores das componentes da corrente no decorrer dos 10 experimentos de vento total, foi constatado que durante o experimento SVT3, configurado com frentes frias com $11.4 \mathrm{~ms}^{-1}$ de propagação, a radial Cananéia exibiu os maiores valores para a componente paralela à costa, com valores acima de $0.4 \mathrm{~ms}^{-1}$ na região ao largo e acima de $0.8 \mathrm{~ms}^{-1}$ de velocidade perpendicular na superfície da $\mathrm{PCE}$, como mostra a Figura $3.52 \mathrm{a}$. 
Tabela 3.6: Período estimado, em horas, das oscilações naturais após a passagem das frentes frias na PCI, PCM e PCE nas radiais Cananéia, Santos, Ubatuba e Cabo Frio.

\begin{tabular}{ll|c|c|c|c|c|c|c|c|c|c|c|c|c}
\hline \hline & & SVT1 & SVT2 & SVT3 & SVT4 & SVT5 & SVT6 & SVT7 & SVT8 & SVT9 & SVT10 & $\bar{x}$ & $\sigma^{2}$ & std $(x)$ \\
\hline \hline \multirow{3}{*}{ Radial Cananéia } & PCI & - & - & - & - & - & - & - & - & - & - & - & - & - \\
& PCM & 27.7 & 26.2 & 27.1 & 26.9 & 26.6 & 26.8 & 26.9 & 27.8 & 26.6 & 27.5 & 27.0 & 0.267 & 0.52 \\
& PCE & 25.8 & 24.9 & 26.1 & 26.1 & 26.6 & 25.6 & 26.9 & 27.8 & 25.8 & 27.5 & 26.3 & 0.796 & 0.89 \\
\hline \hline \multirow{3}{*}{ Radial Santos } & PCI & 30.4 & 34.5 & 31.3 & 26.9 & 29.7 & - & 29.0 & - & - & 38.4 & 31.4 & 14.749 & 3.84 \\
& PCM & 26.8 & 26.9 & 26.8 & 26.9 & 26.6 & 27.2 & 26.9 & 27.4 & 28.2 & 30.5 & 27.4 & 1.377 & 1.17 \\
& PCE & 26.8 & 26.9 & 27.8 & 27.6 & 27.4 & 26.4 & 26.9 & 26.9 & 28.2 & 29.7 & 27.5 & 0.912 & 0.95 \\
\hline \hline \multirow{2}{*}{ Radial Ubatuba } & PCI & 27.7 & - & - & - & - & - & - & - & - & - & 27.7 & - & - \\
& PCM & 26.5 & 21.1 & 21.9 & 24.7 & 29.7 & - & - & 31.6 & - & - & 25.9 & 17.554 & 4.18 \\
& PCE & 27.7 & 21.2 & 28.1 & 26.1 & 27.4 & 26.4 & 27.8 & 27.8 & 28.9 & 30.5 & 27.2 & 5.939 & 2.44 \\
\hline \hline \multirow{2}{*}{ Radial Cabo Frio } & PCI & - & - & - & - & - & - & - & - & - & - & - & - & - \\
& PCE & 31.4 & - & - & - & 32.0 & 28.8 & - & - & - & - & 30.4 & 5.120 & 2.26 \\
& PCI & -1.1 & 30.2 & 29.1 & 29.7 & 29.6 & 33.7 & - & 32.0 & 32.5 & 29.9 & 13.269 & 3.64 \\
\hline \hline
\end{tabular}


A radial Santos, como discutido anteriormente na Secção 3.3.2 apresentou componente perpendicular ressonante as frentes frias do experimento SVT4, onde apresentou valores acima de $0.8 \mathrm{~ms}^{-1}$ ao largo da plataforma continental. A componente paralela da corrente também apresentou valor máximo nesse experimento, apresentando velocidade acima de $0.4 \mathrm{~ms}^{-1}$, como mostra a Figura $3.52 \mathrm{~b}$. Durante o experimento SVT4 também foi aferido que a radial Ubatuba apresentou ampliação da magnitude da componente paralela da corrente, atingindo valores acima de $1.0 \mathrm{~ms}^{-1}$, podendo indicar que a região mais central da PCSE pode ser ressonante com frentes frias com velocidade de propagação de $9.5 \mathrm{~ms}^{-1}$.

A Radial Cabo Frio, apesar de ter apresentado elevações positivas apenas nos dois últimos experimentos, exibiu ampliação da componente paralela durante o experimento SVT10, onde as frentes frias com velocidade de propagação de $4.7 \mathrm{~ms}^{-1}$ acarretaram em uma velocidade da componente $\mathrm{V}$ acima de $0.6 \mathrm{~ms}^{-1}$ na superfície da $\mathrm{PCI}$, Figura $3.52 \mathrm{~d}$.

Como discutido anteriormente, a amplificação das componentes da corrente podem estar relacionados com a similaridade dos valores de intensidade do vento que age localmente na região com a velocidade de deslocamento do sistema frontal. Para corroborar este raciocínio, se faz necessário a interpretação dos valores de magnitude do vento das frentes frias em setores diferentes da PCSE

Observando a Figura 3.53 , é possível estimar a intensidade do vento de frente fria sobre cada uma das radiais, onde na região de Cananéia a intensidade foi acima de $11.0 \mathrm{~ms}^{-1}$ na PCE e de $8 \mathrm{~ms}^{-1}$ na PCI (Figura 3.53a). A região central da PCSE esteve sob influência de ventos entre 7 a $10 \mathrm{~ms}^{-1}$ (Figura $3.53 \mathrm{~b}$-c). A região norte da PCSE esteve sob influência de ventos de 4 a $5 \mathrm{~ms}^{-1}$ (Figura $3.53 \mathrm{~d}$ ).

Considerando que cada uma das radiais de estudo apresentaram ampliação das componentes em experimentos diferentes, e que cada experimento difere entre si apenas no que se refere ao deslocamento dos sistemas frontais, pode-se atribuir que: a corrente gerada pelo cisalhamento do vento de frente fria foi ressonante na parte sul da PCSE com frentes se deslocando a 11.4 $\mathrm{ms}^{-1}$, associado com o vento máximo acima de $11.0 \mathrm{~ms}^{-1}$ na região; a região central da PCSE, por sua vez, apresentou correntes superficiais ressonantes com frentes com propagação de 9.5 $\mathrm{ms}^{-1}$, em associação a ventos de até $10 \mathrm{~ms}^{-1}$; e por fim, a região mais ao norte da PCSE as correntes apresentaram maior amplitude com frentes se propagando a $4.7 \mathrm{~ms}^{-1}$. 

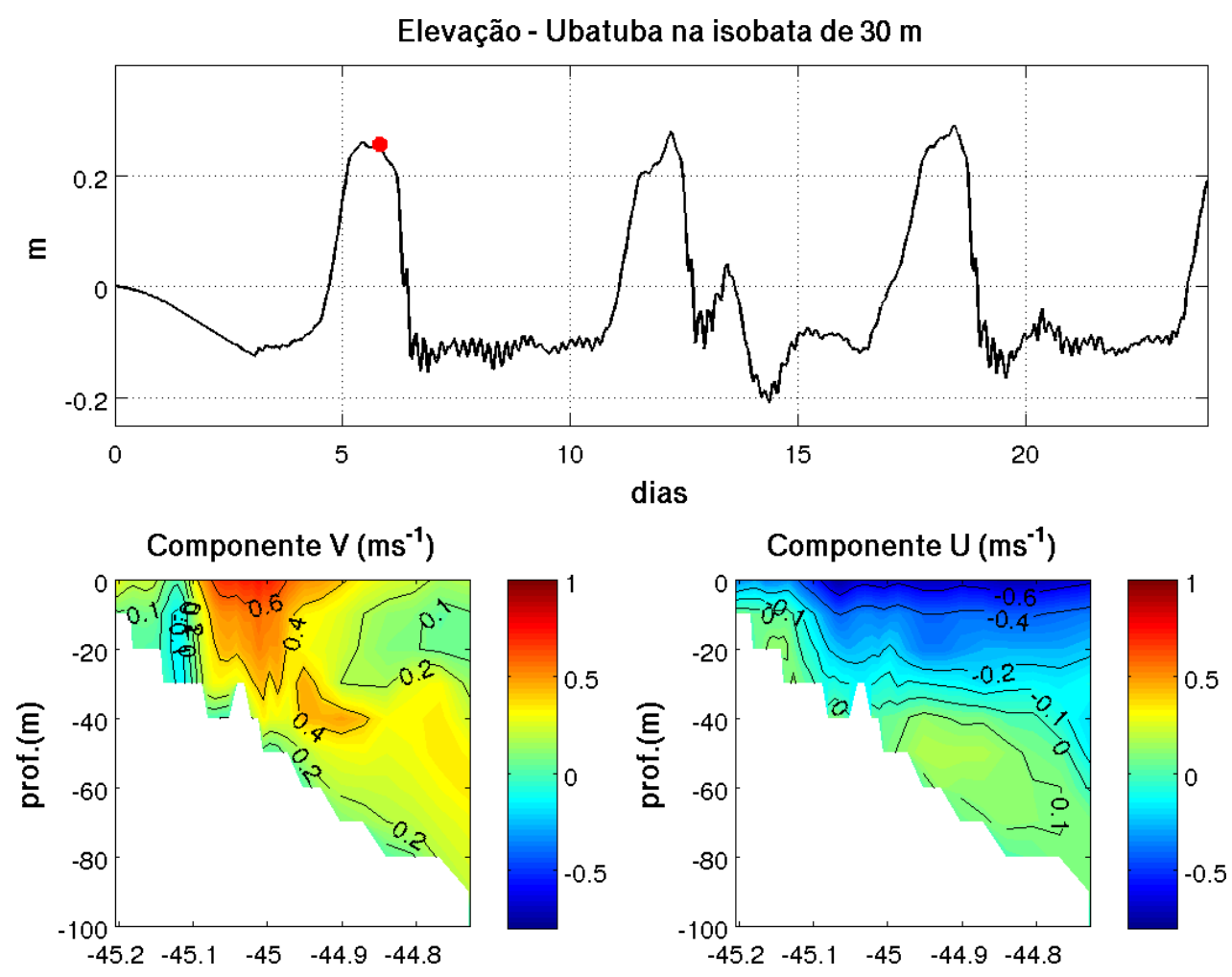

Figura 3.50: Série temporal de elevação e perfis verticais de velocidade perpendicular (U) e paralela (V) durante a passagem da primeira frente fria na radial Ubatuba, experimento SVT10.
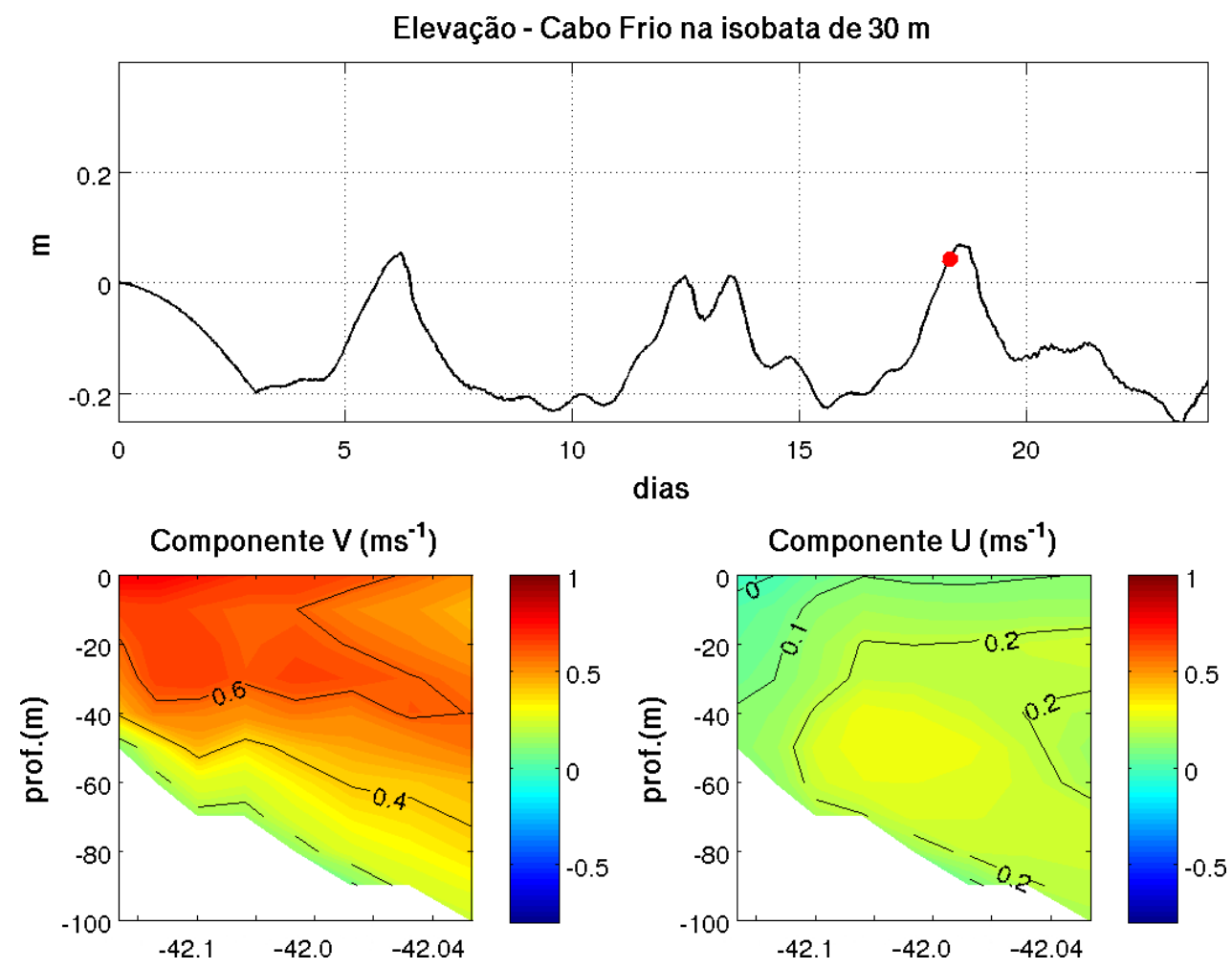

Figura 3.51: Série temporal de elevação e perfis verticais de velocidade perpendicular (U) e paralela (V) durante a passagem da terceira frente fria na radial Cabo Frio no experimento SVT10. 

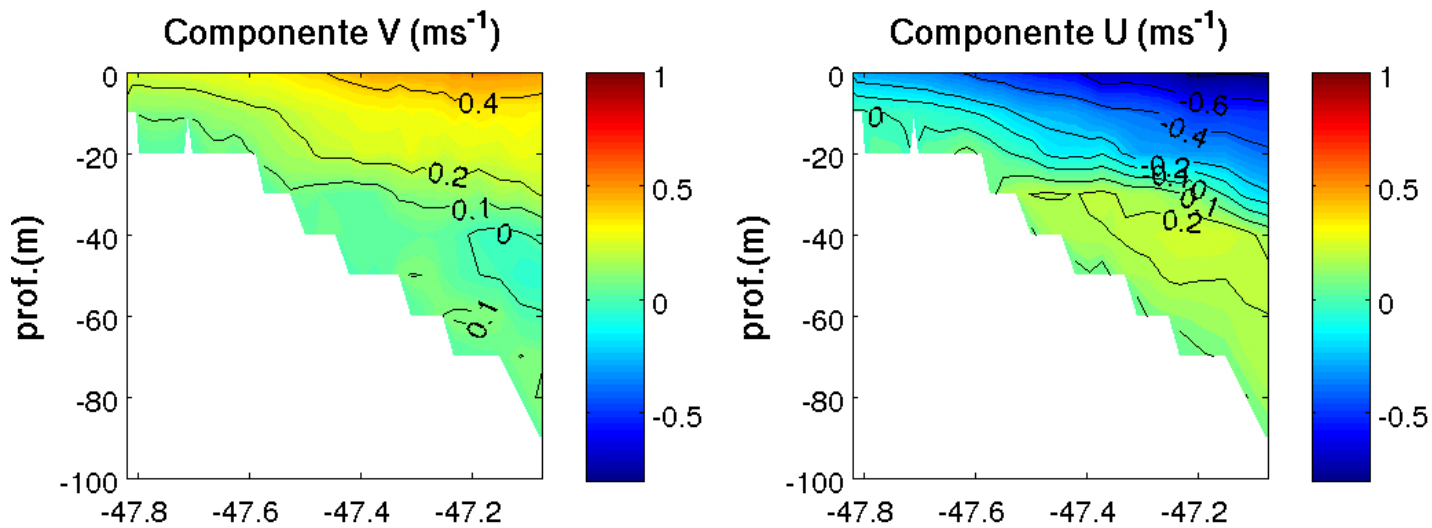

(a) Cananéia
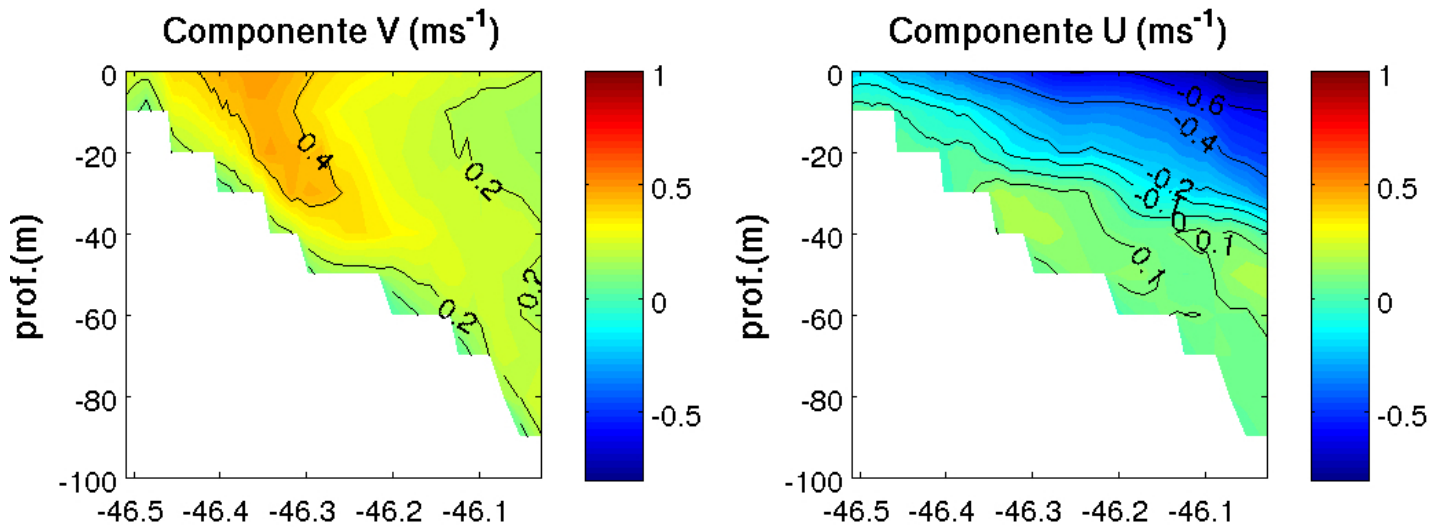

(b) Santos
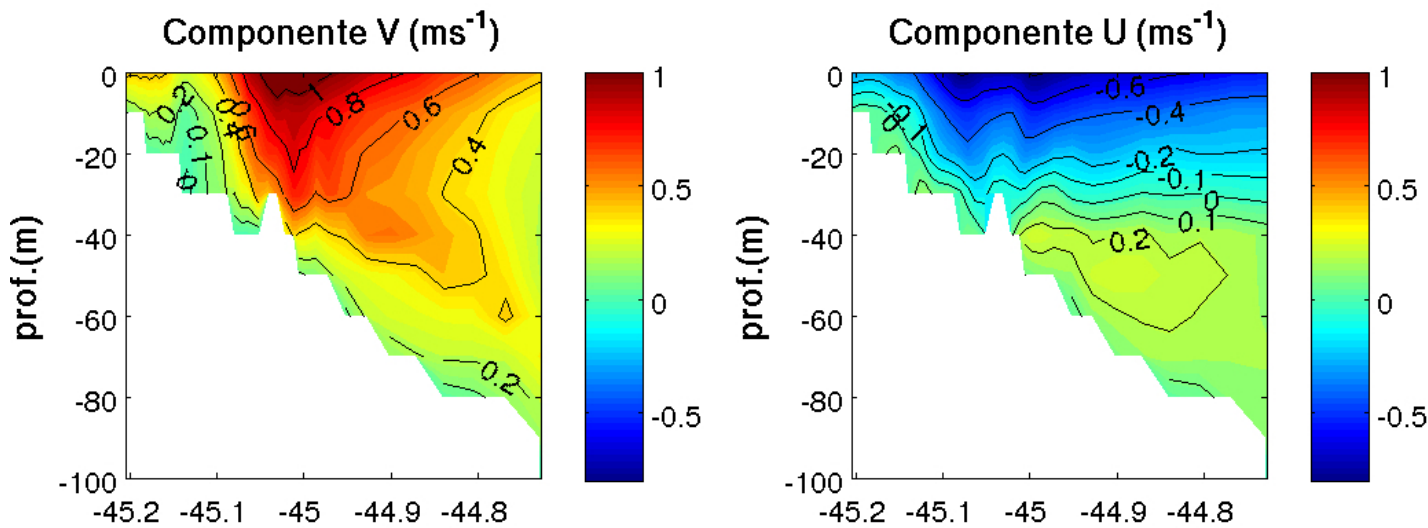

(c) Ubatuba
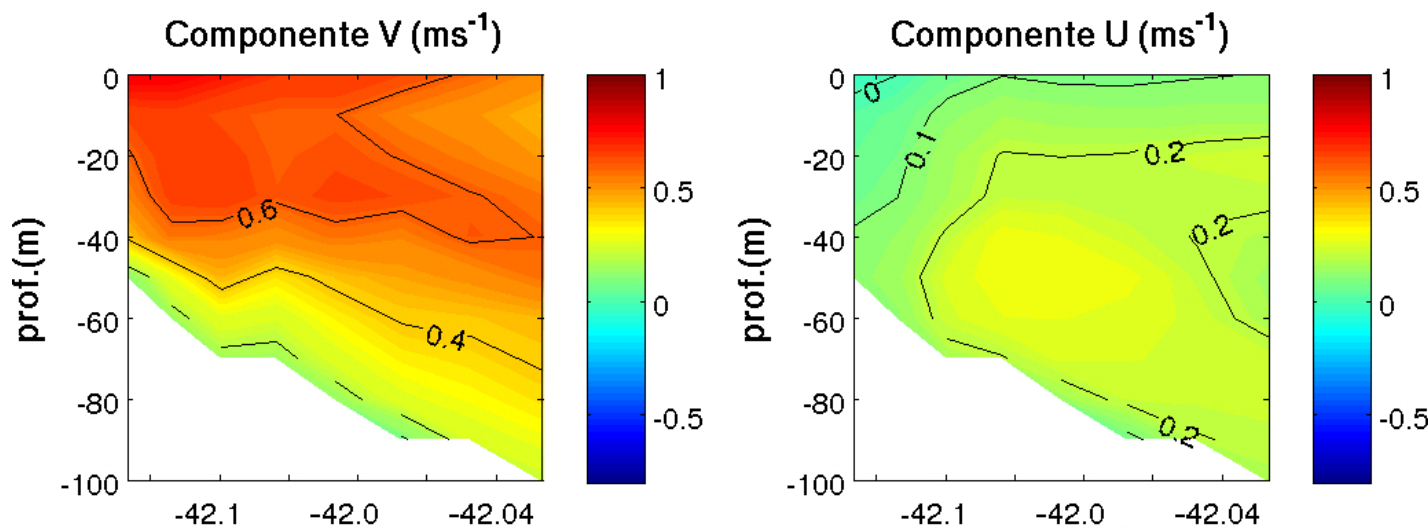

(d) Cabo Frio

Figura 3.52: Componentes da velocidade, sob ação de frentes se propagando a (a) $11.4 \mathrm{~ms}^{-1}$, (b)/(c) a $9.5 \mathrm{~ms}^{-1}$, e (d) a $4.7 \mathrm{~ms}^{-1}$. 

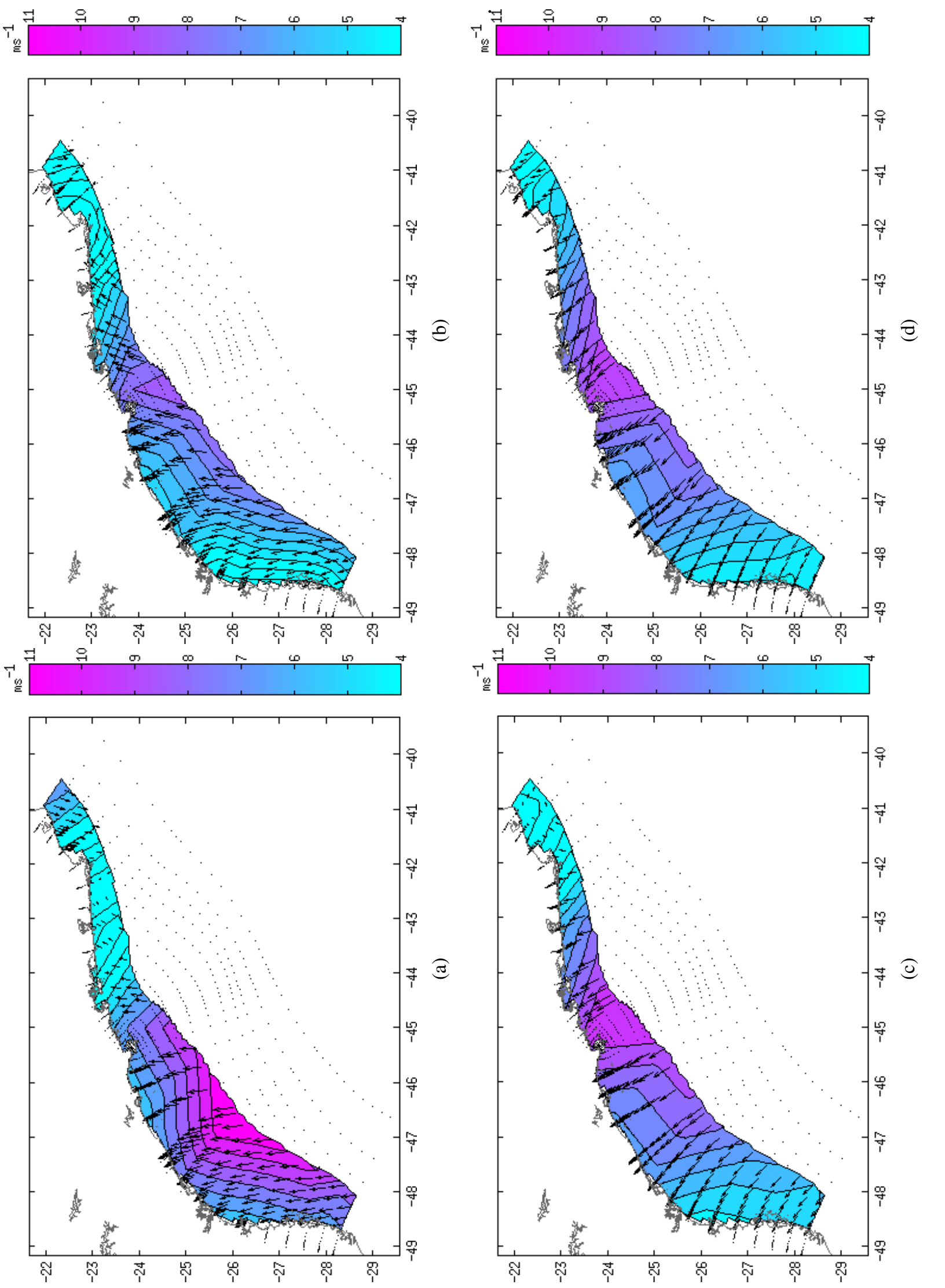

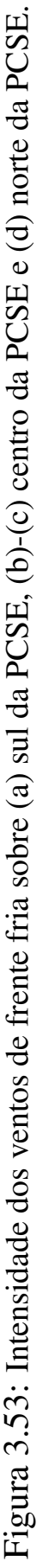




\section{Capítulo 4}

\section{Conclusões}

As características das ondas de plataforma continental para a região da PCSE foram estudadas do ponto de vista da modelagem numérica, com resultados bastante coerentes com as observações e estudos disponíveis até o momento. De maneira geral, foi possível identificar o comportamento distinto destas ondas em suas porções SW e NE, com padrões de ressonância associados à passagem de frentes frias. De fato, nota-se que não apenas a intensidade do vento paralelo é importante para se determinar a hidrografia da região, mas a velocidade de deslocamento das frentes frias também interfere nesta dinâmica. De maneira mais específica, este trabalho chega as seguintes conclusões:

- A resposta da Plataforma Continental Sudeste aos ventos de nordeste provenientes da ASAS promove, em um cenário de águas com temperatura e salinidade homogêneos, rebaixamento do nível do mar mais tênue se comparado a simulação com campos climatológicos de verão de temperatura e salinidade, sugerindo que o nível do mar é influenciado pela forçante baroclínica, principalmente na região de Cabo Frio, mas não se limitando à esta;

- No que se refere a resposta das correntes superficiais, o cisalhamento do vento de nordeste gera correntes mais intensas quando imposto um campo homogêneo de densidade, onde foram observados correntes na ordem de $0.1 \mathrm{~ms}^{-1}$ na $\mathrm{PCI}$ e na $\mathrm{PCM}$ na região sul da PCSE PCSP, e cerca de $0.2 \mathrm{~ms}^{-1}$ foram obtidas em toda a plataforma continental na região norte da PCSE, no experimento controle. As correntes mais intensas ao norte de Cabo Frio-RJ podem estar associadas a maior tensão de cisalhamento do vento nessa região, questão discutida anteriormente por Coelho (2007) e Ruffato (2011). Quando foi imposto um campo climatológico de densidade, as correntes superficiais praticamente preservaram as mesmas intensidades, contudo apresentaram oscilações naturais, principalmente na PCE com período entre 26 e 30 horas;

- Em relação ao sentido da corrente superficial, no experimento com campos estratificados de temperatura e salinidade, a corrente na $\overline{\mathrm{PCI}}$ e a porção interna da $\mathrm{PCM}$ ao sul da 
Ilha de São Sebastião ( $\overline{\mathrm{PCSP}}$ ) apresentaram direção para nordeste, oposta a direção do cisalhamento do vento de nordeste, sugerindo que a forçante de flutuabilidade consegue sobrepujar a forçante vento na superfície, o que também foi observado por Castro (1996), Valente (1999), Mazzini (2009) e recentemente por Morais (2016). Além da ação do fluxo de flutuabilidade, o condicionamento das correntes para nordeste na PCI, também pode ser fruto de uma feição anti-ciclônica entre a $\overline{\mathrm{PCM}}$ e a $\overline{\mathrm{PCE}}$ ao sul da Ilha de São Sebastião;

- O sinal remoto do vento de frente fria no sul da PCSE é capaz de excitar perturbações do nível do mar, principalmente na PCI e $\overline{\mathrm{PCM}}$ da região da $\mathrm{PCSP}$, em forma de Ondas de Plataforma Continental (OPC);

- A mudança do tempo de permanência das frentes remotas no sul da PCSE pouco alteram a altura das OPCs na metade sul da PCSE e na região da PCSP, mas ao norte da Ilha de São Sebastião a mudança do regime dos sistemas frontais remotos resultou em maior variabilidade do nível do mar nessa região;

- O aumento no tempo de permanência das frentes remotas no sul do domínio acarretaram em OPC 3 com maior alcance na costa da PCSE, onde nas frentes remotas agindo por 18 horas o comprimento da OPC foi estimado em $1250 \mathrm{~km}$; frentes agindo remotamente por 36 horas geraram ondas de cerca de $1450 \mathrm{~km}$; o aumento da permanência da frente para 54 horas resultou em ondas com $1550 \mathrm{~km}$; e aumento de 72 horas em ondas com cerca de $1700 \mathrm{~km}$;

- De maneira geral, a velocidade de propagação das OPCs geradas por ventos remotos de sudoeste foi entre 9.2 e $10.2 \mathrm{~ms}^{-1}$ na região sul da PCSE, independente do tempo de permanência das frentes remotas. A região norte, assim como observado para a altura do nível do mar, apresentou maior variabilidade na velocidade de propagação da OPC apresentando valores entre 2.4 e $5.0 \mathrm{~ms}^{-1}$. Devido a efemeridade da ação das frentes no experimento RS1, de 18 horas, este foi o único experimento que a OPC apresentou velocidade de propagação próximas entre a região sul e norte da PCSE, exibindo valores de 6.1 e $5 \mathrm{~ms}^{-1}$, respectivamente;

- A corrente superficial gerada pela ação dos ventos remotos apresentou valores máximos associados ao sinal remoto do vento de sudoeste (frente fria), mantendo direção no sentido do mesmo. Após a influência do sistema frontal remoto, as correntes superficiais exibiram oscilações em toda a plataforma, com período na ordem de 30 horas nas radiais mais próximas a região de atuação do vento;

- Assim como observado nos experimentos de vento remoto, os experimentos com a forçante vento atuando em toda a PCSE exibiram maior variabilidade do nível do mar ao norte da Ilha de São Sebastião quando alterado o tempo de permanência das frentes sobre 
o domínio. Na região sul da PCSE, o nível do mar foi máximo durante a passagem dos sistemas frontais, e a $\mathrm{PCI}$ de Cananéia exibiu valores em torno de $0.4 \mathrm{~m}$.

- A ação das frentes frias sobre toda a plataforma continental ocasionou maiores correlações do nível do mar nas regiões ao sul da Ilha de São Sebastião, com valores próximos a 1 na $\mathrm{PCI}$, próximo a 0.8 na $\mathrm{PCM}$, e acima de 0.5 na região mais interna da PCE. Já na região ao norte da Ilha de São Sebastião, os valores irrisórios de correlação do nível do mar obtidos sugerem que as irregularidades da costa associadas ao estreitamento da plataforma continental nessa região promovam maior dissipação de energia da OPC, diminuindo a correlação se comparado a região sul da PCSE;

- A alteração do regime de propagação das frentes frias, aumentando o tempo de permanência das mesmas sobre a PCSE foi responsável pelo progressivo aumento do comprimento das $\mathrm{OPC} \beta$, fazendo-as atingir menores latitudes a cada experimento. Considerando o comprimento total da PCSE em cerca de $1020 \mathrm{~km}$, os comprimentos das ondas foram de entre 1350 km (SVT1) e 1750 km (SVT10);

- A velocidade de propagação das $\mathrm{OPC}$ n na região sul da $\mathrm{PCSE}$, da Baía de Paranaguá-PR até a Ilha de São Sebastião-SP, foi de $15.3 \mathrm{~ms}^{-1}$ independente da alteração do regime dos sistemas frontais, com excessão o experimento SVT5, que apresentou velocidades de 18.4 $\mathrm{ms}^{-1}$, e o experimento SVT8, com $10.2 \mathrm{~ms}^{-1}$. A região norte da PCSE, da Ilha de São Sebastião-SP até Cabo Frio-RJ, a velocidade de propagação daOPC apresentou maior variabilidade com a alteração da velocidade de propagação das frentes frias, apresentando valores entre 3.6 e $7.2 \mathrm{~ms}^{-1}$. Estes resultados diferem daqueles obtidos pelos experimentos com ventos apenas na região sul por incluirem uma parcela oriunda de propagação livre e outra forçada localmente;

- Considerando a resposta das correntes superficiais a ação da forçante vento em toda a PCSE, as maiores velocidades foram observadas na face externa e ao largo da Ilha de São Sebastião, sempre acima de $1.0 \mathrm{~ms}^{-1}$. Em todo o domínio de estudo, as maiores correntes foram para nordeste, relacionadas com a ação dos ventos de sudoeste (frente fria), exceto as regiões ao largo da Ilha de São Sebastião e ao norte de Cabo Frio, em que as correntes apresentaram direção para sudoeste, sendo relacionadas com o cisalhamento do vento de nordeste da Alta Subtropical do Atlântico Sul e a estrutura baroclínica da Corrente do Brasil, imposta através dos campos climatológicos de verão de temperatura e salinidade;

- Após a inversão da corrente para nordeste, proporcionada pela passagem dos sistemas frontais, as correntes superficiais apresentaram oscilações, principalmente na PCM] e PCE, com período próximo ao inercial, indicando que a oscilação natural às perturbações nessas regiões são de caráter inercial. Essas oscilações podem, como observado em alguns dos experimentos, aumentar ou diminuir a magnitude das correntes geradas pela inversão do vento; 
- As radiais de estudo apresentaram ampliações máximas das correntes superficiais vinculadas a diferentes velocidades de propagação de frentes frias. A radial Cananéia apresentou amplificação das correntes superficiais sob ação de frentes se deslocando a 11.4 $\mathrm{ms}^{-1}$, a radial Santos e Ubatuba exibiram os maiores valores de correntes associados a frentes frias se propagando com $9.5 \mathrm{~ms}^{-1}$, e a radial Cabo Frio com frentes movendo-se a $4.7 \mathrm{~ms}^{-1}$. 


\section{Referências Bibliográficas}

Blumberg, Alan F. 2010. “Stevens ECOM - Users Manual.” Apendix II.

Blumberg, Alan F, e Nickitas Georgas. 2008. "Quantifying uncertainty in estuarine and coastal ocean circulation modeling." Journal of Hydraulic Engineering 134 (4): 403-415.

Blumberg, Alan F, Liaqat Ali Khan, e John P St John. 1999. “Three-dimensional hydrodynamic model of New York Harbor region.” Journal of Hydraulic Engineering.

Blumberg, Alan F, e George L Mellor. 1987. “A description of a three-dimensional coastal ocean circulation model." Three-dimensional coastal ocean models, pp. 1-16.

Brink, KH. 1991. "Coastal-trapped waves and wind-driven currents over the continental shelf." Annual Review of Fluid Mechanics 23 (1): 389-412.

Campos, Edmo JD, JE Gonçalves, e Y Ikeda. 1995. "Water mass characteristics and geostrophic circulation in the South Brazil Bight: Summer of 1991." Journal of Geophysical Research: Oceans 100 (C9): 18537-18550.

Castro, B. M. de. 1990. "Wind driven currents in the Channel of São Sebastião: winter, 1979." Boletim do Instituto Oceanográfico 38 (2): 111-132.

Castro, Belmiro M, e Thomas N Lee. 1995. "Wind-forced sea level variability on the southeast Brazilian shelf." Journal of Geophysical Research: Oceans (1978-2012) 100 (C8): 16045-16056.

Castro, B.M. de. 1996. “Correntes e massas de água da plataforma continental norte de São Paulo." Livre-Docente Thesis, Instituto Oceanográfico da Universidade de São Paulo.

Castro, BM de, JA Lorenzzetti, ICA da Silveira, e LB de Miranda. 2006. "Estrutura termohalina e circulação na região entre o Cabo de São Tomé (RJ) eo Chuí (RS).” O ambiente oceanográfico da plataforma continental e do talude na região sudeste-sul do Brasil. EDUSP, São Paulo, pp. 11-120.

Coelho, Alexandre Luiz. 2007. "Resposta da Plataforma Continental Sudeste a ventos sazonais e sinóticos de verão: estudos numéricos." Ph.D. diss., Instituto Oceanográfico da Universidade de São Paulo.

Csanady, GT. 1976. "Mean circulation in shallow seas." Journal of Geophysical Research 81 (30): 5389-5399. 
. 1978. "The arrested topographic wave." Journal of Physical Oceanography 8 (1): $47-62$.

Dottori, Marcelo, e Belmiro Mendes Castro. 2009. "The response of the Sao Paulo Continental Shelf, Brazil, to synoptic winds." Ocean dynamics 59 (4): 603-614.

Emilsson, I. 1962. “As correntes marítimas no Canal de São Sebastião.” Ciência Cult., S Paulo 14 (4): 269-270.

Filippo, Alessandro Mendonça. 2003. "Variabilidade do nível do mar em função de eventos meteorológicos de baixa freqüência." Departamento de Geoquímica Ambiental, Universidade Federal Fluminense-UFF, vol. 100.

Fofonoff, NP. 1962. "Dynamics of ocean currents." The sea 1:323-395.

França, Bruna Reis Leite. 2013. "ONDAS CONFINADAS COSTEIRAS NA PLATAFORMA CONTINENTAL SUL-SUDESTE DO BRASIL." Ph.D. diss., Universidade Federal do Rio de Janeiro.

Gill, AE, e E_H Schumann. 1974. "The generation of long shelf waves by the wind." Journal of Physical Oceanography 4 (1): 83-90.

Gregorio, Helvio Prevelato. 2014. “Oscilações Subinerciais na Plataforma Continental Sudeste: Estudos Numéricos.” Ph.D. diss., Universidade de São Paulo.

Huthnance, John M. 1975. "On trapped waves over a continental shelf." Journal of fluid mechanics 69 (04): 689-704.

Kantha, Lakshmi H, George L Mellor, e Alan F Blumberg. 1982. "A diagnostic calculation of the general circulation in the South Atlantic Bight." Journal of Physical Oceanography 12 (8): 805-819.

Kvinge, T. 1967. "On the special current and water level variations in the Channel of SÃO SEBASTIÃO.” Boletim do Instituto Oceanográfico 16 (1): 23-38.

Leite, R Jose Roberto Bairao. 2014. “Oscilaçoes Inerciais sobre a Plataforma Continental Sudeste do Brasil.” Ph.D. diss., Instituto Oceanográfico.

Mazzini, P. L. F. 2009. “Correntes subinerciais na plataforma continental interna entre Peruibe e Sao Sebastiao: observaçoes.” Ph.D. diss., Instituto Oceanográfico da Universidade de São Paulo.

Mellor, George L, e Tetsuji Yamada. 1974. "A hierarchy of turbulence closure models for planetary boundary layers." Journal of the Atmospheric Sciences 31 (7): 1791-1806.

. 1982. "Development of a turbulence closure model for geophysical fluid problems." Reviews of Geophysics 20 (4): 851-875.

Miranda, LB de. 1982. "Análise de massas de água da plataforma continental e da região oceânica adjacente: Cabo de São Tomé (RJ) a Ilha de São Sebastião (SP).” Livre Doce ${ }^{\wedge}$ ncia”Thesis, Universidade de Sao Paulo. 
Morais, Pedro Henrique Lima Silva. 2016. "Hidrodinâmica da Plataforma Continental Interna do estado de Sao Paulo.” Ph.D. diss., Universidade de Sao Paulo.

Oliveira, Alda Santos de. 1986. "Interações entre sistemas frontais na América do Sul ea convecção da Amazônia.” Ph.D. diss., INPE.

Pedlosky, Joseph. 1979. Geophysical fluid dynamics. Springer Science \& Business Media.

Pereira, AF, BM Castro, L Calado, e ICA da Silveira. 2007. "Numerical simulation of M2 internal tides in the South Brazil Bight and their interaction with the Brazil Current." Journal of Geophysical Research: Oceans 112, no. C4.

Peterson, R. G., e L. Stramma. 1991. "Upper-level circulation in the South Atlantic Ocean." Progress in oceanography 26 (1): 1-73.

Rahy, Manuela Quintanilha Tiengo. 2006. "Correntes subinerciais e ondas de plataforma continental presentes na costa sudeste do Brasil.” Ph.D. diss.

Reid, Robert O, e Bernie R Bodine. 1968. "Numerical model for storm surges in Galveston Bay." Journal of the Waterways and harbors Division 94 (1): 33-58.

Rezende, J. H. M. de. 2003. "Intrusões da água central do atlântico sul na plataforma continental sudeste durante o verão.” Ph.D. diss., Instituto Oceanográfico da Universidade de São Paulo.

Robinson, AR. 1964. "Continental shelf waves and the response of sea level to weather systems." Journal of Geophysical Research 69 (2): 367-368.

Ruffato, Daniel Giancolli. 2011. "Circulação na Plataforma Continental Interna e Média do Estado de São Paulo durante o verão: estudos numéricos." Ph.D. diss., Universidade de São Paulo.

Samuels, BL, e M Cox. 1987. "Data set atlas for oceanographic modeling." Ocean Modeling 75:1-3.

Santos, Luis Felipe Silva. 2009. "Variabilidade subinercial das correntes na plataforma continental ao largo de Cabo Frio (RJ): observações.” Ph.D. diss., Universidade de São Paulo.

Scott, JT, e GT Csanady. 1976. "Nearshore currents off Long Island.” Journal of Geophysical Research 81 (30): 5401-5409.

Smagorinsky, Joseph. 1963. "General circulation experiments with the primitive equations: I. The basic experiment." Monthly weather review 91 (3): 99-164.

Stech, José L, e João A Lorenzzetti. 1992. "The response of the South Brazil Bight to the passage of wintertime cold fronts." Journal of Geophysical Research: Oceans 97 (C6): 9507-9520.

Valente, Marcia Helena Moreira. 1999. "Circulação na plataforma interna do litoral norte do Estado de São Paulo.” Ph.D. diss. 
Wang, Dong-Ping, e Christopher NK Mooers. 1976. "Coastal-trapped waves in a continuously stratified ocean." Journal of Physical Oceanography 6 (6): 853-863.

Willmott, Cort J. 1981. “On the validation of models.” Physical geography 2 (2): 184-194.

Zembruscki, Sylvio G. 1979. "Geomorfologia da margem continental sul brasileira e das bacias oceânicas adjacentes." Geomorfologia da margem continental sul brasileira e das áreas oceânicas adjacentes. Rio de Janeiro, PETROBRAS. CENPES. DINTEP (Série Projeto REMAC NUM. 7). 